\title{
Coming to Terms with \\ Information and Communications Technologies: \\ The Role of the Chief Information Officer \\ of the Government of Canada
}

by

David C.G. Brown

B.A. University of Toronto, 1971

M.A. University of Toronto, 1973

A thesis submitted to the Faculty of Graduate and Postdoctoral Affairs in partial fulfilment of the requirements for the degree of

Doctor of Philosophy

in

Political Science

Carleton University

Ottawa, Ontario

(C) 2011, David C.G. Brown 
Library and Archives
Canada

Published Heritage

Branch

395 Wellington Street

Ottawa ON K1A ON4

Canada
Bibliothèque et

Archives Canada

Direction du

Patrimoine de l'édition

395 , rue Wellington

Ottawa ON K1A ON4

Canada
Your file Votre référence

ISBN: 978-0-494-83245-5

Our file Notre référence

ISBN: 978-0-494-83245-5

\section{NOTICE:}

The author has granted a nonexclusive license allowing Library and Archives Canada to reproduce, publish, archive, preserve, conserve, communicate to the public by telecommunication or on the Internet, loan, distribute and sell theses worldwide, for commercial or noncommercial purposes, in microform, paper, electronic and/or any other formats.

The author retains copyright ownership and moral rights in this thesis. Neither the thesis nor substantial extracts from it may be printed or otherwise reproduced without the author's permission.
AVIS:

L'auteur a accordé une licence non exclusive permettant à la Bibliothèque et Archives Canada de reproduire, publier, archiver, sauvegarder, conserver, transmettre au public par télécommunication ou par l'Internet, prêter, distribuer et vendre des thèses partout dans le monde, à des fins commerciales ou autres, sur support microforme, papier, électronique et/ou autres formats.

L'auteur conserve la propriété du droit d'auteur et des droits moraux qui protège cette thèse. $\mathrm{Ni}$ la thèse ni des extraits substantiels de celle-ci ne doivent être imprimés ou autrement reproduits sans son autorisation.
In compliance with the Canadian Privacy Act some supporting forms may have been removed from this thesis.

While these forms may be included in the document page count, their removal does not represent any loss of content from the thesis.
Conformément à la loi canadienne sur la protection de la vie privée, quelques formulaires secondaires ont été enlevés de cette thèse.

Bien que ces formulaires aient inclus dans la pagination, il n'y aura aucun contenu manquant.

\section{Canadä}




\begin{abstract}
The dissertation is a case study of a Canadian public management institution. Its focus is the establishment and evolution of a Chief Information Officer (CIO) as a senior official in the Government of Canada's Treasury Board Secretariat (TBS). The CIO was created on the margins of the June 1993 government reorganization, a conscious institutional response to new information and communications technologies (ICTs) in the economy and society, notably the convergence represented by the then-emerging Internet. Its role and responsibilities define a new functional sector in Canadian public administration, combining an IM/IT (Information Management/Information Technology) space with ICT-enabled management instruments and working relationships.

The dissertation concludes that the weak TBS CIO model can achieve strong results with strong senior public service and political direction but this is difficult to achieve. The CIO is well established but has unfinished business, and there are unresolved issues about its policy mandate, role in collective decision-making and whether it is ultimately an asset manager or the government's chief innovator. The case provides insights to the Canadian variant of the Westminster constitutional model and also to theories of policy and institutional stability, continuity and change.
\end{abstract}

There are five substantive chapters. The first considers the CIO's institutional roots, including the Treasury Board-based collective management model proposed by the Glassco Commission. Another strand is the earlier effects of ICTs on the public sector. The following chapter analyzes the establishment and evolution of the CIO within the Treasury Board model, its successes, failures and organizational "roads not taken." Drawing on e-government literature suggesting the federal government has a "weak" CIO model, a third chapter surveys the IM/IT space, the instruments available to the $\mathrm{CIO}$, and 
the implications of its relationships within government and with the citizen, private sector and other jurisdictions. A fourth discusses constraints on the CIO's effectiveness imposed by its weak IM role and tensions between IM and IT; the most serious is the political sensitivity of government information and communications. The fifth chapter is a minicase study of the Ontario Corporate $\mathrm{CIO}$, a contrasting "strong" $\mathrm{CIO}$ model that presents an alternative to its federal counterpart. 


\section{Acknowledgements}

This dissertation has had a long genesis. In 1973 I was accepted to the $\mathrm{PhD}$ program in Carleton University's Department of Political Science but instead joined the Canadian Foreign Service. After a career in the federal public service, in 2005 I was given a second chance to enter the same program. Both before and since I started my doctoral studies I have had experiences and was given advice and help that deserve recognition.

The topic of the dissertation grew out of two phases of my earlier career. From March 1994 until late 1997 I was Executive Director of the Information, Communication and Security Policy Division and its successors in Treasury Board Secretariat (TBS) and worked under the first three Chief Information Officers (CIOs), Andy Macdonald, Bob Little and Paul Rummell. In a turbulent, at times difficult, period I developed a high regard for both the policy areas and staff for which I was responsible and for the CIOs as individuals and as an office. Later, when I was a research manager at the Public Policy Forum (PPF), I conducted several studies of aspects of the Government On-Line (GOL) initiative on behalf of the then CIO, Michelle d'Auray, and her successor, Helen McDonald. This exposure to the day-to-day life of the CIO has proved invaluable.

My earlier experience gave me insights as a practitioner and as an independent researcher. This has proved to be both a challenge and an opportunity. The challenge has been in making the transition to the academic world and finding the balance between practitioner experience and scholarly detachment. I accept full responsibility for any failure to find that balance.

The opportunity relates to the direct origins of my $\mathrm{PhD}$ studies and this dissertation. While at the PPF I was invited by Prof. Sandford Borins of the University of Toronto to join a team of Canadian and international researchers that received funding from the 
Social Science and Human Research Council (SSHRC) under its Initiative for the New Economy (INE). An INE condition was that research teams include at least one practitioner, a role I was offered. The funding permitted me to study the Gateways and Clusters - the electronic client-service single window aspect of GOL - that led to a chapter on GOL in the publication of the team's work, Digital State at the Leading Edge (Borins et al. 2007). My contribution did not focus specifically on the CIO, but the experience did encourage me to pursue a PhD program after leaving the Public Policy Forum and helped me to identify the $\mathrm{CIO}$ as a fruitful topic for a dissertation.

My thanks therefore go to Sandy Borins for involving me in the Digital State project and then serving as a referee and mentor for my $\mathrm{PhD}$ studies. My other two referees, who have continued to provide support and encouragement, were Prof. Ken Kernaghan of Brock University and Dr. David Zussman, President of the PPF for much of the time I was there and now at the University of Ottawa.

Many others have contributed to both my academic and my practical learning over the years. I owe much to my staff and colleagues at TBS, in particular Ian Sinclair and John Riddle who have served as sounding boards during my research and read individual chapters. Jim Mitchell of Sussex Circle, John McDonald, formerly of the National Archives, and Nahum Goldmann, an astute private sector observer of the federal government, have all read sections of text and provided wise counsel on facts and judgments. The responsibility for what has resulted is entirely my own, however. A major part of my research was the interviews listed in Annex 3, all of whom readily agreed to share their perspectives. Among them, I should particularly mention the seven incumbent CIOs and four Acting CIOs who have held the office since 1993. 
My supervisor, Prof. Jonathan Malloy of the Department of Political Science at Carleton University, has given me sound advice and gentle encouragement at all of the project's many stages. The other advisory committee members, Prof. Leslie Pal of Carleton's School of Public Policy and Administration and Prof. Scott Bennett of the Political Science Department, have also provided judicious - and very welcome - advice that I hope I have adequately reflected in the final result.

I would like to express my appreciation to two other individuals, even though they are not here to receive it. As an undergraduate and first year graduate student at the University of Toronto, my greatest influence and earliest mentor was Prof. J.E. (Ted) Hodgetts, who taught me two undergraduate and one graduate courses in Canadian Government and Politics, Public Administration, and Political Institutions. I have drawn extensively on his historical and analytical perspective and continue to be deeply impressed by its contemporary relevance. More recently, Don Yeomans, who worked with Hodgetts at the Glassco Commission and did much to put its work into practice, was more than generous in providing information about the work of the Commission and much else, including giving me his personally annotated copy of the complete Glassco Report shortly before he died in 2010. I would like to dedicate this dissertation to them both, respectively a scholar and a practitioner.

Last, but by no means least, my PhD studies, and especially writing this dissertation, have given me an appreciation of the genuine depth of feeling of authors who thank their families for the support they have provided at all stages of a project that they must at times think will never end. My wife Margaret and daughters Catherine and Alison have been more than supportive, and my heartfelt thanks and love go to them. 


\section{Table of Contents}

Abstract

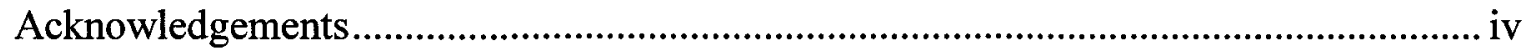

Table of Contents ........................................................................................... vii

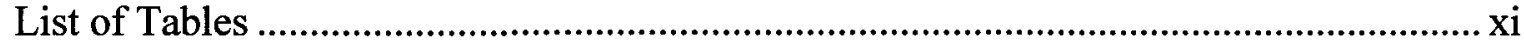

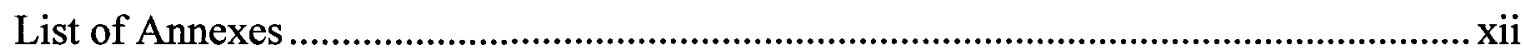

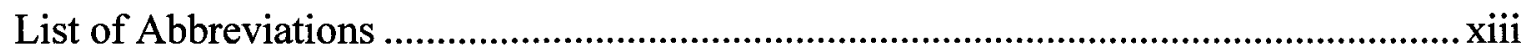

Chapter 1 - Introduction ............................................................................... 1

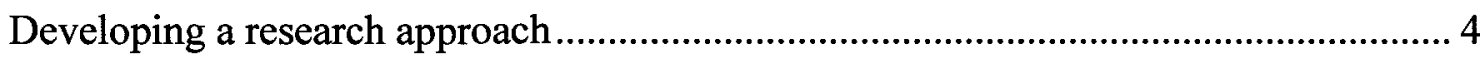

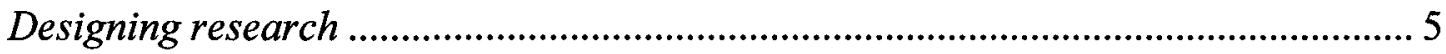

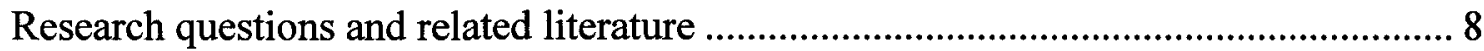

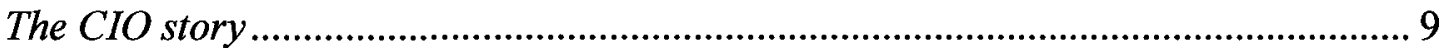

Treasury Board and the Canadian Westminster model .......................................... 15

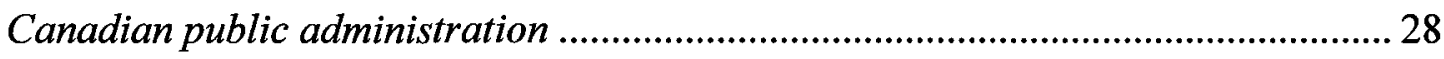

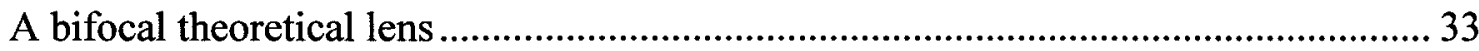

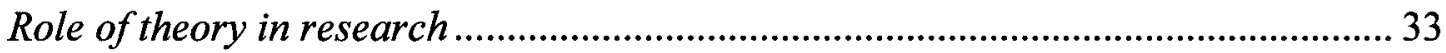

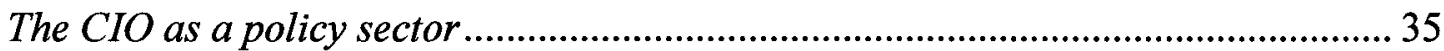

Theories of policy and institutional continuity, stability and change ....................... 38

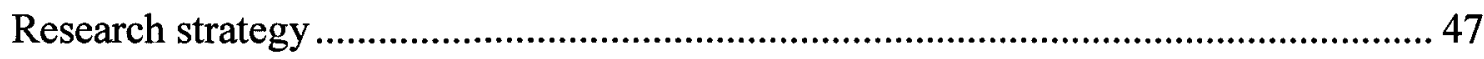

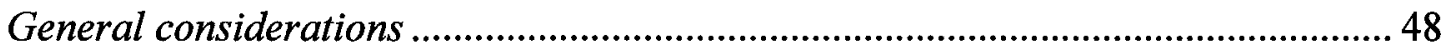

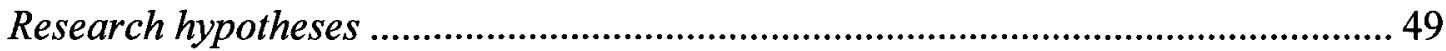

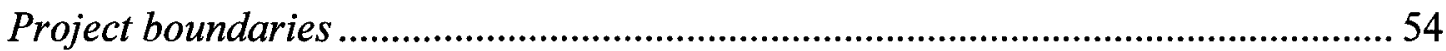

Research methodology - data collection and analysis ........................................... 57

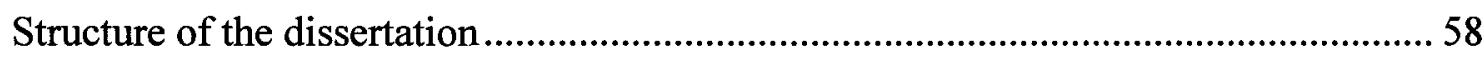

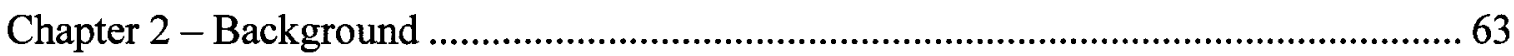

The external variable: information and communications technologies .....................6 65

The internal context: corporate management in the Canadian Westminster model ...... 74

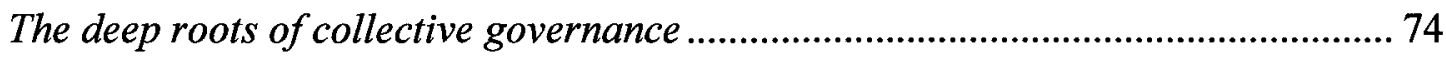

Treasury Board's first century: managing the public purse .................................. 81

Treasury Board's first century: organizing the civil service ................................. 86

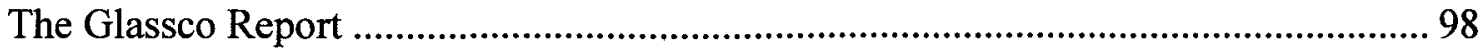


Implementing Glassco 106

After Glassco: continuous organizational change and administrative reform 111

The Prime Minister and the machinery of government ............................................. 113

The evolving Treasury Board Secretariat and administrative reform agenda ......... 116

Public policy-oriented organizational responses to ICTs......................................... 125

Conclusions: management of information and technology in the early 1990s............ 130

Chapter 3 - Establishment and Evolution of the CIO...................................................... 134

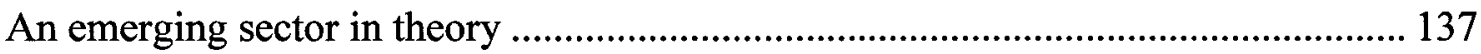

E-government perspectives on the CIO........................................................... 140

Establishment and evolution of the CIO................................................................... 147

The situation immediately before the 1993 reorganization ......................................... 148

The Campbell reorganization - June 25, 1993 .................................................... 150

Establishment of the CIO in Treasury Board Secretariat ........................................... 153

The Chrétien transition (November 1993) and policy direction ................................ 158

The CIO under Chrétien (November 1993-December 2003).................................... 163

The CIO under Martin (December 2003-February 2006) ........................................ 174

The CIO under Harper (February 2006-present) ………….................................. 178

Roads not taken: structural alternatives to the TBS/CIO model ................................... 182

Power and limitations of the CIO governance model................................................... 187

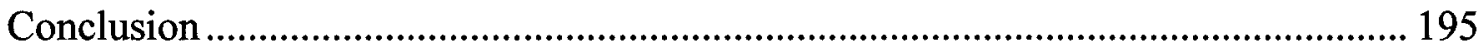

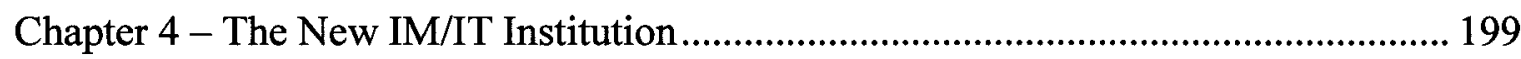

The Treasury Board model and collective responsibility ............................................. 202

The Treasury Board policy model .......................................................................... 203

Collective responsibility in Canada ...................................................................... 207

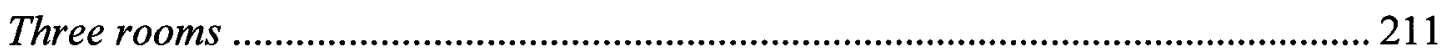

The Treasury Board model in practice - shaping the IM/IT space ........................... 213

Current CIO policy responsibilities ............................................................................. 215

Policies previously administered by CIOB ............................................................... 224

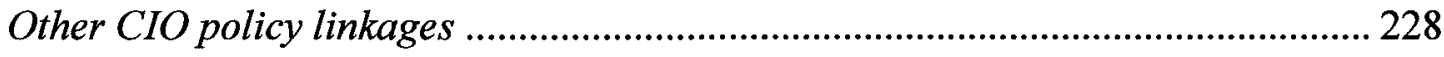

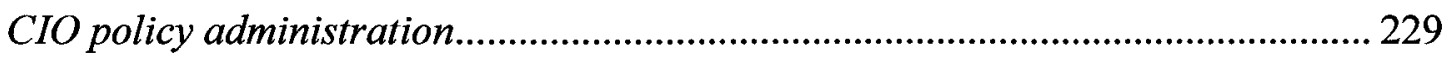

The Treasury Board model and IM/IT-defined relationships...................................... 231

Policy agents in departments ................................................................................ 231 


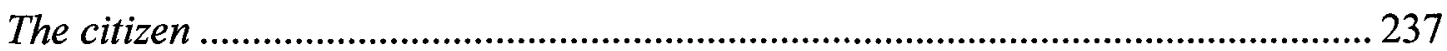

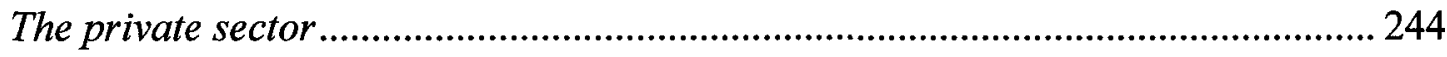

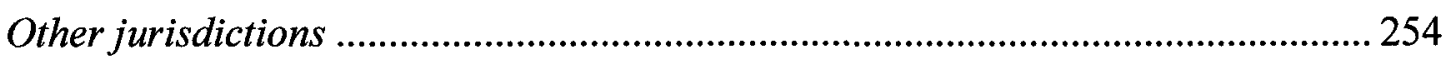

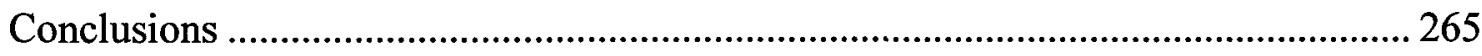

Chapter 5 - The Pivotal Role of Information Management ……………………....... 270

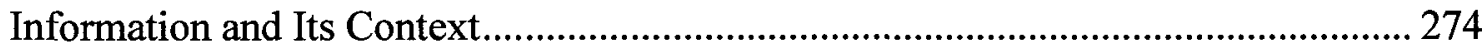

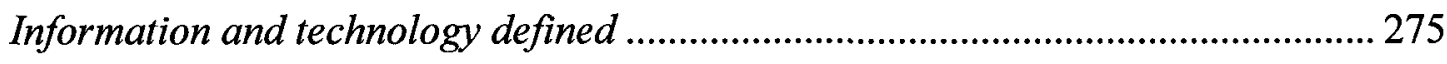

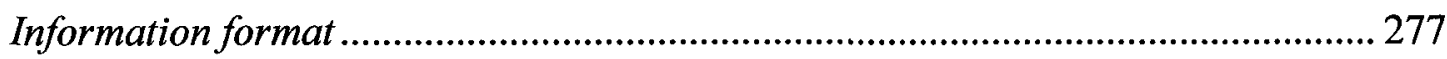

Information hierarchy ...................................................................................... 280

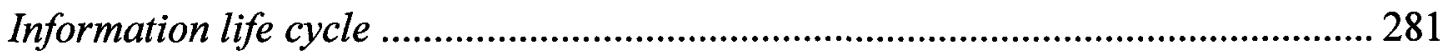

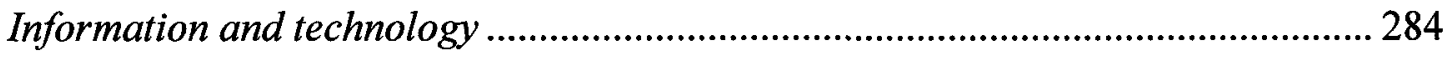

Information and public administration ................................................................. 286

The Challenges to Effective Information Management and CIO Success ................... 291

Historical roots of records and information management ....................................... 292

The $C I O$ and information management in a technological context ........................... 298

The internal dynamics of information management .................................................... 303

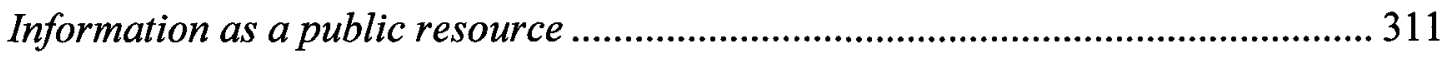

The governance and politics of information management ......................................... 318

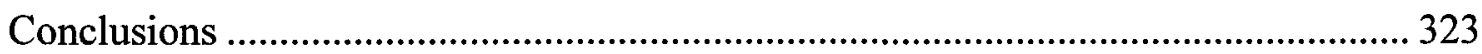

Chapter 6 - A Faster Lane on the Information Highway: The Ontario Corporate CIO. 328

Relevance of the Ontario Case and Research Sources ............................................... 329

Institutional Pathways (1867-1995)........................................................................ 335

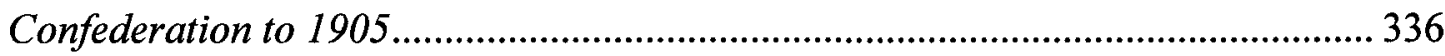

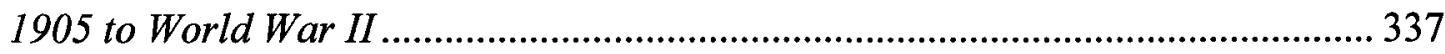

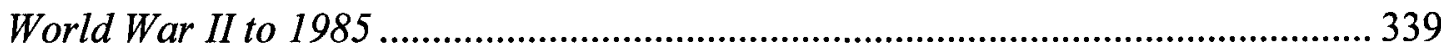

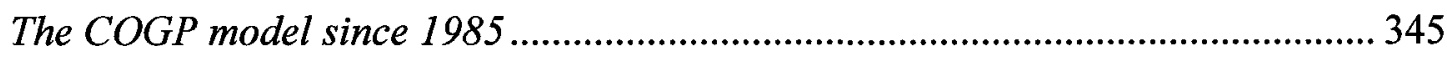

Establishment and Evolution of the Corporate CIO .................................................... 353

Cabinet and central management agencies under Harris, Eves and McGuinty...... 353

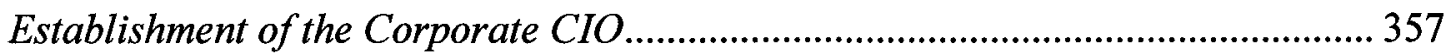

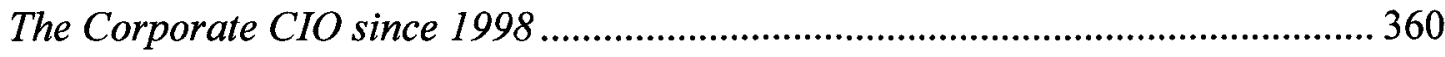

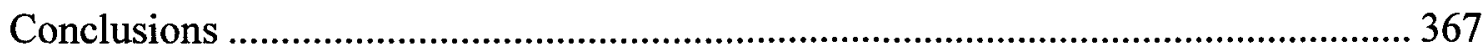




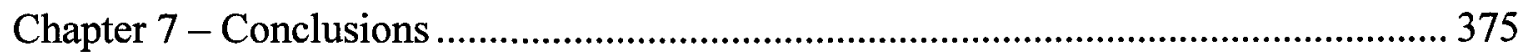

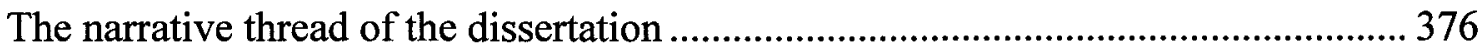

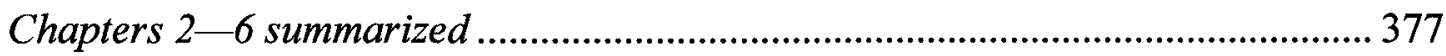

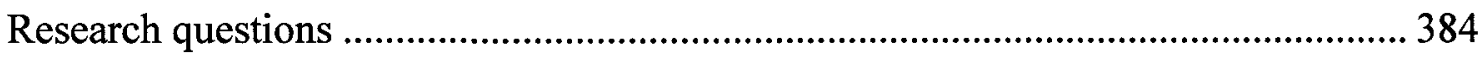

The impact of networked information and communications technologies ................. 386

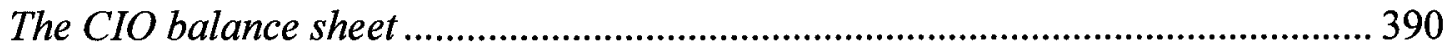

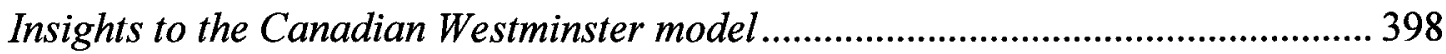

Implications for the study of Canadian public administration ................................. 402

A theoretical lens on the continuity of change ........................................................... 404

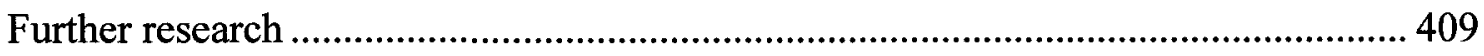

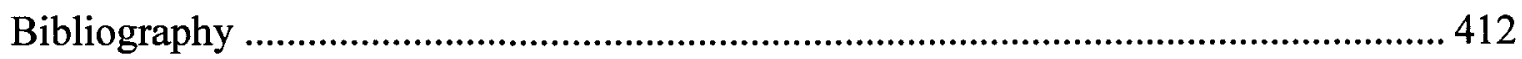

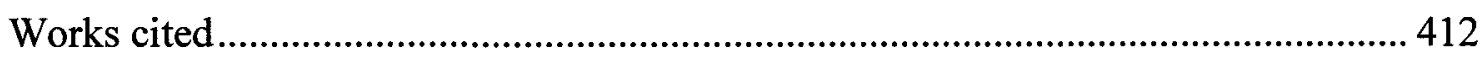

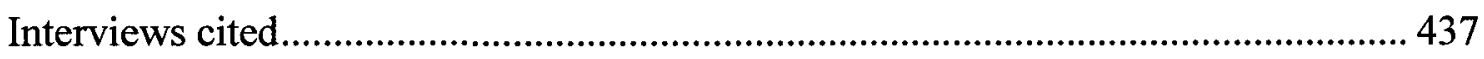

Annex 1: Treasury Board Chief Information Officers and Acting Chief Information Officers

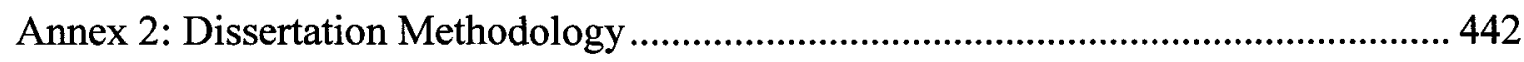

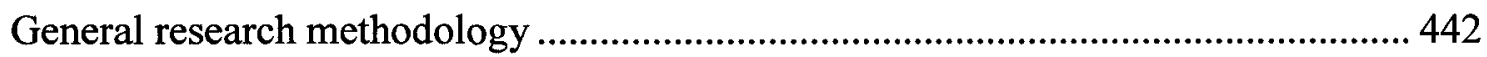

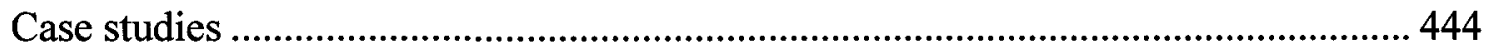

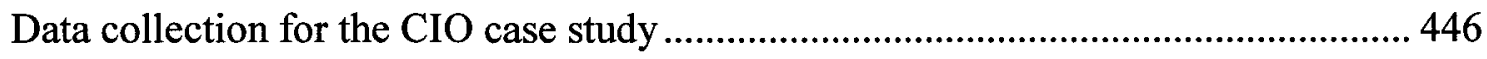

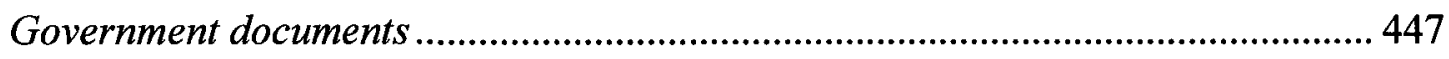

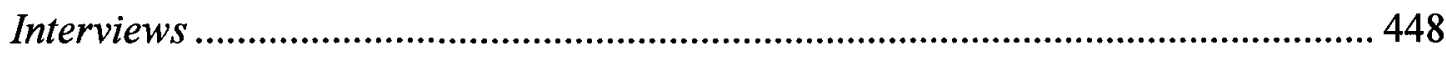

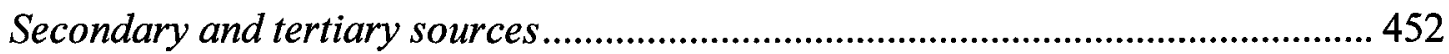

Administrative aspects of the dissertation research project.......................................... 453

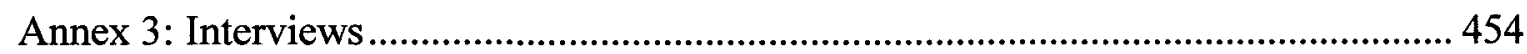

Annex 4: Interview Protocol and Consent Form ........................................................ 460

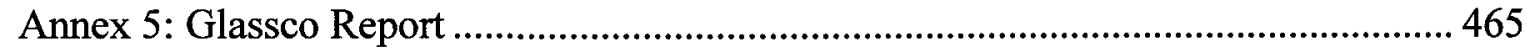

Annex 6: CIO and CIO-related Treasury Board Policies .................................................. 466

Annex 7: CIO and CIO-related Legislation and Regulations .......................................... 470

Annex 8: CIO and CIO-related Government Institutions ................................................. 474

Annex 9 - CIO-related occupational groups (October 2010) .......................................... 476

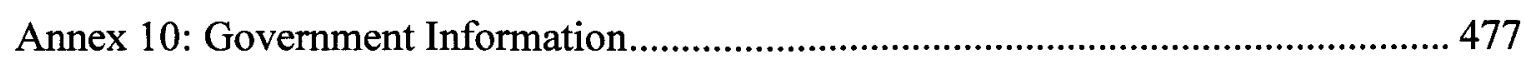




\section{List of Tables}

\section{Chapter 5}

Figure 1: Records and Information Management Life Cycle .................................. 281

Figure 2: Planned Universe of Information Management Policy Instruments .............. 315 


\section{List of Annexes}

1. Treasury Board Secretariat Chief Information Officers

2. Dissertation methodology

3. Interviews

4. Interview protocol and consent form

5. Glassco Report

6. $\quad \mathrm{CIO}$ and CIO-related Treasury Board policies

7. CIO and CIO-related legislation

8. $\mathrm{CIO}$ and CIO-related institutions

9. CIO-related occupational groups

10. Government information 


\section{List of Abbreviations}

ACIM Advisory Committee on Information Management

APB Administrative Policy Branch

ATI Access to Information

ATIP Access to Information and Privacy

BGO Bureau of Government Organization

BNA British North America

CAR Council for Administrative Renewal

CATA Canadian Advanced Technology Association

CCIO Corporate Chief Information Officer (Government of Ontario)

CSPS Canada School of Public Service

CHRO Chief Human Resources Officer

CIO Chief Information Officer

CIOB Chief Information Officer Branch

COGP Committee on Government Productivity

CRTC Canadian Radio-television and Telecommunications Commission

CSC Civil Service Commission

DPW Department of Public Works

DSS Department of Supply and Services

FAA Financial Administration Act

FIP Federal Identity Program

FOIP Freedom of Information and Privacy

GOL Government On-Line

GTEC Government Technology Week

GTIS Government Telecommunications and Informatics Services

HRDC Department of Human Resources Development

HRSDC Department of Human Resources and Skills Development

ICTs Information and Communications Technologies

IM Information Management

IMST Information Management Systems and Technology Sector

IPAC Institute of Public Administration of Canada 
ICA International Council for Information Technology in Government Administration

ICCS Institute for Citizen-Centred Service

IHAC Information Highway Advisory Council

IT Information Technology

ITAC Information Technology Association of Canada

ITSB Information Technology Services Branch

LAC Library and Archives Canada

MAF Management Accountability Framework

MBS Management Board Secretariat (Government of Ontario)

MGS Ministry of Government Services (Government of Ontario)

MIB Management Improvement Branch

NPM New Public Management

OCG Office of the Comptroller General

OECD Organisation for Economic Cooperation and Development

OPS Ontario Public Service

ORO Organizational Readiness Office

PCO Privy Council Office

PMO Prime Minister's Office

PS 2000 Public Service 2000

PSC Public Service Commission

PSCIOC Public Sector CIO Council

PSSDC Public Sector Service Delivery Council

PWGSC Department of Public Works and Government Services

SEN Senior Executive Network

SII Service Improvement Initiative

SITT Spectrum, Information Technology and Telecommunications Sector

STAC Treasury Board Secretariat Transition Advisory Committee

TBS Treasury Board Secretariat

TBSAC Treasury Board Secretariat Advisory Committee

TIMS TBSAC Information Management Sub-committee

UPC United Province of Canada

Y2K Year 2000 


\section{Chapter 1 - Introduction}

Little systematic research has documented the evolving style and capacities of central agencies in different functional domains.

(Lindquist 2006: 31)

On June 25, 1993 Andy Macdonald was appointed Chief Informatics Officer (CIO) of the Government of Canada, reporting to the Secretary of the Treasury Board, Ian Clark. While his responsibilities were not precisely defined at the outset, and continued to evolve during his 20-month tenure, they did combine a number of previously unconnected public sector management concerns into a higher-level and more integrated package of responsibilities within the horizontal governance of the Government of Canada. Macdonald's appointment as CIO was linked to, although not explicitly part of, the major reorganization of the federal Cabinet and public service undertaken by Kim Campbell when she became Prime Minister after the retirement of Brian Mulroney. He owed that appointment to a number of circumstances, not least the abolition of his previous position as the Comptroller-General of Canada, an independent office that was wound up in the reorganization and folded into Treasury Board Secretariat (TBS).

While the establishment of the CIO position and its supporting office within TBS was at least in part personality-driven, these developments were also a response to internal and external forces that were reshaping Canadian society and public administration as a result of the movement into the economic and social mainstream of new information and communications technologies (ICTs) ${ }^{1}$. These included, notably,

\footnotetext{
${ }^{1}$ North American usage generally refers to information technology (IT) or information systems (IS) while Europeans and multilateral organizations more often refer to information and communications technologies (ICTs) when discussing essentially the same phenomena. "ICTs" is more evocative as it clearly encompasses the various communication and telecommunication policy fields as well as IT in the narrower sense of computing, data processing, office automation and related infrastructure. North American use of the term information technology/IT generally does not distinguish between the narrower and broader dimensions. The dissertation uses "ICT" as the umbrella term, while "IT" refers to the narrower sub-set.
} 
distributed computing technologies and their convergence with telecommunications and broadcasting technologies through the Internet and the World Wide Web.

A related change that was part of the Campbell reorganization was the merger of two existing agencies that provided computing and telecommunications services to the government into a new Government Telecommunications and Informatics Services (GTIS) and its incorporation into a consolidated common services department, Public Works and Supply and Services. No direct link was drawn between GTIS and the CIO in the reorganization announcement (Canada PMO 1993), but in the nature of the federal government's established organizational doctrine, its responsibilities made it an important actor in the domain in which the CIO could be expected to provide leadership.

In the years since 1993, the CIO position has become well established in TBS, although with numerous changes in title and organizational responsibilities. Still reporting to the Secretary to Treasury Board, the $\mathrm{CIO}$ - which became the Chief Information Officer in 1997 - is recognized as the government's senior advisor on the use of ICTs and the management of information in its internal administration and in the provision of services to the Canadian public. Supported by a CIO Branch within TBS, much of the CIO's day-to-day authority is based on the suite of information and technology-related Treasury Board policies for which the CIO is responsible. These in turn define some or all of the responsibilities and roles of several other ICT-related federal organizations. Seven CIOs have been appointed, most recently in May 2009 (Canada TBS 2009). There have also been four acting CIOs for periods ranging from four to 16 months (see Annex 1 for the list of CIOs and Acting CIOs). These developments have been parallelled by the establishment of CIO positions in most federal departments 
and agencies, as well as in the provincial and territorial governments, creating a public sector functional universe in which the federal CIO plays a leadership role.

The creation and evolution of the CIO in response to ICTs but within Treasury Board and the larger Canadian Westminster model is the subject of this dissertation. It argues that the $\mathrm{CIO}$ is the product of an historically-conditioned institutional environment that has been well suited to absorbing new external forces such as ICTs. In the nature of the federal government's collective internal governance, the CIO's role and responsibilities have facilitated the systematic introduction of ICTs into the public sector, defining a new functional sector of public administration that has become well established (although still maturing), with a combination of traditional and new elements. At the same time, the circumstances of the creation of the CIO - linked to but not directly part of a major restructuring of the federal government - put in place an inherently weak CIO position that can, however, achieve strong results under the right circumstances. Whether the CIO is confined to being the public service's functional leader in the management of an expensive, inherently risky but growing asset base or serves as the government's chief innovator in moving towards a vision of knowledge-based government depends on the level of support and direction provided by the senior public service and politicians. A reinforcing factor is the degree to which the CIO's agenda is connected with related areas of economic and social public policy. The CIO's long-term prospects are most closely linked, however, to resolving tensions between the management of information and of technology and in particular overcoming the limitations imposed by the political sensitivity of government information. 


\section{Developing a research approach}

The appointment of the TBS CIO in 1993 and the subsequent evolution of the position and related administrative environment have created a new institutional phenomenon in the Canadian public sector that is worthy of description and analysis in its own terms. These developments also raise questions with respect to their implications for the structure and dynamics of the institutional environment in which they have occurred (i.e., the Treasury Board model of collective management within the Canadian variant of the Westminster governance model) and for understanding and conceptualizing an emerging new functional component of Canadian public administration.

These three sets of issues provide the context for this dissertation. It is based on a program of research that is described in this chapter. The chapter begins with a discussion of considerations in designing research about a social phenomenon that provide a framework for the dissertation. It then outlines the research questions that the dissertation seeks to answer, growing out of the circumstances of the CIO case and literature related to the three dimensions of the case. The questions provide the frame of reference for the dissertation's research strategy. The dissertation is structured around a single case study, and the research strategy section of the chapter begins with a discussion of the general approach followed by a discussion of the working hypotheses that were used in data collection and analysis. The next section summarizes the theoretical lens that is used to frame the data collection and analysis. This is followed by a section summarizing the data collection and analysis methodology, which includes extensive use of key-informant elite interviews and other qualitative sources. (A more detailed discussion is found in Annex

2.) The chapter concludes with an outline of the dissertation's five substantive chapters. 


\section{Designing research}

In his book Designing Social Research: The Logic of Anticipation (Blaikie 2000), Robert Blaikie describes five types of objectives in basic social science research: to explore, attempting to develop an initial, rough description or understanding of a social phenomenon; to describe, providing a detailed account of a phenomenon including establishing regularities; to explain, establishing the elements, factors or mechanisms (i.e., the causes) that are responsible for producing the regularities or phenomenon; to understand, establishing reasons for social action derived from the ones given by social actors; and to predict, using established understanding or explanations to postulate certain outcomes under particular conditions (72-78). Three additional types of objectives relate to applied research: to change, to evaluate and to assess the impacts (78-82). While the analysis in the dissertation may in some areas point towards policy-oriented lines of enquiry, this is not its purpose; the focus is on basic research, as defined by Blaikie's initial five questions.

In Blaikie's model, research objectives shape the research questions that define the nature and scope of the research project. He identifies three types of research questions that can be associated in various combinations with the types of research objectives: what, how, and why? These are inter-related, but generally "what" questions apply to exploration and description, looking for characteristics and patterns. "Why" questions relate to explanation and understanding, looking for causes and relationships. Prediction is a form of "what" question ("what is likely to happen?), whereas "how" questions enter into the realm of using research to support a case for change (83). 
The means of answering research questions is a general research strategy, which provides the logic of the enquiry and, based on that, a specific research design which can include one or more methods of collecting data and sets the boundaries of the project, including those in time and space. Within the assumptions of the research design, the data should provide a basis for reaching research conclusions (9-11). While Blaikie considers that a case study is a method of data selection $(10,213-225)$, Yin sees it as a form of research strategy (Yin 2003: 2-4). This dissertation adopts Yin's case study approach, within Blaikie's broader research framework, and its application is discussed in the section on research methodology later in this chapter and in Annex 2.

Blaikie describes four major research strategies, each with its own logic and embodying different combinations of ontological assumptions about the nature of reality and epistemological assumptions about how that reality can be known. Induction accumulates observations or data to produce generalizations or "laws" as patterns to explain further observations. Deduction seeks to test hypotheses based on theory by matching them with data, eliminating false theories and corroborating others. Retroduction uses a process of model building to discover an underlying mechanism in order to explain observed regularities. Abduction seeks to describe and understand social life in terms of the motives and accounts of social actors (Blaikie 2000: 101). The first two are particularly relevant to this dissertation.

Each of these strategies, by its nature, emphasizes a particular combination of research objectives and questions. Inductive strategies are well suited to "what" questions with a view to exploration and description. Deductive strategies do well at explanation ("why"), while deductive strategies - and inductive to a lesser degree - are best suited to 
prediction. A combination of strategies can be pursued to develop answers to different questions, although, according to Blaikie (ch. 5), they need to share ontological assumptions (as do induction and deduction) in order to be used in the same context or else they should be used in sequence (one approach answers "what," another "why").

Theory plays an important role in social research, used to generate research questions and as a reference point for theory testing. Theory is particularly relevant to "why" questions and some aspects of "how," but not to "what." Hypotheses are tentative answers to research questions - whether theoretically or empirically generated - stated in the form of a particular kind of relationship between two concepts (27). Blaikie argues that each research strategy entails a different view of what constitutes theory and how it enters into the research process, including the extent to which theory is required at all. (26) Induction seeks to develop theory from an accumulation of observations. Deduction uses established or newly-developed theory to shape data collection and analysis, with a view to testing and refining theory (139-140). Theories operate at several levels, sometimes simultaneously, ranging from "grand" theories (system theory applying to society as a whole) through "middle range theories" to substantive theories in specific problem areas (143-145).

These considerations are drawn upon to structure the research strategy for this dissertation, which constitutes a major project in basic social research. The next section considers the research questions that are raised by the $\mathrm{CIO}$ case, in its three dimensions, and in that light the following section outlines the research strategy that was adopted. 


\section{Research questions and related literature}

This section sets out the three major research issues and related questions that are discussed in the dissertation. These are derived in the first instance from the empirical context of the CIO case study - to the extent that that is possible - and also from a review of the relevant literature. The section provides the reference point for the research strategy that is outlined in the following section, including the working hypotheses that provide the structure for data collection and analysis.

Because the full impact of contemporary ICTs has been felt in the public sector only in the past twenty years, the literature that is directly related to the topic of the dissertation is in most cases relatively new, although rapidly expanding. There is no single body of theory and knowledge to draw on to describe the political, administrative and theoretical context for the $\mathrm{CIO}$, to explain its emergence and evolution or to assess its future prospects. The three research areas that provide the framework for the CIO case study do each have a related literature that is useful in varying degrees. Much of the discussion is at the level of Blaikie's exploratory and descriptive research, providing an initial comprehensive description of the $\mathrm{CIO}$ as a social (more precisely, an institutional) phenomenon and an initial account of its regularities. This provides a basis for explanatory discussion and some prediction.

The federal CIO has counterparts in all the provinces, most OECD countries and a growing number of developing countries, some with very similar arrangements. Indeed, as discussed in chapter 4 , a characteristic of the CIO position and the ICT-oriented sphere of public administration is the degree to which there is - both within Canada and internationally - interjurisdictional awareness, comparison, learning, collaboration and 
even competition. This is therefore a topic that lends itself to comparative analysis, and over the longer term the comparative and interjurisdictional aspect will be a fruitful area for research. Nevertheless, this research project has not taken up that challenge, with the partial exception of the Government of Ontario Corporate CIO, which is presented in chapter 6 as a mini-case study. The single-case focus is partly to keep the scope of the project manageable but also to ensure that there is a comprehensive base of research on the Canadian federal case, among other things to make future comparative studies more fruitful. As a result, the discussion of research questions does not draw systematically on literature from other countries - notably Australia, the United Kingdom and the United States - that addresses the issues in this dissertation, although international literature is used in various contexts.

\section{The CIO story}

The most basic research questions relate to the CIO case in its own terms: what happened in 1993; what has happened in the intervening years, in terms of roles and responsibilities as well as of actors; and how can this be explained by those involved? This is particularly important in a context where the major technology drivers and many of the ideas about how to deal with them came from outside government - including the concept of a $\mathrm{CIO}$ as well as several of the CIOs themselves. Another set of issues relates to the impact of change at the political and senior administrative levels and of related changes in government policies and priorities.

As a new and relatively recently-created position and institutional environment within the Government of Canada, there is as yet no institutional history of the CIO, either internal or in the academic literature. Interviews conducted during the research for 
this dissertation revealed a limited corporate memory within the TBS CIO Branch (CIOB), in terms either of an oral history understanding among current incumbents of the origins and evolution of the office or of an organized documentary record (rather ironically, given that it is the organization responsible for record- keeping policies and procedures within the federal government.) This is reflected in the fact that there is no historical information about either the position or the branch on the CIOB website (TBS 2010a), underscoring Marson's lament about "organizational Alzheimer's" in the federal government (Marson 2005).

There is therefore scope for a case study that provides a comprehensive account and analysis of the $\mathrm{CIO}$ and its related institutional and management policy environment. A number of authors have provided sightings of aspects of the CIO story in the context of a discussion of thematic issues or of major government initiatives in which the CIO has been involved. A rare conceptual discussion of the organizational challenges in establishing a CIO position is provided by Borins and Wolf (2000), in the context of the then new phenomenon of Alternative Service Delivery. Brown gave a brief early account of the CIO position in the context of a practitioner's view of information technology as an emerging issue for Canadian public administration (Brown 1997) and updated that sighting in more recent papers on the federal government's Government On-Line (GOL) initiative, which was led by the CIO (Brown 2005a and 2007). This dissertation builds on that earlier work and gives it a more academic orientation.

Indirect, but evocative, sightings of the federal CIO are provided by three comparative e-government studies. Borins and Wolf's analysis is primarily based on research on the federal CIO conducted in the late 1990s, after it had been in place for half 
a decade, although they generalize their findings beyond the federal institutional context. Their conclusion that the federal government CIO corresponds to a "weak CIO" model provides the basis for one of this dissertation's working hypotheses. A few years later, Culbertson summarized the findings of an OECD study of e-government, including its organizational dimensions (Culbertson 2004), that drew on the early stages of GOL. A couple of years later, Dunleavy et al. (2006) included the federal government in a sevennation comparative study of "digital era governance," basing their Canadian observations on GOL at its height. The view provided of the CIO in these three studies is discussed in greater detail in chapter 3. On the other hand, Charih and Robert (2004), writing about the organizational issues relating to GOL, discuss the implications of ICTs for how government delivers services to the public and interacts with society at large, but they do not look at the CIO or other impacts on TBS and the federal government.

The closest to a CIO case study is Borins' account of the Ontario Corporate CIO (CCIO), although it is primarily from the point of view of the related agenda, rather than institutional dynamics (Borins 2007b). Borins and Brown take a comparative look at the federal $\mathrm{CIO}$ and Ontario CCIO in the context of discussions of e-consultation and digital leadership (Borins and Brown 2007a and 2007b). The Ontario mini-case study in chapter 6 builds on this literature.

Several authors have considered issues which touch on aspects of the CIO's role and responsibilities. The most wide-ranging thematic discussion is by Roy, who provides numerous sightings of the federal and some of the provincial CIOs, including the working relationships among them (Roy 2006). His focus, however, is on four themes of service, security, transparency and trust, within the larger rubric of e-government, and he does not 
provide a systematic analysis of the $\mathrm{ClO}$ as an institution or of its place within the federal machinery of government. His analyses of service and security do look critically at GOL and the Secure Channel, one of its major components, while his discussion of trust focuses on privacy and security issues for which the CIO has policy responsibility. With respect to transparency, he looks at public consultation and access to information - again areas where the CIO has had a policy role.

The CIO's work relates to both internal government administration and service to the public. One body of literature considers the internal administrative impacts of ICTs, in particular the effects on records and information management, two closely-related areas for which the CIO is responsible. Crossing Boundaries, a not-for-profit initiative jointly financed by the federal and provincial governments, argues that information should be understood and treated as a public resource (Lenihan et al. 2002), while Bontis advocates leveraging the public sector's intellectual capital through knowledge management (Bontis 2007b). A related, but largely distinct, literature concerns the relationship between access to information and accountability (for example, Robertson 1978, Reid 2004, Roberts 2006). The CIO's role in these issues is discussed in chapter 5.

A growing literature looks at the impact of ICTs on government services to the public, both in conceptual terms (Kernaghan and Gunraj 2004, Kernaghan 2005 and 2007a, Heintzman and Marson 2005) and in the context of the adoption in government of private sector e-commerce tools such as client relationship management (Bontis 2007a). Some authors have looked specifically at two major initiatives in the federal government: GOL, which was led by the CIO (Charih and Robert 2004, Brown 2005a and 2007, Roy 
2008); and Service Canada (Flumian et al. 2007, Marson and Heintzman 2009), with which the CIO has had a more complex relationship - as discussed in chapters 3 and 4 .

Much of this discussion intersects with a rapidly expanding literature under the heading of e-government, an underlying question being whether this constitutes a new academic field or merely a cross-disciplinary lens for interpreting recent developments relating to the public sector through the common filter of the effects of the introduction of ICTs. The e-government literature is international, largely independent of national institutional contexts and looking at what it argues is a universal set of phenomena. It can have a relatively narrow focus on specific areas of government where ICTs have had an impact, probably the most prominent being service to the public, echoing e-commerce literature about similar developments in the private sector. The authors cited in the previous paragraph can be seen as part of the Canadian branch of this literature, which exists with respect to most if not all systems of government and is a fruitful area for comparative research. The same can be said about related issues such as IT procurement and the closely related issue of public-private partnerships, (e.g., Langford and Harrison 2001 and Dutil et al. 2005 with respect to Canada and Dunleavy et al. 2004 and 2006 from a comparative perspective). Reflecting continuing technological innovations, a more recent international literature has begun to analyze "m-government" (mobile government - see for example Kushchu and Kuscu 2003 and Kushchu 2007), but it has not yet been captured in Canadian writing.

Broader definitions are also given to e-government, with the public policy and political processes sometimes included in this term (e.g., Brown 2005b) while at other times these are linked through concepts such as e-democracy (Barney 2005) or 
knowledge-based governance (Tapscott 1997) or placed under an umbrella description such as the digital state (Borins et al. 2007). Oliver and Sanders (2004) represents the most comprehensive survey of the various dimensions of e-government in the Canadian context. Issues that are covered by other authors in this broader territory include: the relationship between parliamentarians and public servants (Malloy 2003b), electronic democracy (Alexander and Pal 1998), use of ICTs by political parties (Cross 1998), in election campaigns (Kernaghan 2007b) and in the legislature (Kernaghan 2007c), as well as electronic consultation (Borins and Brown 2007a) and electronic networks in the policy process (McNutt 2006, McNutt and Carey 2008). There are so far only limited debates within this body of literature, however, as the emphasis has been on understanding a new phenomenon. In addition, its relevance to the $\mathrm{CIO}$ has varied over time, related in particular to the extent to which the CIO's institutional universe has included government communications with the public. Chapter 3 discusses how the egovernment literature treats institutional concerns embodied in the CIO.

An account of the CIO, then, has a significant "what" dimension to it, both to explore a still emerging area of public administration and in particular to provide a comprehensive description of the position itself and of the areas of government activity that are linked to its responsibilities. These have changed over time, and there is also an important "why" dimension, to explain both the establishment of the position and its evolution. The elements of the CIO story are discussed in chapters 2 and 3. Chapter 2 discusses the historical background and chapter 3 looks at the establishment of the position and the evolution of its role and responsibilities to the present day. An important 
part of this discussion, however, is the governance model in which the TBS CIO is embedded, and this is considered in the next part of this section.

\section{Treasury Board and the Canadian Westminster model}

A second line of enquiry is to situate these developments in the continuing evolution of the role of the Treasury Board committee of ministers and of the Treasury Board Secretariat (TBS), the central agency that supports it. This is one of the unique features of the Canadian version of the Westminster model of public sector governance and provides the institutional context for the establishment and evolution of the CIO. The Westminster model is multi-faceted, establishing a comprehensive governance environment that focuses on the division of labour between the executive and legislature as well as between levels of government, in the Canadian case through the system of federalism. The elements of the Canadian Westminster model are interconnected, and change in one area can be expected to have consequential effects in most, if not all, areas. This dissertation concentrates, however, on the dynamics within the executive branch, focusing on Treasury Board, TBS and the CIO in the context of an organizational taxonomy and doctrine that has been in place in the federal government since the 1960s. In the nature of the effects of ICTs on federal public administration, it also looks at their impacts on the practice of Canadian federalism.

The Treasury Board model is well-established, and it is tempting to regard the creation of a CIO within TBS in response to externally-driven ICT forces as a case of an immovable object meeting an irresistible force. The reality is of course more subtle, but it does raise the dual questions of how that model influenced the introduction of the CIO position and in turn what adjustments have been made to it in response to the particular 
nature of ICTs and the agenda they carry with them. A common theme in the egovernment literature is that ICTs can be "transformative" with respect to public sector institutions and administrative processes, so it is important to explore whether this is indeed happening - and to what extent - in the government of Canada. An important contextual factor, even before the wave of ICTs in the 1990s, was the growing influence of the New Public Management, with its emphasis on decentralization and empowering managers. This has intersected with a longstanding debate about whether ICTs are inherently centralizing or decentralizing and, in turn, with an endemic tension in the Canadian system between collective and individual ministerial responsibility. An underlying debate is whether Canada's Westminster-based governing and administrative institutions are suited to the networked world and in need of reform.

The Canadian Westminster model has been characterized since colonial times by a strong executive and weak assembly and has three features that are particularly important in the context of the introduction of the CIO position. The first is a highly institutionalized concept of collective authority and accountability, with Treasury Board as a statutory committee of Cabinet exercising specified management and expenditure control authorities on behalf of the government. The modern Treasury Board grew out of the Glassco Report (Canada Glassco 1961-1963 1-5), which for the purposes of organizing management made a distinction between the general interests of government and those of departments (Canada Glassco 1962 1: 51). Treasury Board combines oversight of the aspects of management practice that have been considered important traditionally financial and personnel management - with central control of government spending. Oversight is primarily in the form of management policies approved by the 
ministerial committee that provide a horizontal (i.e., government-wide) framework of goals, requirements, procedures and accountabilities that are superimposed on the vertical accountabilities in individual program areas. These policies also define the responsibilities of functional experts in departments, who under the Glassco model have a dual role of supporting departmental program management in carrying out their work while ensuring that government-wide management policy objectives are met.

A second feature is an organizational doctrine, coming out of the Glassco Report, that uses three departmental models - program departments, central agencies and common service organizations. Program departments are the organizational instruments of government policy and delivery of programs and services to the public and society; they and their ministers are the public face of government and their accountability includes both policy development and implementation of the program instruments for which they are responsible. Central agencies are defined as the public service support to Cabinet (i.e., collective) decision-making and resource allocation (Sutherland 1993: 90); they are relatively small and oriented to supporting the collective decision-making process and the ministers who provide collective leadership to the government, notably the Prime Minister, the Minister of Finance and the President of the Treasury Board, as chair of Treasury Board. A key tenet is that central agencies do not have program delivery responsibilities, both because they do not have the necessary skills or sustained interest and because the line departmental model is more conducive to accountability for operational activities. Treasury Board Secretariat (TBS) is defined by its role as the secretariat to the Treasury Board committee of Cabinet and by extension as the administrator of Treasury Board management policies. When the CIO was created in 1993 it was situated in this central agency model. 
There are, however, a number of administrative functions - primarily services to government - that for various reasons of policy, cost and practicality government wants to centralize. Generically these are performed by common service organizations, by far the most important of which is Public Works and Government Services Canada (PWGSC). A crucial principal of common service organizations, however, is their unique accountability model. Because of their operational nature they are organized on the vertical hierarchical model of program departments. But, unlike program departments, the related policy development and oversight functions are housed in central agencies, usually the Treasury Board Secretariat (TBS). This creates a dual accountability model in any given area of corporate management: TBS is accountable for developing and overseeing implementation of policies that apply in a common manner to all departments, relating to management of the government as a whole; common service organizations are accountable for implementation of service functions assigned to them by government management policy. This model was in play when GTIS was created to provide information technology common services within PWGSC in the 1993 reorganization.

The third notable feature of the Canadian Westminster model is the systematic use of organizational design as a policy instrument. Formally the Royal Commission on Government Organization, the Glassco Commission represented a conscious attempt to embed systematic management principles into the institutional structure of the federal government. Implementation of its report was overseen by a Bureau of Government Organization, initially located in the Privy Council Office (PCO) and later forming the nucleus of a freestanding TBS (Hodgetts 1973: 260-261, Yeomans interview). Subsequently, a Machinery of Government unit was established in PCO to advise the 
Prime Minister on the organization of Cabinet and changes and innovations in the structuring of ministerial portfolios, within the framework of the organizational taxonomy outlined above (Campbell and Szablowski 1979: 33). This capability lay behind a continuous process of policy-driven government restructuring from the late 1960s onward, including the 1993 reorganization. While the machinery of government function has not been a major focus of Canadian academic writing, there has been some discussion of the application of the systematic central agency model in particular, initially as an important new development (Campbell and Szablowski 1979, French 1980), later as a source of concern (Savoie 1999 and 2003).

A key research question, then, is how these features of the Canadian Westminster model influenced the introduction of the CIO and its subsequent evolution. The evolution and details of the model are elaborated and its influence is discussed in chapters 2 and 4 in particular. The introduction of the CIO came in the context of three sets of more conceptual debates that are also relevant. These relate to: the balance between centralization and decentralization within the government as a whole; the influence of private sector management practices, embodied in but not confined to the New Public Management (NPM); and the impact of ICTs on public administration. The centralization-decentralization debate was initially in the context of the post-Glassco organizational doctrine, but later it was subsumed by discussion about the application of NPM principles. Interest in the potential impact of technology grew gradually in parallel with the other two but became intertwined with them as networked technologies came into the mainstream, giving a second wind to NPM. Cumulatively these issues point to the issue of how transformative ICTs have been in the Canadian case. 
The first debate is inherent in the post-Glassco model: striking the balance between managing the government as a single entity and as a series of departmental programs, building on the Glassco commission's distinction between the general and departmental interests. The commission recommended replacing an interventionist central control regime, epitomized by the old Comptroller of the Treasury, with a more decentralized management environment based on common standards and supporting institutions. This has since been articulated in terms of striking a balance between collective and individual ministerial responsibility (Canada PCO 1977 \& 1993, d'Ombrain 2007).

Finding this balance was a common thread in much of the literature on Treasury Board and TBS in the post-Glassco period, with particular attention being paid to its budgetary role and the effort to link budgeting and management, especially in the area of financial management (White and Strick 1970, Johnson 1971 and 1973, Hicks 1973, Hartle 1973 and 1983, Veilleux and Savoie 1988). A related context where the centralization/decentralization debate played out was with respect to the post-Comptroller of the Treasury financial management control regime, shaped by Auditor General concerns after a decade of post-Glassco experience (Sutherland 1980), the subsequent establishment and report of the Royal Commission on Financial Management (the Lambert Commission - Canada Lambert 1979) and the evolving office of Comptroller General - all with implications for Treasury Board (Charih 1989 and 1991) including, as discussed in chapters 2 and 3 , for the CIO.

This earlier literature was primarily in the context of the theory and dynamics of the Glassco organizational model. By the late 1980 s it, and TBS, were increasingly challenged by broader debates about the role and management of the public sector and the extent to 
which it should adopt private sector practices and even collaborate with the private sector in the management of public services. This school of thought, which has variously been characterized as managerialism (Pollitt 1990 and 1998) and the New Public Management (NPM - Charih and Daniels 1997), was a major factor in the launching of Public Service 2000 (PS 2000), a reform initiative under the sponsorship of Prime Minister Brian Mulroney with the goal of clarifying and simplifying systems of personnel and administrative control (Canada PMO 1990). A 1990 White Paper committed the government to a program of management renewal based on principles of service, innovation, people and accountability (Canada PCO 1990), all compatible with $\mathrm{NPM}^{2}{ }^{2}$ with the developmental work carried out by a series of task forces (Tellier 1990 and 1992, Kernaghan 1991, McIntosh 1991, Rawson 1991). A follow-up effort sought to strengthen values and ethics in the public service, at least in part as an alternative to control-based management regimes (Kernaghan 1994, Tait 1997).

The shift in emphasis towards empowerment of managers and values-based control was reflected in concerns in the literature about deregulation and empowerment (for example, Aucoin and Bakvis (1988) refer to the "centralization-decentralization conundrum") and the cumulative effect on TBS when the severe Program Review budget cuts of the mid-1990s were factored in (Clark 1994). Program Review also gave rise in the 1990s to Alternative Service Delivery agencies such as the Canada Revenue Agency and other experiments in

\footnotetext{
${ }^{2}$ There is a comparative public administration debate that is not directly addressed in this dissertation as to why Canada was a less enthusiastic adopter of NPM than the United States or other Westminster model countries such as New Zealand and Britain. For example, Dunleavy et al. (2006) rank Canada behind most others among seven leading OECD countries in terms of sensitivity to NPM. An important part of the answer is that Canada already had a long tradition of importing private sector management practices into public administration, not least the Glassco report but going back to the introduction of a classification system based on scientific management principles in the years after World War I (Hodgetts 1973: 24 - see also chapter 2). In the years after the Glassco Report, this translated into what can be seen as a process of continuous improvement - an NPM core principle - that includes the 1993 reorganization. Arguably the federal government was already well advanced in addressing the issues raised by NPM and as a result NPM was systemically less challenging.
} 
organizational design intended to limit the reach of Treasury Board policies and tailor management regimes to program delivery in highly operational areas (d'Ombrain 2000, Brown 2009b).

In the past decade there has been less written specifically about Treasury Board and TBS, apart from Savoie's general critique of an overly powerful centre of government and the resulting emergence of "court government" in both Canada and the UK (Savoie 2008). The centralization-decentralization issue was an underlying concern, however, in the discussion following the grants and contributions and sponsorship scandals, which can be seen as a turning of the wheel back towards common standards and procedures, again with a particular emphasis on financial management and comptrollership issues (Bakvis and Juillet 2004, Good 2003 and 2007, Lindquist 2004). Another wave of commentary relates to the Harper government's 2006 Federal Accountability Act, which sought to strengthen line accountability by establishing a new set of common rules and entrenching the accounting officer principle (Franks 2009), reinforced by a variety of parliamentary oversight mechanisms (Pross 2009) - although possibly going too far (Thomas 2009, Canada Tellier/Emerson 2011).

Very little of this literature considers the cumulative impact of recent developments on the post-Glassco government organization model and the balance between the centre and departments, or connects these issues to the establishment of the federal CIO position. ${ }^{3}$ Clark notes the creation of the CIO in the context of a larger update on TBS during his tenure as Secretary (Clark 1994: 242), but more recent Treasury Board Secretaries have not had the same urge to chronicle the evolution of TBS. There are

\footnotetext{
${ }^{3}$ Borins and Wolf (2000: 224-233) do ask how a CIO should be structured more generically, providing a reference point to which chapter 3 returns.
} 
several treatments of individual areas where the CIO has responsibility, including the GOL literature cited earlier, related issues such as IT security (Roy 2006), a pre-CIO sighting of Treasury Board information policy (Morton and Zink 1991) and a distinct strand of writing on Access to Information and Privacy (e.g., Roberts 2005 and 2006). With the exception of Roy, none of these focuses on the CIO or its TBS role to any extent. Similarly, there is little discussion of the implications for the CIO position of its location in TBS, with its well-entrenched pre-existing organizational doctrine (Brown 2007 is a partial exception). Indeed a question that was explored in the interviews for this dissertation was how CIOs and their staff have understood the traditional TBS model and whether they have seen themselves as governed by it; it is not clear, for example, that all CIOs or their staffs have seen their role in terms either of supporting collective accountability or of providing policy direction to common service functions. This is discussed in chapters 3 and 4.

There is only a very limited literature specifically about the impact of ICTs on the Westminster model (see below), but a number of authors address the broader context, beginning with an historical and philosophical literature about the impacts of technology on society and the state that pre-dates contemporary ICTs. Harold Adams Innis provides a classic account of the relationship between technology and empire in Empire and Communications (Innis 1950). In the context of ancient civilizations, Innis looks at the interplay between a number of communications technologies and governance dynamics; technology is an instrument of efficiency, and effective government of a large area - an ancient empire in his analysis, although he probably also has Canada in mind - "depends to a very large extent on the efficiency of communication" (5). Similarly, Jacques Ellul's 
The Technological Society argues that public administration and related ideas such as efficiency are themselves "techniques," i.e., forms of technology (Ellul 1964). This is borne out by the fact that the most effective uses of ICTs in public administration have occurred when they are harnessed with New Public Management concepts, for example the application of the citizen-centred service delivery concept (itself based on self-service models) through World Wide Web portals.

In discussing the evolution of communication technologies from early forms of the telegraph to the Internet, Rowland (2006) notes the continuing role of public administration and the military as sponsors and clients for new technologies, while also commenting on the fact that each new development surprised even its inventors, not to mention its government sponsors, when it was widely adopted by the public and forced adjustments that went well beyond the originally envisaged potential. He argues that the Internet is, along with the telephone, one of the few information and communications technologies that have realized its interactive potential, creating a more equal relationship between sender and receiver. He does not, however, explore the implications for the role and organization of government or its relations with citizens.

There has also been public administration-oriented writing about the management of various aspects of technology in administration since at least the 1950s. The impact of technology was one of the themes of Hodgetts' two histories of federal administration (Hodgetts 1955 and 1973), and paperwork and systems management were the subject of the Glassco Commission's Report 4 (Canada Glassco 1962 1). In the 1970s, well before networked computing, Braibant wrote about technology as an aid to decision-making and its effects on the distribution of powers in government, speculating that it had the 
potential both to strengthen the positions of those in ruling positions and to "create general assemblies in our urban and industrial societies and thus revive Rousseauism" (Braibant 1977: iii). Another analysis in the same publication discussed the dual elements of vertical centralization, giving coherence to government, and horizontal decentralization, bringing the citizen closer to government (Gallouedec-Genuys 1977).

These are themes that run through all the more recent literature. Snellen and van Donk (1998) talk about the inter-relation between hierarchy and network, while Fountain (2001) addresses the organizational implications of the networked model. While arguing that ecommerce and other private sector models are not always appropriate to the public sector, Andersen (1999) suggests that business process reengineering - a methodology linked to the introduction of IT - can provide both benefits and woes, rebuilding organizations while threatening management control and organizational culture, rebuilding relationships with citizens and companies while wasting money, creating "clean slate" changes in government but also damaging policy processes; the challenge is to balance the inherently non-rational political environment with managerial rationalism. Perri 6 (P6 2000) proposes that ICTs lead to "holistic governance." These commentaries have all been written in the international context, but much the same observations can be made with reference to Canadian experience, and in many ways they all return to the basic issue of striking a balance within a large institution between centralization and decentralization, the horizontal and the vertical.

Before concluding a discussion of the impact of ICTs on the Canadian Westminster model, there is at least one effect that deserves comment: on federalism, a defining element of the larger model. A major topic in its own right, this has received only limited treatment in the academic literature. A rare instance is Courchesne's analysis of the implications of the 
knowledge-based economy (KBE) for Quebec, arguing that "KBE sovereignty," by its nature, is more about exercising existing provincial powers than acquiring further powers (Courchesne 2004: 11) - in effect, ICTs do not change the structure of federalism but do have implications for how it operates. Telecommunications and broadcasting have long been subjects of federal-provincial jurisdictional debate; this has helped to condition the broader public policy environment in which the CIO has operated (see also chapters 2 and 3). More recently, the adoption of citizen-centred service delivery methodologies has brought the federal, provincial and even municipal governments closer together in providing Internetbased services to common citizen-clients. As discussed in chapter 4, the federal CIO has played a leading role in the emergence of a number of interjurisdictional institutions and processes that link together CIOs and service agencies.

Taken together, these issues bring the discussion back to the question of whether the Canadian Westminster model is able to meet the needs of the ICT-shaped networked economy and society (this is the reverse side of the coin to asking how "transformative" ICTs have been at the systemic level?) While this is a question that extends well beyond the realm of the CIO, a common thread is whether the federal governance environment is part of the problem or of the solution. There is very little directly related literature, but two starting points in such a debate can be cited. A negative answer is advanced by Roy, who argues that our Westminster-based governing and administrative institutions are ill-suited to the networked world and need to be reformed (Roy 2006 and 2008). McNutt and Carey are more positive, concluding that the move to digital government has been less fundamental in its implications, leading to a re-evaluation of service delivery but not requiring a significant reorganization of the state (McNutt and Carey 2008). Borins provides a third perspective, 
arguing that IT-enabled government demonstrates a number of important structural differences from traditional government, entailing a realignment into three organizational models: integrated service delivery to the public; joined-up policy development and knowledge management; and integrated support to government (Borins 2007a: 17). While he does not make a direct link to the Westminster model, Borins' e-government-inspired model is presented in the introduction to a book about the impact of ICTs on the governments of Canada and Ontario (Borins et al. 2007). The new organization described by Borins is sometimes referred to as the "three rooms" model and is elaborated in chapter 4.

The research questions that arise in the context of the implications for each other of the Canadian Westminster model and of the CIO are largely descriptive and explanatory, in the realm of "what?" and "why?" The post-Glassco organizational model was under stress when the CIO was established, so a central issue is to what extent it was consciously applied at that time and what its influence has been in later developments. Chapter 2 has a more detailed discussion of the development of the Canadian Westminster model and some of the related issues. The impact of ICTs on the Treasury Board Secretariat and its governance role within the federal public service is discussed in chapters 3 and 4 . Chapter 3 looks at the organizational adjustments that were made in TBS, PWGSC and elsewhere in the government following the establishment of the $\mathrm{CIO}$ position. Chapter 4 considers the nature of the TBS responsibilities that were defined by the CIO's mandate. As a point of comparison, chapter 6 traces the evolution and impact of the Westminster model as applied to the Government of Ontario. 


\section{Canadian public administration}

A third research area is the place accorded to the management of information and ICTs and to related leadership positions such as the CIO in Canadian public administration theory and academic writing. This is not a central concern of the dissertation, but it is evident from the research that there is scope for broadening the space that is assigned to these matters.

Traditionally, public administration as a discipline has been particularly concerned with systemic issues such as accountability or functional areas such as human resources management and financial management/comptrollership and associated policy concerns such as merit and financial integrity. To the extent that there is an institutional focus on individual management sectors, it is on the organizations and processes associated with these traditional spheres. While there is a considerable literature on the use of ICTs in public administration, in particular in the provision of services to the public, much less attention has been paid to the management of information and technology as a sector of public administration or to the institutional and governance dimensions of that sector. Where these issues are addressed it is invariably in a piecemeal fashion.

The situation can be illustrated by the various forms of scholarship sponsored by the Institute of Public Administration of Canada (IPAC), the primary national organization that convenes practitioners and academics to consider public sector management issues. In an article marking the $50^{\text {th }}$ anniversary of IPAC's journal, Canadian Public Administration $(C P A)$, Carroll and Kpessa reported that 28 articles published in $C P A$ between 1958 and 2006 - about $2.2 \%$ of the total of over 1200 - were on topics related to technology use and management, with the proportion rising to $4.7 \%$ in the final decade of 
the survey (Carroll and Kpessa 2007: 485). A similar result is arrived at in looking at the 190 "original articles" that were published in CPA in the decade from 2000 through 2009. Of these, 11 could be described as being about technology use and management or other topics that relate to the federal CIO's sphere of responsibility. The 11 articles, which cover all three levels of government, can be further categorized into five topic clusters: public-private partnerships (3), citizen-centred service (2), internal staff management (2), Access to Information and Privacy (3) and broader conceptual issues (1). Only the latter article (Kernaghan and Gunraj 2004) specifically addresses the issue of the integration of information technology into public administration, including a two paragraph discussion of the creation and role of the CIO (533-534). One article on public-private partnerships (Langford and Harrison 2001) also refers to the CIO in the context of the need for government-wide leadership in addressing partnership issues. The CIO is not mentioned in the remaining articles.

In the same vein, McConkey and Dutil analyzed 950 articles published over two years in 48 scholarly journals around the world, comparing this with the results of a survey of members of IPAC members, who are mainly practitioners (McConkey and Dutil 2006). "Technology change" and "Policy" came eighth among the ten areas that attracted the most interest in the articles, just behind "governance" (which includes New Public Management and horizontal governance) but well behind the leading topics, organizational culture, health policy, and regulation. The technology articles concentrated on two major subjects - the Internet and biotechnology - but there is no mention of CIOs or internal leadership of ICT-related functional disciplines within governments $(7-8)^{4}$.

\footnotetext{
${ }^{4}$ Even so, Carroll and Kpessa comment that the relative priority that McConkey and Dutil found was accorded internationally to technology was not reflected in CPA (Carroll and Kpessa 2007: 488).
} 
On the other hand, information sharing was ranked fifth by IPAC members, linked to the larger issue of balancing horizontal integration with increasing flexibility of governance $(34-38)$ - echoing debates referred to earlier about centralization and decentralization. A similar pattern of continuing but somewhat limited attention to ICTs and related issues can be found in other literature that helps to define Canadian public administration. An article on information technology (Brown 1997) was included in an edited collection on the public administration research agenda that was prepared to mark IPAC's $50^{\text {th }}$ anniversary (Charih and Daniels 1997). Two other indications are in IPAC's book publications. In the New Directions series of monographs, five out of 21 publications touch in a significant way on ICT-related issues - three are about service to the public (Fyfe et al. 2004, Dutil et al. 2005, Marson and Heintzman 2009), one is on the impact of technology on the relationship between MPs and public servants (Malloy 2003), and one on the issues raised by the cross-cutting nature of ICTs, including privacy (Schacter 1999). None looks at the administrative governance dimensions that lie behind these questions or gives the CIO more than a passing mention, if at all. Among the 24 books in the Public Management and Governance book series, only one addresses ICT-related topics (Borins et al. 2007).

One other indicator of how ICTs and the CIO are addressed in Canadian public administration scholarship is the attention given to them and related questions in Canadian public administration textbooks. The picture is similar - a few give them some attention, others give very little or none at all. Probably the most direct treatment is in the two editions of Dunn's Handbook of Canadian Public Administration (Dunn 2002 and 2010), each of which has a chapter on information technology and information 
management (Borins 2002, Brown 2010a). Kernaghan and Siegel's Public

Administration in Canada (Kernaghan and Siegel 1999), a standard text for many years, has sections on Computers and Management Systems and on public service, the media and the bureaucracy, including a discussion of access to information. Barker's update of Kernaghan and Siegel has a briefer treatment of both areas and like Kernaghan and Siegel does not link them or mention the role of the CIO (Barker 2008). Both texts have considerably more developed discussions of financial and human resources management. The discussion of CIO-related issues is even less complete and more scattered in two other current textbooks, Inwood (2009) and Johnson (2011), neither of which mentions the $\mathrm{CIO}$ although again providing extensive treatment of public sector human resources and financial management institutions and processes. These patterns are not new: in a book of Classic Readings in Canadian Public Administration, none of the 28 classics addresses technology or information - or even service - issues (Carroll et al. 2005).

The relatively limited and unfocused attention given to the management of ICTs in public administration thinking is undoubtedly a function of their relatively recent arrival on the scene as a central component of a high-level administrative sector and also of the fact that this sector is still evolving rapidly and has yet to mature institutionally. It is also a function of the fact that the sector extends beyond the traditional boundaries of public administration, a feature that is better captured under the heading of e-government. Two important elements are added by this broader rubric, both of which shade into issues more commonly addressed under the heading of public policy. The first is the various components of government communications, including the many dimensions of information dissemination and public consultation - all of which have been given greater 
prominence by ICTs, often under the label of e-democracy. The second is the emergence of new ICT-oriented sectors of public policy in both the economic and social policy spheres, where an explicit linkage has been made between goals and dynamics within government and those in the larger economy and society, reflected in the call by the Information Highway Advisory Council for government to be a model user of the Information Highway (Canada IHAC 1995: 21-23; see also chapter 3). These two "egovernment" facets, especially the first, have posed major challenges to any attempt to define a CIO-led functional management policy space within the traditional Treasury Board model. This too is a point that will be explored in later parts of the dissertation.

The research questions in this area, then, are largely exploratory ("what?"), addressing the issues of whether and how well the CIO and ICT-shaped administration fit into the larger discipline of Canadian public administration. To the extent that this gets into an argument that the scope of the public administration discipline should be broadened, the questions are oriented towards promoting change, entering into the realm of "how?" Implicitly these questions point to the fact that Canadian public administration is largely descriptive and pragmatic in its analysis. While it does get into the territory of explanation and understanding ("why?"), this is most often in a situational rather than a theoretical context and drawing on substantive rather than mid-level or grand theory. While this dissertation does not propose to explore higher-level theoretically-oriented research questions, it does make use of a theoretical lens that is based on well-established theories of policy and institutional stability, continuity and change. This lens, which is discussed in the next section, helps to structure the research strategy linked to the three 
sets of research questions that is discussed in the following section. By applying the theoretical lens, the CIO case study also helps to validate it.

\section{A bifocal theoretical lens}

In order to address the research questions, it is important to understand the theoretical lens that is being used. This section begins with a discussion of the role ascribed to theory in research by Blaikie. Its main focus is a discussion of two related sets of theories of stability, continuity and change that are used in the dissertation in the process of data selection and analysis. The first focuses on decisions and decisionmaking, while the second takes a broader view of the environment in which decisionmaking occurs. A link between the two is provided by the proposition that the administrative sphere defined by the $\mathrm{CIO}$ is analogous to a public policy sector and can be addressed in similar terms.

\section{Role of theory in research}

Any basic social research must be informed by one or more theoretical lenses and the selection of such lenses is a crucial element in developing a research strategy. As stated earlier, theory is particularly important in providing explanation and understanding - "why?" questions - and in some aspects of applied research ("how?"). Although it is less central to purely exploratory and descriptive research, even then theory is important in selecting relevant data and in ordering the findings. In discussing the role of theory and its relationship to research (Blaikie $2000 \mathrm{ch}$. 5, in particular 141-159), Blaikie notes that there is a spectrum of theory, ranging from the "grand," relating to society as a whole, to the purely substantive, arising from the context of a given problem area. A more granular 
variation on such a spectrum is from meta-theory to empirical generalization. There is also a considerable zone of middle-range theory or propositions, which are both the terrain where theory is most useful in focusing research and where there is the greatest potential for theory-validation and building through research.

This dissertation draws on a number of theoretical frameworks, both individually and - more particularly - in combination. Many of them have in common the fact that they are essentially forms of substantive theory, the concepts and rules of the game that have shaped the development and operation of roles and institutions in the federal political and administrative process. This is particularly true when looking at the Canadian Westminster model and the Treasury Board within it, although much the same can be said at a higher level of generality about theories of Canadian public administration. E-government moves into middle-range theory - if only in the sense that it is mainly independent of the institutional context of individual systems of governance and has a higher level of abstraction - although it is probably more in the territory of middle-range propositions than of analytical models or formal propositions (Blaikie 2000: $156-157)$.

In order to knit the contextual and substantive theories together but also to provide a means for analyzing their dynamics and relationships, some sort of higher level theoretical framework is required. Blaikie, drawing on the sociological theorist J.H. Turner, refers to analytical and propositional schemes as the most useful formats for social research, the former being "conceptualizations of the key properties of and relationships in the social world" (154) and the latter "a statement of a relationship between two or more concepts [with the claim] that a variation in one concept is 
associated with a variation in another concept." Propositional schemes are the most useful and in turn can be divided into theories that are axiomatic (expressed in formal language using strict logic), formal (drawing on abstract and general propositions but with less logical rigour when the facts are applied) and empirical generalizations (theories derived from but extending beyond specific events in particular social contexts). Axiomatic theories are used in deductive research while empirical generalizations provide the theoretical building blocks for inductive research (155—156), recognizing that in the real life of social research there is a cyclical, even circular, relationship between the two (158).

\section{The CIO as a policy sector}

The mid-level theories that the dissertation draws upon are primarily found in the realm of public policy and policy studies. A first step is to apply public policy theory's concepts of policy sectors and sub-systems to the areas of functional management within the federal government. Public policy theory is as a rule oriented to policy with respect to the realm outside the state, although one in which the state plays a part: society and the economy as a whole and especially their major facets. This body of theory is built around a model of policy universes that are "encompassing aggregation(s) of all possible international, state, and social actors and institutions that directly or indirectly affect a specific policy area." (Howlett et al. 2009: 81). Within each such policy area or sector ${ }^{5}$ there is a set of actors and institutions "that can be said to constitute a policy subsystem within the larger political economic system" (ibid.). This policy subsystem establishes

\footnotetext{
${ }^{5} \mathrm{Pal}(2006)$ refers to policy fields, without giving a precise definition of the space within which the dynamics of public policy-making play out. Howlett, Ramesh and Perl in the next sentence of their book refer to "sector or issue area" (Howlett, Ramesh and Perl 2009: 81). Without cataloguing the policy sectors, John argues that each one is unique and should be studied in its own right (John 1998: 7). This dissertation uses the terms sector, field and issue area interchangeably, with a preference for "sector."
} 
the environment within which the dynamics of policy-making and implementation are carried out in any given sector; combined with a common set of policy ideas (a policy paradigm), the result is a policy regime that "over extended periods of time infuse(es) a policy sector with both a consistent content and set of typical procedures through which policies are developed" (87).

As stated by Howlett et al. (2009), public policy literature applies this model to sectors within the larger political economic system. In any given policy sector there is a range of institutions, actors and processes shaped by ideas and interests, with each sector having its own unique combination. Much of the policy studies discussion focuses on the dynamics of networks and communities that feature both governmental and nongovernmental actors, with a crucial role assigned to an inner "sub-government" and within that to a key group of governmental decision-makers, typically featuring a lead agency within government ( $\mathrm{Pal} 2006: 248)$. While the linkage is not generally made in the public policy literature, for purposes of this discussion such lead agencies are equated to program departments in the post-Glassco terminology. Put differently, federal program departments can, by their very existence and set of powers and responsibilities, be seen as defining and/or reflecting ${ }^{6}$ major sectors of public policy, each with its own policy regime and subsystem.

The dissertation applies this sectoral model to the internal management of government. There is a debate about the extent to which the state, as an institutional environment, is autonomous from society in a given policy sector and therefore what

\footnotetext{
${ }^{6}$ Federal program departments are probably some combination of shapers and reflectors of the sectors to which they are linked, with the precise dynamic depending on the sector and other forces at work, including constitutional division of responsibility among jurisdictions. A safe working assumption, however, is that the universe of public policy sectors in Canada roughly corresponds to the array of federal program departments, with the addition of sectors that are solely in the provincial domain, notably education, where the lead agency is the provincial ministries of education.
} 
relationship it has to the dynamics of stability, continuity and change in that sector (Howlett et al. 2009: 43 - 48). There is little doubt, however, that the Canadian state is largely autonomous - within the broad framework of liberal democratic oversight - in its own internal governance and in that respect can be regarded as a multifaceted system in its own right, with an internal policy regime that parallels that which is found in the larger political economy. It follows that this internal environment can be understood as being made up a series of sectors and subsystems, each with an inner decision-making process, lead agency and policy paradigm.

Specifically, the policy-driven areas of functional management that come under Treasury Board authority lend themselves to this line of analysis. While Treasury Board is responsible for several hundred individual policy instruments, these have since the introduction of the modern Treasury Board in the 1960s been clustered under a small number of functional branches or offices led by a senior TBS officer at a level immediately below the Secretary. Each functional cluster defines a sectoral universe of policies, actors, interests and institutions across government, linking specialist communities in departments and common service organizations and touching the work of program managers and staff as well. Two functional subsystems with long histories are financial management (or comptrollership) and human resources management. Following this line of reasoning, the $\mathrm{CIO}$ and related policy responsibilities define a third sectoral subsystem. Chapter 2 discusses the antecedents of this sector, chapter 3 its formal establishment and evolution, and chapter 4 its elements and dynamics.

The application of the sectoral model to the internal administrative system is reinforced by a second public policy concept that is drawn upon in the dissertation, the 
use of organizational design as a policy instrument ( $\mathrm{Pal} 2006: 160)$. There is a long history in the federal government of using organizational design to structure both program delivery and internal management to meet current and anticipated needs (Hodgetts 1973). This was the focus of the Glassco Commission, and structuring the machinery of government to deliver current and anticipated policy and political agendas remains one of the key prerogatives of the Prime Minister (d'Ombrain 2007). The 1993 reorganization was a policy-driven exercise of this prerogative (Mitchell 2002) - chapter 2 discusses how the prerogative became institutionalized in the wake of the Glassco report and chapter 3 explores how it has been used in the history of the CIO.

Theories of policy and institutional continuity, stability and change

Two related sets of theories are drawn upon in this dissertation, with elements of a third. The two major bodies of theory are both found in the field of public policy and it can be argued that they constitute complementary parts of a larger whole. They relate to the dynamics of policy stability, continuity and change, on the one hand, and of institutional stability, continuity and change, on the other. The third body of theory that is woven into the analysis is the concept of capability maturity, which is drawn from ecommerce thinking, linking in particular to stability and continuity.

Peter John argues that a public policy theory should have four explanatory dimensions, with respect to: policy stability over a period of time, policy change, dynamics within a policy sector, and policy in a comparative context (John 1998: 1219). According to him, a good policy model situates a number of elements of a policy environment and the causal links among them. These elements include institutions, policy networks and communities, underlying socio-economic dynamics, individuals and 
their choices - all representing a dynamic between ideas and interests and all in the political context of public policy-making and implementation. He identifies a number of synthetic theories of public policy that meet these tests in varying degree, arguing in the end for an evolutionary theory that incorporates elements from other theories but gives greater emphasis to the role of ideas married to interests, which can explain sudden change and, when integrated into institutions, policy continuity as well (201).

John's approach builds on earlier models in public policy literature, notably Baumgartner and Jones's punctuated equilibrium model, which in turn draws on Sabatier's concept of external shocks to a policy system (Sabatier and Jenkins-Smith 1993) and Kingdon's concept of a policy window of opportunity and the role of policy entrepreneurs (Kingdon 1995). A good deal of the Baumgartner and Jones model speaks to policy and institutional changes made in the federal government in and since the $1990 \mathrm{~s}$ in response to the widespread introduction of ICTs. They attach considerable importance to agendas, how they are developed and how they change. Much of policy change results from agenda expansion - for example, through changes in institutional responsibilities and the introduction of new groups or the activation of previously dormant groups into the policy discourse. They also pay considerable attention to the process by which agendas change in definition and in priority, in particular in the thinking of politicians and the public, and the process by which new ideas become prominent and institutionalized in the political system. This is linked to the key role played by an intermediary institution, the media, in providing "positive feedback" to policy entrepreneurs and the public that serves to accelerate the change process (Baumgartner and Jones 1993). 
John's evolutionary theory adds features that provide a more complete understanding of the rapid and pervasive introduction of technology into government. His starting point is that institutions, interests and networks, social and economic factors, ideas and individual policy makers all play a role in a process that is never entirely stable or predictable. He emphasizes the complex and interactive nature of policy development and decision-making, both within sectors and in the spillover among sectors and actors. Ideas and actors may not be new - indeed the policy "soup" contains many that have been previously rejected or never tried - but the dynamic nature of the policy environment provides opportunities for them to emerge, sometimes on short notice, when the conditions are right. This applies to implementation as well as to policy development. John argues that actors and ideas can consciously adapt to their changing environment, which creates a non-linear continuous selection mechanism for the ideas and interests that will prevail in a given set of circumstances. Another key dimension is that change is not necessarily just the result of expansion of the policy agenda due to forces within established policy communities but often is also the result of change occurring elsewhere, for example in the economy, and of political events (John 1998: 167-195). A background influence is also exercised by random processes, competition, and selection (John 2003). The rise of ICTs and the associated management technologies represents such external forces.

Most public policy theorists, including Baumgartner and Jones, focus on individual policy sectors, recognizing that each has its particular characteristics that need to be incorporated when applying the model. The sectoral spillover aspect of John's theory positions it to apply to cross-sectoral policy dynamics or in situations where sectoral 
boundaries are being redefined. Both of these dimensions are important in looking at ICTs. A central public policy concern during the period in question has been how to develop new industrial and cultural sectors in the Canadian economy and how to address new social issues. The new ICT-based industrial sector, for example, carries with it a set of ideas that by its own claim represents a paradigm shift, in which changes in technology (notably the full adoption of networked computing) combine with changes in the world economic and political order, in the business environment and in the nature of organizations to create new types of business organizations and of economic activity (Tapscott and Caston 1993, Tapscott 1996). Harnessed with new management thinking, the result is a different approach to the provision of public services (organizing from the perspective of the citizen-client) that cuts across traditional administrative boundaries to transform the services and government itself (Accenture 2005). These changes extend into all aspects of business, society and government, bringing profound change into daily personal life (Negroponte 1995). This represents a major injection of ideas and interests into the evolutionary environment. Some of the more influential ICT-inspired ideas are discussed in chapter 2 .

While public policy theory can go a considerable distance in describing the making and implementation of decisions, it is not as useful in describing the dynamics of the environment in which these occur, especially where a sector has a highly institutional dimension, as in the case of an arm of internal state management. This is where institutional theory can be drawn upon, providing a lens for looking at the larger context.

The second major body of theory that is drawn upon in this dissertation, therefore, is new (or neo-) institutionalism, which relates to the role and nature of institutions in 
public policy and their influence on the dynamics of stability, continuity and change. This is for two reasons. One is that the focus of the dissertation is on the federal government's response as an institution to ICTs and it is therefore important to have an understanding of institutional dynamics in describing and explaining that response. The second reason arises from characteristics of policy-oriented theories of stability, continuity and change. John argues that institutional approaches are better at explaining policy continuity and constraints on policy innovation; they are also essential in explaining differences between countries but are weaker at explaining policy change and differences in policy-making across sectors (John 1998: 38-58, 63-64).

At the same time, institutions themselves do change, a point that John acknowledges but effectively dodges by arguing that there is not enough competition and cooperation within a national system to generate change (187). Arguably he is thinking of the role of institutions in a policy environment, as opposed to an institution as a policy environment, which is closer to the reality of the CIO within the federal government (see the discussion of the IM/IT space in chapter 4). In any case, an explanation of the dynamics of institutional change needs to be found elsewhere, although institutionalist explanatory models draw on the change mechanisms in public policy models (which stands to reason in cases where institutional change is policy-driven in particular). At a more basic level, institutional theory is needed in order to explain what is an institution. John argues that new institutionalism, which incorporates values and norms as part of institutions, is too broad in scope and a more limited definition is required (64). This is a less significant consideration, however, when looking at governance institutions. 
There are several strands of new institutionalism (Lecours 2005), all agreeing that political analysis best starts from an institutional perspective. Rooted in different social science disciplines, they give different weight to history, actors and interests, societal and cultural factors, and to chance in explaining institutional stability, continuity and change. Three are particularly influential: historical, rational choice and sociological institutionalism (Lecours 2005). All three provide useful insights to the CIO and the impact of ICTs on public administration, and it is tempting to seek a synthesis of them. ${ }^{7}$

Historical institutionalism starts from an assumption that institutions are largely autonomous in the public policy process and have inherent agendas based on their formal and informal patterns of development. The relationships among institutions, individual actors, ideas and chance shape public policies and events and are in turn shaped by them (Thelen and Steinmo 1992). Historical institutionalists give more weight than most public policy theorists to formal state institutions and their historical antecedents; this is a view that builds on, but is not limited to, a more traditional materialist view of institutions. In this analysis, history matters; pathways chosen early have an impact later, creating "path dependency" which, along with positive feedback, reinforces policy direction and stability but also contains its own (mainly incremental) change dynamics. Major changes occur at "critical junctures" arising from external forces - a stone thrown into a pool flowing into a stream (Lindquist and White 1994) - which can open new pathways or reopen ones previously abandoned or not taken. They can arise from tensions between institutions created in different historical periods. They also need to meet the test of being "generative cleavages" and of being significant, swift and encompassing (Hogan 2006).

\footnotetext{
${ }^{7}$ The summary accounts in the following paragraphs of the three main schools of new institutionalism are drawn from Lecours 2005, in particular pp. 14-20, although other authors are used as indicated.
} 
A sharper test of critical junctures is that they should incorporate ideational changes that lead to paradigm shifts (Hogan and Doyle 2007).

Rational choice institutionalism is a more empirical view linked to economics. Institutions are strategic, embodying formal rules of the game in an equilibrium distinct from society. This definition can include state institutions but is not limited to them. The rules of the game and the self-interests of the individual actors make institutions selfstabilizing, seeing change as risky. Change comes when institutions become dysfunctional and produce sub-optimal results, leading the actors to make changes. Punctuated equilibrium theory can also explain change in this model.

Sociological institutionalism is a more normative approach, linked to organizational theory. Institutions are cognitive, rooted in society and culture - state institutions are captured by this approach but they are not its focus and it goes beyond them. Institutions, which can include socio-economic forces such as class, shape the use of power and include symbol systems, cognitive scripts and moral templates. The logic of appropriateness guides behaviour within institutions. Change arises from organizational learning and convergence in responses by different institutions or parts of an institution to a similar dynamic. It comes from within institutions, growing out of a loss of legitimacy when the institution is no longer in touch with social and cultural codes.

These theories are of course independent of any given institution, each of which has its own formal, as well as informal, structures and formalized cultural norms (conventions, in the terminology of the Westminster system) and even defined change mechanisms. So, the federal government has its particular history, rules of the game and values and norms, both articulated in statute and policy and expressed through its 
organizational culture. New institutionalism, then, is helpful in identifying and situating these contextual elements.

A limitation of both public policy and institutional theory, but especially the latter, is that they tend to assume, or at least imply, that during periods of stability or continuity the situation is static. While there is a recognition that both policies and institutions respond to daily events and cases, not much attention is paid to gradual processes of growth or maturation - that is not always linear in nature or even stable - within a broad pathway of continuity. This is reflected in the proposition that the hallmark of change is a qualitative or order-of-magnitude shift in the state of affairs, involving a "transformation," in the e-government vocabulary, or a "paradigm shift," in terminology borrowed from the natural sciences. This view is also reflected in John's criticism of historical institutionalism (John 1998: 49-57) that the change it records is incremental, or at least deeply rooted, amounting to no real change at all.

This criticism can be answered at two levels. Howlett et al. argue that what are really involved are different levels of analysis and of focus rather than alternative frameworks: public or rational choice theory relates in particular to the individual actor; sociological theories look at the collectivity; while structural theories, including neoinstitutionalism and "statism," focus on the state and closely related societal actors. Statism, in their use of the term, incorporates much of the analysis found elsewhere in historical institutionalism and addresses the issue of the origins of institutions (Howlett et al. 2009: 45 and 31-48 more generally). From this perspective, taking a historical view naturally emphasizes continuity, even in times of profound change, but it does not mean 
that there cannot be significant change, even instability, within that continuity - nor does it mean that continuity is stasis.

Such an approach is also consistent with the concept of institutional maturity and life cycle, which resonates with an organic approach to change such as John's evolutionary approach. This is in fact not new. Hodgetts adopted a similar view in his 1973 text subtitled "A physiology of government," which was based on an "ecological approach" to public organizations (Hodgetts 1973: xii). In discussing factors affecting the degrees of concentration and deconcentration in a department, he states that one of the most important is the maturity of the organization, driven by organizational learning linked to the character of the activity and the nature of the governing procedural rules and substantive regulations. Suggesting that administrative historians should study organizations with Shakespeare's "ages of man" in mind, Hodgetts speculates that electronic communications and processing equipment "may hasten the maturing stage" (Hodgetts 1973: 232-236). ${ }^{8}$

The technology industry itself has a concept of institutional maturity. Working under contract to the United States Defense Department, the Software Engineering Institute (SEI) of Carnegie-Mellon University in the 1980s developed a Capability Maturity Model for Software, which later became the Capability Maturity Model Integration (CMMI). Originally developed as a means of assessing the state of organizational maturity of firms in the software engineering industry, the model is based on the proposition that firms go through staged levels of maturity that involve increasing

\footnotetext{
${ }^{8}$ Although Hodgetts presents greater decentralization as the mature organizational end-state he does cite in a footnote another author's argument that the aggregation of financial data that comes with performance budgeting and other reporting concepts can lead to centralization (Hodgetts 1973: $236 \mathrm{fn} .10$ ). On the larger theme of decentralization, Hodgetts points out that two other forms of decentralization besides internal organizational delegation are by means of federalism and the use of non-departmental agencies anticipating measures taken in the wake of Program Review over 20 years later (Hodgetts 1973: 237).
} 
degrees of linkage and integration among the various processes involved. At one end of a five-level progression is atomized dysfunctional institutional environments and at the other end highly synergized, innovative organizations. In some versions this is regarded as an ideal rather than a realizable goal (Paulk et al. 1993). The model has since been applied to process improvement activities in a wide range of areas in the technology and other service industries. Applications in the Canadian federal government have included in the areas of financial and records management (McDonald 2002) and more recently in TBS monitoring of major IT projects, where an Organizational Project Management Capacity assessment tool is under development (Canada TBS 2010b). A similar approach has been used by Accenture in its annual e-government ratings, which look at government capacity to provide services to the public using ICTs (see, for example, Accenture 2005, in which the federal government was assessed as having a high level of maturity in its service delivery capability).

An earlier section of the chapter generated three sets of research questions. In light of the theoretical lens described in this section, the next section discusses the research strategy that has been adopted in order to provide answers to the questions.

\section{Research strategy}

In Blaikie's approach to research design and execution, the identification of research objectives and questions is followed by the establishment of a research strategy - Blaikie also describes this as the "logic of enquiry" (Blaikie 2000: 86) - for answering the research questions. While the research strategy is important in addressing all types of research questions, it is particularly important in providing explanation and 
understanding - "why" questions - and through that in providing a basis for prediction. A research strategy provides the context for identifying research hypotheses, which in turn shape selection of a data collection and analysis methodology. This section discusses the considerations in establishing the research strategy for the dissertation and then outlines the hypotheses that have guided it. The actual process of data collection and analysis is discussed in the following section.

\section{General considerations}

Blaikie proposes four types of research strategies that differ in their ontological and epistemological assumptions and, as a result, in their suitability for dealing with different types of data collection and answering different types of research questions. While Blaikie presents the research strategies in their pure form, he notes that research projects are rarely so simple. Often in practice the strategy emerges de facto from the research process rather than determining it - indeed this can be characteristic of the strategies and in many research projects more than one strategy is selected, either in combination with respect to a given line of enquiry or in sequence, with respect to different lines of enquiry (Blaikie 2000: 102). This is notably the case with respect to the use of theory, which in the pure form is seen as the end product of one strategy (induction) and the starting point of another (deduction), but as often as not is used iteratively in the process of research enquiry. As a logic of enquiry, a research strategy determines what is looked at and how (especially the latter) but also the research project's boundaries in time and space. The latter are discussed at the end of this section.

As already noted in the introductory section on developing a research approach, Blaikie identifies four broad research strategies: inductive, deductive, retroductive and 
abductive. Each specifies a different starting point, series of steps and end-point (100). Given their common ontology, induction and deduction can logically be used in combination, and pragmatically are when they are used together in theory formulation and testing (158). Blaikie suggests that inductive research is particularly effective in answering "what" questions with a view to exploration and description, while the strength of deductive research is explanation ("why") and prediction (another form of "what") - indeed it generally has little to offer to the first two objectives (124). A common assumption of inductive and deductive strategies is that there is some sort of objective reality, the difference being in how it is approached and analyzed.

This dissertation is based on a combination of inductive and deductive approaches. This is because of the nature of the research questions, which involve exploratory and descriptive research - for which inductive methods are well suited - as well as prediction and theory testing, for which deductive methods are a fit. The fact that inductive and deductive approaches can be used in combination is another advantage. As discussed in the next section, they are also well suited to a case study.

\section{Research hypotheses}

An earlier section identified a range of research questions growing out of a review of the literature and the CIO's known circumstances relating to the three research areas that frame the dissertation. In order to address these questions it is necessary to state research hypotheses that shape data collection and analysis in order to provide research answers. This section summarizes the dissertation's three research objectives and questions and states the related hypotheses. A fourth, cross-cutting, set of questions arises from the first three. Each of these sets of questions generates a working hypothesis. These 
are listed below for each research area. The formulations seek to give a focus to the dissertation and to provide a reference point for conclusions in the final chapter.

1. Description, explanation and prediction of the CIO case. This is the core of the dissertation and has many dimensions. Important research questions include: what conditioned the environment for the establishment of the CIO position in 1993; what happened at the formative moment and subsequently; how can these developments be explained, looking at historical and structural forces, exogenous drivers (notably ICTs and related ideas), and internal and external events, notably those involving changing politics, policies and personalities; predictions about likely future courses of events; and a judgment about the extent to which the changes have been transformative (the underlying question being whether the observed changes constitute a direction or a destination)? These questions are situated in the empirical fact-base of the CIO case and both draw on theory, using deductive strategies, and illustrate it, using inductive strategies.

The working hypothesis is that the establishment of the CIO position occurred during a window of opportunity, constituting a critical juncture, that grew out of circumstances driven by politics, policy entrepreneurs and ideas. These proximate causes were shaped by a larger context of societal forces (the widespread adoption of ICTs in society and the economy) and a historical legacy of organizational models and institutional practices. The result was a CIO with weak authority and institutional leverage.

The evolution of the CIO was driven by the circumstances of the moment, interacting with the accumulated legacy of previous decisions, as much as by the efforts of the individual CIOs. It was most successful when there was focus and 
high-level public service and political support, but choices made at a given moment have also created hostages to fortune. Always vulnerable to the complex, openended and inherently risky nature of ICTs, the CIO was at other times limited by the lack of an over-all vision or understanding of its institutional role and legacy and of the extent and nature of its associated sector and responsibilities. After 18 years, the CIO position and the sector it defines are well established and likely to endure as a permanent feature of TBS and the federal government. Under current circumstances, however, they are not realizing their transformative potential. Their future is constrained by a lack of institutional maturity, characterized by the failure to integrate the management of information and of ICTs. Their place in the internal governance of the federal government is not entirely clear, with uncertainties about mandate, political ownership and internal leverage. Underlying this tension is a fundamental role dilemma: is the CIO an asset manager or an innovator and change agent?

2. Insights to Treasury Board and the Canadian Westminster model. The Canadian variant of the Westminster model has several distinctive features, including for the purposes of the dissertation: a highly institutionalized concept of collective accountability, situating Treasury Board; a tri-partite organizational taxonomy within the executive branch of government, including a defined role for central agencies such as the $\mathrm{CIO}$; and the systematic use of organizational change as a policy instrument. A general question is what impact ICTs have had on the Canadian Westminster model and these features in particular. More concretely, the issue is whether the latter have facilitated the adoption of ICTs within government (and by society), on the one hand, and what effects 
ICTs have had on them, on the other? A variation is to ask what have been the role of and consequences for the internal governance model that came out of the Glassco Report and that underpins Treasury Board - how well has it come to terms with ICTs? How has the balance between centralization and decentralization in the management of the Government of Canada been affected? What about its relationship with other economic and social actors, including the private sector and other jurisdictions?

The working hypothesis is that the Canadian Westminster and Treasury Board models have facilitated the adoption of ICTs and were able to respond to them relatively easily. In some respects, ICTs have reinforced these models, with their capacity to link the entirety of the executive in a holistic way. At the same time, ICTs have introduced skills, relationships and administrative dynamics that are new in many cases and that potentially cut across well-established organizational models and processes. These are likely to prove more challenging in the longer run and will force adjustments to the Westminster and Treasury Board models. However, a tradition of continuous organizational adaptation makes it unlikely that the basic models will change fundamentally.

3. Implications for Canadian public administration. The dissertation "maps" a new terrain in the field of public administration, some of which represents new actors and dynamics, much of it assigning new combinations and prominence to older features. The most important question is whether the $\mathrm{CIO}$ and related dynamics with respect to the management of ICTs and of information can be considered to be a major sector of Canadian public administration, both as a field of practice and as an academic discipline? If so, what are the dimensions and outer boundaries of this sector and its internal and 
external relationships? How important are the relationships that cross traditional public administration boundaries, notably with the public, private sector and other jurisdictions? Overlaid on this map are questions about the relationship between the disciplinary orientations of traditional public administration and of contemporary e-government.

The working hypothesis is that the federal CIO and associated responsibilities have permanently added a new sector to Canadian public administration. A new dimension has been brought to the discipline by the extent to which they reach beyond traditional boundaries: within the federal public sector; externally with the public, the private sector and with other jurisdictions; and with other disciplines, in particular (under the common rubric of e-government) with public policy.

4. The impact of Information and Communications Technologies.

Although not one of the research areas defined earlier, questions about the characteristics and impact of ICTs cut across all three of the areas that are explicitly in the scope of the dissertation. By and large, the ICTs are treated as an independent variable, something to which government has had to adjust without themselves needing to adjust to government. There is still room for several questions: what sort of administrative capacity and skills are called for to deal with ICTs; to what extent are these new to public administration or in new combinations with existing capabilities; what features of the post-1990s generation of ICTs have had the greatest impact; are ICTs an asset to be managed or a tool for innovation; what is their relationship to management practice; and are politicians and senior public servants able and willing to make full use of the potential of ICTs? More broadly, what are the implications of the open-ended nature of technological change? In the longer run, are they transformative, as claimed? 
The working hypothesis is that ICTs are having a profound effect on public sector management that will only continue. Even when addressed as an asset they require new capabilities and linkages, a particularly important one being to harness the management of information technology with that of information content. Although many individual components of this relationship are in place, it poses a particular challenge to the effectiveness of the CIO. The costs and risks associated with ICTenabled change create vulnerabilities with politicians and senior public servants. They will also play an important role in determining the balance between managing ICTs as an asset and realizing their innovative potential, which also involves linking ICT management to broader management theory and practice.

\section{Project boundaries}

Limits have been drawn to the dissertation project in four important respects. The primary focus is on the internal government management policy and governance (i.e., the public administration) responses to ICTs. Public policy responses to the same forces are discussed only to the extent that they are linked to internal management dynamics, for example through the influence of the Information Highway Advisory Council's goal of the government becoming a model actor on the information highway.

A second boundary is with respect to the time frame, from 1993-2011. These dates are set by the arc of the CIO case, reflecting the fact that there has been almost continuous change in the structure and responsibilities of the position since it was created as well as changes in key personalities. The earlier date is significant (and firm) because it marks the introduction of a number of important organizational changes by the Campbell government - including the establishment of the $\mathrm{CIO}$ - and their later 
confirmation by the Chrétien government; it also coincides with the emergence of the World Wide Web and some of its early uses by the public sector. The end date is less clear cut. Originally, it was intended to be 2006 , which captured the conclusion of Government On-Line (GOL) - the major initiative with which the CIO is associated and such institutional changes as were made by the Harper government on coming into office. The Martin government changes in 2003 provided another possible end date, but the beginning of the Harper government, which also involved a change in party, on the face of it more clearly marked the beginning of a new phase.

In the event, the Harper government has not launched a major reform initiative to parallel GOL. There have, however, been some low key but noteworthy changes in organizational responsibilities, most recently in 2010 , and in mid-2009 new appointments were made to the three key public service positions relating to the issues discussed in the dissertation, i.e., the CIO, the TBS Secretary and the Clerk of the Privy Council. At the time of writing (Spring 2011), therefore, the CIO position was in a situation of organizational and policy equilibrium that seemed likely to be consolidated by the election of a majority government in the May 2011 general election. This permits some firmer conclusions about the case study itself, recognizing that in the nature of the subject matter any end-date represents at best the closing of a chapter but not the end of the story. ${ }^{9}$

A third limit is that the project focuses on the form of ICTs that were dominant in 1993 and through the first decade of the CIO's existence. These were, notably, distributed computing within large organizations such as government, electronic networking through

\footnotetext{
${ }^{9}$ For example, after the dissertation was submitted for examination, in August 2011 the government announced the creation of an information technology shared services agency to consolidate e-mail services, data centres and desktops.
} 
the Internet, and the electronic interface provided by the World Wide Web. To a very large extent these technologies built on the land-line telephone infrastructure, which was particularly well developed in Canada and a major factor in the rapid take-up of the new ICTs. The project does not directly address the effects of the most recent developments, based on wireless technologies and mobile applications, a number of which have entered into common use: Blackberries and other wireless devices, and related applications grouped under the heading of Web 2.0, including social networking applications such as wikis and YouTube (Tapscott and Williams 2006) as well as later developments such as Facebook and Twitter.

This boundary is partly because these newer technologies and applications have only emerged as central phenomena after the dissertation project was launched. In addition, it is not at all clear that they represent a significantly new set of circumstances, amounting to a critical juncture - to a considerable extent they are a refinement of earlier trends based on the greater data transmission capacity available through the expansion of broadband telecommunications networks. In any case, they have not yet produced any obvious institutional effects (as opposed to some indication of growing impacts on organizational culture - see Wouters 2010), beyond the establishment and use of related technical expertise within the existing structures of government and relatively minor impacts on administrative procedures. There is some anecdotal evidence of behavioural change arising from mobile applications, both within and outside the public service. Based on the experience of the earlier round of ICTs, it is the societal effects that are most likely to generate a significant institutional response in the longer run, but their 
nature and likely direction are not yet evident and at best the subject of speculation. This aspect is therefore left to future researchers, when the longer term patterns clarify.

The fourth major boundary is that provincial and international comparisons are illustrative only and do not constitute case studies in their own right. The partial exception is the Ontario Corporate $\mathrm{CIO}$, the subject of chapter 6 and even then on a limited basis. This omission is notwithstanding the fact that institutional approaches lend themselves to comparative analysis - indeed they are essential in making comparisons (John 1998: 198) - and the CIO has been heavily influenced by the international environment. This restriction on the scope of the dissertation is entirely in the interests of keeping the project manageable, pointing to an essential area for follow up.

\section{Research methodology - data collection and analysis}

The answers to the research questions are provided through empirical description and consideration of the dissertation's hypotheses. The dissertation project is a combination of the data collection and analysis that constitute the research component and the report - i.e., this dissertation - based on that research. The heart of the project, and its most significant contribution to knowledge, is an empirical case study based on primary sources, notably government documents and a series of semi-structured keyinformant interviews with the occupants of the CIO position since 1993, people who have worked with them and knowledgeable outside observers. This is supplemented by secondary and tertiary sources, mainly in the form of scholarly articles and books, although as discussed in the literature review there is relatively little material directly related to the TBS CIO. 
The research methodology adopted for the dissertation, including the data gathering techniques that were used, is discussed in Annex 2. Continuing the application of Blaikie's approach to research, the general research methodology is based on an empirical, qualitative approach that permits "thick" analytical generalizations of a social process (the CIO) in its social setting, which extends to the broader Canadian Westminster model. Within that approach, data selection and analysis are based on Yin's approach (Yin 2003) to case studies as a form of research strategy. The CIO is a single revelatory case study, with data drawn from interviews with 88 individuals. In addition there is a mini-case study of the Government of Ontario Corporate CIO, with which the federal CIO is frequently compared and which has had an influence on its evolution. The list of interview participants is in Annex 3. The generic interview protocol that was used in all interviews is in Annex 4, which also provides the consent forms that have been signed by all interviewees,

Annex 2 also summarizes the administrative arrangements for the dissertation research, including the dissertation advisory committee and compliance with Carleton University's Ethics Review procedures.

\section{Structure of the dissertation}

The balance of the dissertation is organized into six chapters, for a total of seven, plus ten supporting annexes.

Chapter 2 provides the historical context for the CIO. It positions the introduction of the $\mathrm{CIO}$ as building on a legacy of public service reform and institutional adaptation, tracing back most directly to the Glassco report (see also Annex 5) but with even deeper 
roots. There was also a continuing evolution in public service support to Treasury Board that conditioned the environment into which the CIO was established. Developments in TBS were closely linked to the willingness of successive Prime Ministers to keep the machinery of government under review as a policy and planning instrument and the adaptation into Canadian thinking of some of the precepts of the New Public Management. This was juxtaposed with generally low political interest in public sector reform and organizational change. The chapter also looks at the organizational and public policy response to ICTs in the lead-up to the 1993 reorganization. Two threads running through the chapter are to identify factors that influenced the 1993 reorganization directly but also others that were not involved at the outset but had an influence later.

Chapter 3 concerns the 1993 decision to establish the CIO and the subsequent evolution of the office and related environment. After discussing some sightings of the $\mathrm{CIO}$ in the e-government literature, it organizes the CIO chronology under the four prime ministers since June 1993, recognizing both the windows of opportunity created by changes of government but also the effects of sustained periods of political continuity in between, where other evolutionary and institutional forces come into play. The chapter looks at how the Treasury Board model absorbed the CIO but the CIO found it more difficult to come to terms with being part of Treasury Board. It also analyzes the fluctuations in the CIO's role and mandate and in the associated agenda. Factors considered include external technology drivers and management ideas, the political and public policy context, the effects of changes in the CIO's mandate and related institutional dynamics, and the influence of key actors, including the CIOs themselves. The chapter concludes with organizational alternatives that were considered but not 
adopted (among them the Ontario model described in chapter 6) and an assessment of the power and limitations of the resulting weak CIO governance model.

Chapters 4 and 5 build on chapter 3 to explore two dimensions of the case study. Chapter 4 looks at the new horizontal management institution created by the marriage of ICTs and information in the context of the Treasury Board model. Chapter 5 considers the unfulfilled role of the management of information as a defining resource of government and as a key to the longer term prospects of the CIO.

Chapter 4 traces the universe within government - the new information management (IM)/information technology (IT) institutional space - that is defined by the CIO's role and responsibilities. Its sub-text is the two research concerns about the evolution of the Treasury Board organizational model and the role accorded to the CIO and ICTs in thinking about Canadian public administration. The chapter begins with a discussion of how the Treasury Board management policy model is structured as an instrument of collective accountability. It also sketches out a new organizational model that is emerging in response to ICTs. Against this discussion it looks at the application of the Treasury Board model to the IM/IT space, supported by Annexes 6-9, respectively on CIO-related Treasury Board policies, legislation and regulations, government institutions, and occupational groups. The final section considers relationships that define the CIO, several of which take it outside the traditional boundaries of Treasury Board concerns, including with policy agents in departments, the citizen, the private sector and other jurisdictions. These factors together create an ongoing agenda and set of dynamic tensions that will have a major influence on the CIO's future prospects. 
Chapter 5 examines the more prominent role given by ICTs to information management as a discipline of public administration, offering the prospect of knowledgebased government in the knowledge-based economy and society. The chapter begins with a review of aspects of information theory that are important in a public administration context, and Annex 10 summarizes major types of information acquired and used by government. The balance of the chapter discusses why the promise of knowledge-based government and the CIO's potential impact have been difficult to realize. Factors considered include the historical neglect of information and records management in public administration, compounded by the lack of a unified understanding of what those activities encompass and tensions among competing IM objectives. A critical tension has been between IM and the management of IT. There has also been a weak recognition and consequent undervaluing of information as a public resource, exacerbated by uneven management of that resource in the electronic era. At the heart of these dilemmas is uncertainty about the role to be played by the $\mathrm{CIO}$ and the priority to be assigned to IM within the CIO's mandate. A final dimension is wariness at the political level towards information-related issues and a weak connection to senior public service governance structures and the public sector reform agenda.

All governments in the OECD and in Canada have introduced some version of a $\mathrm{CIO}$ and the federal $\mathrm{CIO}$ has both interacted with and been influenced by its counterparts in other jurisdictions. Chapter 6 provides a mini-case study of the approach adopted in the province of Ontario, which is probably the closest variant to the federal of the Canadian Westminster model and has in fact adopted a CIO governance model that is both stronger than the federal and has proved more stable. The Ontario case is interesting 
in its own terms but especially so for the contrasts and insights it presents to the federal case, where it is considered to offer the primary organizational alternative to current arrangements. The chapter begins with a discussion of the relevance of the Ontario case and the public administration literature on comparisons among Canadian jurisdictions. It then reviews the institutional development of the Ontario Public Service, including the influence of the Committee on Government Productivity, which echoed the Glassco report. This is followed by a discussion of the establishment of the Ontario Corporate CIO in 1998 and its more recent evolution. The chapter concludes by considering the factors contributing to Ontario's experience and their relevance to the federal case.

The final chapter returns to the research questions and hypotheses raised in this chapter. It presents the conclusions that can be reached about the impact of ICTs on the federal government and about the CIO, in descriptive and explanatory terms but also in terms of its place in the Canadian version of the Westminster model. A third element is the implications for an understanding of the concerns and dynamics of Canadian public administration. The chapter then reflects on the applicability of theories of policy and institutional continuity, stability and change. It concludes with a summary of areas identified in the dissertation where follow-up research is warranted. 


\section{Chapter 2 - Background}

In each of these areas we observe movement that today seems inevitable but that was probably not evident to the participants.

(Gow and Hodgetts 2003: 183)

The primary test of organization is external and political.

(Canada Glassco 1963 5: 24)

The appointment of a CIO in 1993 broke new ground. There were no known precedents for either the title or the range of responsibilities in the federal government or elsewhere. ${ }^{10}$ Although the concept was borrowed from the private sector, it was new there too and there was no established CIO model to draw upon, especially one that would be suited to an institutional environment as large and complex as the Government of Canada (Macdonald interview). At the same time, the creation of the position and the responsibilities assigned to it as a central agency did not occur in a vacuum, and the individual building blocks had lengthy histories.

Chapter 3 discusses the decision to create the CIO in June 1993 and the subsequent evolution of the position. The CIO was established in a well-defined Treasury Board organizational model. Within that model, the original CIO mandate was notable for what was not included as much as for what was. Some areas that were part of the original package of responsibilities have since been taken out, while others that were excluded at the outset were later brought in. In some cases they have gone full cycle. A number of explanations will be offered in later chapters for this churn, not least changing government priorities and personalities in key positions, but also the changing nature and understanding of the technology agenda. This chapter frames these explanatory perspectives by looking at the historical influences on the moving parts in the CIO story.

\footnotetext{
${ }^{10}$ A number of provinces appointed CIOs during the 1990s, including Ontario in 1998 (see also chapter 6). Australia, Britain and the United States appointed CIOs or equivalents in 1995, 1999 and 2009.
} 
The chapter has four sections. The first looks at some of the most significant external forces at work on the early development of Canadian public administration and public policy, notably the changing nature of earlier information and communications technologies (ICTs) and government responses to them. This sets up many of the substantive actors and moving parts in the later CIO narrative. The second section considers the origins and formative development of the institutional environment for corporate management (including eventually the $\mathrm{CIO}$ ) in the federal government, leading up to the Glassco report. A continuing thread is the role played by key politicians as the Canadian State matured, notably the colonial governor and later the Prime Minister.

The first two sections set the stage for the third, about the Glassco reports in 1962 and 1963, which laid the foundation for the management environment and dynamics that continue to prevail in the federal government. The fourth section looks at the quarter century between the initial implementation of the Glassco report in the second half of the 1960s and just before the 1993 reorganization. This period saw a consolidation and evolution of Treasury Board Secretariat (TBS)'s role and activities in the policy areas that later were part of the CIO's mandate in various combinations, often influenced by changes in other areas of TBS, notably the financial management sector. There was also regular organizational change in the machinery of government in response to accelerating technological change, highlighting the use of government organization as a policy instrument. The conclusion comments on the significance of these earlier developments as a reference point for discussion in later chapters of the events in and since 1993.

The discussion in chapter 2 is based primarily on secondary literature and government documents, including over a dozen Royal Commission reports and other 
studies that influenced the development of the pre-Glassco civil service. The Glassco Report was a major source in its own right. In addition, a substantial portion - in five cases all - of 24 dissertation interviews addressed pre-1993 developments, several from more than one perspective. One interview was with a senior member of the Glassco commission staff; four worked on machinery of government issues in the Privy Council Office in the 1970s and 1980s; nine worked in the pre-1993 TBS, including one former Secretary and two former heads of the Administrative Policy Branch; five played senior roles in interdepartmental committees, including the first two chairs of TIMS; nine were pre-1993 departmental IT or corporate services managers; five played a role in developing IT and IM common services; one helped develop early IT industrial policy; and one was a private sector consultant to government.

\section{The external variable: information and communications technologies}

Hodgetts argues that the need for the kind of organizational model proposed by the Glassco commission grew out of developments since World War II in management technique, organizational theory, and the government's electronic processing capacities (Hodgetts 1973: 257). The next section of this chapter discusses the first two of these factors, as part of setting the context for the Glassco report in the early 1960s. This section provides some of the early background to the government's administrative and policy response to information and communications technologies (ICTs) - its electronic processing capacities - as a reference point for later chapters. All of the developments referred to by Hodgetts were significantly influenced by experience and thinking outside the federal government, or even the public sector, but this was particularly true of 
emerging ICTs. Technology has pervaded and shaped life in every era. However, until the 1950 s its public administration impacts were primarily on office practice and indirectly on the reach of government in society, and it was only in the mid-1950s that there was an institutional public administration response. There were earlier institutional responses, however, in programs and services to the public - the public policy sphere which provided an important part of the foundation for later developments.

This section begins by briefly reviewing the long-running interplay between information, technology and governance as context for looking at how they played out in the formative period of the Canadian constitutional and administrative regime, up to the 1960s. It then notes some of the effects on internal government administration, including the origins of the government's public information functions. When combined with an account of the evolution of the government's collective management regime in the second and third sections, it sets the stage for the fourth section's discussion of the more overt impacts of ICTs on both public administration and public policy in the period immediately before the 1993 reorganization.

Information, technology and governance have been integrally linked since earliest times, providing a dynamic for social and governance change. The adoption by the Greeks in about 700 B.C. of an alphabet facilitated the lengthy transition from an oral to a literate society, creating a wider, more unified public (Eisenstein 2005) and an openness to new thinking and science, as well as the basis for democracy in the Greek city state (Havelock 1982). Later evolution was largely driven by changes in the medium on which texts were recorded. Communication theorists comment on the varying effects of different media on combinations of time and space, with more solid forms such as stone, 
clay tablets or parchment also being more enduring while more ephemeral forms such as papyrus and later paper were more transportable and amenable to the conquest of space and the growth of empire (Innis 1950: Introduction). Innis argues that early empires resulted from harnessing technological developments in both the communication and transportation spheres. Good roads, fast means of transport and lightweight records, with supporting military and engineering capacities, all contributed to expansion of empires well beyond the city state, the Romans being the most successful pre-modern example. The most revolutionary development, however, was the printing press in the $15^{\text {th }}$ century. Its later expansion using increasingly sophisticated technology led to uniformity within European languages and fostered the appearance of the nation state (Rowland 2006: 30).

Until the electric telegraph in the early $19^{\text {th }}$ century, communication - the movement of messages between sender and recipient over space and time - was closely linked to available modes of transportation (34). While communication and transportation increasingly diverged in the $19^{\text {th }}$ and early $20^{\text {th }}$ centuries, they remained linked well into the $20^{\text {th }}$. In Canada, the expansion and improvement of water and road transport, and in particular the introduction of the steam railway from the 1840s onward, fostered major improvements in communication, and a major influence on daily life and the consolidation of the Canadian polity was the consequential extension of postal service and its ability to disseminate services such as newspapers (Osborne and Pike 1994).

The political importance of these technologies is reflected in the fact that at Confederation the federal government was assigned significant or complete jurisdiction 
over railways, canals, telegraph and the post office, ${ }^{11}$ and the courts have since extended this jurisdiction to telephone, radio, television and the Internet - all seen as offspring of telegraph in particular. ${ }^{12}$ By the same token, railways were vital to the political, economic and later (through promotion of migration to the West and other frontier areas) social maturing of the country (Charland 1986). The first federal regulatory body, the Board of Railway Commissioners, was given authority over telephone services when it was created in $1908,{ }^{13}$ and then over radio after World War $\mathrm{I}^{14}$ While these developments focused on the technological media and their economic possibilities, the emergence of radio highlighted a growing awareness of and concern with the content of the messages that they transmitted, reflected in the later separation from transportation regulation of radio and then television regulation and their linkage instead to national cultural and social development. By the time of the Glassco report, the awareness of the link between communication content and cultural development was heightened by three Royal

\footnotetext{
${ }^{11}$ The federal government is assigned postal services under s. 91 (5) of the British North America Act 1867 and Railways, Canals and Telegraphs "connecting the Province with any other or others of the Provinces, or extending beyond the limits of the Province" under s. 92 (10) (a).

${ }^{12}$ In 1994, the Supreme Court decided that federal jurisdiction includes locally-owned telephone services within a single province (Téléphone Guévremont Inc. v. Quebec (Régie des Télécommunications) [1994] S.C.R. 878). The 1932 Radio reference decision by the Judicial Committee of the Privy Council (JCPC) found that radio fell within the constitutional meaning of telegraph and was a federal responsibility (Russell 1965: 128-133). The Radio decision served as the basis for later confirmation of federal jurisdiction over cable, telecommunications and most recently the Internet. Federal jurisdiction over television broadcasting has also built on it, leaving room for provincial educational broadcasting.

${ }^{13}$ This followed a decision, based on a parliamentary enquiry in 1905, to regulate rather than nationalize the federally-chartered Bell Telephone Company's virtual monopoly over telephone services (Barney 2005: 31). The three Prairie provinces then bought out the Bell operations within their territory, but the Supreme Court decided in 1989 (Alberta Government Telephones v. CRTC [1989] 2 S.C.R.) that provincially-owned telephone companies also came under federal jurisdiction.

${ }^{14}$ Radio was first promoted by the newly nationalized Canadian National Railways (CNR) to broadcast to train passengers after World War I, leading to the establishment of the forerunner of the CBC by CNR. While telegraph and telephone stayed with the transportation regulatory authorities until the 1970s, the popularization of radio led to the establishment of the $\mathrm{CBC}$ and a related broadcasting regulatory authority in 1932. Following the post-World War II spread of television and the Fowler commission (Canada Fowler 1957), broadcasting regulation was assigned to an independent Board of Broadcast Governors in 1958.
} 
Commissions in the previous decade that addressed national policies on the arts and culture, broadcasting and publishing. ${ }^{15}$

In the years leading up to the Glassco report, the evolving impacts of ICTs on the society and economy at large were parallelled in public administration; there was also a steady, although uneven, growth in the government's public information activities. While the federal government had a major influence on the development of transportation infrastructure, as a financer, regulator, builder and owner, its role with respect to ICTs was more responsive to externally-driven technological developments, acting largely as a regulator of the resulting economic activity but also as a major user in its own right of telecommunications and data processing services (much less so of broadcasting services). ${ }^{16}$ This can be seen in three important respects: office equipment and related procedures and skills; modes of communication among government offices and between government and the public; and spheres of public policy, which influenced the sectoral organization of government.

The influence of technology on the internal operations of government in the lead-up to the Glassco commission was slow but cumulative. In their 2003 survey of Canadian administrative evolution, Gow and Hodgetts assert that, "At the level of material technologies, one could argue that the nineteenth century saw changes as big as those we

\footnotetext{
${ }^{15}$ The Aird Royal Commission on radio (Canada Aird 1929) first made a connection between medium and culture, and this was a major part of the constitutional dispute between the federal and Quebec governments over radio regulation. After World War II, three Royal commissions looked at aspects of culture and content in the new technological environment: the Massey Commission (Canada Massey 1951), which did not consider the impact of television, the Fowler commission, which did, and the O'Leary commission on the publishing industry and related areas such as commercial advertising (Canada O'Leary 1961).

${ }^{16}$ In certain areas, especially telecommunications, the federal government also played a significant role in conducting primary research and then in promoting development of industrial applications. An indirect effect was the influence of the presence in Ottawa's Western suburbs of the government's Communications Research Centre (CRC) on the development of a telecommunications-oriented "high-tech" industry in the Ottawa region, a major influence on federal IT procurement strategies.
} 
saw in the second half of the twentieth century," but that "(e)ven with calculating machines and photocopiers, a nineteenth century middle manager could have adapted to work in most public offices until recently." The new variables that made the modern office unrecognizable were the computer, the Internet and e-mail (Gow and Hodgetts 2003: 189) - all post-Glassco phenomena. The mid-nineteenth century office was entirely paper-oriented (Hodgetts 1955: 55). Two important developments later in the century that changed the nature of work were the introduction of the typewriter - requiring more attention to record keeping systems - and of the telephone, dramatically changing both internal and external communication. In the early $20^{\text {th }}$ century these innovations were joined by adding machines, calculators and other forms of office automation, including increasingly sophisticated and wide-spread typewriters.

Advancing communication and transportation technologies also had a major impact on the reach of government. In the pre-Confederation United Province of Canada (UPC), the poor state of transportation and associated communications severely limited the extent to which government services outside the headquarters area could be centrally administered or even controlled, contributing to the establishment of the separate Inside and Outside Civil Services. The federal government's ability to operate as an entity and to connect with all parts of the country improved considerably with the mid- $19^{\text {th }}$ century railway construction boom and associated expansion of telegraphic services (which became wireless in 1890 (Rowland 2006: 140-141)) and then the telephone. In the early $20^{\text {th }}$ century, the automobile further extended the reach of government (Hodgetts 1995) and its ability to connect directly with the public. This was compounded by the 
introduction of radio as a broadcast medium in the 1920 s, reinforced by the use of radio and film as public communication vehicles during World War II.

The government installed its first large computer in 1957, to audit Army payroll, and shortly after added, or had plans for, major computer acquisitions in other areas of national defence, the census, civil service payroll, processing tax returns, weather forecasting and various areas of research (Canada Glassco 1962 1: 586 - 589). Their upgraded successors, along with large computers for issuing Unemployment Insurance and pension cheques, remain the major mainframe computing environments in the federal government. Probably in recognition of the scale of the equipment and the anticipated costs, these planned acquisitions prompted the first internal institutional response to ICTs, the creation in 1956 of an Interdepartmental Committee on Electronic Computers, made up of the main user departments, to advise Treasury Board Secretariat on these purchases. Just a few years later, however, the Glassco commission was already critical of a lack of leadership by Treasury Board with respect to data processing and transmission and related areas of records management (496-500, 584-608).

The public information function also had deep roots. The Canada Gazette was established in 1841, building on earlier arrangements, as the official publisher of statutes and other government notices for the UPC. In 1867 it was re-established as the federal government's official newspaper. Its role was broadened with the creation of the Queen's Printer in 1869 (Kennedy and Foote 2001), which in 1886 was incorporated into a new Department of Public Printing and Stationery that remained in existence until 1969 (Osbaldeston 1992: 472). From early days, departments conducted public information activities related to their work: the Department of Agriculture began issuing bulletins to 
farmers in 1887 (Canada Glassco 1963 3: 61), the Department of the Interior advertised heavily to attract European immigrants to Canada in the early $20^{\text {th }}$ century (Rose 2000: 49-56), and the Laurier government established a permanent Exhibition Commission in 1902 to market Canada overseas (Canada Task Force on Government Information 1969: 123). As early as 1905 the Laurier government had a list of friendly agencies with which its newspaper advertisements could be placed (Rose 2000: 51).

Both world wars saw a major expansion of government information activities, with the establishment during World War I of a Press Censorship Branch in the Department of the Secretary of State (Canada Task Force on Government Information 1969: 127). A Bureau of Public Information ("fraught with political legitimacy problems" - Rose 2000: 65) was formed in the Department of National War Services at the beginning of World War II, as well as a ministerial Censorship Coordination Committee. (132) (Murray also refers to a Cabinet Committee on Public Information created in December 1939 - Murray 1988: 12.) In 1942, a Wartime Information Board (WIB) reporting to the Prime Minister (ibid.) was given a broad mandate that included dissemination of war news and coordination of government information activities (Canada Task Force on Government Information 1969; 133-134; Osbaldeston 1992: 369). In 1945, the WIB was replaced by the Canadian Information Service, which retained a co-ordination function but whose operational roles were limited to distributing abroad information about Canada. It was wound up in 1947, with its international activities absorbed by the Department of External Affairs (Osbaldeston 1992: 197; Canada Task Force on Government Information 1969: 134). After World War II there was a major growth in government information activities, including advertising, but no interdepartmental liaison (Murray 
1998: 14), another situation later criticized by Glassco, and a lingering suspicion of government communications as a propaganda instrument that has had long-term effects.

In the realm of sectoral public policy, the role of Royal Commissions and parliamentary enquiries in policy-making has already been noted (see footnotes 14 and 15 above), as has that of the Board of Railway Commissioners (BRC) in regulating telephone and telegraph services. The BRC and its successor agencies, the Board of Transport Commissioners and the Canadian Transport Commission, remained the telecommunications regulatory authority until 1976 (Osbaldeston 1992: 173, 212-213). The BRC exercised policy authority through its decisions, and the federal government retained a more direct degree of control of the industry through periodic renewal of statutory charters for Bell and other federally regulated telephone companies. The federal department responsible for operational concerns with respect to railways and related activities including telecommunications was the Department of Marine, Railways and Canals; it evolved into the Department of Transport in 1936 (247). Broadcasting policy also largely followed its regulatory authority, again punctuated by Royal Commissions and parliamentary inquiries, although in the aftermath of the Massey report the Department of the Secretary of State became increasingly involved in cultural policy, including broadcasting. The early development of the computing industry was largely beyond the purview of mainstream public policy, and government was primarily involved as a purchaser of computing equipment. 
The internal context: corporate management in the Canadian Westminster model

The Treasury Board, which houses the CIO, is one of the central features of the Canadian Westminster constitutional model. The Glassco Report gave Treasury Board its current form, building on a foundation that was over a century old. This section surveys those origins.

The Canadian Westminster model developed as an off-shoot of the British original, in large part in parallel with British institutions rather than as a replication of an established model. Pre-Confederation roots established the foundation for more recent institutional development and are discussed in the first part of this section, up to the establishment of Treasury Board on July 2, 1867. The 1962 Glassco report developed the contemporary paradigm for thinking about management in the federal government and crystallized many of the distinctive features of the Canadian Westminster model. It did not happen in a vacuum either, however, and by the time the Commission was established there had been several post-Confederation attempts to introduce management ideas and experience in aid of public service reform from elsewhere, notably from the British public sector and the US private sector. The section's second and third parts review influential developments in this period, focusing on the entrenchment of the collective management model embodied in Treasury Board. A continuing theme is the role played by senior politicians but also increasingly by senior public servants.

The deep roots of collective governance

Collective responsibility of the ministry to Parliament is a central feature of the Westminster model in all its variants. Canada has, however, gone further than Britain in collectivizing the institutions of the executive, giving substance at Confederation to 
formal roles assigned to the Privy Council/Governor in Council and the Treasury Board that the British had long since abandoned (Hodgetts 1973: 243). This may, as Hodgetts suggests (ibid.), have been the result of "an unawareness of the realities of British practice" and a failure to distinguish between British form and substance. It also grew, however, out of the structure of British administration in the colonies that eventually formed Canada and in particular out of the institutional evolution of the United Province of Canada, which at Confederation provided the nucleus of the federal public administration. Two features of this historical experience were especially important: the early establishment of a strong-governor-weak-assembly model, succeeded by a strong first minister with full adoption of responsible government; and collectivized management of politically important areas of public administration.

In her essay on the enduring influence of governance models from preRevolutionary British America (Mancke 1999), Elizabeth Mancke notes that all the Canadian colonies were established in an environment in which the British state had a strong influence over the establishment and operation of colonial institutions. British American colonies established after the installation of the Hanovers in 1714 were created by Crown charter and subject to more direct control by central authorities in London than were earlier colonies, which followed no single governance model. Of the thirteen colonies that formed the United States, all but Georgia were in the latter group while all of those that eventually became Canada were in the former. The Hanoverian model of colonial governance included strong governors, weak assemblies and local government, state claims to control of natural resources, state oversight of commercial activities and 
funding of local economic development; it also accorded property and civil rights to minority populations, especially where a colony had been acquired by conquest $(10-16)$.

This model was imposed on all British American colonies, including retroactively on those established under the Tudors and Stewarts, and its application was a major source of the grievances that led the thirteen US colonies to declare independence in 1776. From the outset, the model shaped the development of the colonies that eventually became Canada as instruments of Imperial policy, contrasting with the early largely laissez-faire development of their US American counterparts. When the federal government was established in 1867 , its organizational structures, civil service staff and physical plant were all taken over from the United Province of Canada (UPC), the linear descendent of the polity established in the province of Quebec after the Treaty of Paris in 1763. For much of the first seventy-five years, the British military commander in Canada also had authority over the civil administration, from 1786 (after the end of the American Revolutionary War) also serving as the Governor-in-Chief and then Governor General of all the British North American colonies. An appointed legislative council and elected assembly were established to enact "Laws for Peace, Welfare and good Government" in Lower and Upper Canada under s. II of the Constitutional Act, $1791,{ }^{17}$ which contained many of the embryonic features of the British North America (BNA) Act, 1867.

Well into the early days of the UPC, the Governor had pre-eminent political and executive authority, with much the same model applying in the other colonies. But, as one of very few officials sent by the British colonial authorities, the Governor drew on

\footnotetext{
${ }^{17}$ A similar authority was given to the Council of the Province in s. XII of the Quebec Act, 1774.
} 
the settler community to perform administrative functions in a growing number of areas ${ }^{18}$ and also to form an Executive Council ${ }^{19}$ that presided over an administrative regime which Hodgetts, summarizing Lord Durham, characterizes as "a most disheartening scene of administrative incompetence" (Hodgetts 1955:22-23) - a situation that contributed directly to the Rebellions of 1837 and 1838 in Upper and Lower Canada.

Lord Durham's report on the Rebellions reflected growing concern with the organization of the state apparatus in the Canadas, as well as of local government. Without waiting for it to be acted on, the elected Legislative Assembly of Upper Canada asked the Lieutenant Governor to create a Royal Commission to take a comprehensive look at the range of public departments. ${ }^{20}$ Its investigations were used to provide supporting detail for the follow-up to Durham's recommendations (24), the first but not last major investigation of the state of Canadian public administration. Durham's diagnosis, which was endorsed by a reform-minded government in London, led to Lord Sydenham's term as Governor General (1839-41), during which many of the modern institutional forms were introduced in the context of the creation of the UPC in 1841 and permanently entrenched over the following two decades. The most important of these was the departmental model. Departments brought together all of the civil service units involved in a common area of administration, headed by a minister with executive

\footnotetext{
${ }^{18}$ For most of the pre-Confederation period the Governor supervised both the settler-based provincial civil service, which was locally financed and broadly under the authority of the Executive Council, and functions that were directly controlled by the British authorities through the Colonial Office. Responsibility and costs for the latter were gradually transferred to the often reluctant Canadian administration. By 1860 all had been turned over to the UPC, except defence. Saul suggests that both the Canadian and British authorities desired that Canada finally assume responsibility for defence, explaining the last-minute substitution of "Order" for "Welfare" in the preamble to the BNA Act's s. 91 (Saul 2008: 153-157). ${ }^{19}$ Both the Constitutional Act, 1791 and the Act of Union, 1840 refer to but do not constitute an Executive Council with various roles advising or assisting the Governor.

${ }^{20}$ Report of the Royal Commission Set Up to Investigate Business, Conduct and Organization of Various Public Departments of Upper Canada, published in the Journals of the Legislative Assembly of Upper Canada, 1839-40, vol. II. Hodgetts 1955 (24 fn 3) makes a comparison with the Hoover Commission.
} 
authority over all related staff and activities; while not part of the original model, the minister fairly quickly came to be drawn from the legislature and in 1857 was given a permanent deputy minister (26-34 and 91-95). By 1863 , the departmental model was well enough established - but also with enough problems - that another study was conducted, led by Thomas D'Arcy McGee, then President of Council, on the "Origin and Organization of the Public Departments" (37 fn1 and ff).

These innovations in the administration of individual program areas were complemented by the consolidation of the Executive Council as an instrument of collective management. Initially the Council supported the Governor in both theory and practice, but by the time of the full implementation of responsible government in 1849 it had become accountable to the legislature in practice although still nominally advisory to the Crown. A parallel development was the emergence of a minister drawn from the elected Legislative Assembly to replace the Governor as the leader of Cabinet and in practice to assume the Governor's powers within the executive. ${ }^{21}$ Another enduring development was of a central (although initially largely passive) Office to keep track of the decisions and actions of the Executive Council, the foundation of the modern Privy Council Office (86-87). ${ }^{22}$ Sydenham also began efforts that continued for the next 25 years to introduce a central discipline and transparency into government revenue raising and spending, laying the foundation for the modern budgetary process $(96-117)$.

\footnotetext{
${ }^{21}$ Responsible government came with the formation of the LaFontaine-Baldwin government in 1848, based on winning a majority of seats in a general election, and the signature of the Rebellion Losses Act the following year by the Governor General, Lord Elgin, who personally opposed it. Cabinet leadership was based on chairing the "Committee of Council", which in the 1850s emerged as the deliberative forum of the Executive Council, without the Governor present (Mallory 1971: 13). It remains the conventional basis for Cabinet as the sub-group of the Privy Council that enjoys the confidence of Parliament.

${ }^{22}$ McGee's 1863 report called for greater discipline in Executive Council decision making.
} 
Several Executive Council mechanisms began to provide collective ministerial oversight of government spending. Since 1849 the Council's Board of Works had met regularly to supervise one of the largest, politically most sensitive and administratively most elusive areas of government; Council established a Board of Audit in 1857 (making more systematic an older, mostly theoretical, Council role of reviewing audits of public accounts); and in 1858 it set up, possibly for the first time, a process for a detailed review of departmental spending in the face of low revenues (89-90). Taken together these paved the way towards the post-Confederation Treasury Board (Hodgetts 1973: 242) ${ }^{23} \mathrm{~A}$ practical reinforcement of collective decision-making was provided by Macdonald's centralization of government patronage, which began when he first became Premier of the UPC in 1857 (Johnson and Waits 1990: 595). ${ }^{24}$

These mid- $19^{\text {th }}$ century developments established a number of the foundational characteristics of the Canadian Westminster model, notably a strong executive focused on the Governor and later the Prime Minister, the departmental model and associated nomenclature, and collective decision-making by the Governor in Council about appointments, spending and public works. All of these represented variations on or even departures from the British model, especially the extent to which the Governor in Council was used to collectivize policy decision-making in general and appointments and

\footnotetext{
${ }^{23}$ There were British precedents for Boards of Privy Councillors to supervise areas of government, including the Board of Trade, which oversaw colonial administration from the $17^{\text {th }}$ until well into the $19^{\text {th }}$ century (Clark 1960; Steele 1968).

${ }^{24}$ The hand of Sir John A. Macdonald can be discerned in most of the important developments in the decade before Confederation. Johnson and Waits describe him as a "competent if somewhat spasmodic administrator" (1990: 593). As Attorney-General for Canada West for most of 1854-67 and Premier for much of the period after 1857 he was involved in most of the major institutional reforms, including the decision to create a permanent capital in Ottawa, the Civil Service Act of 1857, introduction of deputy ministers, establishment of a Department of Finance in 1859 and patriation of most of the remaining Imperial administrative responsibilities, notably Indian affairs in 1860 . He also strengthened the legal frameworks for the legislature, local government, and corporations. He was therefore well versed in administrative and constitutional issues by the time it came to drafting the BNA Act.
} 
regulation-making in particular. A fourth characteristic, in comparison with the United Kingdom, was the extensive involvement of ministers in matters of internal administration, reflecting the origins of Canadian ministerial offices as administrative positions before they were assumed by elected politicians. A fifth feature, that also contrasts with the UK, was the assertion of the right of the legislature to approve organizational changes in the executive, including the establishment of government departments and other entities by statute, a practice that began with Sydenham and has been jealously guarded by Parliament ever since (Hodgetts 1955: 59). Combined with the requirements of accountability to the Colonial Office, this reinforced the hand of the Governor and then that of the Prime Minister as the focal point in matters of organization and administrative procedure within the executive.

Confederation and the $B N A$ Act 1867 thus represented a broadening and deepening of a well-developed constitutional and administrative model that is readily recognizable as containing the central features of Mancke's account of early modern Imperial governance. The $B N A$ Act directly established the formal structures of the federal government that have remained in place, notably the Crown and office of Governor General as the source of executive authority, ${ }^{25}$ the Privy Council and Governor in Council as the locus of executive decision-making, and Parliament as the legislative authority to legitimize and control executive action. Through the preamble, it indirectly sought to replicate the Westminster model's conventional basis for the selection, role and

\footnotetext{
${ }^{25}$ This includes the indirect but clear characterization, in s. 10, of the Governor General as Chief Executive Officer of the Government of Canada.
} 
operations of the Prime Minister and Cabinet as the "efficient" collective executive, working within the "dignified" institutions formally created by the Act. $^{26}$

\section{Treasury Board's first century: managing the public purse}

One of the first acts of the new government of Canada was to create a Treasury Board, by Order in Council, on July $2,1867 .{ }^{27}$ Originally made up of four Ministers and chaired by the Minister of Finance, the Board was established to act on behalf of the Governor in Council to oversee government spending and revenue collection. It also established common administrative procedures in the new government and, in the years before the Civil Service Commission was created in 1908, approved terms and conditions of employment for the civil service (White and Strick 1970: 14). Building on the UPC's practical experience, the more polished concept of the Treasury Board was adapted from the British Commissioners of the Treasury, which had provided a collective basis for managing money in the British government since 1714 but by the 1860 s had, like the British Privy Council, become something of a constitutional fiction and in any case was not made up exclusively of Ministers. ${ }^{28}$ Treasury Board assumed a life of its own in Canada, however; it was established in legislation in 1869 (White 1965: 27) and

\footnotetext{
${ }^{26}$ This is using Bagehot's terminology and meaning (Bagehot 1928: 4 and throughout). The fact that the Crown, Governor General, Privy Council and Governor in Council, along with an explicit framework for constitutional conventions, are all set up through a written constitution is of course itself a major deviation from the Westminster original. It was probably necessary if Canadian institutions were to be genuinely autonomous but also had the virtue - from the point of view of the $19^{\text {th }}$ century Colonial Office - of making Canadian colonial and post-colonial administration more transparent and easier to oversee because it gave their appointee, the Governor General, a hand on all the important levers of power.

${ }^{27}$ P.C. 3. In practice this was a continuation of the UPC's Expenditure Control Board and Board of Works combined. It can be speculated that although most of the new federal institutions were carry-overs of UPC predecessors there was a recognition of the importance of "re-branding" them (in today's terminology) to emphasize that a new level of government was being created. Adopting terminology - even if obsolete from Westminster gave an extra cachet to the new national institutions, implicitly positioning Canada as more than a colony, a new phenomenon within the Empire. Within Canada, it was important to minimize connotations of central Canadian domination, so the "skin" of the old UPC needed to be shed.

${ }^{28}$ The contemporary British Treasury also has a Treasury Board, made up of the Permanent Secretary, other senior managers, and outside ("non-executive") members (UK HMT).
} 
increased to six ministerial members in 1885 (White and Strick 1970: 9-10). It still has six members, with provision for six alternates, and remains the only statutory committee of the Privy Council and Cabinet.

In their account of Treasury Board between Confederation and the Glassco report, White and Strick argue that it played an important part in facilitating the adaptation of the federal government to the changing demands that it faced as both the country and the role of government within it expanded and grew more complex (1970: 11). A primary early role was integrating regional interests in areas of politically sensitive decision-making (8-9), creating a "federalization of responsibility" (Mallory 1971: 103) that remains a defining reality of Canadian public administration. (This was a serious challenge: as

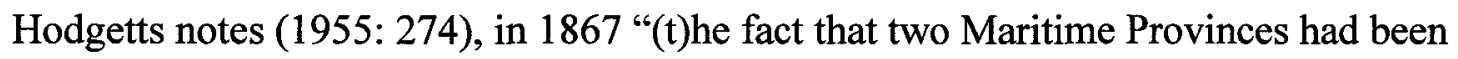
added to the larger union was scarcely registered in the new bureaucracy.")

At times Treasury Board aspired to the role of Cabinet executive committee (White 1965: 6). More often it was second-guessed by Cabinet, with Cabinet able to insist on confirming all Treasury Board decisions (Hodgetts 1973: 246-247; White and Strick 1970: 11) until passage of the Financial Administration Act in 1951. Even today, Cabinet has over-riding policy authority. In the 1920s Treasury Board was virtually dormant (26). An important variable was the degree of interest taken in administrative matters by the Prime Minister, who only once has been a member of Treasury Board, while the Minister of Finance always has. Another was the demands of the wider public policy environment, which went through identifiable phases, each requiring a new set of administrative responses from the federal government and contributing to its growing sophistication (Gow and Hodgetts 2003; Roberts 2010). These reforms and adaptations accumulated in 
largely linear fashion, most building on earlier changes, but with at least one dramatic shift in direction and many smaller twists. While there were numerous efforts to circumvent Treasury Board and (only) one serious recommendation to abolish it, the cumulative effect was to entrench it in internal federal governance. Some of the developments that have had lasting effect are reviewed in this and the next part of the chapter.

Treasury Board's evolution between 1867 and the mid-1960s can be understood in terms both of the functional areas of administration that it addressed and of the role it played with respect to them. The most enduring functional area was expenditure control and related areas of financial administration. Treasury Board had a more varied but equally lengthy involvement in management of the civil service, arising from a close interest in its costs - in many ways this area had a greater influence on Treasury Board's development. Both of these areas saw the emergence of central oversight institutions outside of Treasury Board's direct control - the Comptroller of the Treasury and the Civil Service Commission - raising issues about their relationship that eventually became a major concern of the Glassco Commission. A third, less clearly defined but also ongoing, functional area was administrative procedures in the civil service and related issues of government organization and efficiency. (A subset was public records and archives; see chapter 5 on the fitful attention paid to them during this period.) In the nature of its role, Treasury Board acted as a centralizing force within the federal government, with its ministerial members playing a hands-on role. A continuing theme in reform efforts, therefore, was pressure to reduce ministerial involvement in administrative issues and to provide deputy ministers of line departments with greater autonomy. Throughout the 
piece there was debate about the application of externally-derived models, balancing British administrative forms and practices with American management ideas.

For most of its first century, Treasury Board's primary function was processing decisions on individual cases, acting on behalf of Cabinet (until World War II almost invariably referred to as Council) and with Orders and Minutes of Council as its decisionmaking output. The federal government grew slowly in the first thirty years after Confederation, and the volume of Treasury Board activity was relatively low. The most important development in the financial area was the separation in 1878 of the post of Auditor General from that of Deputy Minister of Finance and its establishment as an officer of Parliament. Treasury Board became busier under Laurier's more activist government, was part of the expansion of government during World War I and went into overdrive in World War II, processing 36,148 decisions, with Cabinet taking over 40,000 additional decisions on awarding contracts (Heeney 1946: 282). During most of this period, government financial means kept pace with the calls on its resources, so the Board had little or no role in what would today be termed as public policy; any role in administrative policy was a function of the accumulation of individual decisions as opposed to a coherent effort to manage the government as a whole. Until the 1960 s, even government policy-making more generally was largely based on political discussion among ministers, without the support of dedicated civil service policy staff, punctuated periodically by studies by Royal Commissions and parliamentary committees on both internal and external policy issues. ${ }^{29}$

\footnotetext{
${ }^{29}$ For example, this dissertation cites over a dozen reports of Commissions of Inquiry and Royal Commissions that addressed administrative matters, up to and including the Glassco Report. Up to the end of World War I in particular there were also several influential studies by Parliamentary committees.
} 
The first time that Treasury Board assumed a more systematic expenditure role was in the early 1930 s, when the Bennett government responded to the Depression by reducing and tightly controlling civil service spending. Treasury Board was mandated to be the "corporate negative checking device" (White and Strick 1970: 29), with the Prime Minister for the first 18 months assuming the Finance portfolio (and therefore the chair of Treasury Board) in order to enforce an internal regime of economy. The Board's role was reinforced by the Consolidated Revenue and Audit Act [S.C. 1931 (21-22 Geo. V c.27)], which for the first time established uniform departmental estimates, reviewed by Treasury Board before tabling in Parliament, and created the Comptroller of the Treasury as the agent of central authority, enforcing the discipline of pre-spending expenditure comptrol and post-spending audit. The Comptroller of the Treasury reported to the Minister of Finance, although after a time its decisions were made appealable to Treasury Board. Its staff were physically located in departments and signed off on all expenditures before they were made as well as conducting post-expenditure internal audits. This model was severely criticized by the Glassco commission and was the reference point for its proposals to comprehensively restructure management authorities and control mechanisms (Glassco 1962 1: 83-230).

By the end of World War II it was recognized that Treasury Board decisions had wider policy implications that should be approached in a more positive fashion, and in 1947 the position of Secretary of Treasury Board was separated from that of Deputy Minister of Finance and assigned full-time to an Assistant Deputy Minister, R.B. Bryce, one of the Department's rising stars. Bryce interpreted Treasury Board's role as assisting in the general management of government, with the result that it began to become more 
deeply involved in departmental affairs (White and Strick 1970: 34). After the passage of the Financial Administration Act in 1951, Treasury Board increasingly acted as the administrative inner Cabinet, with the dynamics of its weekly meetings placing the Secretary and his officials in the position of challenging the authority of departmental ministers (34-37). The resulting political-administrative tension was compounded by the deteriorating budgetary situation in the late 1950s, and by 1960 Treasury Board was considered to be excessively involved in the details of departmental administration, as well as imposing practical constraints on policy decisions by Cabinet (38). This situation was part of the context for the Glassco Commission, and Treasury Board's relationship with Cabinet on the one hand and departmental ministers on the other has remained an endemic tension in its role.

Treasury Board's first century: organizing the civil service

The functional area that had the greatest influence on the evolution of collective management institutions during the period before the Glassco report was organizing and running the civil service, reflecting the political importance and costs of government employment, balanced against the growing need for a professional public sector workforce. The creation of the Board of Civil Service Examiners in 1857, inspired by (although not entirely copying) the Northcote-Trevelyan reforms in the $\mathrm{UK},{ }^{30} \mathrm{did}$ not resolve the pressures for a responsive civil service - initially achieved through patronage, especially outside Ottawa - on the one hand and competence on the other. This tension was the dominant concern in the first half-century after Confederation. Rasmussen

\footnotetext{
${ }^{30}$ In introducing their reforms to the British civil service in the $1850 \mathrm{~s}$, Northcote and Trevelyan were inspired by British experience with the Indian civil service, where a small group of rigourously-selected élite administrators oversaw a large and complex territory. This model has continued to influence developments in Britain and was frequently cited in reform debates in Canada but never fully took hold.
} 
identifies three distinct phases within this period, punctuated by seven major external inquiries, arguing that a key factor was the desire of Deputy Ministers to expand their autonomy from other elements of the state $(1994: 1)^{31}$. The first three inquiries - in $1869 / 70,1877$ and $1881 / 2^{32}$ - developed the notion that public administration was distinct from politics (7) and established the building blocks of open competition and merit for Ottawa-based jobs as a move towards an efficient and business-like civil service. Inquiries in 1892 and $1908^{33}$ featured efforts to strengthen Deputy Ministers as administrative heads of government departments, at a time when government activity was expanding rapidly and reflecting a growing argument that ministers were too involved in administration (10). Their continued criticism of patronage was echoed by the opposition Conservatives, who included a comprehensive set of reform proposals in their 1908 election platform (Rasmussen 2009: 11-13), leading to Laurier's establishment in 1908 of the Civil Service Commission (CSC) with a mandate to supervise recruitment and promotion, based on merit, in the Inside (Ottawa-based) civil service (Rasmussen and Juillet 2009).

The move towards a decentralized Cabinet combined with an increasingly professional civil service - Rasmussen's third phase - was largely accomplished under Borden, who Rasmussen describes as Canada's first managerial Prime Minister (5). He

\footnotetext{
${ }^{31}$ Juillet and Rasmussen 2008 have a more complete account of the first five of these inquiries.

${ }^{32}$ Canada Langton 1869 \& 1870, Canada House of Commons 1877, Canada McInnes 1881/1882. The Langton commission was the first Royal Commission appointed after Confederation and was headed by the Auditor General, who after the report was also named Deputy Minister of Finance and Secretary of Treasury Board. Its focus was on the Inside (Ottawa-based) civil service. The 1877 Casey committee was headed by a Conservative MP during the Liberal Mackenzie government. The McInnes commission was headed by a prominent Conservative businessman who was appointed to the Senate by Macdonald between its first and second reports and then made civil service reform a personal cause (Forster 1990: 633-634).

${ }^{33}$ Canada Hague 1892, Canada Courtney 1908. Hague was a banker but the other members of the commission were two Exchequer Court judges and John Courtney, the Deputy Minister of Finance (and Treasury Board Secretary). Courtney chaired the 1908 commission.
} 
appointed two further inquiries, the first of which, by a former Newfoundland Minister of Finance (Canada Morine 1913), confirmed the continued existence of patronage in the civil service, especially in the Outside service (i.e., outside Ottawa, which was not covered by the CSC) and pointed to the overworked state of ministers arising from Cabinet's detailed scrutiny of administrative activity. The recommended solution was greater delegation within Cabinet, to either Treasury Board or a sub-committee of Council (Rasmussen 1994:11). Ministerial overload was also a major theme of Sir George Murray, the recently retired Permanent Secretary to the British Treasury, who was given a broad mandate (Hodgetts et al. 1972: 32) to advise on the operations of the Canadian government in light of British experience.

Murray's report (Canada Murray 1912) set the stage for events that played out over the following ten years against the backdrop of World War I and eventually established the Canadian hybrid framework within which Glassco later worked but did not significantly recast. Murray recommended a comprehensive plan that, as Rasmussen has noted, went further than Borden had anticipated (Rasmussen 2009: 20) ${ }^{34}$. He was very critical of the Cabinet bottleneck created by the heavily developed structures of collective responsibility, his solution being to devolve the collective powers of the Governor in Council to individual line ministers. Complementing this, he advised ministers to assume a more policy-oriented role and to devolve administrative authority to their senior officials, requiring greater care in their selection. This pointed to concentrating the role of the CSC on initial recruitment, building on an embryonic two-tier personnel classification system to focus on individuals headed towards more senior positions, with promotions and career incentives placed in the hands of Deputy Ministers. At the same time, he

\footnotetext{
${ }^{34}$ The summary of Murray's report in this paragraph is largely based on Rasmussen 2009: 20-24.
} 
recommended that there be greater executive control over spending, combined with stronger Parliamentary scrutiny of the executive - to that end the Minister of Finance's internal control role should be strengthened and Treasury Board abolished, being "an administrative anachronism" (Hodgetts et al. 1972: 31).

Fully implemented, Murray's recommendations would have brought the federal government in line with British practice, involving significant realignment in the roles of Cabinet, ministers, senior officials and the CSC. More significantly, for the purposes of this discussion, it would have meant a major scaling back of formal collective management institutions, leaving collective controls to the realm of convention and policy direction. Murray's report also implied re-structuring the civil service more closely along the lines of the Northcote-Trevelyan model and its élite administrative class, which by then had been fully implemented in Britain. Perhaps without intending to, Murray called the bluff of those in Canada who in principle advocated following British practice, even Borden, who later judged that Murray had gone too far (31-32).

Most of Murray's key recommendations were not acted upon, in no small part because the report was overtaken by World War I. In addition, Borden was not prepared to reduce the well-established role of either the Governor in Council or of Treasury Board, arguing in his memoirs that Macdonald had had good reasons for involving them in expenditures and administrative matters; nor did he wish to see Deputy Ministers strengthened at the expense of the $\mathrm{CSC}$ - for which he felt considerable ownership especially in the area of promotions (24-25). ${ }^{35}$ In that sense, Murray's insight may have been clouded by a misreading of the actual scope for change. In any event, from this time

\footnotetext{
${ }^{35}$ At the same time, Hodgetts et al. note that the CSC itself (whose leading member was the anglophile Adam Shortt), "had no such qualms" about the Murray report (1972: 33). Indeed, in keeping with the Report it delegated some personnel authorities to Deputy Ministers in 1915 (Roberts 1996: 38).
} 
onward, the Canadian variant on the Westminster model was solidly entrenched, with no serious attempt to shift the centre of gravity away from a significant ministerial role, at both the individual and especially at the collective level, in internal administration. These events also closed the door to moving fully in the direction of the British model of civil service and personnel administration, although they left a number of unresolved issues.

Borden did make one bow in the direction of British practice, when in 1918 he obtained passage of the Public Service Rearrangement and Transfer of Duties Act [S.C. 1918 , c.6, amended by S.C. 1925 , c. 23$]$. Growing out of the rapid war-time expansion of government, the Act enabled the Governor in Council to restructure, even combine, departments and to transfer functions and units among them, removing the need to seek prior Parliamentary approval. While not going as far as British practice, where Parliament's involvement in the structure of the executive is almost exclusively through the appropriations process, it did weaken, but not totally remove, the longstanding Canadian Parliamentary control over decisions about organization of the executive. This legislation continues to be used extensively, and its heyday was the generation after the Glassco report when organizational change came to be seen as a policy instrument, culminating in the 1993 Campbell government reorganization.

In balking at moving systematically towards the full British Westminster model, Borden (possibly without fully meaning to) set in train events that deepened the hybridization of the Canadian system, with the introduction of ideas and structures from the United States. The war effort highlighted weaknesses in the federal personnel system and placed Borden, the erstwhile reformer, open to criticism for not dealing fully with patronage, which was perceived to be out of control, especially in the Outside Service. 
The situation was aggravated by the formation of the Unionist government in 1917, which among other new situations meant that in many ridings Conservative and Liberal constituency associations (historically "sworn enemies" - Hodgetts 1973: 266) were asked to work together in taking decisions about the appointment and promotion of federal civil servants in their ridings. The practical difficulties of getting them to "fraternize and cooperate" risked pulling the coalition apart (Roberts 1996: 42), and the way out was to eliminate patronage altogether by extending the CSC's jurisdiction and the merit system to the Outside Service. This was confirmed in amendments to the Civil Service Act in 1918 and 1919, which gave the Commission wide powers to re-organize and classify the entire unified civil service.

Borden asked the CSC to carry out a two-stage reform: first to reorganize the civil service in light of post-War requirements, and then to classify its jobs as a basis for patronage-free personnel administration. But, with two new members following Shortt's departure and only eight staff to devote to the task (44), the CSC was in no position to undertake a systematic restructuring of the civil service population under its expanded jurisdiction, which had increased over ten-fold. ${ }^{36}$ The events that followed are a good example of Kingdon's policy entrepreneur taking advantage of a window of opportunity (Kingdon 1995) and perhaps also of the cosmic law of unintended consequences.

The long-serving Secretary of the CSC, William Foran, had in 1915 attended the annual meeting of the US National Association of Civil Service Commissions. Given a warm reception, he was elected President at the Association's 1917 annual meeting, held

\footnotetext{
${ }^{36}$ Roberts estimates that at the time of the 1918 changes the Inside Civil Service had 3,000 employees (1996: 33). Hodgetts et al. state that the total civil service in 1919 was 41,825 , almost double the 1913 figure (1972: 66).
} 
in Ottawa. ${ }^{37}$ Faced with its new task, the Canadian CSC, at Foran's prompting, turned for help to Robert Catherwood, an influential figure in the reform of the corrupt municipal administration in Chicago and a leading proponent of the resulting Chicago Plan as a model for civil service reform across the United States. On Catherwood's advice, the CSC in the Spring of 1918 hired Edwin O. Griffenhagen and a team of 27 from the Chicago office of Arthur Young and Co., a firm of management consultants. Responding to pressure to bring the former Outside service into the realm of merit, Griffenhagen began with the classification task; he and his team set out to review every position in the newly consolidated civil service, applying the Chicago Plan in almost the identical form in which Catherwood was promoting it within the US National Association (Roberts 1996: 45-46). ${ }^{38}$ In record time, 1729 job classifications were developed, approximately one for every 20 federal employees (46); these were recorded in a massive "Book of Classification" that was released in June 1919. Implementation was placed entirely in the hands of the CSC, largely working through Griffenhagen and his staff, with no discretionary role for Deputy Ministers.

After the classification plan was completed, attention turned to organizational issues. Reflecting the continued interest in Ottawa in British experience, the Senate had formed a special committee to study the "Desirability of Betterment in the Machinery of Government," which reported in 1919 (Canada Senate 1919). The committee was inspired by the report of the Haldane Committee (UK Haldane 1918), commissioned by the British Ministry of Reconstruction to advise on the post-World War I organization of

\footnotetext{
${ }^{37}$ The account in this paragraph is largely based on Roberts' description of these events, which asks how a group of management consultants were successful in promoting a plan that clearly did not take account of the client's circumstances (Roberts 1996).

${ }^{38}$ Citing the Canadian experience, Catherwood later persuaded the US Association to adopt model legislation enacting the Chicago Plan, leading to its implementation in virtually identical terms in the US government as well as in city and state governments across the US.
} 
government. (In view of his wartime contacts with the British government it is likely that Borden also had the Haldane report in mind in the actions that he took.) The Senate committee's recommendations included establishing a permanent Cabinet secretariat to improve internal coordination, a classification scheme for organizing government departments, based on which they recommended halving Cabinet to ten portfolios, and echoing Murray - measures to reduce ministerial workload through devolution of responsibilities to non-departmental bodies (White 1965: 82-86; Canada Senate 1919).

The organizational agenda was already in the hands of the CSC. Griffenhagen was hired in his own right to support the CSC's new Organization Division, set up with "inquisitorial power" (Roberts 1996: 45) to conduct efficiency studies in the civil service, with a view to removing incompetent and supernumerary staff, adjusting defective organizational structures, and maintaining standards of efficient service to the public. Its mandate was almost identical to that of the efficiency branch that Griffenhagen had run in the Chicago municipal administration before joining Arthur Young (ibid.). This work found significant savings in organizations that were examined, but by 1920 the CSC was worn out (Hodgetts et al. 1972: 77). The cause was taken up, however, shortly before Meighen became Prime Minister in 1920, when a Council sub-committee was set up to oversee an ambitious effort to reorganize the government, supported by the CSC and Griffenhagen. Anticipating the Glassco commission forty years later, 74 reports were prepared on all aspects of government, with a view to consolidating government departments from 25 to 11 , overhauling expenditure control, systematizing routine clerical work common to all government departments, and reorganizing major departments with a view to major savings (Hodgetts et al. 1972: 79). The process had 
already begun to lose momentum, however, by the time the ministerial sub-committee died with the change of government after the December 1921 election (81-82), and Mackenzie King allowed the increasingly unpopular reform process to peter out by 1923 , without reversing its main elements (see also Hodgetts et al. 1972, chapters 3 \& 4).

The changes between 1918 and 1923 represented a sea change in the civil service. Although the reorganization did not get off the ground and several elements of the classification were trimmed, the classification reforms in particular had enduring effects. In the short run they represented a major power shift away from Deputy Ministers towards the $\mathrm{CSC},{ }^{39}$ reinforcing the continued collectivization of administrative decisionmaking. The pendulum eventually moved back somewhat, leaving the CSC vulnerable in the longer term, but the core model of a service-wide centrally determined and implemented administrative system was solidified. So too were the system of classifying jobs rather than people and a related merit system based on the process for filling jobs rather than the management of careers - both significant differences from the British civil service. Treasury Board had virtually no role in these developments, but in the longer run it was the beneficiary as it gradually displaced the increasingly discredited CSC. Perhaps the longest-lasting effect, however, was cultural and intellectual. The Chicago Plan and Griffenhagen were imbued with the new school of scientific management and its link between organization and efficiency; the classification plan, tied to efforts to control patronage, was one of the first major applications anywhere to the public sector of the private sector-inspired "one best way." The classification plan was vigorously opposed in

\footnotetext{
${ }^{39}$ Roberts (1996: 62 - 63) argues that when the Chicago Plan was implemented in Canada, legitimate concerns about corruption among line managers in Chicago were translated into an attack on the legitimacy of Deputy Ministers, who were not nearly as tainted by patronage. They were given no role in developing and implementing the classification plan and their vigorous public objections were brushed to one side for several years. Classification and staffing authorities were later delegated to Deputy Ministers, but they never achieved the autonomy implied in the Murray proposals.
} 
many areas of the civil service, but the cultural assumptions associated with it took root, providing the reference point for later reforms.

The following 40 years saw consolidation of the situation that emerged after World War I, combined with periodic fluctuations in the three-cornered relationship between departments, Treasury Board and the CSC. In the 1920s there was some retrenchment in government spending from wartime levels, but also relatively little central intervention in departments, with a bruised CSC responsible for most personnel administration functions including pay determination and departmental organization. While Treasury Board had numerous roles, notably expenditure control, "in practice it appeared to be something of a paper dragon fretting over detail at the expense of its major assignments" (Hodgetts 1973: 251). The situation changed during the Depression, as the Bennett government put Treasury Board in charge of severe restrictions on departmental spending, which also limited the CSC's autonomy on pay issues. Treasury Board was strengthened by more systematic estimates and accounting procedures and indirectly by the establishment of the Comptroller of the Treasury.

World War II brought a radical transformation in the size and duties of the civil service, with an inevitable relaxation of central managerial control (254). In addition, it marked the beginning of structural changes to address some of the issues of ministerial overload first raised by Murray a generation earlier, notably the appointment of the Clerk of the Privy Council as Cabinet Secretary, the designation of the Privy Council Office as the Cabinet Secretariat, and the creation of a Special Committee of Council to take the volume of Orders in Council off the Cabinet table (Heeney 1946). These represented the first steps towards a more systematic and policy-oriented approach to collective decision- 
making, marking a shift away from the case-by-case transactional approach that had previously characterized both Cabinet and Treasury Board. A further step towards rationalizing collective management was passage of the Financial Administration Act in 1951, authorizing Treasury Board to take final decisions on behalf of Cabinet in a wide range of areas, in particular where the substance was settled (Hodgetts 1973: 255).

Two Royal Commissions addressed personnel administration issues during this period. The Beatty commission (Canada Beatty 1930), headed by the President of the CPR, which reported in 1930 - at the beginning of the Depression and just before a change in government - addressed issues left unresolved by Griffenhagen's classification plan and the related salary plan with respect to classification of technical and professional staff. These were becoming increasingly important in light of the growing complexity of government and the extension of its activity into new and more technical fields, requiring skills that went beyond the largely clerical nature of the civil service until then. The Beatty report had limited substantive influence but underscored the desirability of private sector comparisons, while further weakening the CSC (Hodgetts et al. 1972: 131).

The Gordon Commission on Administrative Classification (Canada Gordon 1946), appointed in the aftermath of World War II and headed by a leading businessman, sought to address recruitment delays and other problems with the CSC's role after a generation of experience with the 1918 Civil Service Act. With a senior British civil servant among its members, it echoed Murray and Beatty in recommending changes that would have brought the civil service more in line with British practice, notably the transfer of most CSC functions, including those relating to organization and pay, to a division under Treasury Board headed by a Deputy Minister-level Director General of Establishments, 
leaving the Commission to concentrate on recruitment. These recommendations were not acted upon, partly because of a successful intervention with the Prime Minister by the chair of the CSC, as well as reluctance by Treasury Board staff to take on the proposed role (Hodgetts et al. 1972: 214) and concerns that the heavily anglophone Treasury Board would not be as sympathetic to francophone employees as the CSC (Mallory 1971: 157). It did result, however, in a more pragmatic working relationship between Treasury Board and the CSC over the next fifteen years (Hodgetts 1973: 256).

When the Diefenbaker Conservatives came into office in 1957 after 22 years of Liberal government there was a well established tradition of continuous improvement in the federal government. Reform had been largely cumulative, albeit with a significant course adjustment after World War I. The deep foundation of collective governance was solidified and there were significant steps towards a professionally managed civil service. From Confederation onward, most Prime Ministers, from both major parties, took an interest in improving federal public administration, which was linked to how they organized and ran their ministries as well as to the individual and collective roles of Ministers. Most sought publicly-tendered advice, principally from Commissions of Inquiry and Royal Commissions, which typically provided the reference point for subsequent action, although the advice was not always precisely followed. Perhaps more important was the advice providers, who included deputy ministers, parliamentary committees, and civil servants and politicians from related systems; business leaders were part of the mix from early days and later on management consultants were increasingly prominent. This openness to a range of perspectives, with a combination of internal and 
external as well as of practical and more theoretical experience, was well established in the first half of the $20^{\text {th }}$ century.

While the most enduring focus was on expenditure control and professionalization of the civil service, there was also a continuing concern with the use of organization to improve efficiency in government and the quality of service to the public. In the postWorld War II period it was increasingly apparent that further change was needed, reflecting the growth both of the positive state and of the influence of new technologies. The stage was therefore set for the next round. The most pressing concern that Diefenbaker inherited in 1957 was the increasingly unsatisfactory system for pay determination in the civil service and associated tensions between the CSC and Treasury Board. The St. Laurent government had appointed a former Cabinet Secretary, Arnold Heeney, to chair the CSC and commissioned him to conduct a study of the system of personnel administration. Although Diefenbaker amended the Civil Service Act in 1961 based on his recommendations (Canada CSC Heeney 1959), there was still considerable pressure for change. This was the immediate context for the Glassco commission, which was appointed in 1960 .

\section{The Glassco Report}

The Royal Commission on Government Organization (the Glassco commission), was appointed by Diefenbaker on September 16, 1960, submitted the first volume of its report on July 18, 1962 and the fifth and final volume on February 28, 1963, shortly before Diefenbaker was defeated (Canada Glassco 1961-1963 1-5). If Griffenhagen was Canada's first Glassco (Hodgetts et al. 1972: 75), Glassco built squarely on the 
foundation laid by Griffenhagen. Like Griffenhagen's organizational studies a generation earlier, the commission was asked to take a comprehensive look at the entire government administration and all aspects of administrative activity, an undertaking that has not been attempted since. Also like Griffenhagen, Glassco represented a massive injection into the public sector of private sector management ideas and techniques, drawing extensively on the expertise of the management consulting industry and benefitting from the more sophisticated array of management tools and insights developed since Griffenhagen, giving a major boost to the Canadian management consulting industry, which was still in its formative stage (Saint-Martin 2000). ${ }^{40}$

Glassco represented a less radical change in direction than Griffenhagen, but its recommendations were largely acted on and the changes it did bring about were more complete, broadening and deepening the existing base and addressing a number of accumulated problems. ${ }^{41}$ This impact resulted at least in part from Glassco's more propitious political circumstances. It was appointed by an established Prime Minister with a majority government, attracted bipartisan support, and was largely implemented by a successor government headed by a former civil servant who was familiar with the issues being addressed and prepared to act on the proposed solutions. The fact that Glassco was a Royal Commission rather than staff support to a committee of ministers made it less action-oriented to begin with, but undoubtedly it was easier to obtain support

\footnotetext{
${ }^{40}$ Griffenhagen was US-based and did not leave a significant footprint in Canada after his contract with the Canadian government ended in 1923.

${ }^{41}$ Glassco's research methodology, which made extensive use of study teams using scientific management methodologies as well as drawing on civil service inputs, also created a bias towards improving rather than replacing the status quo. This is an important contrast with Griffenhagen, which was oriented to implementing an external model, consciously seeking to over-ride the interests on the ground but also ignoring their realities (Roberts 1996: 62-73).
} 
for its proposals in the longer run, both from the public and from within the civil service. It probably also helped to make the process less vulnerable to a change in government.

Diefenbaker had several reasons for appointing the Glassco commission. After 22 years of Liberal government, he was suspicious of the political sympathies of the civil service. As a Red Tory he did not fundamentally question the growth in the size and role of the state but he did want it to be more "businesslike" and draw more on private sector values and experience to improve public administration (Mallory 1971: 163). To that end, he admired the work of the two post-World War II commissions on the organization of the US executive branch led by former President (and businessman) Herbert Hoover. By the time the Glassco commission was appointed, Diefenbaker had had three years' experience working with the civil service and was familiar with the issues relating to its management, most recently dealing with the Heeney report, which left open as many questions as it resolved. It also is likely that he was encouraged to take a more systematic approach by his Cabinet Secretary (and former Treasury Board Secretary), R.B. Bryce, who provided an experienced pair of hands to handle the process and its aftermath.

Chaired by J. Grant Glassco - a private sector executive, accountant and management consultant who was known in Ottawa ${ }^{42}$ - the commission's other two members were a retired Auditor General and a francophone private sector lawyer. Its senior staff reflected its expected sources of advice, drawn from the private sector, the civil service, the academic world (for the first time in a major Canadian study of public

\footnotetext{
${ }^{42}$ A Progressive Conservative (Churchill 2006: $74 \mathrm{fn} 15$ ), Glassco prepared a research study (Glassco 1956) for the 1956 Royal Commission on Canada's Economic Prospects, chaired by Walter Gordon who had earlier chaired the 1946 Royal Commission on Administrative Classification and was an influential Liberal. Later, as Pearson's first Finance Minister, Gordon had an important role in facilitating the implementation of Glassco's recommendations about Treasury Board. He was supported by Bryce, who had moved to be Deputy Minister of Finance, at least in part at Gordon's request (Pearson 1975: 104).
} 
administration), and from the management consulting industry. ${ }^{43}$ Although the commission's three members were Canadian, it actively reached out to American and British experience, acknowledging in the first report the "informal advice and assistance" of Herbert Hoover, Lords Bridges and Plowden, C.P. Snow, Col. Lyndal Urwick and Peter Drucker, among others (Glassco 1962 1: 23-24). ${ }^{44}$ Scoping its work into 18 major project areas, each with a private sector advisory committee (Canada Glassco 1961 Interim) and supported by 176 expert advisors from outside government and another 21 from within (Canada Glassco 1 1962: 22) the commission prepared 24 thematic reports published in 5 volumes (Canada Glassco $1962 \& 1963$ 1-5), making a total of 268 formal recommendations (Yeomans interview).

The structure of the report mirrored its line of argument. Under the heading of "Management of the Civil service," volume 1 contained four complementary reports relating to management of the government as an entity. Report 1 outlined the commission's unifying "concept of management" and proposed an organizational taxonomy based on a government-wide division of labour, while Reports 2-4 discussed three major sectors of functional management that were considered to be common to all departments and needed to be addressed in an integrated and consistent manner by the agents of collective responsibility (i.e., Treasury Board): financial, personnel, and paperwork and systems. A theme in Report 1 was that supporting services to government should be consolidated, where justified, in specialized common service organizations

\footnotetext{
${ }^{43}$ Respectively: the Executive Director was Roland Ritchie, a manager at Imperial Oil and later its chair; the research director was F.A. Milligan, a civil servant; the editorial director was J.E. Hodgetts, professor of political studies at Queen's University; and the director of organization research was D.R. Yeomans, from the management consulting firm Urwick Currie (Canada Glassco 1963 5: 13-14).

${ }^{44}$ Throughout the dissertation, page numbers are cited for the unabridged version of Volume 1 . An abridged version was also issued of Volume 1 only that omitted appendices and other supporting material for Reports 2-4.
} 
operating under the discipline of "make or buy" - this was the subject of the seven reports in volume 2 and two additional reports in volume 3 . Volume 3 continued with five reports on aspects of services for the public. Volume 4 had five reports on "Special Areas of Administration," while the single report in volume 5 contained a summary of organizational changes required in order to implement the full report. (A complete list of the reports is in Annex 5.)

The Glassco commission is commonly considered to have advised government to "let the manager manage." While this admonition can be inferred from its commentary, it does not in fact fully reflect the commission's concerns or the breadth of its recommendations. In an environment conditioned by the rapid growth of government, its growing complexity, a proliferation of controls, but also the availability of new resources and techniques (Canada Glassco 1962 1:35-47), Glassco called for a new approach to the tasks of effective management, divided into two general but complementary categories of needs: "those associated with the administration of departmental operations; and those involved in the central direction and co-ordination of government activities as a whole" (48). The starting point was the task of departmental administration, a high level role $^{45}$ that the commission saw as encompassing five functions:

first, to advise the minister on policy matters and to serve as the channel through which the minister's direction flowed to departments; second, to plan future programs and the resources necessary to meet future needs; third, to ensure the availability of the necessary qualified personnel and other resources; fourth, to adapt the department's organization to its responsibilities; fifth, to provide control and evaluation of personnel and operating units. (Canada Glassco 1963 5: 54)

\footnotetext{
${ }^{45}$ Glassco adopted a British view of administrative functions, regarding them as more strategic and linked to the policy process, as opposed to executive functions, which relate to program operations within established policy. This distinction has since been lost - even reversed - in the Canadian public service. It can be speculated, however, that it lies behind the approach taken to accountability by the Lambert and Gomery commissions, in which accountability for administration falls squarely under Ministerial responsibility while Accounting Officer accountability/answerability is with respect to executive roles.
} 
Effective departmental administration required qualified senior administrative staff and proper tools of management and control - with the private sector offering useful experience - combined with appropriate ministerial and Parliamentary accountability (Canada Glassco 1962 1: 50-51):

\begin{abstract}
Above all, departments should, within clearly defined terms of reference, be fully accountable for the organization and execution of their programs, and enjoy powers commensurate with their accountability. They must be subject to controls designed to protect those general interests of government which transcend departmental interests. But every department should be free of external controls which have no such broad purpose. (51)
\end{abstract}

At the same time, each department "is only a segment of a single entity - the Government of Canada," reflected in the concept of a single public service, in which the authority of each department is subject to "the overriding needs of the government for unity, coherence and a proper regard for the general interests of the Canadian public" (52). The report then enumerated eight functions of central administrative direction, operating within "the overriding task of political leadership:" (ibid.)

- determining the annual budget, within an overall financial plan and weighing public desires and means;

- assessing the financial, administrative and organizational implications of existing and proposed programs, within priorities and the limits of the financial plan;

- setting policies and standards governing the use throughout the government of money, staff and other resources;

- ensuring strong administrative leadership in departments;

- fostering the development and application of effective management practices;

- assessing the effectiveness of departmental activities and the performance of departmental administrators in discharging their functions; 
- maintaining the public accounts; and

- adapting the machinery of government to changing tasks and objectives.

Although "the collective responsibility of the government as a whole" (53), these tasks required the focused attention of a single minister, which the commission recommended be a "presiding minister" of Treasury Board, separate from - but working closely with - the Minister of Finance and with no departmental responsibility (54). Given that Treasury Board exercises Cabinet authority, the Treasury Board staff should be transferred to the Privy Council Office, with the Secretary of Treasury Board having deputy ministerial status and a complementary relationship to the Prime Minister with the Clerk of the Privy Council, the latter concerned with policy and the former with administrative direction (55-56). Operating under tests of "relevance to the essential functions of central direction" (55), the reconstituted Treasury Board would step back from detailed controls - it then processed 16,000 submissions annually $(i b i d)-$. to provide policy direction and functional oversight to departments in three areas that should provide the organizational structure of Treasury Board Secretariat: 1) analysis of departmental programs, review of spending estimates, and framing of general standards of administration; 2) personnel policy, standards of personnel management, and staff relations; and 3) administrative improvement in operating systems and procedures "throughout the machinery of government" (64). This would bring under a single central organization responsibility for providing direction in all areas of administration and management, with the exception of a much narrowed range of functions for the CSC: certification of appointments, final hearings in disciplinary cases, and pay research (65). 
A third leg to the stool concerned the provision of "administrative services for which departments have common needs" (57-59). Complementary to the formulation of common administrative standards was the creation of common supporting services where that was warranted as an alternative to independent action by departments. Reasons for setting up such common service organizations included serving the public interest and "economy or administrative advantage," especially in support of smaller organizations and field operations (although smaller organizations becoming clients of larger departments was also envisaged). In addition, while departments should be in full control of defining their needs for supplies and services, the commission considered that meeting those needs may in fact be a distraction from their essential public functions. With proper safeguards against common service organizations becoming control organizations on the one hand and inbred and complacent on the other, they could provide important services both to departments and to Treasury Board, not least as a source of technical guidance in the framing of administrative policies and standards. What common service organizations were not intended to do was to intervene directly in departmental administration; instead, operating within Treasury Board administrative policies that applied to both them and their departmental clients, they represented a clear alternative to the much-criticized Comptroller of the Treasury model.

The final component of the Glassco concept of management was strong administrative leadership in departments and across government $(59-61),{ }^{46}$ with the Clerk of the Privy Council and Secretary of the Treasury Board jointly responsible for

\footnotetext{
${ }^{46}$ Glassco's proposals in this area closely resemble the system of senior staff management in the British government, variations of which had been frequently proposed in the past, notably by Murray and the Gordon commission. It can be speculated that this time the Royal Commission was influenced by the advice of two prominent British civil servants, Lord Bridges and Lord Plowden.
} 
advising the Prime Minister on the appointment and transfer of deputy ministers, who should be rotated regularly. The centre of government should also take an interest in the quality of other senior administrative staff in departments, starting with the level below deputy ministers. A particular concern was the chief financial officer and the chief personnel officer in each department, who were responsible for implementing Treasury Board policies and standards with respect to the use of staff and public money. While these officers supported departmental programs and administration, the commission emphasized that they should be clear that "their future careers rest primarily - though not exclusively - on the assessment of their performance by the staff of Treasury Board, rather than on their ability to please the heads of their departments" $(60-61)$. On the other hand, TBS staff should work there on rotation from line departments and not depend on Treasury Board for their careers (56).

In concluding its systemic proposals, the report highlighted the importance of checks and balances to keep the new machinery from falling back into unnecessary controls and frustrating good management (61-63). In addition to internal checks, the commission flagged the roles to be played by the CSC and the Auditor General as "the essential safeguards." The ultimate safeguard, however, lay "in the political process itself - in the accountability of ministers, both individually and collectively, to Parliament and through it to the public" (62) - recognizing that this "may well create new problems of accountability to the public and their elected representatives" (63).

\section{Implementing Glassco}

Diefenbaker almost certainly got more than he bargained for from the Glassco commission (Yeomans interview). On the one hand, he was given very little ammunition 
with which to clean out the senior civil service: while numerous administrative weaknesses were found these were almost invariably ascribed to systemic faults, and no grounds were given to doubt the loyalty or general competence of the civil service. To the contrary, in marked contrast with Griffenhagen's deep suspicion of line managers, the report was devoted to strengthening their hand and improving their effectiveness. The commission also made the most of its terms of reference - which as St-Martin has pointed out (2000: 120) closely followed those of the Hoover commission - and addressed virtually the entire structure of federal public administration in a comprehensive and highly systematic way. At the same time it offered numerous examples of how private sector practice could beneficially be applied in the public sector, a result that Diefenbaker could accept.

Although it had its critics (Mallory 1971: 168-170, Tunnoch $1964 \& 1965)$ the main elements of the report were generally well received ${ }^{47}$ and a serious effort was made to act on its recommendations. After the first report was tabled, Diefenbaker stated his "general agreement with the basic philosophy of the report" (Mallory 1971:171) and assigned the processing of the report to Wallace McCutcheon, who had just entered both the Senate and Cabinet as Minister Without Portfolio, as such reporting to the Prime Minister. McCutcheon, who had come to Ottawa from Bay Street, was sympathetic to the tenor of the report but did not get very far with implementing it. Implementation machinery was put in place to support him, however, initially a Committee of Senior Officials chaired by Bryce and, from January 1963, by the Bureau of Government Organization (BGO). Located in the Privy Council Office, its role was to conduct a

${ }^{47}$ For example, a front page story in the January 9, 1963 Montreal Gazette, states that the first two volumes had broad political support but that Diefenbaker was more cautious about recommendations in the third volume, which had just been released, notably advice to close Veterans' hospitals (Blakely 1963). 
systematic review of the Glassco recommendations, with a general presumption that they should be implemented (Hodgetts et al. 1972: 290).

After some persuasion, a senior Deputy Minister, George Davidson, ${ }^{48}$ was drafted to lead the BGO, supported by a small secretariat, including the Glassco Director of Organization Research, Don Yeomans, who brought with him his earlier credentials as a private sector management consultant. When Pearson entered government in April 1963 he retained the $\mathrm{BGO}$ and appointed a Minister to lead the processing of the report, Maurice Lamontagne, who was initially President of the Privy Council (in effect a minister without portfolio reporting to the Prime Minister) and later Secretary of State. ${ }^{49}$ When the ministerial lead for implementation was transferred to the Minister of Finance in late 1965 , Davidson - who had already moved with the BGO to the Department of Finance in May 1964 - became Secretary of Treasury Board, preparatory to it becoming a separate department (Hodgetts 1973: 261). On October 1, 1966, a new ministerial portfolio of President of Treasury Board was established, following the passage of enabling legislation earlier in the same year. ${ }^{50}$

To a remarkable extent, both the letter and the spirit of the Glassco recommendations were implemented. Management of the government as a whole was accepted as a collective ministerial responsibility, entrusted on Cabinet's behalf to Treasury Board headed by a Minister separate from although closely aligned with the

\footnotetext{
${ }^{48}$ Davidson was for a number of years the Deputy Minister of National Health and Welfare and immediately before moving to the BGO was Deputy Minister of Citizenship and Immigration. ${ }^{49}$ Lamontagne took BGO responsibility with him when he moved to the Secretary of State portfolio. He resigned in December 1965 (Churchill 2006: 146), and the ministerial lead was transferred to the Minister of Finance, Mitchell Sharp (a former Deputy Minister), who had replaced Gordon. Bryce was Deputy Minister of Finance throughout the transition of TBS from a unit of Finance to a separate department. ${ }^{50}$ The core legislation was a revised Financial Administration Act. It was complemented by two new statutes in the personnel area: the Public Service Employment Act, which constituted the new Public Service Commission and merit system, and the Public Service Staff Relations Act, establishing collective bargaining in the public service, with Treasury Board as the collective employer.
} 
Minister of Finance and supported by an independent Treasury Board Secretariat (TBS). Initially, TBS was structured much as Glassco had recommended, with three branches: a Program Branch that oversaw the introduction of program budgeting and the allocation of expenditure budgets to departments; a Personnel Policy Branch, which consolidated all personnel management functions other than those considered to be directly related to the merit system, which was left to a reduced and restructured Public Service Commission; ${ }^{51}$ and a Management Improvement Branch (MIB), ${ }^{52}$ which was assigned both a policy role with respect to financial and other non-personnel areas of internal administration (a departure from the Glassco recommendation that these be assigned to the Program Branch) and a more open-ended role in promoting management innovation and evaluation. Complementing TBS was the establishment of consolidated common service organizations, the primary ones, after some evolution, being the Department of Supply and Services - bringing together government purchasing and central supply functions, including for the military - and the Department of Public Works, which managed government real property and construction.

In a given area of management practice, the new Treasury Board's primary instrument was policies and standards, which created a framework of goals, authorities, and related procedures and accountabilities that applied to departments and common service organizations alike; within departments they applied to line managers and staff as well as functional specialists whose jobs were defined by Treasury Board policies and who operated under the leadership of TBS policy centres. A focal point was the

\footnotetext{
${ }^{51}$ This was very similar to the proposal made by the 1946 Gordon Commission. Indeed it can be argued that Glassco took that model and extended it to all areas of management.

${ }^{52}$ The first head of MIB was Don Yeomans, who had moved to TBS with George Davidson and the remnant of the BGO, providing one of the stronger areas of continuity from the work of the Glassco commission. In the same vein, he later moved to head the Supply sector of the Department of Supply and Services, one of the major common service areas commented on by Glassco.
} 
departmental Deputy Minister, who received direction or guidance from Treasury Board on the exercise of management authorities derived from departmental legislation and delegations from their minister. In certain areas, Deputy Ministers also received delegations of managerial authorities from Treasury Board (e.g., classification) or the Public Service Commission (PSC), acting as the agent of Parliament in protecting merit, notably with respect to appointments to the public service but also governing promotions and lateral movement within and between departments.

There were some deviations from the Glassco model. Notably, TBS was not - as the commission had recommended - incorporated into PCO, with its Secretary as the second Deputy Minister to the Prime Minister alongside the Clerk of the Privy Council. In addition, the PSC retained an operational role - in effect as a common service organization, although not described as such - in recruitment and also in the provision of training to public servants - that was more substantial than the one envisaged by Glassco. In the main, however, the proposals in the first volume - the scheme of management and the approach recommended in the areas of finances, personnel, and paperwork and systems management - were followed to a remarkable degree. Even more remarkable has been the durability of the overall model, which a half century later is recognizably still in place, including the collective role of Treasury Board, the associated model of government-wide management policies, and the broad division of labour among central agencies, common service organizations and line departments. Within that framework there has also been a great deal of change, at times amounting to churn, always seeking to improve the Glassco-inspired management model, not always succeeding. The most significant developments between 1966 and 1993 are summarized in the next section, 
touching both arrangements within TBS and the government's management environment and on the public policy-oriented machinery of government. Generally separate spheres, together they conditioned the environment in which the CIO was established in 1993.

\section{After Glassco: continuous organizational change and administrative reform}

The immediate success of the Glassco report depended on a number of factors. The proposals were integrated, extensively researched, systematically organized, clearly written, and - reflecting the influence of the management consultants - rooted in, rather than significantly challenging, the structural assumptions of the federal government, which had already absorbed several generations of external organizational advice and refinements. Commissioned by a government that was looking for a new infusion of thinking from the private sector, the report was implemented by its successor that was more comfortable with the public sector but also aware of its faults. A particularly important factor was the role played by politicians and senior public servants. ${ }^{53}$ Both Diefenbaker and Pearson appointed ministers reporting directly to them to lead the implementation process, and a respected Deputy Minister was assigned to support them, carrying on to become Secretary of TBS, the centrepiece of the new management plan. The Clerks of the Privy Council were also key figures: Bryce, the former Treasury Board Secretary, under Diefenbaker, and Gordon Robertson, who had had extensive PCO experience with King and Saint-Laurent, under Pearson. The fact that Robertson and Pearson had previously worked together as civil servants undoubtedly made the

\footnotetext{
${ }^{53}$ In a slightly different assessment, Mallory states that the Glassco report embodied "a host of specific changes which come from the hearts of frustrated senior civil servants" in a time that was ripe for change (1971: 170-171). Glassco's management consultants can be seen as the handmaidens of the "Ottawa Men" (Granatstein 1982) and their protégés who had played a major nation-building role during and after World War II and were well aware of the importance of healthy national institutions.
} 
relationship easier, just as Bryce's move in 1963 to become Deputy Minister of Finance, working with Walter Gordon, the chair of 1946 commission, would have facilitated the transition of Treasury Board and TBS to the new model.

These conditions led to several early rounds of organizational restructuring, in 1966, 1968 and in 1969, the latter following the arrival in office of Pierre Elliott Trudeau, who remained the dominant figure in Canadian politics and public administration until 1984. A constitutional expert and former journalist who had worked for Robertson in PCO twenty years earlier (Robertson 2000: 89), Trudeau was open to the Glassco view that one of the roles of collective management was that of adapting the machinery of government to changing tasks and objectives (Canada Glassco 1962 1: 52). This he did throughout his tenure, making periodic changes in the structure of Cabinet decision making and of ministerial portfolios to reflect changing government priorities. Linked to these adjustments was a considerable evolution in the structure and understanding of the role of Treasury Board and TBS that did not, however, change its basic assumptions.

While Trudeau's primary successor, Brian Mulroney, did not share his interest in administrative and organizational issues, he continued to make organizational changes, including in the areas of interest to this paper. It was also during Mulroney's time that the public service began to be significantly influenced by the precepts of New Public Management (NPM), ${ }^{54}$ which represented yet another infusion of private sector thinking into public sector management, although one that was as much general to OECD governments as specific to Canadian administration, in contrast to Glassco. This section briefly discusses the developments under Trudeau and Mulroney, as well as noteworthy

\footnotetext{
${ }^{54}$ Interviews indicated that senior public servants involved in public service reform during this period did not see themselves as carrying out an "NPM" agenda; indeed many were not aware of the term until later.
} 
changes made by two shorter-lived Prime Ministers, Joe Clark and John Turner. It begins, however, with one of the distinguishing characteristics of the Canadian system since Glassco, the establishment of an institutionalized capacity to keep organizational arrangements under continuous review.

\section{The Prime Minister and the machinery of government}

In some ways, the most potent element of the Glassco model was its identification of changes to the machinery of government as a policy instrument. This was intended to be a function of the re-focused TBS, but more than most it depended on a close association with the Prime Minister's responsibility for assigning ministerial portfolios and structuring the Cabinet decision-making process. ${ }^{55}$ While at $\mathrm{PCO}$, the BGO built on its access to these organizational instruments to bring about the round of restructuring that culminated in the Government Organization Act of 1966, which created the new Treasury Board ministerial portfolio among a number of Glassco-inspired restructurings. Once the residual BGO moved to become the nucleus of the new TBS, it lost the organizational leverage that came with access to the Prime Minister's authorities, although organizational issues were part of the mandate of the new Management Improvement Branch and throughout the period TBS continued to have a major role in implementing changes in government structures. ${ }^{56}$ In the aftermath of the BGO, however, the task of keeping the machinery of government ever-green was enthusiastically assumed by PCO and found receptive clients in Pearson and especially Trudeau, whose willingness to act on this role was a defining characteristic of the next fifteen years.

\footnotetext{
${ }^{55}$ This is most recently stated in PCO's note on its role and structure (Canada PCO 2010a).

${ }^{56}$ This included approving program structures for budgetary purposes, organization charts, top management positions reporting to the Deputy Minister, and the complement of executive position below them. The middle and lower level executive positions were typically also Responsibility Centre (RC) managers, the basic level to which budgetary and related administrative authorities were delegated under the program/activity structure of budgeting established following Glassco's recommendations (Graham 2007).
} 
In the later years of the Pearson government, much of the organizational advice to Robertson and the Prime Minister came from Michael Pitfield, the PCO Deputy Secretary (Plans), supporting the Cabinet Committee on Priorities and Planning, which was established under Pearson and became the de facto Inner Cabinet under Trudeau (Schindeler 1971: 44). Pitfield, who succeeded Robertson as Cabinet Secretary in 1975, was interested in introducing a more rational model of government decision-making and in harnessing the adaptation of the structure of government with senior appointments in support of implementing the government's agenda. As his responsibilities grew, in particular after the arrival of Trudeau, he strengthened his own staff support on government organization matters, hiring a single staff member in 1971 (Krupka interview) and later expanding to a Government Organization group within the PCO Plans sector (Smith and Darling interviews). At first, this unit was part of a larger Machinery of Government directorate, which also included the staff unit that provided advice on the appointment of Deputy Ministers and other public service-oriented Orderin-Council positions. By 1980, however, the organizational and senior personnel advisory functions were separated within PCO and the organizational unit was assigned the Machinery of Government title, which it has held ever since. For the most part it has also remained within the Plans sector.

The Machinery of Government concept and terminology were borrowed from a similar unit in the British Cabinet Office. Its roots can be traced back to the 1918 Haldane report, which recommended an approach to structuring government to meet anticipated needs based on variants of the traditional ministerial departmental model. The lasting effects of the Haldane report's specific proposals, which relied heavily on a scheme to 
categorize the activities of government, have been questioned (Schaffer 1957, Hume 1957), but it did establish the idea of organization as a policy instrument and led to the creation of dedicated Machinery of Government staff units in the British Treasury, more recently the Cabinet Office, to address organizational issues in the context of the constitutional conventions of Cabinet government. A similar unit was established in the Australian Prime Minister's department, and at least one commentator has identified the Glassco report as a Canadian machinery of government investigation in the Haldane tradition (Subramaniam 1968). Robertson and Pitfield were aware of the British Machinery of Government unit from their regular contacts with Cabinet Office counterparts and drew general inspiration from British practice, but the Canadian version evolved in the Canadian context and to meet the requirements of its Canadian clients, the succession of Prime Ministers and Privy Council Clerks over the past 40 years.

The current description of the role of the Machinery of Government unit is that it "provides advice and support to the Prime Minister and the Clerk of the Privy Council on the structure and functioning of the government as a whole" (Canada PCO 2010a). Behind this bland description are several key functions. The most important is to advise an incoming Prime Minister on structuring their Cabinet, including packaging portfolio responsibilities and defining the organization and decision-making process of their Cabinet (Savoie 1993, Mitchell 2002). The former affects the organization and responsibilities of government departments and the assignment of non-departmental bodies to Ministers, while the latter can affect the role and organization of the central agencies supporting collective responsibility. The unit also serves as a corporate memory for organizational decisions, centre of expertise on the constitutional and administrative 
principles underlying organizational decisions, and advisor on conflicts and gaps among ministers and departments as they arise (d'Ombrain 2007). When a prime ministerial decision is taken to make an organizational change - as part of Cabinet formation or during a governmental mandate - the Machinery of Government unit organizes the immediate reassignment of existing departmental units, using Orders in Council under the Public Service Rearrangement and Transfer of Duties Act, and then works with the Department of Justice to draft a Government Organization Act, to give the plan longerterm effect. At the same time it works with TBS, or sometimes a dedicated task force, somewhat on the model of the BGO, to ensure that the budgetary, personnel, real property and other administrative details of a reorganization are attended to.

The evolving Treasury Board Secretariat and administrative reform agenda

Two features of the original, Glassco-inspired, TBS organization had inherent tensions that contained the seeds of later debates and change. A central element of the role assigned to the new Program Branch, with its focus on departmental expenditure budgets, was the introduction of program budgeting, which had recently been popularized by the US Defence Department under Robert McNamara. The result was a concern with program results and effectiveness, looking at the programs and activities of individual departments as a whole. This added another dimension to traditional Treasury Board concerns with economy and efficiency, leading to considerable attention being paid to planning on the one hand and evaluation on the other. At the same time, the Management Improvement Branch (MIB) was given responsibility for administrative policies and practices in the various areas of management, including innovation and effectiveness, looking at each area on a cross-government basis; their focus was on the functional 
communities in departments whose expertise was tied to Treasury Board policies, together with the related common service organizations. In principle this created a matrix structure, with the program and management policy interests complementing each other and reconciled through the internal processes of TBS and the Treasury Board itself. ${ }^{57}$ In practice it proved difficult to bring the budgetary and regulatory spheres together, especially in areas that each could plausibly claim as its own, such as evaluation.

The first of many restructurings of TBS came in 1970. In effect, the MIB, with its combined concern with administration and innovation, was disbanded. Its evaluation and innovation roles were assigned to a new Planning $B r a n c h,{ }^{58}$ and its responsibilities for the non-personnel areas of functional management were consolidated in an Administrative Policy Branch (APB). Even without its innovation role, APB had a wide range of responsibilities. Of greatest interest to this paper, it was asked to provide central direction to departments in the areas of technology and records, responding to criticisms in Glassco's Report 4. It also had policy oversight of real property management, contracting, procurement and services to government (not least, technology and telecommunications services); all these areas of administration had a significant "make or buy" dimension, and an important part of APB's mandate was to oversee the relationship with the newly restructured common service organizations. Another area of APB responsibility was the regulation of the newly decentralized accounting, auditing and other financial management practices - with the associated functional communities and

\footnotetext{
${ }^{57}$ The situation was even more complex with the addition to TBS of the Personnel Policy Branch, seeking to introduce the Glassco policy management model while establishing a new staff relations regime.

${ }^{58}$ MIB also had a machinery of government unit, which was the residue of the BGO, with a role of promoting and evaluating Glassco report implementation (White and Strick 1970: 105, 107-108). While Treasury Board continued to approve departmental organization charts and regulate the related senior management complements, these were treated as personnel policy functions and the more policy-oriented role envisaged by Glassco of keeping the machinery of government up to date shifted to PCO.
} 
common service organizations - which were designed to replace the old interventionist Comptroller of the Treasury model.

APB remained in place until 1994, although its mandate changed in some areas, notably financial management. Reflecting ministerial concerns about containing costs in the increasingly stringent fiscal circumstances of the early 1970 s, and infused with values of prudence and probity, APB's policies during most of its existence generally sought to ensure "adequate equity, control and restraint" (Paton and Dodge 1995: 8). This orientation particularly shaped APB's approach to information technology, where Glassco had noted that electronic data processing and telecommunications were largely left to departments, resulting in a "hit and miss approach" (Canada Glassco 1962 1:208), but deserved more central attention as they were likely to become increasingly important in administrative practice. The commission found there was no policy guidance from Treasury Board on management of the newly purchased computers or on encouraging collaboration among departments. The development of new technology-related skills was also neglected. In the area of data transmission, the commission expressed concern about the lack of compatible equipment and common coding, limiting the government's ability to realize "the benefits from integrating the flow of information ... by automatic handling throughout, which will facilitate the exchange of common information through different systems" (Glassco 1962 1: 210). They concluded that, "(t)he duplication and mistakes of the past, when automatic data processing was in its infancy, will be multiplied many times in the future unless concerted action is taken promptly to ensure skillful application of this new technology" (210-211). 
An early APB policy directive on the management of IT included moves towards common IT standards, but through most of the 1970s and 1980s APB's role primarily involved reviewing major IT project proposals and preparing an annual summary of departmental IT spending plans, which were growing substantially as departments acquired new mainframes and expanded their inventories of automatic data processing equipment and other forms of office automation. At the same time, in line with Glassco's recommendations, common service organizations were developed for both computing and telecommunications. A Central Data Processing Bureau was set up in MIB, and when the Department of Supply and Services (DSS) was established in 1969 it became the Computer Services Bureau, operating on a cost-recovery basis (Canada Information Canada 1970: 3-P-5) to provide access to computers for departments that did not have the requirement to obtain their own mainframes. The telecommunications common service was originally located in the Department of Transport and then became the Government Telecommunications Agency in the Department of Communications, part of a larger unit that advised on telecommunications policy and international telecommunications issues (3-CO-2). Both units operated in the context of Treasury Board management policies, although computing became the more significant as departments invested heavily in support of their programs. Computing also began to be used to support internal administration, notably in financial and personnel management, and software applications began to be developed for a variety of program and administrative purposes. Having lost the MIB focus on innovation, however, APB maintained only a limited capacity to look at broader issues of technology management or the implications of technological change. 
One by-product of these developments was that government purchasing became a significant element in the expansion of the Canadian computing industry, one of the relatively few areas where government demand for goods and services was linked to industrial policy. This created a longer term dilemma, however. An early policy to support the computer industry generally, and to avoid becoming overly dependent on a single supplier (notably IBM), led to a proliferation of mainframe environments (Glassco 19621 : 587-588). In later years, this proved an obstacle to efforts to standardize software applications, compounded by the fact that departments with a significant mainframe presence have tended to "in-source" their staff while smaller and newer departments have tended to "outsource," making it more difficult to establish a comprehensive longer-term approach to human resources in the IT field. Although APB was also responsible for Treasury Board policy with respect to contracting - a significant component of technology management - the approach to contracting policy was also oriented towards procedural correctness and cost containment, and administration of the IT management and the contracting policies was not linked to any degree.

A slightly different story occurred in the area of government record keeping, where Glassco's Report 4 had noted its importance in the relationship between government and citizens but criticized both the processing and the costs and efficiency of all aspects of records management (Canada Glassco 1962 1). APB began to address some of these concerns with a first Information Management Directive in the early 1970s, which parallelled efforts to strengthen the ability of the Public Archives to deal with the disposal and retention of out-of-date government records. The relationship between TBS and 
Archives is discussed in greater detail in chapters 4 and 5 and the issues relating to information and records management are the focus of chapter 5.

A major change occurred in 1983 with the passage of the Access to Information and Privacy Acts (ATIP), giving citizens a right to ask for internal government records and have them produced within 30 days. This led to an integrated set of Treasury Board policies for the management of government information holdings, encompassing records and published material, based on a comprehensive life-cycle model, both to meet public rights of access under ATIP and to improve the quality of government decision-making. The ATIP legislation assigned Treasury Board and TBS the lead role in administering the access to information and privacy regimes, following the now-standard Treasury Board policy model, but in the nature of the public (as opposed to administrative) policy underpinnings of the legislation, the two Acts also created separate Information and Privacy Commissioners to support Parliamentary oversight of their implementation. ${ }^{59} \mathrm{In}$ 1988 , an additional set of policy tools was created with the introduction of the Government Communications Policy, covering all aspects of public communications, including publishing, federal identity, advertising, public opinion research and sponsorship - again addressing issues raised by Glassco (Canada Glassco 19633 Report 13). The other side of the coin to information dissemination is information protection, and the need to reconcile ATIP with the system of security classification also led to the drafting of a Government Security Policy in 1991, covering all aspects of security in government but treating it fundamentally as an information policy. The combined

\footnotetext{
${ }^{59}$ ATIP's public policy objectives and its impact on information management are discussed in chapter 5 . Chapter 4 describes the administration of the Treasury Board ATIP policies.
} 
policies were developed and administered as a "suite" by an information, communications and security policy division until APB was disbanded in $1994 .{ }^{60}$

These developments in the late 1980s coincided with the growing impact of New Public Management (NPM) thinking on TBS's understanding of its role, leading to a shift in focus from control to enabling management in departments, a process accelerated by the Public Service 2000 (PS 2000) exercise from 1989-91 (Clark 1994). PS 2000 was widely seen as an effort to reform Treasury Board policies, without, however, seriously challenging underlying assumptions about the need for or general approach to collective management of the public service. It also represented another effort, supported by Prime Minister Brian Mulroney, to continue the process of introducing private sector practices into public administration. ${ }^{61}$ Driven by ten internal task forces in response to a government White Paper (Canada PCO 1990), PS 2000 was primarily concerned with personnel policies and led to adjustments in staffing policies and moves to reform the job classification system, a direct descendent of the one established by Griffenhagen. The process also led to a more values-based approach to information and other administrative policies (Paton and Dodge 1995) and a growing appreciation of information and technology as strategic tools.

A PS 2000 task force on service to the public (Rawson 1991) argued for a more client-centred approach and became a reference point in later initiatives to take services on line. The issue of improving service to the public had a pedigree (Marson and

\footnotetext{
${ }^{60}$ Chapter 3 discusses the institutional evolution of these policy responsibilities following the creation of the CIO in 1993, while chapter 4 describes the universe of institutional relationships and policy concerns created by the policy suite and related policies. Chapter 5 discusses the resulting dilemmas, in particular in the area of information management.

${ }^{61}$ On coming into office in 1984, Mulroney launched a Ministerial Task Force on Program Review, headed by Deputy Prime Minister, Erik Nielsen. 19 study teams of public servants and consultants and a private sector advisory committee evaluated several hundred government programs, reporting in 1986. Some savings were identified, but the exercise is generally regarded as having had limited impact (Schmitz 1994).
} 
Heintzman 2009) that extended back to Glassco's third volume and well before. A landmark was guarantees in the Official Languages Act 1969 that services would be provided to the public in both official languages in accordance with demand - an early bow to citizen-centred service. The Access to Information Act 1983 was in the same spirit of empowering citizens in their relations with government. By the early 1990s, the convergence of computing and telecommunications was generating interest in the potential of electronic communications, both for internal government work and especially for service to the public. This led APB in 1992 to issue "Vision 2001," outlining the potential for innovative use of information and technology (Canada TBS 1992).

During this period, the comptrollership function had its own, largely separate experience. The Glassco report led to winding up the earlier system of pre-audit financial controls through the Comptroller of the Treasury and their replacement with a regime based on financial management policies administered by TBS - initially MIB and then APB. By the mid-1970s the Auditor General was characterizing the government's finances as being out of control, ${ }^{62}$ which led to the creation of a separate Financial Policy Branch within TBS and then, in 1978, of an Office of the Comptroller General as a separate central agency under Treasury Board. This was the first significant variant on the Glassco model of a unified collective approach to management practices.

In a related move, Trudeau also appointed a Royal Commission on Financial Management and Accountability, chaired by Alan Lambert, a bank executive. In its report (Canada Lambert 1979), the commission called for a strengthened OCG and

\footnotetext{
${ }^{62}$ See Sutherland's commentary on the soundness of this criticism (Sutherland 1980). Saint-Martin (2000) argues that in the era after Glassco the management consulting industry had not been able to establish itself as advisors to government - perhaps because it had previously done too good a job, or because government had established too strong a capacity of its own - and instead allied itself with the Auditor General's office, contributing to some of the friction that continues to exist.
} 
tighter controls of departmental financial management practices, without going back to the pre-Glassco environment. The Lambert commission saw itself as correcting some of the mistakes in implementing Glassco and perhaps also in the original diagnosis. Its philosophy has been described as "making the managers manage," enforcing accountability of Deputy Ministers in particular - a theme to which Gomery returned. It also proposed establishing an OCG-like central agency for personnel management.

The Lambert commission has proved to be the last of the lengthy series led by a senior private sector executive; one of the Commissioners was J.E. Hodgetts, who was the editorial director for the Glassco commission and had had a major role in writing its reports. The Lambert report in the end had a more limited impact than Glassco (Charih $1989 \& 1991$ ), partly because it also had a more limited mandate and the report was less ambitious in scope, fine-tuning rather than fundamentally questioning the Glassco model. Another factor was that it coincided with the uncertainty surrounding the interlude of the 1979-80 Clark government, which took the issue of financial control in another direction by introducing (on PCO Machinery of Government advice) the Policy and Expenditure Management System, which sought to link financial oversight more directly to collective ministerial policy making. These changes, which were confirmed by Trudeau on his return in 1980 - rather than acting on Lambert - gave a stronger role to PCO and sectoral ministries of state, at the expense of Treasury Board and TBS (Campbell and Szablowski 1979). Finally, it can be speculated that the senior public service was generally comfortable with the post-Glassco status quo and not very interested in pursuing Lambert's refinements. The conditions that led to the wholesale implementation of Glassco did not exist for Lambert. 
It can be speculated that OCG's genesis made it more immune for longer to the winds of NPM, but in any case it was not actively involved in the soul-searching about role and mandate that TBS went through in the late 1980s and early 1990s. During this period, OCG did launch an initiative to automate financial information, but this was largely in isolation from thinking in APB, which with policy centres addressing the management both of IT and of information was structured to tackle the issue of reconciling these two areas. OCG had also become isolated from other central agencies when the government's fiscal situation began to deteriorate again in the early 1990s. Combined with being culturally out of tune with other units supporting Treasury Board ministers - in many ways closer to the Auditor General than to the government - this contributed to the decision in the 1993 reorganization to fold OCG back into TBS.

\section{Public policy-oriented organizational responses to ICTs}

At the same time that the federal government's ICT-related central management machinery was evolving, there was a separate evolution of departmental arrangements for programs and services to the public dealing with the same technologies. A major influence was the creation of a Department of Communications, providing a public policy response to both ICTs themselves and the content they generated. A new generation in telecommunications and broadcasting policy came in the wake of Trudeau taking office in 1968. An early step, within weeks of his arrival, was the consolidation of a number of telecommunications functions in a Telecommunications Establishment in the Post Office. This brought together the Department of Transport's telecommunications functions under the Radio and Telegraphs Acts (which included the Communications Research Centre), the non-military portion of defence telecommunications research, and the Domestic 
Satellite Communication System project office from the Privy Council Office Science secretariat (Osbaldeston 1992: 412). In 1969, as part of a larger government reorganization, the consolidated telecommunications functions were incorporated into a new Department of Communications, which encompassed communications research and policy functions as well as operational roles that included the Government Telecommunications Agency and portfolio oversight of two government-owned service providers, the Canadian Overseas Telecommunications Corporation (COTC) and Telsat Canada. The latter was also set up in 1969 , as a joint venture with the private sector telecommunications carriers. A motive for these changes was to bring institutions into line with economic reality and government priorities, but it also reflected a move towards more activist government, in which the full range of state instruments were deployed in support of politically driven public policy (Doerr 1981: 4).

The period that followed saw the gradual convergence of the broadcasting and telecommunications sectors, both technologically and from an institutional perspective. In 1967, the Board of Transport Commissioners was amalgamated into a new Canadian Transportation Commission (CTC), which retained responsibility for regulating telecommunications. In April 1968, the Canadian Radio-Television Commission (CRTC) replaced the Board of Broadcast Governors as the regulatory body for broadcasting, and in 1976 the CRTC became the Canadian Radio-Television and Telecommunications Commission, with the transfer of telecommunications regulation from the CTC. By 1966, responsibility for broadcasting policy had moved from the Department of Transport to the Department of the Secretary of State and became part of Arts and Culture policy, along with policy for film, libraries and museums (Canada, 
Information Canada 1970: 3-S-2). This shifted the institutional location of broadcasting policy from one concerned with infrastructural and technical issues to one concerned with content and national unity. The transformation was completed in 1980 when the Arts and Culture branch was transferred to the Department of Communications, echoing the CRTC's combined telecommunications and broadcasting roles and marking an effort to bring together consideration of technology and cultural policies with respect to telecommunications and broadcasting. One consequence was that government policy for these sectors of the economy was developed and carried out outside the institutional context for policy in other industrial sectors, which went through a considerable evolution in the 1980s and 1990s (Doern and Tomlin 1996). This later strengthened the ability of Industry Canada to foster and support the initiatives discussed in chapter 3, including spawning Government On-Line, one of the CIO's signature initiatives.

In the 1980s, the Department of Communications played an important role in laying the ground for what eventually came to be known as the information highway. This included sponsoring research on interactive technologies (Telidon) and on technology applications in the workplace. Towards the end of its existence, it was influential in developing the Canadian Network for the Advancement of Research, Industry and Education (CANARIE), a public-private sector partnership that has been central to the development of the national high-speed electronic networks that underpin the Internet in Canada. There was also a major overhaul in the early 1990s of the legislative framework for broadcasting and telecommunications. During this same period, the National Research Council (in particular what became its Canada Institute for Scientific and Technical Information - CISTI) took on the role of national science library 
and became a major force in the development of electronic information standards, working closely with the Department of Communications and the National Library.

Two other Department of Communications relationships were more difficult, however. One was with the Ministry of State for Science and Technology (MOSST), which was set up in 1971 to lead the development and application of government science and technology policy, including in relationships with industry and university researchers (Osbaldeston 1992: 297). Tensions with Communications and other sectoral departments led in 1990 to MOSST being combined with the Department of Industry to form a Department of Industry, Science and Technology (DIST). The other difficult relationship was with the various incarnations of the Department of Industry, especially as the latter moved increasingly in the direction of market-driven approaches to industrial support, while Communications had a more protectionist orientation by virtue of its cultural promotion mandate (and, under the Mulroney government, a greater sensitivity to the provinces, which were also more protectionist - Schultz and Brawley 1996: 98).

Threaded through, and in many ways driving, these organizational changes were profound changes in the related information and communications technologies, eventually affecting and linking together every aspect of economic and social activity, the lives of individual Canadians and the internal dynamics of government. ${ }^{63}$ Much of the foundation was laid in the 1960s with the development of electronic networks of university researchers, using telephone lines to link mainframe computers. These networks were fairly quickly further linked to form a network of networks, which in time came to be known as the Internet. In the course of the 1970s, a number of capabilities

${ }^{63}$ The information in this and the following two paragraphs is summarized from Rowland 2006, in particular chapters $25-29$. 
were developed for use on the networks, including the ability to exchange data electronically among computers, to send text messages both to individuals (e-mail) and to large groups (listervs), and to post messages for others to view (bulletin boards).

Financial institutions built on these features to develop self-service cash dispensing machines as well as electronic funds transfers among banks and between them and their clients - this became a central feature of on-line service provision by both the private and the public sectors.

The 1970s and 1980s also saw the development and gradual expansion of word processors, at first essentially electronic typewriters but gradually evolving into personal computers (PCs), with increasingly powerful memory and capabilities. Linked to a "client-server" distributed computing model, connecting PCs to each other and to mainframes using electronic networks, this led to the progressive expansion of computing and electronic technologies both in office environments and in society at large, notably private homes.

This process accelerated with the development in the early 1990s of "graphic user interface" technologies, permitting individuals with little or no computer training to use them, and then the development of "user-friendly" technologies to facilitate navigation on the Internet and the retrieval of information. The introduction of the World Wide Web, based on non-proprietary computing protocols and the first Web browser programs, in 1993, was followed quickly by the introduction of on-line directories and search engines. This is considered by many observers to represent a tipping point when these technologies - commonly linked under the umbrella heading of the "digital era" or simply the Internet - entered the mainstream of both private life and institutional 
environments, to the point that they and their technological successors (freed by wireless technologies from a dependence on land-line telephone infrastructure) are now considered to be part of mainstream private and public life in developed countries and increasingly in the developing world as well. This has created a powerful "pull" on governments to meet the public in the "virtual" as well as more traditional spheres - the single greatest influence on the environment in which the CIO has operated.

\section{Conclusions: management of information and technology in the early 1990s}

The June 1993 reorganization of the federal government had a deep historical foundation. While this was not the only factor that shaped it, the reorganization occurred within the context of an historical institutional legacy that significantly conditioned the choices that were made at the time and had important implications for their chances of success. This was particularly true of the Treasury Board Secretariat CIO, whose appointment was in fact tangential to the actual reorganization. At the same time the CIO grew out of the same institutional matrix as the rest of the reorganization and was in response to the same external forces, notably a change in Prime Minister and the cumulative pressures of new ICTs that were beginning - and expected - to have transformative effects on society at large and on public administration.

The CIO was established in the context of an entrenched tradition of collective internal management, rooted in the strong Governor-weak assembly model that underlay all the British North American colonies. According to Bourgault and Dion (1990), the Canadian version of the Westminster parliamentary system, with its centralized political control, is well suited to the bureaucratic system. Pre-Confederation circumstances had 
established a tradition of substantial ministerial involvement in administration, growing initially out of the non-political origins of ministerial offices but reinforced by the emergence of Treasury Board as a hands-on collective institution, by the lack of legal (as opposed to conventional) distinction between the roles of Ministers and their Deputy Ministers, and by the pressure on Ministers to be involved in the chain of accountability to Parliament for the actions of their officials. In principle, Treasury Board represents an effort to distinguish between circumstances where the government is to be administered as a single entity and those where it is treated as a series of operational programs. The distinction has proved difficult to apply in practice, however, with the default position favouring the collective over the individual and more rather than less ministerial involvement in administration.

These are distinguishing characteristics of the Canadian variant of the Westminster model, ones that grow out of a largely continuous evolution over more than a century and a half. This experience has also resulted from regular applications of organizational solutions to administrative problems, often based on external advice, from both the public and the private sector and from Canadian, British and US sources. There has been a broad arc of responding to external events, in particular the restructuring of program-oriented departments and services to meet changing national needs and circumstances, but also to evolving ICTs. Changing political personalities have also been a factor - not least the attitudes of Prime Ministers and their advisors - although there has been a remarkable continuity across political parties of efforts at administrative improvement.

The single most important element of the historical legacy that shaped the CIO was the Glassco report and the elegant Treasury Board model that it proposed. The report 
took an unprecedented comprehensive approach to collective and individual management that has not been attempted since. Building on the foundation laid at the end of World War I, it provided solutions to many earlier problems and a considerable array of instrumental resources for dealing with future ones. It embedded external influences from both the private sector (especially from the US) and the public sector (especially from the UK) as well as several injections of the ideas and tools of scientific management. In 1993 the model remained remarkably resilient, but its sophistication also required an awareness of its features - and weaknesses - in order to make it work well. By then the federal public service had had considerable experience with the model and not surprisingly a certain amount of weariness had set in. In some respects, the Glassco model represented an ideal that was never fully achieved, but it remained powerful and needed to be conjured with nonetheless.

A less immediate element of the historical legacy, but one that was growing in importance, was the impact of technology on public administration. Its early effects were largely on office procedures and did not impinge overtly on central management until shortly before Glassco when Treasury Board established a committee to advise it on major computer purchases. After Glassco there was a growing technologically-related institutional presence in TBS and common service organizations, but this was largely minor-key in relation to the larger preoccupations of those organizations. One of the pre1993 catalysts was the importance given to the previously neglected area of records management by the passage of the Access to Information Act, driven by a vision of more open and responsive government. This gave a new conceptual coherence to a number of related areas of administration, notably public communications and government security, 
but in the period before the 1993 reorganization this coherence in matters of content was not reconciled with the dramatic changes in the media in which it was housed and carried that were coming to a head at much the same time.

In 1993, these developments played out against a larger backdrop that included continuing pressure for administrative reform, encapsulated in a global phenomenon, the New Public Management set of ideas (increasingly harnessed with the new ICTs represented by the Internet), a growing recession leading to an increasingly untenable fiscal situation in the federal government, and a government in political decline, with the pending retirement of a long-serving Prime Minister. The stage was set for the seemingly immovable object of the federal government's entrenched institutional assumptions to meet the irresistible external forces then at work. That is the subject of chapter 3 . 


\section{Chapter 3 - Establishment and Evolution of the CIO}

The problem of central control was related to the inability of the technician and the political layman to communicate properly with each other.

(Hodgetts 1955: 279)

The arrival of the Internet and the digital era required governments to raise their game technologically.

(Dunleavy et al. 2006: 42)

The Canadian federal government was an early responder to the technology environment represented by the Internet. It was one of the first - possibly even the very first - public jurisdictions anywhere to appoint a senior official as a CIO or to establish a government home page on the World Wide Web. ${ }^{64}$ While most other governments in Canada and the OECD had followed suit within the following decade, from a public administration point of view these developments largely came in a conceptual vacuum, using current ideas and experience in the context of existing institutional dynamics to respond to a largely unknown and open-ended social and economic phenomenon.

Hodgetts' observation in 1955 related to the situation in the Department of Public Works a century earlier, reflecting on whether the engineers should - in a later turn of phrase be on tap or on top. The institutional response to the technological changes of the past generation has simply been the latest illustration of the dilemma of reconciling technical truth and political power.

Since June 1993 there have been seven federal government CIOs and four acting CIOs for extended periods (see Annex 1 for a complete list). Hodgetts' conundrum is illustrated by the fact that three CIOs have been career public servants, three have been technologists recruited directly from the private sector (including the current incumbent), and the seventh was based in the private sector but came to the position from a public

\footnotetext{
${ }^{64}$ Dunleavy et al. (2006: 48) state that the Canadian CIO was established "much earlier" than any of the other case countries in their comparative study of seven major OECD countries, including Canada.
} 
service interchange assignment. ${ }^{65}$ There have been few constants in the CIO institutional story. The Chief Information Officer title and the nature of the supporting Treasury Board Secretariat (TBS) unit were not fixed until four years after the first CIO was appointed, and it took another five years for basic issues about role and mandate to be worked out. Significant changes in the CIO's scope of responsibilities were made as recently as 2010. Lying behind this trajectory has been considerable movement in the political environment and the key institutional actors who have influenced the evolution of the CIO and its prospects for success: four Prime Ministers of both major political stripes, eight Treasury Board Presidents, six Clerks of the Privy Council/Secretaries to Cabinet, ${ }^{66}$ seven Treasury Board Secretaries, and six chairs of TIMS, ${ }^{67}$ the committee of program Deputy Ministers that had a major influence on the CIO's first dozen years.

The resulting situation has been characterized by considerable fluctuation in how the office supporting the CIO has been organized, how the position has been understood and positioned in the public service, and in what it has been asked to do. There has been important forward progress in a number of the CIO's areas of responsibility, but many of the items on the CIO's original agenda remain. This partly represents re-visiting issues that were put to one side because they were earlier judged to be low priority or too difficult to resolve; it also reflects relentless forward movement both in technology and in the government's circumstances and priorities.

\footnotetext{
${ }^{65}$ The four long-term acting CIOs were all career federal public servants and deputies to the CIO.

${ }^{66}$ The dissertation follows common Canadian usage of using the Clerk title, although both apply. The Public Service Employment Act (PSEA) designates the Clerk/Secretary as head of the public service and requires the Head to submit an annual report to the Prime Minister on the state of the public service. ${ }^{67}$ TIMS - Treasury Board Secretariat Advisory Committee (TBSAC) Information Management Subcommittee. During their approximately 20 -year existence, beginning in the mid-1980s, TBSAC and its TIMS sub-committee were made up of departmental deputy ministers assigned to them by the Clerk. TBSAC was chaired by the Treasury Board Secretary and TIMS by a line deputy minister who was also a member of TBSAC. TIMS is discussed at several points in this chapter.
} 
This chapter is concerned with the establishment and evolution of the CIO position and the key issues related to its mandate and location in public service governance. The discussion is primarily exploratory and descriptive, but it also seeks to explain. It is divided into four sections. The first summarizes some of the theoretical issues that lie behind an analysis of the CIO as a case study, in particular how the Canadian CIO has been viewed by authors in the emerging field of e-government. This provides a reference point for telling the CIO institutional story. The core of the chapter is the second section, which gives an account of the establishment and institutional evolution of the CIO from 1993 to the present, organized by Prime Ministerial mandate. This is followed by a section on organizational "roads not taken." The fourth section considers strengths and limitations of the CIO model. The chapter's concluding section offers initial comments on the issues raised in the theoretical discussion.

In addition to secondary literature, in particular in the theoretical discussion, the chapter draws on a range of government documents and reports, many issued by or about the CIO and related initiatives. It also makes extensive use of the interviews that were the core of the primary research for the dissertation. 53 interviews were substantially or entirely about the events discussed in chapter 3 . Categorizing by the role for which individuals were primarily interviewed, there were 11 with the universe of CIOs and Acting CIOs, 9 other current and former staff of the CIO Branch, 10 senior officials from other areas of TBS (including the seven Secretaries from 1993 onward - the current Secretary is a former CIO), 4 individuals who played prominent roles in GOL or the Information Highway Advisory Council, 2 former Clerks and 3 others who had held senior positions in PCO, 5 from common service organizations, 3 former departmental 
Deputy Ministers, 3 former departmental CIOs and 2 from the private sector. Many played more than one role over the period in question, for example 4 chaired TIMS and 2 others were members of that committee, at least seven had previously been CIOs or corporate services ADMs in departments, and 12 were or had been departmental Deputy Ministers. There were at least three sightings of each of the CIOs, apart from the incumbents, with the most extensive coverage of the early years and the GOL period. At least 22 were in government or working with it as consultants for the entire period since 1993, although in most cases in more than one role; 20 (including some of the previous group) had worked in the private sector either before or after their time in the roles for which they were interviewed.

\section{An emerging sector in theory}

This dissertation is a case study that seeks to describe, analyze and explain the introduction and evolution of the TBS CIO in the context of the corporate governance of the government of Canada. As discussed in chapter 1, the paper draws on both mid-range and substantive theories (Blaikie 2000), in particular the latter.

In the former category are public policy and neo-institutional theories of stability and change. The dissertation uses Peter John's evolutionary theory of policy continuity and change (John 1998), which synthesizes and builds on theories developed by Baumgartner and Jones, Kingdon and Sabatier. It seeks to explain the manner and the terms under which a combination of ideas and interests (both of which are embedded in institutional arrangements) become central to the public policy agenda and are acted upon: thus, the 1993 reorganization provided a window of opportunity for policy 
entrepreneurs within the federal government to establish a CIO. Many of the elements were pre-existing but changes in both internal and external circumstances, catalyzed by new ideas, brought about significant and lasting change.

With its focus on institutional continuity and change - treating institutions as longterm policy instruments - the dissertation also makes use of neo-institutional theory, with a particular interest in historical explanations. In this body of theory, a key dynamic is the relationship among pre-existing institutions, new and recycled ideas, current actors, and chance (Lecours 2005). Change is generally incremental, shaped by path dependency, a function of roads taken but also those not taken; the model adopted for the CIO and its evolution were strongly influenced by the historically derived institutional environment within which it was introduced, while its successes and failures over time were shaped as much by what was not as by what was included in the original configuration. Change can be more significant at critical junctures, arising from external forces, that represent a genuine change in direction from previous patterns. Such generative cleavages (Hogan 2006) are characteristically significant, swift and encompassing. And indeed, there is a clear break between the CIO model as established in 1993 - literally overnight as part of a change of government against the backdrop of a technological revolution - with what preceded it. By the same token, these changes were reinforced by later developments and have remained the CIO's organizational core.

The primary area of substantive theory addressed in the dissertation relates to the Westminster model as it applies to executive institutions. The evolution of the Canadian variant, which gives more explicit weight to collective institutions and collective accountability than does the British original, was discussed in chapter 2, and resulting 
accountability challenges are an important part of the discussion in chapter 4. This chapter describes how the CIO emerged within that model, in particular its collective management institutions (TBS and common service organizations), with the CIO's characteristics strongly shaped by the model and contributing some new dimensions to it. The CIO is a creature of its institutional context. This undoubtedly helped it successfully take root but has also been the source of significant constraints and issues. The common frame of reference provided by the Canadian Westminster model also provides the basis for comparing the experience of the federal CIO and its Ontario counterpart (chapter 6).

E-government, which as a body of thinking developed in parallel with the CIO, probably best fits Blaikie's category of a middle range proposition discussed in chapter 1: less well developed and rigorous than middle range theory, but not tied to a particular institutional model. There is a growing e-government literature, although much of the early work was an attempt to map out a territory, rather than providing a framework for identifying causal dynamics. Many authors flag the importance of governance of the egovernment environment, but relatively few delve into what that means in practice, perhaps assuming that it depends on the underlying institutional context. Governance is a major focus of this dissertation, however. The discussion that follows draws on two Canadian and international studies that have looked specifically at the organizational implications of the move towards e-government and of the role of a public sector CIO within that. It also summarizes a British study that offers useful insights into the first decade of Canadian e-government experience in a comparative context. All three drew on the federal CIO in their research and they provide both an evocative quick sketch of the 
$\mathrm{CIO}$ and an analytical reference point for the narrative discussion of the establishment and evolution of the CIO.

E-government perspectives on the CIO

Based on interviews with a number of departmental CIOs and the first TBS CIO, Borins and Wolf (2000) provide an early attempt to address the organizational dimensions of e-government, treating it as an important factor in realizing the potential of public sector IT. They identify success factors - overcoming obstacles - for organizing the IT function both in government departments and at the government-wide level. In a department, the goal of the IT function is to support operations effectively (189), and Borins and Wolf identify seven success factors (190-202): centralization of IT within a department; well-managed relations with program areas; a highly situated IT head (ordinarily, a departmental CIO reporting to the CEO/Deputy Minister); formalized engagement of managers throughout the organization (for example, through a senior management committee); recognition that IT and IM must be considered jointly; and an ability to acquire and retain needed expertise.

Borins and Wolf's test for organizing the government IT function is its ability to realize the potential for interdepartmental partnership (207), characterized by integrated information collection, storage and access and by IT-enabled cooperation in program and service delivery. The CIO has a leading role in overcoming obstacles to cooperation, which include (209-224) technological, cultural and other forms of organizational incompatibility among departments, lack of incentives for horizontal partnerships, risk aversion in government, privacy and security concerns, lack of awareness by (nontechnological) senior management of what IT can do, and lack of buy-in to an IT-enabled 
innovation agenda from users and managers. Borins and Wolf define a spectrum of organizational models between a "strong" CIO (226 - DM rank, has resources and a strong mandate, forcefully impresses IT change on departments) and a "weak," collaborative CIO (more consensus-based approach, a task force or senior committee to oversee implementation).

Borins and Wolf analyze the federal CIO's first five or six years' experience, essentially the first three CIOs, before they were fully engaged with Year 2000 preparations and the launch of Government On-Line (GOL). As discussed later, this was also the period of greatest turbulence in the CIO's mandate and organizational arrangements. They conclude (228-233) that the CIO had helped increase awareness of the possible uses of IT in government but the potential for horizontal partnership was far from being realized. The CIO had had mixed success in the five areas in which it had taken major initiatives: government-wide infrastructure and interconnectivity; shared applications, especially in administrative systems; improved IT project management; overcoming organizational incompatibility; and engaging senior departmental managers. Overall, they assess the federal CIO as being at the collaborative and consensus-building - the "weak" - end of the spectrum, noting in particular the problem of being a small central agency dictating to large mature departmental IT functions. In order to move to a stronger $\mathrm{CIO}$ model - to effect a stronger shift within government from a vertical to a horizontal focus for the management of IT and information - the federal CIO needed to have more "carrots" at its disposal, in particular greater control over the IT capital budget, akin to the stronger budgetary role assigned to the Ontario Corporate CIO (235). 
Writing four years later, Culbertson (2004) draws on his own experience as a provincial CIO and as a participant in an OECD e-government working group (OECD 2003), which looked at practices across the OECD. He also uses the 2002 Accenture study of public sector electronic service delivery (Accenture 2002), which covers most OECD countries plus Singapore and in which Canada for the second year in a row was ranked first internationally. This was during the tenure of the fifth federal $\mathrm{CIO}$ and at the height of GOL. Echoing Borins and Wolf, Culbertson postulates that government-level organizational arrangements should address both the push (the transformational potential) and the pull (overcoming barriers to change) of e-government (60). Among measures in support of the former are integrated information, shared business processes and clients, simplification of processes built on citizen self-service, quicker response time, and advancement of broader good government goals such as accountability and citizen participation in policy making (61). Barriers to overcome include the vertical structure of government, lack of the necessary budgetary commitment, technological illiteracy on the part of senior management, risk aversion, and worries about generating new demand (and related costs) for government services.

Culbertson identifies critical success factors at two levels. There needs to be sustained political sponsorship for e-government, including aligning e-government and public administration reform initiatives, led by strong Cabinet-level responsibilities and supporting organization - the Canadian Treasury Board is given as an example (63). This should be supported by senior management-level changes in three areas $(64-66)$ : a senior management-level interdepartmental coordinating organization, linked to the ministerial level and aligned with central management oversight mechanisms; a 
government-wide CIO located in a senior central agency and with a government-wide view of the budget; and an integrated government Internet portal supporting singlewindow service delivery. Depending on a variety of factors, a government CIO will fall somewhere on a continuum of roles ranging from cheerleader through collaborator and controller to commander (65). (Culbertson does not specifically assess the Canadian CIO, but his commentary suggests that it is at the cheerleader/collaborator end of the spectrum.) In addition to factors cited by Borins and Wolf, the variables affecting the CIO's role include its ability to forge links between the management of e-government and the government's economic development objectives.

Dunleavy et al. (2006) position the CIO in the broader governance environment. They present a comparative study of seven major OECD countries: Australia, Canada, Japan, Netherlands, New Zealand, United Kingdom and the United States. Writing more than a decade into the global spread of the Internet and related technologies, they look at the growth of e-government in the countries concerned, with a particular focus on development of central government contracting for IT systems and the resulting relationships with the private sector (3). Dunleavy et al. argue that more recent theories of bureaucracy have overlooked the importance assigned by Weber to information management $(6,40)$ and marginalized the IT function in government $(28-40)$. They also consider that New Public Management (NPM) is "intellectually dead" (7) and propose that the central role of IT, with all its associated dimensions, has in fact created a postNPM "new constellation of ideas and modernization changes as a coherent picture of what could be the future of public management" - offering the prospect of a "reform transition" to "digital era governance" (217). 
A central component of their study is a comparison of the performance of government IT in the seven countries, explaining the results by looking at two sets of factors, the impact of governance institutions and bureaucratic cultures (ch. 4) and competitive tension in the national IT marketplace and the power of the IT industry (ch. 5). While echoing Borins and Wolf and Culbertson, this model offers a more holistic view of the context in which government IT operates as well as a more recent snapshot of the Canadian experience, one that is consistent with the research findings in this dissertation. Their research came towards the end of GOL and includes the fifth successive annual Accenture report on the introduction of electronic services that ranked Canada first internationally (Accenture 2005). That was also the last report to do so.

Dunleavy et al. compare the performance of government IT in the seven countries against three tests: the IT scrap rate (the success of government IT schemes); the government's weight in the IT market (are its IT purchases at competitive prices?); and the modernity of IT in government service provision, compared with the private sector. These measures are combined for a cumulative assessment of the effectiveness of government IT performance. Canada does well on all four measures, coming second to the Netherlands in each area, in some tied with and in others ahead of the US, which is ranked third overall. With respect to the scrap rate (70), the study concludes that most IT projects in Canada have worked most of the time, at least in part because Canadian government departments have kept substantial in-house IT competence but also due to relatively close supervision by TBS. IT failures have been turned into major reputational blows for the firms involved. The Canadian government has been at some, but not major, cost disadvantage in obtaining IT (74), because it has largely had to work with firms that 
are geared to the generally competitive US market but requiring additional costs for adapting to Canadian government requirements. Canada has had a good record in keeping many of its systems up-to-date (77-78), helped by high levels of investment, strong public usage of e-government facilities, and joined-up policies in the context of good buy-in by a public service that is more integrated than many of its counterparts. However, Canada suffers from substantial problems relating to the large legacy systems introduced in the 1950s and 1960s. In looking at Canada's overall performance, the most notable feature is its consistency across all the variables.

In explaining these results, Dunleavy et al. consider two sets of variables. The first is the impact of governance institutions and bureaucratic culture. It has four components: the presence of checks and balances on the executive; the strength of cultural and institutional systems for handling technology decisions and projects; the degree of openness to New Public Management (NPM); and the presence of a strong and centralized e-government initiative. Overall Canada is ranked third (the Netherlands is first), although effectively tied with the US which is ranked second. In this model, Canada's weakest area is in the extent of external controls on executive action (88); the Westminster model generally is seen as entailing a stronger executive and weaker scrutiny by the legislature, and the Canadian version is further weakened by federalism, a complex party system, more powerful caucus, political turnover and a public service that has characteristics of both British generalists and US specialists. The Canadian public service is seen as having a bureaucratic culture that generally supports the introduction of technology (90-92), at least in part due to the infrastructure demands of operating across a large country and reflected in the early introduction of a CIO. While Canada did 
introduce elements of NPM (96-103), it resisted others and was seen as having taken a more humanistic and less technocratic approach than New Zealand or the UK in particular. Canada did have one of the earliest and strongest e-government initiatives, with sustained government commitment (but relatively modest total resources) and more collaboration within government and with other levels of government.

The second major explanatory dimension concerns the relative power of the IT industry in its dealings with government. A judgment builds on three components: the extent to which there is open competition for government IT contracts; the market and technology dominance of large IT firms; and the extent of in-house IT development and management capacity in government. Canada ranks fifth out of seven in Dunleavy et al.'s cumulative assessment of these factors (128-132), with the Canadian IT industry relatively less powerful than most of the countries looked at, although in a stronger position vis-à-vis government than in the US or the Netherlands. Canada has forces that pull it in the direction of both deviating from and promoting competition (120-121), much of this complexity arising from dealing with many of the same firms that the more open US government deals with, complicated by the filter of NAFTA. Canada is in the middle with respect to the dominance of large firms (122-123), with the top five firms holding between $1 / 3$ and $2 / 5$ of the market, a relatively high concentration. On the other hand it has a relatively high potential for running government IT in-house (125-126), although there is a polarization between larger departments with substantial IT capacity and smaller organizations with little or no capacity.

Overall, Dunleavy et al. conclude (130) that there is a clear negative relationship between the power of the IT industry in a given country and its government IT 
performance, and this relationship is stronger than the positive relationship they found for the influence of public management factors. Put differently, the most important factor that they found in government IT performance (132) was maintenance of "competitive tensions" in government IT markets, even when there are relatively few suppliers. There was little evidence, however, of policy learning or transfer among the seven countries with respect to their relationships with the IT industry: the seven differentiated cases were "not in any sense seven facets of a single globalized picture." (134)

The picture that emerges from these descriptions is of a CIO whose powers and position in the public sector governance structure place it at the weak end of the spectrum, but it has had some successes and has a relatively balanced relationship with the IT industry. These conclusions resonate with the findings from the dissertation research. This chapter focuses on the CIO in the context of public sector governance, while chapter 4 discusses the relationship with the private sector. The next section of this chapter knits together the threads from chapter 2 to describe and explain the emergence of the Canadian CIO.

\section{Establishment and evolution of the CIO}

On the face of it, the establishment of the CIO position is not a strong candidate for a critical juncture: it was tangential to the June 1993 reorganization and initially represented as much a clustering of a disparate set of activities as something really new. The new course was quickly reinforced, however, and after some turbulence settled into a pattern that has persisted. The evolution of the CIO position and the field of public administration that it defines has been shaped by a number of factors, beginning with its 
institutional context and antecedents. Personalities, policy ideas and politics have also played a significant part, all conditioned by continuous change in information and communications technologies (ICTs) and in the larger economic and social environment.

This section provides a chronological account of the establishment of the TBS CIO in 1993 and its later evolution. It tracks a number of forces that shaped events, including: influential technological developments, the political and public policy context, institutional and public administration dynamics, changes in the CIO's mandate and structure, and the role of other key administrative structures. Two key variables relate to personalities. In view of the importance of Prime Ministerial decisions in conditioning the overall machinery of government and the environment in which it functions, the section is structured around the four Prime Ministers since June 1993: Campbell, Chrétien, Martin and Harper. The other focal point is the seven permanent and four acting CIOs - their mandates and the personal influence of individuals. The institutional evolution of the CIO office is a major part of the narrative thread, and the next section has a brief account of organizational alternatives that have been considered but not adopted. This section begins with a brief summary of the situation at the time of the June 1993 reorganization, picking up the story from chapter 2.

The situation immediately before the 1993 reorganization

The 1993 reorganization came at a time of pressures for change on a number of fronts within government and in society. Chapter 2 describes the public policy and institutional dynamics created by the convergence over the better part of a generation of telecommunications, broadcasting and computing. The resulting generation of ICTs was rapidly entering into daily life as well as business and office practice, creating 
increasingly networked desktops and breaking down many of the barriers between work and private life. Just as these pressures created institutional tensions between departments such as Communications and Industry Science and Technology, there were similar tensions between government common service organizations in the areas of computing and telecommunications.

Under the direction of a Progressive Conservative government led by a Prime Minister, Brian Mulroney, with private sector experience, the public service was still working its way through the aftermath of Public Service 2000 (PS 2000), the federal government's most systematic effort at reform in the era of New Public Management (NPM). In the midst of a recession and growing deficit, it also needed to find savings and reduce staff. This had led to efforts to harness the potential of ICTs and related management techniques developed in the private sector to modernize internal administrative systems and services to the public while also reducing costs. Mulroney was not initially considered to be very sympathetic to the public service or interested in public sector management issues, but he was persuaded by his Clerk, Paul Tellier, who in turn was encouraged by private sector leaders, that reform was desirable. This resulted in PS 2000 as a public service-wide reform initiative, sponsored by Tellier (Tellier 1990 \& 1992) and led by senior interdepartmental committees coordinated by a project office located in PCO, although with much of its focus on Treasury Board policies and TBS, provoking union criticism that it was unduly management-led and oriented (McIntosh 1991). Several of the committees addressed important parts of the CIO's early terrain.

By early 1993 Mulroney had been in office for over eight years and it was over four years since the November 1988 election. It was clear that there would be an election at 
some time in 1993, with a growing possibility that Mulroney would retire, creating a potential scenario similar to the one in 1984 when a new party leader and Prime Minister needed to create a distinctive profile before calling an election within months. Glen Shortliffe, who had replaced Tellier as Clerk in July 1992, was familiar with Prime Minister-driven organizational change, having played a major role in implementing the 1982 merger of External Affairs and International Trade, while the head of the PCO Machinery of Government unit, Jim Mitchell, had been closely involved with the 1984 transitions between Trudeau and Turner and then Turner and Mulroney.

Recognizing the organizational window provided by a post-election transition even with no change of Prime Minister - and with the possibility of one or even two new Prime Ministers in 1993, Shortliffe had by the end of 1992 put a transition planning exercise in motion, preparing to brief an incoming Prime Minister on outstanding organizational pressures as well as options for longer-term policy-driven organizational change. An early step was to commission Treasury Board President, Robert René de Cotret, when he retired in January 1993, to conduct a study of organizational issues that could be addressed in a transition context. In accordance with past practice, informal contacts were also made with transition planners in the office of the Leader of the Opposition, as well as with the staffs of the leadership candidates when Mulroney announced his retirement as Progressive Conservative party leader in February, to take effect after a leadership convention in June of that year.

The Campbell reorganization - June 25, 1993

The Progressive Conservative leadership party convention that chose Kim Campbell was held in Ottawa on June 10, 1993. Following a well-established pattern 
(d'Ombrain 2001), Shortliffe and his officials almost immediately met with her to prepare for her to take office two weeks later. She was briefed on a wide range of issues and asked to take decisions with respect to the organization of government departments, the structure and operations of her Cabinet, and related senior public service appointments. These were reflected in the allocation of ministerial portfolios when she and her Cabinet were sworn on June $25^{\text {th }}$. The briefings included detailed proposals for a restructuring of government, drawing on the de Cotret report and extensive staff work and behind-the-scenes consultations (Mitchell interview). According to Campbell, the organizational proposals were approved in their entirety (Campbell 1996). As events turned out, the reorganization was her main legacy as Prime Minister.

The reorganization was presented as preparing the government of Canada for the advent of the knowledge economy and society (Mitchell 2002). In line with deCotret's recommendations, the Department of Communications was dismantled; its "hardware" side - including spectrum management, sectoral policy for the high technology and telecommunications industries, and communications research functions - were included in the new department of Industry, and the "software" side - including arts and culture policy - became part of the Department of Canadian Heritage. Broadcasting policy was included in Canadian Heritage and responsibility for the Canadian Radio-television and Telecommunications Commission (CRTC) was initially assigned to that portfolio but shortly after transferred to Industry. Another major change was the establishment of the Department of Human Resources Development (known by the acronym HRDC), responsible for skills development for the new economy as well as employment services and administration of major social services such as the Canada Pension Plan. New 
departments of Health and of Public Security were also established. The focus of these changes was the creation of new ministerial portfolios, which defined the allocation of individual ministerial responsibilities within Campbell's Cabinet.

In anticipation of later organizational legislation, the departments were administratively structured on the same day, through the transfer and consolidation of units using the Public Service Rearrangement and Transfer of Duties Act, complemented by a shuffle of Deputy Ministers to support the new array of portfolio ministers; enabling Orders in Council were passed at Campbell's first Cabinet meeting immediately after the Cabinet swearing-in. In order to drive through these changes, Shortliffe created an Implementation Board of senior officials which he chaired. The Board was supported by a small secretariat in PCO, linked to the Machinery of Government unit and headed by Art Silverman, previously Assistant Deputy Minister of Corporate Services in the Department of Fisheries and Oceans and a known advocate of consolidation of government services. The head of Campbell's Prime Minister's Office, Jodi White, was kept informed of the work of the Board and attended some of its meetings.

The reorganization included two sets of changes involving internal management portfolios. The most visible was the consolidation of common services into a single department, Public Works and Supply and Services, bringing together the former departments of Public Works and of Supply and Services as well as common service units from other departments. Within that structure, the two units most directly concerned with ICT-based services to government - the Government Telecommunications Agency and the Central Computing Bureau - were combined to form the Government Informatics and Telecommunications Services (GTIS), an operational agency in principle working 
within the policy framework set by Treasury Board ministers. The other change was the elimination of the Office of the Comptroller General (OCG) as a separate department within the Treasury Board portfolio, which it had been since 1978, and its consolidation with TBS under the Secretary of Treasury Board, Ian Clark, who assumed the Comptroller General title. ${ }^{68}$ Although a Deputy Minister in his own right, the outgoing Comptroller General, Andy Macdonald, was not reassigned as part of the shuffle of Deputy Ministers and was left with TBS and Clark to assign as he felt appropriate (Clark interview).

\section{Establishment of the CIO in Treasury Board Secretariat}

Clark had advance notice of the details of the June 25 reorganization and prepared his own restructuring of TBS to coincide with the government reorganization. This included a new Comptrollership Branch within TBS, based on the policy centres for the Treasury Board financial management policies that had previously been in OCG. The branch did not, however, include policy centres for program evaluation, internal audit and contracting, which had remained with Administrative Policy Branch (APB) after OCG was formed in 1978.

Macdonald was designated as the government's first CIO, reporting to Clark as a de facto Associate Secretary to Treasury Board, in view of his personal DM rank. ${ }^{69}$

\footnotetext{
${ }^{68}$ There are various explanations for this move. It was widely felt within the senior public service that OCG had lost its vocation as a central agency, especially under Macdonald's predecessor, and had aligned itself too closely with the Auditor General. A related concern was the lack of integration between OCG, with its financial management responsibilities, and broader TBS-led efforts to reform public administration following PS 2000, in which OCG had not actively participated. More generally (shades of Haldane!), an important aspect of the Campbell reorganization was an effort to streamline Cabinet and reduce the number of ministerial portfolios and government agencies.

${ }^{69}$ In the public service hierarchy an Associate Deputy Minister or Secretary has a personal rank of Deputy Minister, is senior to the senior line managers (usually Assistant Deputy Ministers) but subordinate to the Deputy Minister. An Associate's responsibilities can vary from having direct line authority over a segment of the department to being an alter ego to the Deputy Minister, in the same box on the organization chart.
} 
Macdonald, who had an undergraduate engineering degree, was also chair of TIMS, the interdepartmental committee of Deputy Ministers that had been established in the late 1980s to give senior officials an opportunity to study the impact of new ICTs on the public sector (Steinsky-Schwartz interview) and that Macdonald had revived in 1991. Through the OCG's efforts to automate financial administration and introduce electronic funds transfer to the federal government, Macdonald had also had extensive discussions with senior Canadian banking executives about their experience with electronic banking and had been invited by one of them to attend meetings of the Research Board, a New York City-based organization that was introducing ICTs and e-commerce to CEOs of major corporations.

Those contacts made Macdonald aware of the growing private sector trend to appoint senior executive-level CIOs, and on that basis he proposed to Clark that he be appointed corporate CIO for the federal government, based in TBS. Clark, who had a science $\mathrm{PhD}$ and was himself an advocate of making greater use of technology in public administration, agreed (Clark interview, Macdonald interview). When a proposal was taken to Treasury Board ministers later in the Summer to authorize the related changes in TBS's organizational structure, however, they balked at giving the position the title of Chief Information Officer because it sounded too much like a government propaganda agency, reminiscent of Trudeau's reviled Information Canada. After some quick deliberation, Macdonald proposed calling it Chief Informatics Officer, and Treasury Board agreed (Paton interview).

Macdonald was given considerable latitude to define his own mandate within the parameters of the activities and responsibilities that were assigned to him. An Office of 
Information Management Systems and Technology (IMST) was created to support him, headed by an Assistant Secretary, one level down from the Deputy Secretaries who headed TBS branches in the areas of personnel and administrative policy - and now comptrollership. IMST built on five main elements (Clark 1994). Its core was the OCG financial management information and systems unit, which had been working on automating the public accounts and related government bookkeeping and which Bernie Gorman, the new IMST assistant secretary, had previously headed. This was supplemented by the unit that had been working on automating human resources information in the Personnel Policy Branch. A second major element was the APB unit responsible for Treasury Board policies and standards with respect to the management of information technology (the only unit rooted in the post-Glassco TBS policy management model.) A third component was work begun earlier by APB in the aftermath of PS 2000 to look at the use of ICTs in support of service to the public, and a fourth was a parallel effort begun by APB to modernize administrative functions in government through shared services and the application of technology. The fifth component was a small office to support the federal government's IT functional community of practice, growing out of and modelled on similar work in OCG to support public service financial administrators.

This package of responsibilities had no precedent and brought with it a significant agenda that created high expectations within the public service. There were also a number of challenges, beginning with the fact that each of the five strands had its own history and organizational culture but there was much less history of working together. The CIO also faced the need to develop a working relationship with GTIS and Public Works and Supply and Services more generally, which had their own challenges of integration and 
role and mandate definition. In addition, there were at least two major Treasury Board concerns with a significant bearing on the CIO's responsibilities that were not included in the original package of responsibilities. An overarching influence was shifting assumptions and debates about the role of Treasury Board.

The OCG had not been an active participant in the internal TBS debate about its role, post-PS 2000, and the unit working on automating financial systems was even further removed from thinking about Treasury Board instruments - to the extent that those were discussed in OCG it was in the financial management policy centres, which became part of the new Comptrollership Branch. The other major unit assigned to the CIO, the management of IT policy unit from APB, had been part of the TBS discussions, but it had until very recently been oriented towards control of new IT capital spending and standard setting, in the context of public and political concern about the costs and risks of major investments in technology. Its role in monitoring IT spending had been deemphasized even before the reorganization, and after an initial interest in IT spending oversight the CIO largely left this function to the TBS expenditure branches to follow on a department-by-department basis. This loss of sensitivity to IT costs was accentuated by the IT management policy unit's separation from policy units concerned with contracting and major project management generally, which remained in APB.

Another significant feature of the internal TBS reorganization was that it separated the CIO's IT policy unit from the information, communications and security policy centre, which remained in APB and which had participated actively in discussions both about TBS's role and about the wider implications of technology for the government as 
an information-intensive organization (Paton interview, Sinclair interview) ${ }^{70}$ In other words, the reorganization was a reconfiguration of existing organizational cultures and professional disciplines as well as of responsibilities, separating some that had a history of working together and combining others that had not.

But the CIO's greatest and most enduring challenge was that in the absence of a clear central agency role assigned by the government - which being an overt part of the 1993 reorganization would have provided - these factors disproportionately conditioned its environment and created pathways that had a profound influence on the evolution of the position of $\mathrm{CIO}$ and the management policy sector it defines. A package of responsibilities was approved by Treasury Board ministers when they authorized the CIO position, but it was no substitute for a policy-based machinery of government mandate from the Prime Minister. Apart from the issue of management of major IT projects, the CIO's initial agenda was below the political radar. The CIO did inherit another recent APB file, however - the implications of technology for service to the public - and this became a major focus, even its salvation, in the office's first decade or more. Even so, the $\mathrm{CIO}$ at the outset had an orientation and an agenda of projects rather than a mandate, with only tenuous links to the government's agenda, collective management processes or mainstream TBS roles.

Nevertheless, in the first few months after the reorganization the ClO did enjoy strong internal support from Clark and Shortliffe. Macdonald's most immediate concern was addressing the desire of the Implementation Board to realize significant savings - up

\footnotetext{
${ }^{70}$ Clark had discussed the possibility of including the information, communications and security policy unit in the original CIO mandate with both Macdonald and Richard Paton, the head of APB. While interviews with all three and others involved at the time provide slightly varying accounts of events, it would appear that in the end Paton was more focused on this area than Macdonald and Macdonald regarded it as less central to his mandate. In the event, the unit did not move organizationally but it did work closely with the $\mathrm{CIO}$ and IMST on a number of their initiatives.
} 
to $\$ 1 \mathrm{~B}$ - from using IT to consolidate administrative services and applications across government. This highlighted the importance of two interdepartmental networks that the CIO had inherited: TIMS, which Macdonald continued to chair, and the Advisory Committee on Information Management (ACIM), the descendant of the Interdepartmental Committee on Electronic Computers created in 1956 to advise TBS on major computer purchases and which in 1993 was chaired by Ivan Fellegi, the head of Statistics Canada, a major user of technology in support of its program operations. By the end of the decade, ACIM had evolved into the CIO Council, convening the CIOs that were created in most departments in fairly short order in the wake of the establishment of the TBS CIO. Chaired by the TBS CIO, ACIM and then the CIO Council continued to be one of the CIO's most important leadership instruments within the public service.

The Chrétien transition (November 1993) and policy direction

Running up against the constitutionally-prescribed end of the current Parliament, ${ }^{71}$ Campbell called a general election for October 25, 1993. Losing massively, she resigned in favour of Liberal leader Jean Chrétien, who with his majority government Cabinet came into office on November 4, 1993. Again, the intervening period was used by Shortliffe and PCO - with Mitchell heading the Machinery of Government unit - to brief the incoming Prime Minister and confirm the structure of ministerial portfolios and Cabinet. The key question was whether to make changes to the Campbell reorganization, which was well advanced through the efforts of the Implementation Board.

Chrétien's transition advisors had been caught by surprise when Campbell's decisions were announced. While the June 25 plan was not what was contemplated by the

\footnotetext{
${ }^{71}$ Parliament was due to be automatically dissolved five years after the return of the Writs from the previous election, held on November 21, 1988.
} 
Liberal planners, it went in the same direction as measures they had been considering, including a social policy super ministry similar to HRDC, a reconfiguration of Industry, and a CIO, with a particular interest in establishing single-window service to Canadians. While not part of their original thinking, they also judged that splitting the Department of Communications made sense in theory, although it later created political tensions among the ministers in the successor departments. In any case, Chrétien made it clear to his transition team that he was not prepared to reorganize the government twice in four months, and by the time he was elected the Liberals - who by then had a copy of the de Cotret report - had concluded that the only substantial change they would make was to undo the Department of Public Security (Zussman interview). Public Works and Supply and Services was renamed Public Works and Government Services (PWGSC).

Chrétien's priority was to implement his party's campaign platform, the detailed Red Book (Liberal Red Book 1993). Of the many initiatives that it foreshadowed, two that had an impact on the CIO were launched in the first half of 1994, and there were also important changes in senior-level personalities. Chrétien had little experience with the new technologies - learning most of what he knew about the Internet from his grandchildren (Zussman interview) - but several of his new ministers were interested in their potential, notably Industry Minister, John Manley, and the Minister of Finance, Paul Martin (each of whom had been considered for both jobs - Goldenberg 2006: 66-67).

A significant role was played by the Spectrum, Information Technology and Telecommunications (SITT) Sector, which had moved intact to the Department of Industry from Communications in the 1993 reorganization. Its major responsibilities included spectrum licensing for broadcasting and wireless telecommunications as well as 
sponsoring communications research, including overseeing the work of the

Communications Research Centre which had links both to the National Research Council and to the growing private sector ICT research industry, much of it by and spinning off from Bell Northern Research/Nortel. Growing out of these roles, the sector assumed the lead role for government programs to promote the private sector high technology and telecommunications industries, a role that in other economic sectors was played by the industry sector branch of Industry Canada. (This distribution of labour continues within Industry Canada.) Prompted by SITT, Manley and his Deputy Ministers ${ }^{72}$ became enthusiastic advocates for new technologies, both in government programs and in internal administration. ${ }^{73}$ The fact that he and Martin remained in the same portfolios for the first seven years of the Chrétien government (as did SITT ADM, Michael Binder, another science $\mathrm{PhD}$ ) was a significant factor in sustained follow-through to the 1994 initiatives. Announced in the January 1994 Speech From the Throne, Manley launched a blueribbon Information Highway Advisory Council (IHAC), chaired by David Johnston, the former Principal of McGill University (who in 2010 was appointed Governor General). A key factor was support from the early Chrétien PMO, notably Dave McInnes (Zussman interview) and Chaviva Hosek, the PMO policy director who had co-authored the Red Book (Binder interview). IHAC was asked to develop a strategic plan for addressing

\footnotetext{
${ }^{72}$ Initially Harry Swain, who in 1995 was replaced by Peter Harder, who became Treasury Board Secretary in 1996, succeeded by Kevin Lynch, a career Finance official who later went on to become Deputy Minister of Finance and then Clerk. Both Harder and Lynch chaired TIMS while at Industry.

${ }^{73}$ As part of its contribution to PS 2000, SITT had sponsored the launch of an intranet, the Senior Executive Network (SEN) for Assistant Deputy Ministers, many of whom were participating in the Project on Governing in an Information Society led by the Institute on Research and Public Policy (Rosell et al. 1993 \& 1995). With the encouragement of Ian Clark at TBS, SEN expanded to all government executives by 1991 (Binder interview). In 1993 SEN began posting Budget and economic statement documents on its internal bulletin board, and it supported Finance in posting the 1994 Budget on the Internet (Richard interview). Another entrepreneurial SITT initiative was the launch of SchoolNet, which set out to link every school in Canada to the Internet - notwithstanding the lack of federal standing in K-12 education. This was featured in the 1994 Budget.
} 
three sets of issues relating to the newly emerging information highway: competitiveness and job creation in the knowledge economy; Canadian content and culture; and universal access and social impacts of ICTs. The Council's first report made 224 recommendations in all these areas (Canada IHAC 1995), and its second report, reacting to a government strategy paper issued in response to the first report (Canada Industry Canada 1996) added another 101 recommendations (Canada IHAC 1997). A key theme in both IHAC reports was that the federal government should aggressively embrace new information technologies in all aspects of public policy and that the government should itself serve as a model actor on the information highway. ${ }^{74}$

The first IHAC report was warmly received by the government (Canada Industry Canada 1996), and the two reports provided policy energy for SITT and Industry Canada well into the next decade, including a follow-up National Broadband Task Force that was also chaired by Johnston (Canada Industry Canada 2004). In response to IHAC's recommendations, the 1997 Speech From the Throne included an undertaking that information and knowledge infrastructure would be accessible to all Canadians by the year 2000, thereby making Canada "the most connected nation in the world" (Canada Governor General 1997). In fulfilment of this commitment, SITT developed a "Connecting Canadians" strategy, which included building on SchoolNet to link libraries, Indian reserves and remote communities to the Internet and promoting the development of e-commerce in the private sector, in particular among small and medium business.

\footnotetext{
${ }^{74}$ SITT provided the IHAC secretariat and Mitchell, who left PCO in 1994 to form a consulting firm, Sussex Circle, in partnership with Shortliffe, was the primary drafter of its reports, drawing on Council proceedings and the thinking of both Manley and Johnston. The TBS CIOs were not actively involved in the process, but there was regular staff-level contact with it. The concept of government as a model actor did not come from TBS, and SITT continued to follow it closely (Simpson 1997, Binder interview).
} 
Another pillar that was to have major implications for the $\mathrm{CIO}$ was to move government services to the public on-line - pointing the way to Government On-Line (GOL).

The second development that conditioned the CIO's environment during the remainder of the 1990s was Program Review, the Chrétien government's successful effort to tame the fiscal situation. Also foreshadowed in the Red Book, restraint measures were announced in the February 1994 Budget but were not seen as sufficient. They were intensified in May 1994 in a structured review of all government spending against six tests that allowed cuts to be tailored to policy goals and administrative circumstances (Bourgon 2009). ${ }^{75}$ Although the levels of cuts were centrally driven, with departmental budgets reduced by up to $60 \%$, it was decided to give departments the maximum possible latitude in meeting their targets. Accordingly, TBS sought to reduce Treasury Board regulation of departmental management, and it was decided not to pursue Implementation Board horizontal management initiatives such as common infrastructure and back office solutions, or the associated savings (Giroux interview). Departments were, however, encouraged to make use of IT in restructuring their own responsibilities, although investment funding had to come from departmental savings. Dealing with some of the largest cuts, Industry Canada sought to transform itself into an IT-enabled knowledge organization, supporting business through information brokerage rather than traditional financial subsidies (Brown 1997). Less systematic, although cumulatively significant, were cuts to record keeping and other clerical functions in all departments. In principle, these cuts paved the way for the automation of information management, although as discussed in chapter 5 they also weakened the government's information base.

\footnotetext{
75 A likely influence on the design of the Chrétien Program Review was the 1984-86 Nielsen task force on Program Review, which was only loosely tied to government decision-making and had a limited impact.
} 
The change of government resulted in changes in key personalities. After seeing through the transition, Shortliffe retired in April 1994 and was replaced by Jocelyne Bourgon. Shortly before her arrival, David Zussman, an academic who had headed Chrétien's transition team, moved to PCO to set up the secretariat to the committee of ministers that oversaw Program Review; when Mitchell left PCO shortly after he also took over the Machinery of Government directorate, ensuring that organizational and budgetary decisions were aligned. ${ }^{76}$ In May 1994 , Clark was succeeded as Treasury Board Secretary by Robert Giroux, an experienced line Deputy Minister with a background in labour relations, who had a mandate to bring the public service unions along through the Program Review process.

The CIO under Chrétien (November 1993-December 2003)

During the ten years of the Chrétien government, the CIO position went through numerous changes, for a while disappearing as a distinct organization, later rising to a leadership role in public service modernization. At the beginning of this period the CIO's major technological focus was on projects to automate the management of major government programs and to establish internal electronic communications infrastructure, a major challenge being to keep pace with expanding demand for bandwidth in response to the spread and growing power of networked computing, both within government and in society at large. The Internet and World Wide Web were beginning to impinge on the CIO agenda, and initial thinking had begun about the Year 2000 (Y2K) date problem. There was also a growing appreciation of the challenges relating to IT security in a postCold War environment in which non-state actors posed at least as great a threat as hostile governments. By the end of the period, $\mathrm{Y} 2 \mathrm{~K}$ had passed without incident, many

\footnotetext{
${ }^{76}$ He was succeeded as secretary to the Program Review committee by Wayne Wouters, the current Clerk.
} 
government systems were in their second generation, most others were at some stage of automating, networked desktops were the norm within government, and the Internet had become a central focus. Most major government services to the public were on-line, aided at least in part by the introduction of broadband capacity in many parts of the national telecommunications infrastructure. Wireless communication was beginning to be noticed as a technology with its own implications. Many earlier issues had been resolved, some had not, and new ones had entered the mix.

Macdonald's most visible initiative as CIO was development of a Blueprint for Renewing Government Services Using Information Technology (Canada TBS 1994), building on Vision 2001 issued by APB two years earlier (Canada TBS 1992). Prepared through the combined efforts of "business line" managers and IT specialists mobilized from across government, the Blueprint addressed both external and internal services and was issued as a discussion draft with the intention of later turning it into a more strategic document. While this did not happen under Macdonald, it remained the reference point for later work. ${ }^{77}$ In late 1994, Giroux wound up APB, assigning most of its functions to the Comptrollership sector and the information, communications and security policy unit to IMST, reporting through it to the CIO. Giroux considered that TBS needed to be streamlined and APB had run its course (Giroux interview). De-emphasizing APB's focus on administrative procedure was also consistent with giving departments more room to cope with Program Review cuts.

In early 1995, Macdonald left TBS to become the first Chief Information Officer for the Australian government. Giroux again reorganized TBS, combining IMST and the

\footnotetext{
${ }^{77}$ Macdonald later stated that he regretted not taking the Blueprint to Treasury Board or Cabinet for endorsement (Macdonald interview).
} 
Comptrollership sector into a new Financial and Information Management Branch (FIMB). Bob Little, a former departmental Corporate Services Assistant Deputy Minister (and earlier in his career a Canadian Forces Major General with a background in logistics) was appointed Deputy Secretary of the new branch, assuming the CIO functions although not the title. Little was chair of the Council for Administrative Renewal (CAR), a post-PS 2000 committee of corporate service ADMs that advised TBS on policy and systemic reforms in government administration. One of its projects was a paperburden reduction initiative, seeking to streamline reporting requirements for small businesses by moving them on-line using the newly developed GST electronic remission system. CAR gave Little greater familiarity with Treasury Board policies and the postGlassco model than any other CIO, and he continued to take an interest in CAR's work as well as an IT security strategy initiative that the CIO had inherited from APB. Although interested in technology and information policy issues, however, Little's major preoccupations - in the midst of Program Review - were with issues arising from the Comptrollership sector (Little interview).

IMST did continue promoting projects under the Blueprint and introduced the first government Internet strategy, building on the Government Communications policy and common corporate identity guidelines under the Federal Identity Program (FIP). IMST worked with GTIS to adapt PubliService, the Web-technology based intranet that had succeeded SEN, to launch the Canada Site (www.canada.gc.ca), which continues to be the Government of Canada Internet portal (Richard interview). With Macdonald's departure, the chair of TIMS moved to a succession of Deputy Ministers of departments with major service delivery roles. During this period TIMS began to generate its own 
agenda, which included sponsoring pilot projects to develop the model of client-centred Internet-based single windows to provide services from a range of departments to a common client. The pilots included hypothetical cases of a job seeker and a business seeking to enter the export market. These pilots became a source of tension between Little and TIMS, however, over the extent to which TIMS should determine his priorities as opposed to Treasury Board and the TBS Secretary (Little interview, Harder interview).

The situation came to a head in the Fall of 1996 when Giroux retired and was replaced as Secretary of Treasury Board by Peter Harder, an experienced departmental Deputy Minister who was Deputy Minister of Industry and chair of TIMS during Little's tenure in FIMB (which was also the later stages of IHAC). In an earlier position as Deputy Minister of Citizenship and Immigration, Harder had sought to delayer the department by eliminating its ADM positions and to empower the next level of management by having it report direct to him. He set about doing the same thing in TBS, eliminating all of the Deputy Secretary positions, at which point Little also retired. Harder stated his intention to reconstitute a CIO - reconstituted as a Chief Information Officer - reporting to the Secretary and to fill the position from the private sector. Bernie Gorman, the head of IMST, served as Acting CIO during the interim.

The new CIO, Paul Rummell, took up the role in the Spring of 1997, at which time IMST was converted to become the CIO Branch (CIOB), although with its management tier continuing to report through Gorman. Rummell was a partner in one of the big-five management consulting firms, with experience in both the private and public sectors, and had served as the CIO of a large hospital. The first TBS CIO with an IT and private sector background, his mandate from Harder was to build a strong IT/IM function in 
government, including strengthening IT infrastructure, management of major IT projects and the IT/IM community. The Y2K agenda also required considerably more attention and proved to be Rummell's major preoccupation. (Harder interview, Rummell interview) This meant restructuring both CIOB and the IT functional community in departments and becoming more involved in oversight and assessment of major IT projects. Traditional TBS policy functions were minimized, although individual policy areas such as privacy and security were considered important and policies were added to respond to the new situation of the Internet, notably an acceptable use policy for use by public servants of government facilities and continuing efforts to adopt a more strategic approach to the government's Internet presence. The information, communications and security policy unit - which under Little had been assigned the management of the Treasury Board IT management policy as well - was broken up and its components combined with other CIOB units, pending a review of the CIOB policy function by Alex Himelfarb, who joined TBS as Associate Secretary in the Fall of $1997 .^{78}$

Rummell was recruited under an interchange agreement with the Information Technology Association of Canada (ITAC), which allowed the federal government to recruit private sector IT executives for periods of up to five years to fill senior public service positions while paid at their private sector salary levels. Recognized as knowledgeable about IT and technology management, he found himself in a very different role than CIOs in the private sector (Rummell interview), ${ }^{79}$ where CIOs have more control over IT spending but there are few equivalents to the broader TBS

\footnotetext{
${ }^{78}$ A senior manager with a social policy background, Himelfarb had not previously worked in TBS but he had experience with introducing IT into departmental programs and administrative systems.

${ }^{79}$ This was confirmed in several interviews with private sector observers of the federal government, who noted that in large corporations the CIO typically controls the enterprise IT budget and is often at the global executive level. In IBM, for example, the CIO is one of the Vice-Chairmen (Kent interview). Rummell was $\mathrm{CIO}$ while Borins and Wolf were conducting their research on the CIO.
} 
management policy functions. In other major contrasts, human resources issues play a greater role in the public sector, and the government's combination of IT and information management - with IM being as important as IT - was not common in the private sector. During this period, at the height of the Program Review freeze on public sector salaries, the public service was faced with the prospect of major losses of IT professionals to the burgeoning private sector "high tech" industry and Rummell was involved in efforts to create more attractive compensation for IT workers. Originally hired for two years, Rummell left at the end of 1998, after 20 months. Gorman retired at the same time and CIOB was restructured, with all its senior managers reporting to the CIO.

Harder turned for a second time to the private sector, again using an ITAC interchange, and in late 1998 brought in Linda Lizotte-Macpherson, an IT industry executive identified by a head-hunting firm. Based on Himelfarb's advice, he decided to transfer responsibility for most CIOB policy areas to other units in TBS: access to information, privacy, and government security other than IT security were moved to the Government Operations Sector (GOS) in the TBS budget office. The rationale was that GOS was responsible for overseeing the expenditure budgets for both TBS and the Department of Justice, which along with TBS has a policy role under the ATIP Acts. As an extension of its Justice portfolio role, GOS also deals with the budgets of the Information and Privacy Commissioners, creating what arguably was a conflict of interest. The Government Communications policy and policy with respect to service to the public, other than electronic services, were combined to form a new Service sector, reporting direct to the TBS Secretary. This was intended to provide a more strategic 
approach to service to the public in general and also to begin the process of integrating the non-electronic forms of service delivery.

The aim of the reduced CIO mandate was to allow the CIO to focus on IT-related issues, including electronic service delivery, IT infrastructure and major IT projects, and strengthening the IT function. The reorganization also removed from the CIO information functions that on the one hand were not getting enough attention and on the other were politically sensitive, notably the ATIP and Communications policies. A major responsibility was added when Cabinet assigned the CIO the lead role in ensuring that "mission-critical" government-wide IT systems were ready for the Year 2000. The CIO continued to be responsible for policy on information management, narrowly defined, but it was considered that serious attention to the IM agenda would have to wait until the more pressing technology issues had been addressed (Harder interview).

Lizotte-Macpherson concentrated her efforts on two major areas. A Year 2000 office was set up in CIOB to lead a wide range of activities across government as well as extensive collaboration with other levels of government and the private sector (Canada Auditor General 1997 \& 1998), notably the power generation and transmission industries. A major risk management exercise, $\mathrm{Y} 2 \mathrm{~K}$ became an opportunity for the government's technologists to obtain investment funding to upgrade the internal technology environment, much of it to consolidate the piecemeal investments that had been occurring over the previous years. Opinions vary - including in the dissertation interviews - as to whether the apprehended crisis was real or manufactured (or somewhere in between), although it is generally agreed that it placed IT on the wider government agenda and got the attention of senior political and public service decision-makers. 
Lizotte-Macpherson's other major file was to launch GOL as a major public sector reform initiative. GOL's roots were those of the CIO, not least the Blueprint and IHAC reports as well as the TIMS pilot projects. The Canada Site provided a delivery vehicle for electronic services and the government had several years' experience with linking information about federal and provincial on-line services (Brown 1997: 99). More immediately, the Connecting Canadians agenda led by Industry Canada entailed a major effort to promote e-commerce in the private sector, and it was expected that the federal government would follow suit. Additional energy was provided when Mel Cappe became Clerk in January 1999. A former chair of TIMS who had also worked with Clark in TBS, Cappe was a strong advocate of using IT to modernize government (not least TBS), making GOL into a government-wide initiative that engaged all departments and agencies. As such it was a successor to PS 2000 and on a par with similar exercises in the human resources management field, notably La Relève (which Bourgon had sponsored to look at career development and leadership as major elements of public service reform against the backdrop of Program Review, new ICTs and the changing role of government (Bourgon 1997)) and the Public Service Modernization initiative that parallelled GOL.

GOL went through several phases, from its approval as a government-wide strategy in 1999 to its retirement with honour at the end of the 2005-2006 fiscal year, coinciding with the entry into office of the Harper government, which tabled the GOL final report (Canada PWGSC 2006). ${ }^{80}$ The 1997 Speech From the Throne commitment was followed by one in the 1999 Speech From the Throne that by 2004 Canadians would be "able to access all government information and services online at the time and place of their

\footnotetext{
${ }^{80}$ See also the Auditor General's review of GOL (Canada Auditor General 2003b). For a more complete account of GOL, see Brown $2005 \& 2007$, which are the basis of this summary.
} 
choosing" (Canada Governor General 1999). In support of this undertaking, the Cabinet

Committee on Communications - not Treasury Board - approved a strategy for citizencentred service combined with electronic service delivery.

The strategy had three complementary elements: Service Canada, which linked together in-person services building on HRDC's employment service centres combined with telephone-based information services provided by the communications common services organization within the PWGSC portfolio; ${ }^{81} \mathrm{GOL}$, which was focused on on-line services; and the Service Improvement Initiative (SII), which sought to develop government-wide standards for all service channels, based on client satisfaction surveys. ${ }^{82}$ Initially applying to 28 major departments in three tiers, a re-launch of GOL with the new Millennium on January 1, 2001 - was approved by Treasury Board in 2000, based on 30 single-window electronic service clusters framed by three gateways linking 34 federal departments and encompassing the federal government's 130 major transactional and information services to the public. The target completion date was shifted to March 31, 2006, and additional funding was provided in the 2000 Budget to build the electronic clusters and an encryption-based Secure Channel to facilitate on-line transmission of information and money. Financing was also provided for updating the related Treasury Board information management and security policies. ${ }^{83}$

\footnotetext{
${ }^{81}$ This was the residual of the old Queen's Printer after its printing operations were privatized during Program Review. The communications common services, which include publishing, exhibitions, advertising, public opinion research and the Canada Gazette, have always been kept separate from GTIS and ITSB in PWGSC and now constitute the Government Information Services. Until the 1999 changes they also operated the 1-800 0-CANADA call centre, which was transferred to Service Canada.

${ }^{82}$ Following the 1998 restructuring of TBS, Service Canada and SII were led by the Service Sector while GOL was led by the CIO. For a more complete account of the SII and the genesis of Service Canada, see Marson and Heintzman 2009.

${ }^{83} \mathrm{~A}$ total of $\$ 880 \mathrm{M}$ in new funding was allotted over the lifetime of GOL, up to the end of fiscal year 2005-06. An initial $\$ 160 \mathrm{M}$ over two years was included in the 2000 Budget, to restructure the Canada Site around the Gateways and Clusters, launch "Pathfinder" projects to pilot on-line service delivery, begin the development of secure infrastructure (what became the Secure Channel, the single most costly component
} 
In 2000, Harder moved to DFAIT and was replaced by Frank Claydon, the Deputy Minister of Agriculture. The same year, Lizotte-Macpherson, having moved both her major files some distance forward, returned to the private sector. She was replaced by Michelle d'Auray, who came from an ADM position under Himelfarb, now Deputy Minister of Canadian Heritage (and chair of TIMS). Before that, d'Auray had been in SITT at Industry Canada, leading the e-commerce activities under Connecting Canadians, which included a major initiative to extend legislated privacy provisions to the private sector. A career public servant, d'Auray's background was in public communications and arts administration. She had also been the head of communications in the FederalProvincial Relations Office and was well-versed in central agency operations. ${ }^{84} \mathrm{Her}$ primary task was to implement GOL. With the government's wind in her sails, she was supported by an external GOL Advisory Panel that issued three public progress reports in 2002 and 2003 (Canada GOL Advisory Panel 2002 a \& b, 2003) and was able to make full use of the leverage available as an arm of TBS. This included using TIMS as the steering committee for GOL and involving senior operational managers through a system of ADM-level GOL champions in each department, linking them to the well-established network of departmental CIOs that the TBS CIO chaired. The gateways and clusters initiative, which was one of the most distinctive features of GOL, was driven by an empowered structure of front-line departmental staff (Brown $2005 \& 2007$ ) supported by

of GOL), and to provide policies and training in support of GOL. The following year another $\$ 620 \mathrm{M}$ in new money was provided to see GOL through to completion, with TIMS having a role in allocating resources to approved projects (Brown 2005: 44-45). According to the final GOL report, the major GOLrelated spending included $\$ 475 \mathrm{M}$ on the Secure Channel, $\$ 95 \mathrm{M}$ on the Gateways and Clusters, $\$ 26.5 \mathrm{M}$ to support on-line service delivery, and \$47.5M developing policies and standards (Canada PWGSC 2006).

${ }^{84}$ Although not at the Deputy Minister level, it is likely that d'Auray was on the "high-flyers" list of potential DMs administered by PCO and hers appears to be the only CIO appointment in which the Clerk was significantly involved, resulting from consultations between Claydon and Cappe (Claydon interview). D'Auray is the only CIO to move directly to a DM position (Lizotte-Macpherson later came back to government and worked her way up to that level), and in 2009 she returned to TBS as Secretary. 
CIOB and TIMS. The combined result was top ranking for five successive years by Accenture in its monitoring of the introduction of electronic service delivery in the public sectors of developed countries (Accenture 2005).

During this period, the CIO's mandate and larger environment continued to evolve. In 2001, d'Auray took a proposal for a technology-enabled consolidation of administrative services to TBSAC, the nominal parent committee of TIMS that advised the Treasury Board Secretary. The proposal was stiffly resisted and efforts to move towards a common backroom for some years thereafter remained largely in the realm of exhortation and coordination. As a result of expressions of interest from d'Auray, in 2002 Claydon moved the ATIP and security policy centres back to CIOB. He also closed down the Service Sector, which was largely unfunded, and moved the SII and service policy to CIOB as well (Claydon interview). Service Canada, which had become increasingly operational, was transferred to HRDC, which through its employment centres had the government's largest operational network for service to the public. D'Auray did not wish to take on the Communications policy role, however, apart from standards for electronic "common look and feel," and it was assigned instead to the TBS departmental communications office, notwithstanding internal organizational doctrine that TBS's central agency and departmental management functions should be kept separate. ${ }^{85}$

In May 2002, Alex Himelfarb replaced Cappe as Clerk. Himelfarb strongly supported GOL, although by this stage it was well into its implementation phase. Claydon also retired as TB Secretary in May 2002 and was replaced by Jim Judd, the Deputy Minister of National Defence.

${ }^{85}$ This was in spite of - or possibly because of - d'Auray's background in government communications. The policy had recently been updated and her office had a good working relationship with it, so in that sense she may have felt that she did not need to have it as part of her responsibilities. 
By the end of the Chrétien government, the emphasis was on seeing through existing initiatives rather than opening up new ones. The stability and continuity of policies and programs under Chrétien undoubtedly owed a great deal to his majority government election victories in 1997 and 2000 . The energy provided by the IHAC process continued and was even renewed by such initiatives as the Broadband task force, reinforced by the program deputy ministers on TIMS and the greater financial ease that resulted from Program Review. At the same time, the sense of a societal sea-change that had accompanied the technological changes in the early 1990s had abated, shifting to something more like mid-generation consolidation - a state that largely continues.

The CIO under Martin (December 2003-February 2006)

Unlike Campbell ten years before, Martin inherited some electoral room when he became Prime Minister on December 12, 2003, just over three years after the last election. When he did seek his own mandate in June 2004, the result was minority government, followed by electoral defeat in January 2006. As in June 1993, PCO, led by Himelfarb, had prepared transition briefings for the winner of the Liberal leadership convention on November 14 . The transition lasted nearly a month - unusually long - but resulted in only fine-tuning of the array of departmental portfolios that had been established by Campbell. From the perspective of this discussion, the most significant was the division of HRDC into two departments: Human Resources and Skills Development (HRSDC - centred around employment programs and including Service Canada) and Social Development (centred around social assistance programs). At the same time, in the aftermath of $9 / 11$, Martin revived the concept of an integrated portfolio 
in the domestic security area, creating a Department of Public Safety and Emergency Planning along lines similar to the Public Security portfolio rejected by Chrétien. ${ }^{86}$ In addition, responsibility for GOL was transferred to GTIS in PWGSC, which was renamed the IT Services Branch (ITSB), with a stronger mandate in providing IT services and infrastructure to government. ITSB was also assigned the role of "incubating" a shared services special operating agency. Such an agency would provide financial and human resources management support to government departments, using IT to achieve synergies and savings, updating (possibly not consciously) the Glassco common service organization model. The GOL transfer reflected a judgment that it had moved to implementation and that CIOB's involvement had become too operational - especially with respect to the Secure Channel project - and should return to a more strategic central agency role. The CIOB office dealing with CIO-related communities of practice of functional specialists across government was also transferred to ITSB but later returned on the conclusion that it was in fact a CIOB core business. TIMS continued to be the GOL steering committee but in 2004 was re-cast as the TB Secretariat Transition Advisory Committee (STAC), perhaps anticipating a change agenda that never came.

Other measures affecting TBS included converting its human resources policy and comptrollership areas into independent central agencies headed at the Deputy Minister level, although still reporting to Treasury Board under the broad leadership of the TBS Secretary. The new Office of the Comptroller General had a broader mandate than its pre-1993 predecessor, however, including policy responsibility in two areas of

\footnotetext{
${ }^{86}$ Apart from the name change, two mandate differences were that Public Safety did not include immigration but absorbed emergency planning from the defence portfolio. The link to the CIO's Security policy role is discussed in chapter 4.
} 
importance to the $\mathrm{CIO}$ - purchasing of IT goods and services, and management of major Crown projects - as well as audit and evaluation.

Martin had demonstrated his interest in technology-related public policy and administrative issues as Finance Minister and was expected to pursue them as Prime Minister. Unlike Prime Ministers in the previous 15 years he did not sponsor a high level public service reform initiative, but he did appoint as President of the Treasury Board Reg Alcock, a former provincial public servant who had been one of the few backbench MPs to take an interest in public administration in general and in particular the impact of ICTs. (The interviews suggest that the Presidents of the Treasury Board under Campbell and Chrétien had all been generally supportive of the CIO's work, especially GOL, but were not a major factor in its evolution. This is not surprising given the other demands on a President - notably budgetary and labour relations issues - combined with the strong interest taken in ICTs by PCO Clerks and TBS Secretaries.)

In the face of a deteriorating fiscal situation, Alcock commissioned a series of expenditure reviews, including of administrative services, pointing towards a renewed effort to amalgamate the administrative "back room" across government. This was reinforced by the 2005 Budget announcement of a shared services special operating agency $(\mathrm{SOA})^{87}$ in PWGSC, moving towards a consolidated common service model akin to the practice in several provincial governments. This initiative petered out with the 2006 change of government. The expenditure reviews led by CIOB included the first effort since the establishment of the CIO to estimate the total cost of IT in government.

\footnotetext{
${ }^{87}$ The SOA model was developed during the Mulroney government as an effort to adapt the British executive agencies model to the Canadian environment, the general concept being to maximize managerial autonomy and flexibility within the limits of Ministerial authority and accountability. Although it and the related Alternative Service Delivery (ASD) model were widely applied they did not have the same impact as the executive agencies in the UK. Arguably this is because of the different environment created in Canada by the Glassco model and the longer and more sustained Canadian history of administrative reform.
} 
Service Canada also evolved. CIOB remained the TBS service policy centre, in principle integrating GOL with the SII. The February 2005 Budget announced that Service Canada would become a standalone department within the HRSDC portfolio, joining the in-person and telephone services that were previously part of Service Canada with the on-line portal of the GOL-based service-to-individuals Canadians Gateway. Although launched in the Fall of 2005, this version of Service Canada was not confirmed in legislation and reverted to being an arm of HRSDC with the Harper government. A lower profile move was a similar consolidation of storefront and web-based services to business in Canada Business, an arm of Industry Canada.

The most intriguing developments during the Martin government were in the personnel area. After four years as CIO, d'Auray was promoted in 2004 to a Deputy Minister position and replaced on an acting basis by Helen McDonald, the Assistant Secretary in CIOB responsible for GOL, who had been recruited by d'Auray from SITT in Industry Canada. Unlike other interludes between permanent CIO appointments, McDonald was left in place as Acting CIO for over a year and eventually was transferred by Judd to head one of the TBS budget office units. She was then replaced for another eight months by a second internally appointed Acting CIO, Jim Alexander. Interviews for this dissertation indicate that d'Auray's departure provoked a debate between Alcock and Judd about what direction to take the CIO, and perhaps TBS more generally. Alcock was impressed by the organizational structure in the Ontario government and wished to appoint Scott Campbell as federal CIO. Campbell was well known in the national public sector IT community, having been the first Ontario Corporate CIO (see also chapter 6) and then the British Columbia provincial CIO. This was resisted by Judd, if only on the 
grounds that TBS appointments were his responsibility, but neither was he able to appoint anyone else as CIO (Judd interview). Even after Judd moved to CSIS in November 2005 and was replaced by Wayne Wouters, the Deputy Minister of HRSDC, a permanent CIO was not appointed until the government changed.

In the end, the Martin government was affected by its shift to minority government status. As one senior PCO interview commented, it never had the kind of window to pay attention to longer term organizational and governance issues that is available early in a majority government mandate, and it permanently operated in second-half-of-mandate mode, driven by the pre-electoral agenda. On a day-to-day basis, the government was increasingly consumed by the sponsorship scandal and its deteriorating political standing. This made it very difficult to focus on longer term - and at times, politically risky issues of public service modernization.

The CIO under Harper (February 2006-present)

The Harper government came into office on February 6, 2006 with the least experienced ministry in recent Canadian history, including a Prime Minister who had never sat in Cabinet. Suspicion of big government and the activist state compounded its caution, and the fact that it was a minority government during its first five years (i.e., to the time of writing this dissertation) added a second-half-of-mandate focus on political reality rather than longer term issues of administrative modernization. Ironically, perhaps, its reluctance to engage in public service management issues was reinforced in the technology area by the fact that the one experienced group of ministers had served in the Ontario Harris Cabinet, which had been burned by major IT project failures, notably in 
the Ministry of Community and Social Services (ComSoc). ${ }^{88}$ John Baird, who was assigned by Harris to deal with the aftermath of the ComSoc affair, was Treasury Board President for the Harper government's first year. On coming into Treasury Board he asked TBS not to bring forward any IT project proposals (Wouters interview).

Harper was taken through the same transition briefing exercise as his predecessors by Himelfarb and PCO. Again the great majority of the elements of the Campbell reorganization were kept in place. One change was restoration of a single social policy super-department, under the name of Department of Human Resources and Skills Development (HRSDC). Service Canada remained within the HRSDC portfolio but was re-absorbed into the department and its head reduced to the level of an associate deputy minister - reportedly due to PCO Machinery of Government hostility to its separate existence (Flumian interview). As soon as the initial transition was completed, Himelfarb left and was replaced by Kevin Lynch, at the time the Deputy Minister of Finance.

In the Spring of 2006, Wouters appointed a new permanent CIO, Ken Cochrane, previously CEO of ITSB in PWGSC. Cochrane, who had been an IT executive in the insurance industry, was appointed through an ITAC interchange arrangement, having already accumulated government experience as the CIO of Canada Revenue Agency before going to PWGSC. In that respect, his appointment represented a return to a concern for management of the government's IT assets. At the same time, Wouters and Lynch integrated STAC, the committee that had succeeded TIMS, with TBSAC to become the TB Policy Advisory Committee (TBPAC), chaired by the Treasury Board Secretary. IT lost a distinct voice as a driver of reform, although this was also an effort to integrate the management of IT into the administrative improvement mainstream.

\footnotetext{
${ }^{88}$ For an account of this episode, see Whorley 2001 . See also chapter 6.
} 
Having been elected at least in part as a reaction to the sponsorship scandal, the Harper government gave early attention to strengthening accountability mechanisms, and this was one of Baird's priorities at Treasury Board. One manifestation was a renewed emphasis on the Treasury Board policy management model, and one of Cochrane's priorities was to redefine CIOB as a policy organization, occupying a space that had never been fully filled in the early years of the CIO, was largely abandoned in the late 1990s and only partly filled thereafter. In keeping with the renewed emphasis on accountability, Wouters gave a central role to the Management Accountability Framework (MAF) ${ }^{89}$ initiative launched by Judd, and information and IT management were added to the matrix for assessing management performance by departments and their Deputy Ministers (Canada TBS 2010c) after being left out of the first version.

More recent events have involved additional changes in personalities and responsibilities, on the whole with a greater connotation of continuity than of change. Cochrane returned to the private sector at the end of 2008, his interchange term having expired, and was replaced as Acting CIO by the Deputy CIO, Peter Bruce, who had been both a departmental $\mathrm{CIO}$ in the federal government and a cluster $\mathrm{CIO}$ in the Ontario government. In May 2009, Wouters appointed a senior IT executive from the travel industry, Corinne Charette, as CIO (Canada TBS 2009b), again through an ITAC interchange. Lynch retired in June 2009 and was replaced as Clerk on July 1 by Wouters, who in turn was replaced by d'Auray as Treasury Board Secretary. In the same period, the separate human resources and comptrollership agencies were folded back into TBS.

${ }^{89}$ A forerunner of MAF was the Improving Ministerial Authority and Accountability (IMAA) initiative and related Departmental Management Assessments developed by Ian Clark in the post-PS 2000 context. 
While Charette's mandate in many ways parallelled Cochrane's, before her appointment changes had been made in two important areas of CIO interest. In 2008, Wouters re-created a Service sector in TBS, removing CIOB's policy oversight role with respect to both service to the public and service to government, including the perennially vexed issues of shared and common administrative services; the latter area was the new sector's initial priority. ${ }^{90}$ This reflected both a view that service issues were increasingly less about technology and more about management, and a desire to have CIOB concentrate on its technology and information policy-oriented mandate (Senior TBS official interview). For its part, ITSB at PWGSC - with TBS encouragement - had begun to take steps to consolidate government-wide purchasing of common infrastructure and desktop services, attracting critical attention from the Ottawa-based "body-shop" industry of suppliers of temporary IT staff to government departments and, at their behest, the House of Commons Standing Committee on Government Operation (May 2009, Canada House of Commons 2009).

By 2010, Wouters, as Clerk, had launched a review of government-wide administrative services, with a deputy minister-level head based in PCO. Its remit and expected recommendations were closely guarded, but some clues were provided over the following year. Charette's keynote speech to the IT community at the Fall 2010 GTEC week (Canada TBS 2010e) referred to movement towards a common human resources and financial IT platform, support for the Chief Human Resource Officer's HR Business Solutions Project, data centre rationalization and shared services in document management. At about the same time, the Service Sector was folded back into the CIO Branch by d'Auray, its third CIO cycle. Six months later, in the context of its deficit

\footnotetext{
${ }^{90}$ In contrast to the earlier Service sector, the Government Communications policy was not included.
} 
reduction plan, the March 2011 Budget (Canada Finance 2011) referred to "information and opportunities identified through the administrative services review" and to enabling "departments and agencies to find efficiencies through shared services arrangements and transfer of functions." Suggesting a more collective approach to IT-based savings than was adopted in Program Review, it also talked about "looking for ways to improve services and service delivery to Canadians by examining government-wide solutions that will standardize, consolidate and re-engineer the way it does business." In August 2011 the government announced the creation of a shared services agency, with an initial goal of consolidating e-mail services, data centres and desktops across the public service. There was no indication of whether its mandate will eventually extend to the full provision of back room services, as envisage by the Martin government.

\section{Roads not taken: structural alternatives to the TBS/CIO model}

The cumulative effect of the CIO's evolution since 1993 has been to entrench it within TBS and the Treasury Board institutional model. Movement has not always been in a straight line, or even forward - in some areas, notably with respect to Treasury Board policy management in general and Service policy in particular it has had distinctly circular features. Nor has it always been clear how well the Treasury Board model has been understood by successive CIOs and their staffs or how effectively they have used it.

That being said, there have been occasions when institutional assumptions about both Treasury Board and the CIO have been subjected to more searching scrutiny. In principle, all assumptions about the executive are open to re-consideration anytime there is the potential for a transition to a new Prime Minister - especially when there actually is a change - and on other occasions when the Prime Minister is called upon to take 
decisions about the machinery of government. By and large, however, Prime Ministers since Campbell have been content to work within the structures that she put in place. Indeed, there is a notable contrast in the level of organizational change between the relatively quiet period since 1993 and the much more active similar period before that date. Even so, there have been occasions when the Treasury Board model has been questioned - primarily from within Treasury Board and TBS itself. These roads not taken bear examination, both for the light they throw on the evolution of the model and for the reinforcement they have provided. In that sense they also represented critical junctures, or at least critical moments (Lindquist 2006).

The most radical efforts at restructuring came while Harder was TBS Secretary (1996-2000), for much of that time with Himelfarb as his Associate Secretary. Program Review assumed the continuation of existing departments, but there were underlying questions about the government-wide management model within which they operated, in particular a view reflected in PS 2000 that the Glassco model was too strongly weighted in favour of collective management. Harder led two efforts to rethink that model fundamentally (Harder interview). Program Review included a freeze on public service wages, which lasted six years. Even after one or two years, concerns began to emerge about the public service's competitiveness in attracting and retaining professionals and other knowledge workers. In the lead-up to the 1996 Budget, Harder, supported by Bourgon, proposed to provide greater flexibility by ending Treasury Board's role as the single Employer of the public service that was a central feature of the post-Glassco reforms (themselves rooted in the Griffenhagen public service-wide system of job classification). Instead, each department and agency would become a separate employer 
under the Public Service Staff Relations Act and assume responsibility for its own job classification and wage determination. This was rejected by Ministers as too radical and instead three pilot projects were announced in the Budget. ${ }^{91}$ With the resumption of collective bargaining in 1997 this approach became less interesting to both the government and the public service unions, and the pilots were not generalized.

Harder made a second attempt to break up the Treasury Board model, in the PCOled transition planning in anticipation of the federal election that was held in June 1997. Having concluded that the existing model was too sclerotic and cumbersome, he and Ran Quail, the Deputy Minister of PWGSC, proposed to Bourgon that the Treasury Board and PWGSC ministerial portfolios be combined, with a consequential restructuring of supporting public service entities. TBS would be reduced to the budget office and a small secretariat with a high-level view of the various areas of management - echoing, but apparently not consciously modelled on, the mandate that Glassco recommended for a "programmes division" (Canada Glassco 1962: 64) as one of three main TBS units. In a break from Glassco, the various management policy areas of TBS would then each be combined with their common service counterparts in PWGSC to form a galaxy of SOAs in the Treasury Board portfolio, possibly overseen by junior ministers under the Treasury Board President. ${ }^{92}$

\footnotetext{
${ }^{91}$ The three pilots were Canada Customs and Revenue Agency, the Canadian Food Inspection Agency and the Parks Canada Agency. Although they continue to be separate employers, their autonomy from Treasury Board and Finance, at least in the area of wage determination, has been limited (Brown 2009b).

${ }_{92}$ This echoes British practice, where central management policy centres are often combined with their central service delivery arms. In the UK, this has been in the absence of a Treasury Board-type committee of ministers and statutory framework for public sector management. Instead, direct administration of common services (especially ones that ministries are required to use) has been an important instrument of Whitehall collective management. In order to move completely to the British model, Harder would have had to advocate winding up the FAA, PSEA and PSSRA and Treasury Board itself. His proposal did not go that far, although he was aware of British practice in preparing it (Harder interview).
} 
One such SOA would combine the CIO's IT-related policy functions with GTIS, while a separate SOA would be responsible for the government communications policy and related common services in the PWGSC portfolio. ${ }^{93}$ Treasury Board itself would become a Management Board, playing a higher level policy role in place of the heavily transactional nature of its weekly agenda. The proposal was not acted upon, however, not least due to political concerns about loss of a major ministerial portfolio. There are two further "might-have-beens" connected with this episode. One is whether the proposal would have had more of a hearing had there been a change of government in 1997, with an incoming Prime Minister being less tied to the existing configuration of ministerial portfolios. The second is that Himelfarb was at TBS while Harder was developing his proposal. Later, as Clerk, he made some moves towards separating TBS policy and operational roles in the 2003 transition, but it can be speculated that he might have gone back to the issue of the role and organization of TBS, together with its relationship with PWGSC, had the Martin government returned with a majority after the 2004 election.

Later Treasury Board Secretaries have been more oriented towards making the organizational model they inherited work. One endemic question has been whether individual sectors of Treasury Board management policy should be set up as agencies separate from TBS but still reporting to the Treasury Board President and Ministers. The model was first tried with OCG between 1978 and 1993 and more recently was applied with the separate existence of OCG and a human resources management central agency

\footnotetext{
${ }^{93}$ Communications common services, which included advertising, public opinion research and sponsorship programs, had been a problematic area since the wind-up of Information Canada some 20 years before. In 1997, they were part of the newly-created Canada Information Office, which reported direct to the Minister of Public Works and Government Services and was largely beyond the influence of either the Deputy Minister of PWGSC or of TBS. Whether Harder's proposal would have headed off the events that led to the sponsorship scandal is of course a matter of speculation, but it was certainly addressing its institutional context. Harder was particularly aware of the political sensitivity of government communications, having been Joe Clark's Chief of Staff when he was the Leader of the Opposition in the early 1980s.
} 
between 2003 and 2009. (Although the two agencies are currently back in TBS, one legacy of the more recent experience is that the senior TBS comptrollership and human resources officers have been made deputy ministerial appointments under s. 6 of the FAA.) Organizational changes at that level are treated as Machinery of Government issues and together with the related senior appointments require decisions by the Prime Minister and Governor in Council, acting on advice from the Clerk.

In 2001, d'Auray, who had good access to both Claydon, her supervisor, and Cappe, the Clerk, asked Public Policy Forum (PPF) to conduct a study of whether the separate-agency OCG model should be adopted for the CIO, especially in light of the government-wide priority then assigned to GOL. After consulting TIMS and other government stakeholders, PPF concluded that a separate CIO central agency would not have the same weight as TBS and recommended that instead the CIO should make full use of the instruments available to it as an arm of Treasury Board, including the influence of TIMS - which included a number of senior departmental Deputy Ministers - and the network of horizontal committees linked to TIMS (Brown 2001a\&b).

The debate between Judd and Alcock over the Ontario model had elements of issues raised by both Harder and d'Auray. In a somewhat smaller institutional context (although the largest of the provincial governments), the Ontario Corporate CIO, located in the Ministry of Government Services but under the policy direction of Management Board, is stronger than its federal counterpart in at least four respects: it has line authority over the cluster CIOs serving the Deputy Ministers of government ministries; it has an operational role in approving IT budgets and major projects; the government's IT common services report to it; and it is responsible for government contracting in the IT and IM areas. Scott 
Campbell was the architect of this model as well as its first incumbent, and had he been brought into TBS could have been expected to move the CIO's role in that direction as well as to seek greater consolidation of IT-supported government services along the lines that had been attempted but failed more than once since 1993. This could well have set in motion larger issues about the relationship between TBS and PWGSC, but in the event was not to be. ${ }^{94}$

\section{Power and limitations of the CIO governance model}

There is no evidence that those deciding to set up a CIO in TBS saw this as the establishment of a new sector of public administration. At best it can be said that they believed that the management of IT and IT-enabled reform of administrative services and service to the public deserved more attention and that creating a high-level leadership position was one way of providing it. Organizationally the CIO was on the same level as the senior TBS officials responsible for human resources, comptrollership and administrative policy, with the first CIO holding the personal rank of a deputy minister. On the other hand, the initial responsibilities of the $\mathrm{CIO}$ were as much in the nature of a project office as of the leader of a government-wide functional discipline, creating a running tension between the roles of change agent and of asset manager.

Over time the logic of the Treasury Board policy model, combined with the agenda and relationships inherent in the substance of the CIO mandate, have defined an administrative territory that has assumed the characteristics of a sectoral institutional

\footnotetext{
${ }^{94}$ Without wishing to be unduly speculative, there is also a "might-have-been" had the "OCG" model been in place for the CIO when Alcock became Treasury Board President. It might have been easier to bring in Campbell - presumably as a Governor in Council-appointed head of a small central agency - but it would have been more difficult to introduce the full Ontario CIO model, which includes functions found in other parts of TBS, notably in OCG.
} 
environment. The elements of this territory and the major institutional relationships that it carries with it are explored in chapter 4 , as are issues that they raise for public administration. An underlying theme, however, is that the sector is still emerging and that its institutions and relationships are still at a lower level of institutional maturity than its administrative counterparts in the areas of comptrollership and human resources management. An important element is the governance context for the $\mathrm{CIO}$ and the role it plays in public service governance. The emergence of that governance context has been the focus of this chapter.

The only organizational constant about the CIO since 1993 has been that it reports direct to the Secretary of Treasury Board. Just about everything else has changed, in some cases frequently, including the CIO's status, role and mandate, and its relationship to the wider public service governance environment and agenda. Some patterns are discernable with respect to these factors, as well as the backgrounds, priorities and personalities of the major actors, including but not just the CIOs themselves. ${ }^{95}$

One set of factors concerns the powers, organizational location and status of the $\mathrm{CIO}$ within the central agency galaxy. The $\mathrm{CIO}$ operates primarily under the general administrative powers in s. 7 (1) (a) of the Financial Administration Act. As discussed in chapter 4 , it does exercise statutory authorities under other legislation, but these have less weight than other areas of TBS, in a public service heavily conditioned by administrative legislation. The CIO therefore relies primarily on organizational location and policy and political support for its impact. Having a stable reporting relationship with the TB

\footnotetext{
${ }^{95}$ A lesser but still important factor is office location. In 1993, the CIO and IMST were mainly housed in former OCG offices in the Esplanade Laurier in downtown Ottawa, home to most of TBS along with the Department of Finance and the Public Service Commission. Early in d'Auray's tenure CIOB was moved to a shopping centre in Ottawa's West End, some distance away. The CIO has kept offices in both locations, but CIOB's physical separation has compounded the difficulty of cementing its role as a central agency.
} 
Secretary gives the CIO sustained access to that individual and their authority within the system. It also gives the CIO a seat at the TBS senior management table and ready access to the Treasury Board President and to Treasury Board at its weekly meetings. However, the fact that since Macdonald the CIOs have had a personal rank below that of Deputy Minister (DM) has imposed a limitation, especially in comparison to the Comptroller General and Chief Human Resources Officer (CHRO), who are of DM rank, as are most of the second-level senior positions in PCO and the Department of Finance. At the same time, CIOs since Macdonald have been at the same level as the heads of GTIS/ITSB and junior to the heads of Library and Archives Canada, adding an additional challenge to their ability to provide leadership to their primary common service organizations.

Lower rank - both of the person and of the position - is a limitation in the statusconscious public service for at least two reasons. One is that DMs are appointed by the Governor in Council, on the recommendation of the Prime Minister but with a decisive say by the Clerk. In federal government organizational doctrine this creates accountability to the Prime Minister (Osbaldeston 1989) and in practical terms a relationship with the Clerk, who also signs off on their performance appraisals and pay.

In addition to being involved in DM appointments and appraisals, the Clerk also assigns DMs to interdepartmental committees working on government issues, and most DMs attend a weekly breakfast meeting with the Clerk. These are contacts missed by the CIO, whose appointment is made by the TBS Secretary under Public Service Commission rules. The same is true for CIOs on interchange, who have been treated as Senior ADMs - the formal level of the CIO position - although paid a great deal more. This deficiency was compensated while TIMS was in operation, made up of DMs 
assigned by the Clerk and with a strong orientation to meeting the needs of government programs. Some sponsorship has been provided by advisory committees to the Treasury Board Secretary since TIMS and its successor STAC were wound up, but their agendas have been more administratively oriented, going beyond the CIO's domain.

A more fundamental set of factors affecting the CIO's standing and effectiveness concerns linkages to the government's agenda. The process for appointing Deputy Ministers carries with it a sense of ownership for the individual and their activities by the Clerk on behalf of the government. Deputy Ministers frequently receive mandate letters from the Clerk conveying the government's priorities in their area of responsibility but also providing the government's backing in carrying out that mandate.

While these issues of personal status and access are important, their absence can be outweighed by other tangible forms of endorsement by the government. This includes inclusion of initiatives by the CIO in high-level statements of government priorities such as Speeches From the Throne and the annual Budget. Typically these are backed by endorsements by Cabinet (as distinct from Treasury Board) and can be reflected in government-wide modernization initiatives sponsored by the Clerk and the Clerk's annual report to the Prime Minister, a public document.

The CIO has had this level of backing on two occasions, Year 2000 and GOL. The former case was probably the only one where the CIO played a lead role in obtaining the needed government support, although it was very much with the support and backing of the Treasury Board Secretary and TIMS. GOL, on the other hand, with its two Speech From the Throne references and additional Budget funding, was the product of something like a political perfect storm, driven in the first instance by Industry Canada's Connecting 
Canadians agenda, playing off the IHAC reports, but including strong backing from the Minister of Finance, the Clerk and PMO, ultimately to persuade an agnostic Prime Minister that these were desirable measures as good public policy, in both a political and an administrative sense. GOL required skilled follow up by two CIOs, one externally recruited and the second internally, who were selected with the GOL agenda in mind, but GOL is the only instance where there has been this winning combination. Macdonald's Blueprint might have attracted some such backing but it was not taken to Cabinet, was overtaken by Program Review and ultimately was subsumed into GOL.

A third set of factors relates to the substantive administrative "territory" covered by the CIO's mandate and its role within that territory. The substantive dimension has several elements. In the Treasury Board model, the most basic role is the administration of a set of Treasury Board policies, which as chapter 4 discusses constitute operational programs in their own right. CIOs have gone through several incarnations with respect to the policies for which they are responsible, the diligence with which they have administered those policies, and the centrality of policy administration to their mandate. Apart from the management of IT policy, the original CIO configuration did not see itself as having a significant policy role, and this general ethos continued even after the CIO acquired a substantial suite of information-related policies. Over the better part of a decade, the policy management role was gradually submerged, then largely off-loaded and eventually partially repatriated. Policy management is now seen as a central vocation of the $\mathrm{CIO}$, including with respect to information management, which is now regarded as a priority CIO concern although not yet fully reconciled with the management of IT. ATIP and all dimensions of security policy are also accepted as core CIO concerns, 
somewhat warily in the case of Access to Information (see chapter 5). Along the way, the $\mathrm{CIO}$ has gained and then lost a role with respect to the Communications policy and twice has gone through a full cycle of acquiring policy responsibility for service to the public and then losing it to another part of TBS. More recently it has gone through a similar cycle with respect to policy for administrative services to government, although both service areas have recently returned to the CIO.

While the policy role has to a considerable extent been determined within TBS, at times influenced by the CIO's personal background and orientation, a more complex dynamic relates to the CIO's role as the government's senior technologist. This has two dimensions: whether the CIO should personally be trained in an IT-related discipline, such as computer science or engineering; and what role the CIO should play both in providing technical advice to senior levels of government and in leading governmentwide processes of organizational reform and transformation (both versions of the technician vs. layman and the "on tap or on top" questions). A partial answer to the question of technical background is that the key issue is whether the CIO is a credible source of technical advice to government decision-makers. It helps for a CIO to be personally conversant with technical issues, but by virtue of its position in the system the CIO can also bring high level IT expertise into CIOB and can draw on PWGSC, where the heads of GTIS and ITSB have all been engineers or IT specialists. Indeed, while two of the CIOs or Acting CIOs drawn from the career public service (Macdonald and Bruce) had IT or engineering training, all of the public servants have arrived at the position through a combination of substantive and generalist managerial experience. D'Auray, arguably the most successful CIO to date, owed that success at least in part to her ability 
to work with the government's policy process as opposed to her substantive knowledge, which was in any case more oriented towards content than wiring. At the same time, four of the CIOs serving for a total of eight years have been brought in precisely for their technical expertise and in spite of their more limited familiarity with government.

This leads to the issue of whether the CIO should play an innovation and change agent role, going beyond simply keeping the technology infrastructure up to date and well managed. All CIOs have seen themselves as prepared to play this role, although the ones who have come closest to it in a government programmatic sense have done so because they were working with a broader mandate (notably d'Auray and to a lesser extent Macdonald) or IT issues were seen as having government-wide importance (LizotteMacpherson). The resulting picture is somewhat circular: ensuring professional management of the IT plant is a default position; the ability to deploy it in support of a wider government agenda has largely depended on demand from the senior public service and political levels, who have not always had enough expertise, interest, or perhaps necessity, themselves to ask for the CIO's help; CIOs with the skills to market their sector's wider potential have tended to be the career generalists, while the trained technologists have tended to be outsiders who have sometimes had difficulty penetrating the bureaucratic culture but have recognized expertise. The current situation presents an interesting variation: a technologist outsider (Charette) is reporting to a generalist former CIO (d'Auray), working under the lead of a Clerk who - for the first time since the Glassco report - is also a former TB Secretary; time will tell whether this is a winning combination to achieve significant change in areas that are administratively important but below the political radar, such as services to government. 
Yet another aspect of the CIO role has been their relationship to the leverage available to other areas of TBS and the central agencies. No CIO has had direct authority over the government's IT capital budget and only once has the CIO led a comprehensive study of IT spending in government. Basic steps are still being taken on identifying IT costs (Canada TBS 2010e), and IM costing is even further away (see chapter 5). Practice has varied as to the extent to which CIOB is involved in briefing the TBS budget office or Treasury Board ministers on IT proposals from departments, although this has become more systematic. Similarly, $\mathrm{CIOB}$ has developed a more structured role in commenting on departmental management performance in major IT projects, and it is also involved in oversight of IT contracting, although OCG has the TBS policy lead in both areas.

Ultimately the test is whether the CIO is able to mobilize their environment. At a basic level, the environment is the functional IT and IM sector in which the Treasury Board model assigns the $\mathrm{CIO}$ an in-built leadership role, but in the right circumstances it can be the entire government in a way that carries the CIO beyond incremental evolution and into something more like the higher-level transformation promised by the gurus. A final variable, then, is the personality of the individual $\mathrm{CIO}$ and their ability to work with the governance environment they have been given. While training and acquired experience are important, this combines with less tangible attributes such as leadership which takes a number of forms in the digital environment (Borins and Brown 2007b) and especially entrepreneurship. It includes an understanding of the leverage available from the position, both formally and informally, and an ability to use that leverage pragmatically, even opportunistically, while pursuing longer term policy and program goals. Some CIOs appear to have been constrained by their circumstances, while others 
have had a more favourable set of conditions to work with. Either way, the more successful CIOs have also been able to make their own luck.

\section{Conclusion}

Two questions were raised earlier in this chapter: how the federal government CIO case fits with e-government literature that has sought to identify the elements of a successful government IT function; and what insights are provided by the application of theories of institutional continuity and change. The account of the establishment and evolution of the CIO offers some answers to both questions, in particular the first.

The CIO fits well with the models proposed by Borins and Wolf, Culbertson, and Dunleavy et al. This is not entirely surprising as all three included the TBS CIO in their evidence base, in particular Borins and Wolf whose analysis was mainly based on the pre-GOL federal CIO. The TBS CIO illustrates many of the characteristics that they argue contribute to the strength or weakness and to the success of a government CIO. Among the common features of the three models are the importance they attach to integrating the CIO into the larger governance environment and to political sponsorship for the CIO's agenda and a supporting institutional context, including from senior central agencies and empowered interdepartmental committees.

All three authors point to the CIO's limited budgetary role as a major source of institutional weakness. They argue a CIO should have significant influence over the IT capital budget and an ability to create incentives for departments to follow the CIO's lead. This is a continuing CIO structural limitation, although the CIO's access to supplementary, essentially investment, funding was a factor in the success of GOL. None 
of the models, however, offers insights into how the budgetary and other constraints on the CIO can be overcome or the role played by the inherited institutional environment, especially one as well established as the Treasury Board model. Indirectly all three suggest that it is at least partly a matter of organizational culture: overcoming a silo mentality and institutional disincentives to horizontal collaboration in order to realize the potential of IT (Borins and Wolf 2000); demonstrating the potential of IT and overcoming barriers to change (Culbertson 2004); and overcoming the dis-integrating legacy of New Public Management (Dunleavy et al. 2006). A critical role for the CIO in any model is its ability to provide technical leadership in ensuring that IT projects are well managed and that problems of technological incompatibility and risk are overcome.

In the final analysis, all three studies agree that the internal dynamics of government are not enough to explain the role and impact of the CIO and that the relationship with the external environment is also important. Borins and Wolf and Dunleavy et al. both stress the importance of the procurement relationship with the private sector IT industry and the relative strength of the industry on the one hand and the internal IT capabilities of government on the other. Dunleavy et al. in particular paint a mixed picture of the federal government in this regard, with the success rate of major projects and IT management capacity in major departments as points of strength but vulnerabilities arising from dependence on legacy mainframe systems and the structure of the Canadian IT industry. Culbertson goes in a slightly different direction by emphasizing the importance of the linkage between the $\mathrm{CIO}$ and the government's economic development objectives, no doubt having in mind the role played by IHAC in spawning GOL, but also provincial government experience. 
The CIO case offers support for mid-level theories of continuity and change. The central decision in the case study - to create a CIO position in the circumstances of a short, sharp period of substantial change in organizational design and leadership of the government as a whole - is a nice illustration of a policy entrepreneur (Macdonald; two entrepreneurs if Clark is included) taking advantage of an externally-driven window of opportunity (the Campbell reorganization at the time of a change of Prime Minister) to bring to the fore an emerging agenda (IT and IT-enabled services to the public and government) based on linking together previously unconnected ideas and interests (different administrative and professional disciplines, views on potential uses of technologies, different strands of technology) that had been gaining prominence and establishing linkages as a result of forces operating in the larger economy and society (ICTs). The IHAC process and its follow-through to GOL can also be characterized as a policy equilibrium punctuated by points of change driven by forces that were external both in an institutional decision-making sense (central agencies and annual Budgets) and in a broader environmental sense (again, ICTs).

These examples relate to policy agendas and decision-making. In the context of the Canadian Westminster and Treasury Board models they link to the issue of institutional continuity and change when the policies are about institutions, especially government institutions that have legal, programmatic, human and material bricks and mortar form. Institutions also represent a longer-term time-frame than other forms of public policynot that policies and programs cannot endure but that institutions are intended to endure. At the same time, these change models are not deterministic, nor is change simply in response to random or external factors. They include a structured capacity (the machinery 
of government function) to consider institutional design issues from a perspective that links policy, administrative and ultimately political considerations. They also include a set of rules of the game (the role of the Prime Minister and of government transitions), combined with an organizational culture that regards such transitions as opportunities to renew institutions at both systemic and sectoral levels and through that to set the context for renewing policy frameworks and programs in the various sectors of public policy.

These are not, however, complete answers to questions about the nature of successful governance of e-government and about institutional continuity and change. This chapter is particularly focused on change dynamics over time, amounting to half a generation. While these are important, they do not provide the full story. In particular, the focus on the evolution of the CIO within the Treasury Board model does not address a second dimension that is also important: the new functions and agendas of public administration and the new relationships and combinations of relationships that have resulted from the change. In other words, this chapter is largely concerned with the process world shaping the $\mathrm{CIO}$, and related personalities, but a full understanding of the position and its impact also needs to look at its substance. That is the subject of chapter 4 , which offers an extensive view of the sector defined by the CIO, and of chapter 5 , which looks more intensively at information management, its most challenging component. 


\section{Chapter 4 - The New IM/IT Institution}

The Government of Canada's Chief Information Officer_has the responsibility for leading the government-wide pursuit of excellence in service delivery and in the management of information and technology for Canada.

(Treasury Board Policy Framework for Information and Technology

Canada TBS 2007b)

The Chief Information Officer (CIO) has taken root as a new component of the Treasury Board model and shows every sign of becoming one of its enduring features. Treasury Board and Treasury Board Secretariat (TBS) have absorbed the CIO with relatively little apparent disruption to their basic assumptions and methods of operating; the process of integration has been decidedly more difficult and disjointed from the perspective of the CIO. This speaks both to the deeply entrenched nature of the Treasury Board model (but also its capacity for adaptation) and to the novelty of the CIO and the management of ICTs in the administrative context. The novelty arises partly from the individual elements of the CIO's domain - although many of them have been part of public administration for some time - but especially from the combinations of substance and of working relationships inside and outside government that they give rise to. Cumulatively, these elements have broadened Treasury Board's work in ways that begin to push the boundaries of the Glassco model. They also signal the emergence of a new administrative institutional environment within the federal government and of a new sector in public administration. By its nature, this environment raises questions about the current understanding of the Canadian Westminster model, in particular its view of the nature and implications of collective accountability.

This chapter builds on a descriptive account from two perspectives. The first looks at how the Treasury Board model that grew out of the Glassco report - in particular its 
approach to managing the government as an entity and to ensuring consistent management practices (see chapter 2) - has shaped the approach to the management of ICTs as administrative concerns. As discussed in chapter 3, the CIO and the supporting TBS CIO Branch (CIOB) did not initially see themselves in terms of the administration of Treasury Board management policies, but in more recent years this has come to be one of CIOB's defining characteristics. The ambivalence within the Branch about a policy role mirrored a larger ambivalence within TBS in the aftermath of Public Service 2000, Program Review and later public service reform initiatives about its relationship with line departments and managers and the extent to which it should, or even could, attempt to regulate their management practices. Prodded by the Auditor General and the Harper government's approach to accountability, the outcome in recent years has been an effort to refresh the entire "suite" of Treasury Board policies, making the resulting policies more consistent and integrated with each other and also more intentionally administered.

Two consequences of this renewed focus on management policies have been to reinforce the basic dynamics of the Treasury Board model and to bring the CIO and its policy concerns into the TBS mainstream. In recent years, all but one of the Treasury Board policies for which the $\mathrm{CIO}$ is currently responsible have been updated, and both TBS and the CIO have taken ownership for them. The policies have not fundamentally changed from their pre-CIOB structures and requirements, but they are less integrated with each other in their current design and administration. They are more central to the CIO'S work, however, and taken together they define a substantial area of government activity - an IM/IT (Information Management/Information Technology) "space." The first major section of this chapter reviews this space, looking at the content of the policies 
and the roles they assign to the CIO. As chapter 3 has described, however, the boundaries of the IM/IT space have been fluid since 1993, and there are two policy spheres for which the $\mathrm{CIO}$ has been responsible in the past but is not currently. These are government communications and the related Federal Identity Program. Now organizationally separate from the CIO, they are closely related and are included in the IM/IT space.

This chapter's second concern is the CIO's working relationships, growing out of the substance and nature of ICTs. It is in this area in particular that the CIO has moved beyond the traditional parameters of the Treasury Board model, which is focused within government. The IM/IT space draws the CIO into active relationships in three additional directions: with the citizen as a catalyst for administrative arrangements; with the private sector, as a partner and as a significant supplier of ICT-related goods and services; and with other jurisdictions as collaborators, both in developing management techniques and in dealing with the common external environment, in particular in providing services to the public. External linkages can be found in other sectors of public administration, but they are more extensive and central in the CIO's areas of concern.

Taken together, the ICT-shaped substance and external relationships define a new sector of public administration with characteristics that build on the traditional Treasury Board model but add new dimensions and challenges. The chapter's primary purpose is to sketch this sector's features, which are important in themselves. It is also concerned with the theoretical issues that the sector raises, in particular for the internal organization of government but also for the Canadian Westminster model, its larger context. These are outlined in the chapter's first section in order to provide a later reference point. 
The chapter's research base includes secondary sources, but it draws heavily on Treasury Board policies and other government documents and on interviews. In addition to the $11 \mathrm{CIOs}$ and Acting CIOs, interviews with a substantial component addressing issues in this chapter included 9 interviews with CIOB and other TBS policy centres, 6 with departmental CIOs, 6 with PWGSC managers, 5 with Service Canada and service policy units, 6 with private sector managers and consultants, 7 with national associations and conference organizers, 7 with provincial governments and intergovernmental networks, and 3 with Parliamentary commissioners' offices. The majority of those interviewed had experience in more than one of these areas, for example a total of upwards of 30 had had private sector experience at one time or another.

\section{The Treasury Board model and collective responsibility}

As articulated by the Glassco commission (Canada Glassco 1962), the Treasury Board model is concerned with the management of the federal government as a single entity, raising a corollary question: when should there be a common administrative regime in the departments and agencies coming under the authority of responsible ministers, and to what end? Answers have varied over time, but a common thread has been a policy-based approach in which Treasury Board ministers have set a common framework of goals, procedures, delegated authorities and corresponding accountabilities in each of the areas of administration where it has been judged desirable. This approach, which Glassco considered represented private sector best practice and to be preferable to the earlier, more directive Comptroller of the Treasury, has proved to be well suited to the Treasury Board model and has been a central feature of federal administration in the 
half century since it was introduced. The first part of this section summarizes the elements of Treasury Board policies and how they are administered.

Lying behind the Treasury Board policy model is a doctrine of collective ministerial responsibility that is part of all versions of the Westminster model but more highly developed in its Canadian variant. The historical reasons for this more collectivist orientation are discussed in chapter 2, and they are reinforced by the existence of Treasury Board as a statutory expression of collective ministerial management $-\mathbf{a}$ uniquely Canadian arrangement within the Westminster family. Even so, collective responsibility has always been difficult to reconcile in practice with the individual responsibility of ministers to Parliament, the other foundation-piece of the Westminster model, and events in recent years have tended to emphasize individual responsibility. At the same time, the environment shaped by ICTs has given a new emphasis to collective dynamics, and the second part of this section considers some of the issues relating to collective responsibility. The third part looks at the "three rooms" organizational model that arises from the collectivizing forces of ICTs - from the fact that a networked environment lends itself to an integrated approach to managing the entity which can also lead to its rationalization and restructuring. The federal government has begun to move in that direction, representing tentative steps towards its re-collectivization but also requiring a renewed focus on the theory and practice of collective responsibility.

\section{The Treasury Board policy model}

The Glassco commission's recommended approach was defined by both what it was and what it was not. It sought to replace the "costly, frustrating and unproductive" (Glassco 1962 1: 50) Comptroller of the Treasury model, under which officials from that 
office, which reported to the Minister of Finance and indirectly to Treasury Board, were physically located in departments and played a role both in approving the release of funds for departmental purposes and in auditing their use after they were spent. The first task of the new system was to roll back the proliferation of controls and meet the needs of departmental administration, giving it the appropriate management tools (49). The "needs of central direction [should be] designed to protect those general interests of government which transcend departmental interests" (51), but go no further.

Glassco did not spell out how the new system should work but did sketch the broad outlines, mainly in organizational terms. Retaining the Treasury Board committee of Ministers, the commission recommended that it be headed by a full-time President with the task of ensuring "that general considerations of good management find adequate expression within Cabinet" (54). A major role of Treasury Board, acting on delegation from Cabinet, was to adopt policies and standards governing departmental administration in the areas of central concern. These policies were to be in the three areas of general administration, personnel, and administrative improvement, ${ }^{96}$ as elaborated in Glassco's five volumes and 24 reports. An important part of any policy would be to spell out the roles to be played by key actors: common service organizations meeting common needs in support of the unity of the public service (57); Deputy Ministers and Assistant Deputy Ministers (i.e., the senior managers of government programs); and the senior administrative officers - in particular the senior personnel and financial officers - who

\footnotetext{
${ }^{96}$ These are the three categories of administration in the organizational structure proposed in ch. 6 of Report 1, "A General Plan for Management." A slightly different list can be derived from the three Reports in the balance of Volume 1, which sets up Glassco's general framework. These addressed Financial Management, Personnel Management, and Paperwork and Systems Management. Although the original configuration of the post-Glassco TBS was closer to the structure proposed in Report 1, the modern-day structure of the Comptroller General, Chief Human Resources Officer, and CIO comes much closer surprisingly so - to the rubrics created by Reports 2,3 and 4 .
} 
had a dual role of working in and for the department while also being the "presence" (61) of central authority.

After it was reconstituted in 1966, Treasury Board began to issue policies governing the various areas of management. These were consolidated in a Treasury Board Manual, a series of volumes structured around the management policy branches as they evolved. ${ }^{97}$ A major focus of Public Service 2000 was to eliminate unnecessary Treasury Board policies and to streamline and consolidate the rest. With the expansion of desktop computing and the government intranet, the policies were moved into electronic and then database format by the late $1990 \mathrm{~s}$, leading to further efforts to rationalize and integrate them. Another factor was continuing pressure from the Auditor General to ensure that expectations and accountability mechanisms were clearly spelled out for policy users and enforced by TBS.

In the aftermath of the Harper government's 2006 Federal Accountability Act, a Framework-based approach was adopted in 2007 for structuring and reviewing what has come to be called the Treasury Board Policy Suite (Canada TBS 2007a). Most policies directly related to the CIO have been updated, although in some cases implementation is being phased in. A Foundation Framework for Treasury Board Policies (Canada TBS 2008a) provides the over-all structure. It sets out the guiding philosophy for Treasury Board policies and links them to generic accountability requirements placed on Ministers and Deputy Ministers (Canada PCO $2011 \&$ 2003). Stating that Treasury Board policies may serve one or more of the general purposes of ensuring a consistent management approach across government, managing significant risks, and putting into action public

\footnotetext{
${ }^{97}$ The forerunners of the current CIO policies were all in the Administrative Policy Manual (APM), which continued until its sponsoring branch, the Administrative Policy Branch, was wound up in 1994.
} 
service values, the Framework sets out a taxonomy of policy instruments, distinguished by their expected audience and by whether their application is mandatory rules or voluntary best practices. Mandatory instruments are divided into a hierarchy of policies (largely directed at Deputy Ministers) and directives and standards, which focus on departmental managers and functional specialists. Best practices instruments are divided into guidelines and various working tools. Policies may have some, all or none of the other types of instruments associated with them.

Most policies come under one of seven areas of management, each with its own Framework Policy: financial, people (human resources), information management and information technology, assets and acquired services, service, compensation of employees, and official languages. An eighth Framework governs the expenditure management (i.e., budgeting) process, while two others address risk and compliance management - both of particular interest to the Auditor General. When the Policy Suite is fully in place, it is expected (Canada TBS 2007a) there will be 252 Treasury Board policy instruments within the 11 Frameworks, including 44 Policies, 100 Directives, 61 Standards and 47 Guidelines, all following a more or less standard template. The most important are the policies, which lay out general expectations, mandatory requirements and accountabilities of key actors, and monitoring and reporting requirements. Key actors typically include TBS itself but also Deputy Ministers, managers and functional specialists in departments, as well as "lead agencies" that provide mandatory or optional common services, set standards, or play other specialized roles in the administration of a policy. All policies are linked to Treasury Board authorities under the Financial Administration Act (FAA), and many are linked to the 20-odd other statutes that TBS 
operates under and to the even larger number of statutes and statutory instruments that public sector management takes into account.

Most Treasury Board policies apply to the institutional universe of government departments and agencies under direct ministerial authority, but some have wider application, including to Crown Corporations. These include policies relating to federal identity and official languages. Every policy and related instrument has a responsibility centre within TBS that manages the policy, including working with the functional communities and lead agencies defined by the policies. In that sense the policies represent horizontal management programs that cut across government, with the TBS responsibility centres as their leaders. Although recently refurbished, this policy management model has operated in very similar terms since the late 1960s and provides the foundation for the work of the CIO and CIOB.

\section{Collective responsibility in Canada}

Collective responsibility and accountability ${ }^{98}$ are integral features of all versions of the Westminster model. While individual ministers are assigned the powers to manage government departments and carry out government programs, major policy and resource allocation decisions are taken by Cabinet. When legislation or votes of non-confidence are introduced in Parliament, or when there is public controversy, Cabinet solidarity is invoked to support a ministerial colleague. The ministry is appointed by the Crown as a group and the government stands or falls in the House of Commons or before the

\footnotetext{
${ }^{98}$ In this discussion responsibility and accountability are used as distinct terms - the same elements can be found in each but there are significant differences in emphasis. Responsibility is the more basic term and focuses on span of responsibility (ministerial "territory" or mandate) and related authority. Accountability emphasises the process for holding a minister or other office holder - including officials - to account for the exercise of authority or achievement of expected results. The Gomery commission and other recent discussions of the accounting officer principle (e.g., Aucoin and Jarvis 2005) suggest that Ministers are responsible to Parliament, while officials are not, but officials are accountable in the sense that they are expected to answer questions about their executive actions.
} 
electorate as a group. Notwithstanding this collective dimension, however, constitutional practice focuses on the day-to-day responsibility and answerability of ministers individually to Parliament for their own actions and those of their officials. In its most concrete form, departmental spending Estimates and Public Accounts are defended by the responsible minister, and parliamentary questions are directed to them individually.

There is, however, considerable variation among Westminster systems in the degree to which the collective dimension is institutionalized and the formality of the concept of collective responsibility. Whereas in Britain the collective dimension is largely a matter of constitutional convention, often underpinned by the exercise of the Royal Prerogative, ${ }^{99}$ in Canada it has been institutionalized to a considerable extent, supported by explicit constitutional doctrine. How this came to be is discussed in chapter 2 , but the resulting elements include: Treasury Board as a statutory committee of the Queen's Privy Council for Canada (itself a statutory entity); extensive use of the Governor in Council to enact secondary legislation and make appointments (in the UK, these are largely in the hands of individual ministers); and the use of legislation to establish government departments and agencies and also to regulate management practices - both areas where in the UK Parliament is not involved. The Glassco commission broadened and deepened this institutionalized collectivism with its focus on the needs of departmental administration and of central direction as two parts of an integrated whole, embodied in the three-fold organizational taxonomy of vertically-organized program departments, central agencies supporting (horizontal) collective decision-making, and common service organizations supporting collective needs although vertically structured like line departments.

\footnotetext{
${ }^{99}$ i.e., residual discretionary powers of the Crown that have not been circumscribed by legislation.
} 
The resulting Canadian accountability model necessarily gives more explicit weight to collective mechanisms, especially in the realm of public service management. At one level these are relatively straightforward. The focal point for management accountability is the departmental Minister and Deputy Minister, who together are given a package of authorities from a variety of sources, including departmental statutes, delegation from Treasury Board and collective management statutes, ${ }^{100}$ and policy direction from the Prime Minister and Cabinet. In turn, each of these authorities creates a line of accountability to its source - in many areas to collective arms of the executive, notably Treasury Board but also the Prime Minister and even Cabinet committees. ${ }^{101}$ The situation becomes more complex, however, when the chain of accountability is extended to Parliament; at its most basic, the question is which minister answers when a management problem is found - the Minister of the department where the problem occurred or the President of the Treasury Board, who set the rules and oversees their implementation? There is no single answer and it is an issue that Parliament, the Auditor General and Treasury Board have wrestled with for some time (e.g., Canada Auditor General $2001 \&$ 2004). The Foundation Framework for Treasury Board Policies and its associated Framework for the Management of Compliance are among the more recent attempts to codify the situation.

\footnotetext{
${ }^{100}$ An exception is delegation of appointment authority from the Public Service Commission and the Public Service Employment Act, which is to Deputy Ministers only, in order to protect public service appointments from political patronage. Generally, however, the distinction between Ministers and their Deputies is not their formal powers but their manner of appointment, which creates different accountability dynamics. ${ }^{101}$ See the study by Gordon Osbaldeston, then a recently retired Clerk of the Privy Council, on the many dimensions of the accountability of Deputy Ministers, as it is understood in the federal public service (Osbaldeston 1989). With each incoming Prime Minister, Privy Council Office prepares updated guidance documents for Ministers and Deputy Ministers on a variety of issues, including collective and individual responsibility. For the current versions, see Canada PCO 2011 (Ministers) and 2003 (Deputy Ministers).
} 
A major influence on current thinking about accountability has been the Gomery commission report on the sponsorship scandal (Canada Gomery 2006) and the subsequent Federal Accountability Act [S.C. 2006, c. 9], which have sought to accentuate individual lines of responsibility to Parliament, and within that to highlight the accountability of the Deputy Minister as Accounting Officers. This approach was based on the perceived failure of the Deputy Minister of Public Works and Government Services (PWGSC) to control the activities of the common service organization that administered the sponsorship program. It has not addressed the fact, however, that policy direction for common services comes from central agencies and collective Ministerial decision-making, in contrast to line departments where policy and operational responsibility both lie with the departmental minister. In the case of the sponsorship program, the responsible unit was only for part of the time housed in $\mathrm{PWGSC}^{102}$ and throughout the piece policy direction came from an opaque combination of the Privy Council Office (PCO) and the Prime Minister's Office (PMO) in support of the ad hoc Cabinet Committee on Communications, with managerial authority for sponsorship activities coming from Treasury Board's Government Communications policy. ${ }^{103}$

\footnotetext{
${ }^{102}$ From 1996-1997 and again from 2001-2004, administration of the sponsorship program came under the Canada Information Office which reported to the Minister of Public Works and Government Services separately from the department and Deputy Minister (O'Neal 2004). Even when it was nominally part of PWGSC, the head of the sponsorship program had established an independent reporting relationship with the Minister, who for much of the time was also chair of the Cabinet Committee on Communications and as such advised by PMO and PCO. Since the Martin government wound up the Canada Information Office, the responsible unit has been clearly part of PWGSC and under the administrative authority of the Deputy Minister. But for much of its work, which also includes administering advertising and public opinion research common services - all under authorities provided by the Treasury Board Communications policy it continues to take policy direction from the Cabinet Operations Committee, the successor to the $a d$ hoc Communications Committee. How this arrangement is working in practice is an area for further research. ${ }^{103}$ Two Gomery Commission research studies did discuss collective accountability. Bourgault (2005: 279) echoes Osbaldeston in noting the diverse sources of Deputy Ministerial authority and therefore of their accountability. Smith (2005) looks at collective accountability as part of a wider discussion of ministerial responsibility. Notably, he states that the doctrine privileges individual over collective responsibility, as "only by doing so can the relationship between ministers and deputy ministers be explored" (106), adding
} 


\section{Three rooms}

The inherent tension between the treatment of collective accountability in the Canadian Westminster model and recent debates about accountability is heightened by ICTs. Through their ability to link entities and individuals in ways that cut across the standard organization chart, ICTs are seen by commentators as having transformative potential, leading to what has been described as IT-enabled government (Borins 2007a) or even digital-era governance (Dunleavy et al. 2006). Borins describes structural changes resulting from the widespread adoption of ICTs, both in the public service's internal organization and in its external interfaces with society in its various guises of voters, interest groups and users of government services, and with suppliers of goods and services to government. In the context of Government On-Line (GOL), Charih and Robert (2004) conclude that organizational issues arise in dealing with the public and internally to government. The external dimensions are discussed later in this chapter. Within the public service, Borins argues that ICTs will reshape the traditional departmental model, in a sense rotating it on its axis. Traditionally, each department that delivers programs and services to the public has three types of capacities: a policy development core; an operational capacity to deliver services to the public; and administrative support (acting within the framework of Treasury Board policies). Each public policy-defined department deals with the public through its own service channels and with suppliers of goods and services through its own supply arrangements.

that ministerial authority monopolized protects authority, while ministerial responsibility shared depreciates it (109). However, neither these studies nor the report itself explore the implications of this bias towards individual accountability in the context of communications common services specifically or of collectively structured management authorities more generally. 
Borins states that ICTs potentially bring about integration in all three dimensions. The ability to provide single- window services organized around the citizen (rather than programs) - with on-line services linked to in-person and other service channels through electronic networks and common databases - provides the basis for integrated service delivery. In the IT-industry literature this is often referred to as the "front room" or "front office," which can be a distinct organization or part of one organization but providing services on behalf of several. Similarly, support services to government can be integrated in a "back" room or office, providing both a single source of administrative support to more than one department and a single purchaser in obtaining services from the private sector. Again, this can be a separate organization or part of one organization providing services to others. The most enduring element of the traditional model is the middle room or office, the policy component, which defines a policy sector and is linked to a portfolio Minister (echoing Glassco's view that the first task of departmental administration is to advise the minister on matters of departmental policy - Glassco 1962 1: 49). Even the middle office can become more "joined up," achieving greater integration both in the design of policies and programs and in the knowledge base that informs them.

While Borins' three rooms model is idealized, government has taken steps in that direction. This is easiest to discern in the front office, where Service Canada fills an integrated role on behalf of several departments to provide services to individual Canadians. ${ }^{104}$ Canada Business, in Industry Canada, has a front-office function with respect to the business community, especially small and medium business, although its reach does not extend very far beyond its home department. Each organization is rooted

\footnotetext{
${ }^{104}$ See Flumian et al. 2007 for a discussion of the early years of Service Canada as an operational organization and some of the obstacles, not least political-level hesitation, to achieving its potential.
} 
in a single-window electronic Gateway sponsored by GOL; a question raised at GOL's conclusion in 2006 was whether they would overcome the challenges to integrated service delivery and channel integration (Kernaghan 2005) and become the catalyst for further organizational change across the full spectrum of services to the public (Brown 2007). Similarly, the perennial pursuit of stronger shared and common services indicates the potential for an integrated back office in both the IM/IT and other management areas where ICTs can help create a common administrative platform. In the federal government, such steps have met greater initial resistance than those with respect to the front office, but in many ways they build on the Glassco model's common service organizations and are given fresh urgency by renewed financial stringencies. ${ }^{105}$

\section{The Treasury Board model in practice - shaping the IM/IT space}

The allocation of Treasury Board policies within TBS assigns the CIO a defined IM/IT space ${ }^{106}$ on the Treasury Board map. This includes policies for which the CIO is currently responsible and those for which it has had responsibility in the past and with which it continues to work closely. There is also a perimeter of related management policies where there is a close relationship arising from the substance of the policies or the processes they govern. This section provides an overview of the varying degrees of CIO responsibility that arise from the logic of the Treasury Board policy model, although

\footnotetext{
${ }^{105}$ One source of earlier resistance was the view that full Deputy Ministerial accountability depends on their having complete control of all the administrative "factors of production" supporting departmental operations and the desire to tailor administrative environments to the programs they support. Interviews suggest that the resistance may be breaking down in the face of fiscal pressures and continuous technological change. The recent review of administrative services - housed in PCO and reporting to a Clerk who is also a former Treasury Board Secretary - can be seen in this context.

${ }^{106}$ The "IM/IT space" as discussed in this chapter is a construct of the dissertation and is not a terminology used by TBS. While this space can be identified empirically it is not understood normatively as a unified sector of public administration with its own characteristics; the dissertation argues that it should be.
} 
it devotes less attention to the outer perimeter. The next section considers relationships that arise from administration of CIO-related policies, especially outside government.

The IM/IT space, for the purposes of this chapter can be derived from the responsibilities spelled out in the relevant Treasury Board policies. It has three components. The first is responsibility for the policies themselves. Annex 6 lists the policy framework and the Treasury Board policies for which the CIO has lead responsibility, with the associated policy management units housed in the CIOB. It also indicates policies for which the $\mathrm{CIO}$ has been responsible in the past (Communications and Federal Identity Program - see chapter 3), as well as frameworks and policies that have an impact on the CIO's work - many are cross-referenced with CIO policies. Second, many CIO policies refer to legislation and statutory instruments, which in some cases the CIO policy is designed to implement and in others provide additional sources of authority or are taken into account in policy requirements. They include the Charter, 33 statutes (plus two referenced only in the Communications policy) and 5 regulations and statutory instruments. These authorities are listed in Annex 7. Third, most policies and many associated instruments assign "lead" roles to other departments and agencies with respect to specific provisions. In addition to TBS, which by definition has responsibilities under all Treasury Board policies, 14 government departments and agencies are designated as lead agencies under CIO policies; the Communications policy adds a fifteenth and also - unusually for Treasury Board policies - assigns an explicit role to 
Cabinet and Treasury Board ministers. The list of CIO-related government institutions is in Annex 8. ${ }^{107}$

\section{Current CIO policy responsibilities}

The CIO is responsible for administering seven Treasury Board policies. Four come under the Policy Framework for Information and Technology: policies on Access to Information, Information Management, Management of Information Technology, and Privacy Protection. The fifth and sixth, the policies on Government Security and on the Use of Electronic Networks, have a broader scope than IM/IT and are categorized by TBS directly under the Foundation Framework for Treasury Board Policies. The Policy Framework for Service Improvement in the Government of Canada fits the policy format least well and twice has been the responsibility of a separate TBS Service Sector, although it has recently returned to the CIO. The following discussion gives the flavour of the seven policies and how they fit together.

The Policy Framework for Information and Technology (Canada TBS 2007b) provides a strategic context for the Information Management (IM) and Management of Information Technology (IT) policies, although it also "takes into consideration" the two Access to Information and Privacy (ATIP) policies and the policy on Government Security. Noting the centrality of information to democratic governance, the framework articulates eight guiding principles: information as a valuable asset; IT as an enabler; stewardship of information and IT; a whole-of-government approach; respect for individual privacy; effective security of information; transparency in support of public access to information and accountability; and institutional bilingualism.

${ }^{107}$ The listings in Annexes 6, 7 and 8 are generated from the Policy Frameworks and individual policies listed in Annex 6. Many of the Directives, Standards and Guidelines list additional policy linkages, legislative references and lead agencies. This is therefore a conservative depiction of the IM/IT space. 
The Policy on Information Management (Canada TBS 2007c) is the cornerstone of the CIO IM/IT policies, putting into effect the information life-cycle model that provides the foundation for information management in the federal government (see chapter 5). Revised in 2007, it consolidated two earlier policies: the Management of Government Information Policy that was one of a succession of policies in this area going back to the early 1970s; and the Personnel Information Policy, which was introduced when the government decided to adopt a Personal Record Identifier rather than using the Social Insurance Number (SIN) to locate employee records. The policy's general objectives make clear that good information management is the responsibility of everyone (begging the rejoinder that it therefore risks becoming the responsibility of no-one) and that the preferred medium for record-keeping is electronic format. The policy's substance is conveyed in two supporting directives, one on record-keeping, ${ }^{108}$ focusing on records of "business value," and the other outlining roles and responsibilities under the policy. The policy assigns roles to TBS, Library and Archives Canada (LAC), Statistics Canada, PWGSC and the Canada School of Public Service (CSPS), the latter to provide policyrelated training, a role that CSPS is assigned under all the major CIO policies. The most important link is with LAC, which under its own legislation (Library and Archives Canada Act [S.C. 2004, c. 11]) is responsible for the long-term retention of government records that are no longer required by departments; as a result LAC also sets the rules for destruction and long-term disposition of records. Chapter 5 discusses the relationship between LAC and TBS, which has not always been easy.

\footnotetext{
108 "Records under the control of a government institution" are the focus of the Access to Information and Privacy (ATIP) Acts. They may be in any medium and are retrievable when requested under ATIP procedures. They are distinct from published material or material in the public domain, which is excluded from ATIP and covered by the Communications policy.
} 
The Policy on Management of Information Technology (Canada TBS 2007d) was also revised in 2007 and like the IM policy has forerunners that go back to the early days of the Administrative Policy Branch (APB) in the 1970s. Indeed, the two policies have always been, at least in principle, a matched pair, most recently coming jointly under the Information and Technology policy framework. In practice, the IT policy has undergone greater variation in its management, although it is currently enjoying a renaissance. The policy's stated goal is "efficient and effective use of information technology to support government priorities and program delivery, to increase productivity, and to enhance services to the public." Two major objectives are to link IT management to business planning in departments and to encourage sharing of IT resources within the government. In earlier incarnations, the policy was used to promote the development of the federal government's own set of IT standards to guide the acquisition of IT by departments, as distinct from using private sector or international standards. This is currently a less active component of the IT management program, but the CIO still administers a number of Treasury Board Information Technology Standards, known as TBITS. On the other hand, the IT management policy has in recent years been used as the starting point for a more active $\mathrm{CIO}$ involvement in the approval and monitoring of major IT projects, in particular ensuring that risk-based management frameworks are put in place. This has brought $\mathrm{CIOB}$ into a close working relationship with the project management policy centre in the Office of the Comptroller General (OCG) and its common service agent, the Acquisitions (contracting) branch of PWGSC.

The Management of IT policy provides the framework for the management of telecommunications and computing common services to government and is the primary 
context for the CIO's working relationship with PWGSC's Information Technology Services Branch (ITSB), which provides or obtains common services in these areas. Another ongoing concern has been the development of IT applications in support of other areas of administration, notably financial and human resources, and to consolidate those services, with periodic proposals to create a shared or common administrative services organization in PWGSC. Much less use has been made of the policy, however, to monitor IT-related spending in departments, a major preoccupation of the IT management policy centre before the establishment of the CIO (see for example Canada TBS 1993). ${ }^{109}$

In many respects, the Access to Information Policy (ATI) (Canada TBS 2008b) has been the most influential but also the most awkward policy in shaping the CIO's policy role. Revised most recently in 2008 , when its coverage was extended to virtually all federal government institutions including Crown Corporations in response to a Gomery recommendation, its provisions have remained generally constant since passage of the Access to Information Act [R.S. 1985, c. A-1] in 1983. Both the Minister of Justice and the President of the Treasury Board are designated as responsible minister for provisions of the Act; in Treasury Board's case this includes overseeing government records management standards, setting procedures for complying with the $A c t$, collecting statistics and prescribing the format for departmental annual reports to Parliament under the $A c t$. The President is also responsible for meeting the Act's requirement (s. 5) that the government publish at least annually a description of the responsibilities of all government institutions, the nature of the records and administrative manuals that they hold and the name and means of contacting the official in each institution to whom

\footnotetext{
${ }^{109}$ The 2008 CIOB-sponsored profile of IT services in the Government of Canada (Canada TBS 2008e) provides a useful picture of the government IT function but not spending figures.
} 
requests can be made for access to those records. The CIO is responsible for this document, known as InfoSource (Canada Info Source 2009a), and for summaries of statistics and court decisions relating to the ATI Act (Canada Info Source 2009b). Info Source is distributed to public and university libraries across Canada through the Depository Services Program administered by PWGSC (Canada PWGSC 2010).

In comparison with other Treasury Board policies, the most distinctive feature of the ATI policy is the mechanisms put in place by the Act to provide redress to unsatisfied requesters for government records and general commentary on the Act's administration. Modelled on the Official Languages Act [R.S. 1985, c. 31 ( $4^{\text {th }}$ Supp.)] the Act creates an Information Commissioner as a parliamentary ombudsman with powers to receive and investigate individual complaints, conduct systemic reviews of the administration of the $A c t$, and report to Parliament. The Commissioner has powers of investigation and publicity but is not able to order compliance by departments, being designed instead to provide ammunition for Members of Parliament to hold the government politically accountable. ${ }^{110}$ Ignored by Parliament for many years, the Commissioner's reports have since the Martin government been referred to the House Standing Committee on Access to Information, Privacy and Ethics, which has begun to hold regular hearings. A running concern of the Commissioners has been defining the boundaries of Cabinet Confidences (for which PCO has the policy lead), which are government records exempted from the $A c t$, and of the PMO and minister's offices, where the Supreme Court has recently decided that they too are excluded from the Act as they are not under the control of a

\footnotetext{
${ }^{110}$ There is a limited right of appeal to the Federal Court on procedural grounds. Another unique feature of both the ATI and the Privacy Acts is that decision-making authority for responding to ATIP requests is assigned to the Head of the department or agency, i.e., the Minister. Administrative authorities, especially in Treasury Board policies, are ordinarily assigned to the Deputy Head - the Deputy Minister. This formulation is an effort to make decisions to release or withhold records politically accountable, through the Minister's responsibility to Parliament.
} 
government institution within the Act's meaning (Canada (Information Commissioner) $v$. Canada (Minister of National Defence) [2011] S.C.C. 25. May 13, 2011). Chapter 5 discusses the $A c t$ 's political sensitivity, so it is sufficient to note here that as the policy centre for administration of the Act, the CIO is drawn into these issues and into building the capacity of the often beleaguered community of departmental ATIP coordinators.

The Policy on Privacy Protection (Canada TBS 2008c) was introduced at the same time as the ATI policy and designed to interlock with it. The institutional structure of the policy is the same, with TBS and Justice sharing roles under the legislation, the use of Info Source to assist in locating records, departmental ATIP coordinators to receive requests for access to records from members of the public, and a second Parliamentary officer, the Privacy Commissioner, serving as an ombudsman under the Act. The substantive dynamics are different, however. The Privacy Act's focus is personal information collected by the government, often coercively (in the sense that citizens are induced to provide information they might not otherwise volunteer). Based on OECD Privacy Guidelines (OECD 1980), a major concern of the Act is information that has been collected for one purpose being reused for another or linked with information collected for another purpose to form a profile of an individual. While the Act includes safeguards against abuse of these "secondary uses," the possibilities have been greatly increased with the expansion of networked computing and data bases and the use of data mining techniques. Privacy concerns have therefore become central to planning for major IT projects and infrastructure and are at the heart of tensions between the IT and IM worlds, in which IT specialists tend to see privacy as part of the problem - inhibiting the potential 
of data linking - and IM specialists to see privacy's systematic approach to collection and management of information as part of the solution.

The Information Highway Advisory Council (IHAC) report gave considerable weight to ensuring adequate privacy protection in the private as well as the public sector - sharing the public sector's experience with the protection of personal information was part of its contribution as a model actor on the information highway - and an important part of the follow up to the IHAC report, in parallel with GOL, was the introduction of the Personal Information Protection and Electronic Documents Act (PIPEDA) [S.C. 2000 , c. 5]. PIPEDA extended the privacy protection framework to the federallyregulated private sector and also clarified privacy protection for electronic documents in both the public and the private sectors; in addition the Privacy Commissioner was given a redress role under PIPEDA, and as part of its implementation both the Commissioner and Industry Canada, which is responsible for PIPEDA, have had ongoing consultations with their provincial counterparts to ensure alignment of the federal and provincial privacy regimes. These developments have in turn brought the $\mathrm{CIO}$ into collaboration with Industry Canada as well as the various provincial agencies dealing with privacy issues. ${ }^{111}$ The Policy on the Use of Electronic Networks (Canada TBS 1998) was developed in response to legal and ethical concerns about the use of the Internet by public servants for personal purposes while on government time or using government facilities. The policy addresses issues of unlawful and improper use and the role of the employer in authorizing and monitoring the use of its electronic records. As much a personnel as an

${ }^{111}$ The 1980 OECD Privacy Guidelines have formed the basis for all the provincial privacy statutes as well as the federal, providing a common framework for interjurisdictional collaboration in this field. The federal and provincial privacy commissioners have an annual meeting and they have also met as a group with the federal-provincial council of CIOs. 
IT policy, it is administered by the CIO but listed under the Foundation Framework of Treasury Board Policies.

The other CIO policy positioned under the Foundation Framework due to its heterogeneous nature is the Policy on Government Security (Canada TBS 2009a). Again it consolidates two earlier policies: a 2002 Government Security Policy, itself an update of forerunners going back to the late 1980s; and a 2004 Policy for Public Key Infrastructure (PKI) Management in the Government of Canada, which addressed one of the central elements of the GOL Secure Channel dealing with secure transmission of data and funds. The latest policy states that "Government security is the assurance that information, assets and services are protected against compromise and individuals are protected against workplace violence". The policy covers a vast area of public administration, with directives and standards addressing: the management of security in departments, identity management, information protection and identity assurance, security screening of current and prospective public servants, physical security of government premises and assets, IT security, continuity of government business in emergency situations, and security issues arising from government contracting and outsourcing. Many of the elements of the policy date back to the Cold War and earlier (the first Official Secrets Act protecting government information from espionage and leakage was enacted during World War I), but the entire security area has been revamped under the dual influences of the end of the Cold War and 9/11, compounded by the new threats and dynamics posed by ICTs. For a while administration of IT security policy was separated from the rest of the security policy, but they have been combined since 2002 . 
The Government Security Policy is linked to a number of statutes, notably the Security of Information Act [R.S. 1985, c. O-5] (the renamed successor to the Official Secrets Act which was expanded in the wake of the $9 / 11$ attacks), ${ }^{112}$ and identifies a lengthy list of lead agencies, including the RCMP, CSIS, Communications Security Establishment and the Departments of Foreign Affairs and International Trade, National Defence, Public Safety, and PWGSC. This brings it into contact with the government's wider security and intelligence community, which is overseen by the Prime Minister's National Security Advisor in PCO. There is also an extensive functional community of security staff in departments administering the different elements of the policy.

Altogether, the Government Security Policy is probably the most complex policy for which the CIO is responsible and the one that over the years has had the greatest increase in the attention and resources devoted to it.

The final CIO policy is the Policy Framework for Service Improvement in the Government of Canada (Canada TBS 2000). This is different from other CIO-related policies for several reasons. As the name suggests, it is more a strategic statement than a policy, building on the Blueprint for renewing government services using Information Technology (Canada TBS 1994), which was the first major product of the CIO after the office was established. (The Blueprint itself built on numerous previous efforts to focus on and strengthen service to the public, including the Official Languages and ATIP Acts, the Public Service 2000 Task Force on Service to the Public (Rawson 1991) and, even earlier, Volume 3 of the Glassco report (Canada Glassco 1962 3)). The Service Policy

\footnotetext{
112 The recent Wikileaks episode brings home that traditional concerns about leakage remain germane - and vexed - in the networked environment, where massive amounts of material can be combined in a single data base or linked through networks. At the same time the sheer volume of information in the electronic environment, but also the open-ended nature of data mining and matching, make it much more difficult verging on impossible except for the most sensitive information - to screen individual records and data for their sensitivity and to provide corresponding protective measures.
} 
Framework was developed in parallel with GOL as the policy expression of the Service Improvement Initiative (SII), which sought to provide a context for efforts to strengthen services to the public, linking GOL's focus on electronic services with the various other channels of service provision, including telephone, kiosks, mail and in-person.

The Service policy was used to spawn the earliest version of Service Canada, which in 2002 was spun off from TBS to what is now the Department of Human Resources and Skills Development (HRSDC). The policy was not written in the traditional TBS policy format, however, and its concrete guidance largely takes the form of best practices exhortation. There is no explicit link between Treasury Board service policy (and the TBS service policy centre) and Service Canada as a lead agency, although the relationship can be inferred. While part of the original CIO mandate, the ambiguous nature of service policy is reflected in the fact that it has twice been assigned to the CIO and later removed - although now back with the $\mathrm{CIO}$ - making it organizationally the most volatile component of the CIO-related IM/IT space.

\section{Policies previously administered by CIOB}

Two other Treasury Board policies are included in the IM/IT space. They grew out of the same matrix as the CIO policies and have been administered by the CIO in the past although not currently. They still intersect with the CIO policies in numerous ways, however, and in any organizational evolution of the CIO are the most likely candidates for reintegration with the CIO, should that occur. The Communications Policy of the Government of Canada and the closely-related Federal Identity Program (FIP) policy which are administered by the TBS Strategic Communications and Ministerial Affairs Sector - are also categorized under the Foundation Framework. 
The Communications Policy of the Government of Canada (Canada TBS 2006) and its companion, the FIP Policy (Canada TBS 1990) were part of the original set of information, communications and security policies that were developed in the $1980 \mathrm{~s}$ and assigned to the CIO in 1994. In 1998 the two policies were transferred to a separate Service sector and in 2002 transferred again to the staff unit in the TBS Secretary's office responsible for TBS's own public communications activities. (This is the only situation where a Treasury Board policy is administered by a TBS departmental unit. The background is discussed in chapter 3 and its implications in chapter 5.)

Like the Government Security policy the Communications policy covers a wide territory and comes into the closest contact of any Treasury Board policy with the political process. With the stated objective of ensuring "that communications across the Government of Canada are well co-ordinated, effectively managed and responsive to the diverse information needs of the public," the policy includes requirements in 31 areas, many with related directives and guidelines. These can be grouped in three broad areas: $^{113}$

- guiding principles - informing and serving Canadians, charging and not charging for information, plain language, official languages, corporate identity, reflecting diversity;

- $\quad$ substantive components of the communications function - public opinion research, consultation and citizen engagement, risk communication, crisis and emergency communication, internal communication, technological innovation and new media, Internet and electronic communication, media relations, spokespersons, public

\footnotetext{
${ }^{113}$ This categorization is for the purposes of the dissertation only. The policy lists them in a seemingly random order that may be historical.
} 
events and announcements, fairs and exhibitions, advertising, partnering and collaborative arrangements, sponsorships, marketing, publishing, copyright and licensing, film, video and multimedia productions; and

- managing the communications function - environment analysis, management and co-ordination, planning and evaluation, memoranda to Cabinet and Treasury Board submissions, regional operations, cataloguing and securing information, training and professional development.

The policy assigns lead agency roles to: Service Canada, which runs the Canada Site and the 1-800-OCANADA government call centre; LAC, which is the definitive repository of all government publications and archived websites as well as of communications-related records; and PWGSC, which provides communications common services including with respect to publications (among them the Canada Gazette), depository libraries, advertising, public opinion research, and sponsorship.

The Communications Policy's most unusual feature is the explicit recognition of the political importance of government communications, with specific roles assigned to Ministers (which includes determining the role of their political communications staff), the Prime Minister, Cabinet and Treasury Board. Communications is a rare area where a departmental minister is supported by both exempt staff and public service offices and where there are central offices in both PMO and PCO. (The implications are discussed in chapter 5.) The PCO Communications Secretariat has a number of functions under the policy, including coordinating a detailed annual planning process for public opinion research and advertising. More important are its roles, in the PCO context, of working with the media office in the PMO to coordinate the government's political and public 
service media operations and of supporting Cabinet discussions of communications issues and strategies, including the Cabinet Operations Committee's oversight of government communications on a weekly basis. In practice, Communications is a shared policy responsibility between TBS and PCO, with PCO clearly in the lead on matters of substance while TBS is particularly concerned with the administrative underpinnings.

The Federal Identity Program (FIP) Policy (Canada TBS 1990) is the government's corporate branding program. The FIP traces its origins to Centennial Year celebrations and Expo 67 in 1967 and governs the visual aspect of federal presence, providing graphic standards for signage, letterhead, cheques and government Internet sites, among numerous forms of federal presence. It was given a major impetus with the Official Languages Act in 1969, which requires that federal presence and services be equally visible and accessible (interpreted to require that signs and other information for the public also be equally legible and grammatical) in both English and French where there is significant demand and for services across the country catering to the travelling public regardless of demand.

The FIP facilitates access to services but is also an accountability device, as it visually demarcates federal jurisdiction. Its most iconic component is the Canada Wordmark (the word Canada with the flag over the final letter "a"), which has come to identify not just the federal government but the country itself - most dramatically on the Canadarm in the International Space Station. ${ }^{114}$ When the federal government began to establish itself on the Internet, the FIP was used to establish "common look and feel" standards for government webpage design, the one Communications-related policy

\footnotetext{
${ }^{114}$ A primary goal of the infamous post-1995 referendum sponsorship program was to post the Wordmark as widely as possible in Quebec as a visible reminder of federal presence.
} 
instrument that continues to be managed by the CIO. In the nature of Canadian federalism, the FIP has spawned parallel programs in the provinces and territories and the development of blended identity standards in areas of politically-visible joint presence, notably signage for joint infrastructure spending, cheques delivering provincial benefits through the federal income tax system, and joint service-to-the-public storefronts and virtual service windows.

\section{Other CIO policy linkages}

Beyond this clearly demarcated territory, the CIO has numerous linkages to other Treasury Board policies and their networks of lead agencies and departmental functional specialists. The most extensive are with the Office of the Comptroller General (OCG), with which the CIO shares some common origins. The OCG operates within two major policy frameworks, for the management of assets and acquired services and for financial management. The former is especially significant for the $\mathrm{CIO}$ as it includes policies on investment planning, material management, management of projects, contracting, and common services. The management of IT involves significant purchasing and leasing of material assets, including hardware and software of all kinds, major automation projects and systems upgrades, and contracting for a wide range of goods and services. The CIO therefore works closely with OCG policy centres, both on general policy development and on their application in specific cases, as well as with the Acquisitions branch of PWGSC, which is the common service agent for the administration of major IT contracts.

The backbone of the CIOB was the original OCG unit concerned with automating financial information systems and funds transfers, and here again the CIO works closely with OCG policy centres concerned with electronic management of funds. Another 
inaugural CIO unit was concerned with automation of the public service pay system, and the information management policy governs public service personnel records, bringing the CIO into close contact with the TBS Office of the Chief Human Resources Officer (OCHRO) and the PWGSC Accounting, Banking and Compensation branch, the operating arm of the government's pay and cheque-writing systems. As already noted, the policies on Government Security and on the Use of Government Networks also have a significant human resources management dimension, expanding the working relationship with OCHRO, which is also responsible for Official Languages policy. The physical security element of the Security policy is another point of contact with OCG, the TBS policy centre for the administration of government physical premises and other real property, and the PWGSC Real Property branch.

\section{CIO policy administration}

The CIO's mandate is built on a foundation of the "map" of Treasury Board IM and IT policies. All TBS policy centres have basic policy administration roles arising from their position as the expert advisors to Treasury Board ministers and the government collectively on the functional areas of management that the policies define. These roles cover all stages of the policy cycle, including policy development and advice to ministers, promotion of policies to managers and functional specialists in departments and common service organizations, policy interpretation, related training of functional communities, application of policies in the context of the budgetary process and the approval of major projects, policy monitoring and review (including the resulting interactions with the Auditor General and Parliament), and policy revision. How the CIO 
plays these roles will vary among the policies, depending on their nature and the administrative resources that have been devoted to them, both in TBS and in departments.

Treasury Board policy administration in general has been influenced by the renewed emphasis by the Martin and Harper governments on accountability. In 2003 TBS introduced a Management Accountability Framework (MAF) to provide an annual basis for measuring and assessing management performance by departments in key areas of management. Although not part of the first version of MAF, management of information and of technology are now included in the framework (Canada TBS 2010c) through indicators under the high-level rubric of "stewardship of government assets", which also includes financial management and procurement. Two related high-level rubrics are "citizen-centred service" and "risk management". The MAF is used to shape departmental reporting requirements to TBS on their implementation of Treasury Board policies and in turn is an input to performance appraisal of deputy ministers.

A further variable in shaping policy administration is the political and policy priority assigned to the individual and combined policy areas at a given time, which broadly can be translated into whether policy administration is proactive and driven by change-oriented initiatives - such as GOL - or whether it is more responsive and in the nature of policy care and maintenance, which can be regarded as the default position. A final dimension is provided by the relationships, both within and outside the government, that are created by the nature of IM and IT and the substance of the policies. These are discussed in the next section. 


\section{The Treasury Board model and IM/IT-defined relationships}

In the Glassco model, Treasury Board policies are put in place where it is desired to administer the government as a single entity. By their nature they are directed at internal management practices and the public servants who are their agents. The structure and requirements of Treasury Board policies have a significant impact on the organization of departments to carry out those policies. They also shape the job descriptions of functional specialists working in departmental administrative branches, who unlike officials of the pre-Glassco Comptroller of the Treasury are employees of the departments in which they work, although taking functional direction and guidance from TBS. The CIO and CIOB have relationships of this type arising from all of the policies they administer. In addition, the IM/IT space brings the CIO into highly developed relationships outside government, notably with citizens, the private sector and other jurisdictions. The CIO is not unique among TBS policy sectors in having such relationships, but it is fair to say that taken together they are both more extensive in the CIO's case and more central to its work than in the other sectors. This section discusses these four relationships. ${ }^{115}$

\section{Policy agents in departments}

The Treasury Board model separates policy making from implementation. TBS leads the former, in support of collective ministerial decision-making, but with rare exception it has no operational capacity and must work through agents in departments and common service organizations for its policies to be given effect. The role of common service organizations and lead agencies has already been described, arising in

\footnotetext{
${ }^{115}$ A fifth relationship is with the voluntary sector, which has always been an important part of the policy process and more recently has had a growing role in delivering government programs and services. It is less visible from the CIO's perspective, however, and the issues it raises are a combination of the ones that arise with respect to citizens, other jurisdictions and the private sector - see Phillips and Levasseur 2004.
} 
circumstances where for reasons of efficiency or public policy departments are given the option or even required to obtain administrative services from a third party within the government (who may in turn broker the procurement of the service from outside government). Most Treasury Board policy implementation, however, is through managers and staff in program departments acting under the direction or guidance of individual policies and sets of related policies. As a rule, policies assign a leading role to Deputy Ministers; in practice policy requirements focus on some combination of functional specialists and program managers and staff, who are asked to fulfill a policy's requirements as they go about their program activities. ${ }^{116}$ One of the main goals of the IT management policy is to use technology to strengthen service delivery, which brings the $\mathrm{CIO}$ and $\mathrm{CIOB}$ into direct contact with program managers and staff. This reached its height under GOL, where each participating department was asked to name an Assistant Deputy Minister-level GOL "champion" to be the advocate for GOL within the department and share departmental experience through a committee of GOL champions chaired by the CIO. GOL also benefited from the role played by TIMS, the committee of line Deputy Ministers who played a combined role of advisors and goad to the CIO.

Treasury Board policy requirements are generally additional to the primary job descriptions of program staff in departments. In the case of administrative staff they are at the heart of their job descriptions, and every major Treasury Board policy has a network of specialists associated with it. The IM, ATI, Government Security, and Communications policies all include directives relating to their management in departments, and CIO policies typically are reflected in a departmental unit headed by a

\footnotetext{
${ }^{116}$ An example is when a government program follows good record-keeping practices, as called for under the Information Management policy, as it interacts with members of the public. This also creates a basis for meeting related ATIP requests.
} 
middle or even senior manager - a Departmental Security Officer, ATIP Coordinator or Director General of Communications, for example. In the comptrollership and human resources areas, TBS organization is often mirrored by corporate services structures in departments - the Chief Financial Officer typically oversees staff linked to the various OCG policies, and the Chief Human Resources Officer generally covers the range of the Treasury Board human resources policies as well as authorities delegated by the Public Service Commission. This is rarely the case with respect to policies in the IM/TT space. The ATIP coordinator is often located in the staff units linked to the Deputy Minister, partly reflecting the fact that they are operating on the basis of authority delegated by the Minister as Head of the department but also the quick turnaround required by the two Acts for decisions on requests for access to records and the potential political sensitivity of released records. For similar reasons, the Director General of Communications most often reports direct to the Deputy Minister or is part of a central staff unit; occasionally they are part of a policy sector, reflecting the importance of the communications function to policy development and Cabinet submissions.

Most departments have a CIO, who depending on the size of the organization and the extent of the technology plant (especially if mainframe computers are involved) can be at the Assistant Deputy Minister level and often is at the next level down. In accordance with Glassco principles, the TBS CIO generally has a role in their appointment. Practice varies, however, with respect to the departmental CIO's span of responsibilities, in particular whether they include IM and departmental security, which would reflect the TBS configuration. In many cases these are combined instead with the units administering financial management policies under a senior finance and 
administration executive - perhaps reflecting earlier TBS organizational incarnations. One of the TBS CIO's most important policy administration instruments is the CIO Council, made up of all the departmental CIOs. The TBS CIO chairs the Council and makes extensive use of it in discussions about policy development and implementation issues, especially those related to IT. It is generally the case, however, that the members of the CIO Council have a more limited range of responsibilities than the TBS CIO, who also has to work with parallel networks in the other policy areas, notably ATIP, security and communications. This is a significant structural obstacle to an integrated approach to the IM/IT agenda.

In recognition of the importance of functional staff in departments to successful policy implementation, many TBS policy centres are concerned with training and community development for the "communities of practice" defined by their policies. All major CIO policies and the Communications policy assign a lead agency role to the Canada School of the Public Service (CSPS), the federal government's common service training agency. This concern was accentuated by La Relève in the 1990s which sounded warnings about a foreseeable retirement bulge in the public service and the need to prepare future generations of senior specialists and managers (Bourgon 1997). When the CIO was formed in 1993 it included a small IT community relations office that was spun off from an earlier office in OCG working with government financial officers. This unit evolved by the end of that decade into the Organizational Readiness Office (ORO), with training and other human resources-oriented responsibilities ${ }^{117}$ for the IT and IM communities, to which the service community was later added. ORO was transferred to

\footnotetext{
${ }^{117}$ These include participating in a review of job classification standards and development of competencies as a basis for training and career development.
} 
PWGSC along with the GOL secretariat in the organizational changes made when the Martin government came into office in December 2003, but it never moved its offices from the CIOB premises and within months had been returned to CIOB in recognition of its importance to CIO policy administration.

Beyond training and community development linked to specific groups, all CIOs have been closely involved in Government Technology Week (known as GTEC), a professional development conference and trade show in Ottawa that each Fall attracts several thousand public servants, primarily from the federal government but with substantial provincial and international participation. Established in 1993 with encouragement from Macdonald, the first $\mathrm{CIO}$, it has always been organized by a private sector conference organizing firm - originally an independent Ottawa trade show company but now a multinational conference organizing firm, United Business Media (UBM), ultimately based in the UK. With a Board of Governors drawn from both the public and private sector IT communities, GTEC has become a major event, featuring policy updates by the $\mathrm{CIO}$ and other senior public servants, speakers and seminars on current technology issues, a CIO "boot camp," and a trade show with several hundred private sector exhibitors. The GTEC awards ceremony is the leading form of recognition for IT-based reform projects in the federal government, and includes awards for provincial and municipal governments and for interjurisdictional collaborative projects (GTEC 2010).

An abiding challenge for the CIO has been to identify the nature and extent of the functional communities that it is working with. The Griffenhagen-inspired system of job classification that was introduced after World War I was based on the profile of civil 
service work at the time, and as later Royal Commissions attested had difficulty in capturing changing needs of government, especially in the technical and scientific areas (Canada Beatty 1930, Canada Gordon 1946, Canada Glassco 1962). The classification structure was updated and expanded as a result of labour relations reforms in the late 1960s in the context of Treasury Board re-structuring, and most current classification groups date from that period, each represented by a public service union bargaining agent. In an unpublished 1995 study conducted for TBS by Linda Duxbury and Chris Higgins, "Surveying the Federal IM/IT Community," it was estimated that about 40,000 public servants, out of the then total of a little over 200,000 , spread over 12 job classifications, could be categorized as members of the IT or IM specialist communities. Another 40,000 could be defined, or saw themselves, as information workers in a broader sense (Brown 1997: 105-106). A review of the current listing of occupational groups in the public service (Canada TBS 2008d) indicates 15 that relate entirely or substantially to IM/IT policies, with a total of over 45,000 public servants, and five others totalling 86,000 that have a significant number of information workers (see Annex 9). Virtually all these groups are based on occupational profiles that pre-date the establishment of the $\mathrm{CIO}$, and their boundaries are largely frozen by the fact that they are represented by four different union bargaining agents, who are reluctant to lose members through restructuring of occupational groups. ${ }^{118}$ There have been efforts to consolidate groups

\footnotetext{
${ }^{118}$ Since the early 1990 s the federal government has attempted to reform the Griffenhagen-based system of job classification, which generally classifies jobs rather than people. Originally driven by Canadian Human Rights Commission rulings that it violated pay equity principles rooted in the Charter, as well as recommendations from a PS 2000 task force, reform efforts have also tried to respond to the changing nature of work. For more than a decade TBS, working with the public service unions, sought to introduce a Universal Classification System (UCS) but this stalled. See the 2003 Auditor General's report (Canada Auditor General 2003a) and earlier studies of UCS in the 2000 and 1996 reports.
} 
represented by the same union, but the situation has not been very responsive to ICTs and other changes in the work environment in the past forty years. ${ }^{119}$

\section{The citizen}

The Glassco commission devoted 14 of its reports spread over two volumes (Glassco $19622 \& 3$ ) to government services, dividing those into services for government and for the public. Most of the former were areas that are relevant to the $\mathrm{CIO}$, and today they would be seen as shaped (or at least influenced) by public demand. These include telecommunications (report 8), printing and publishing (report 9), economic and statistical services (report 12), and public information services (report 13). Two others address areas that continue to be contextually important: purchasing and supply (report 6), and especially "make or buy" (report 10). All of these were considered in the first instance to support the administrative needs of government departments organized around policy- and program-related functions. Even public information services, which are directed at the public, were intended to encourage compliance with or take-up of government programs and approached from that perspective.

The commission recognized, however, that not all services fit into this functional model and that with the expanding role and complexity of government there was a growing diversity of modes of providing services to individuals. A further catalyst was the recognition that "the ultimate aim of all government activity is the satisfaction of

\footnotetext{
${ }^{119}$ An example is librarians (LS) and historical researchers (HR), both closely involved in information management but members of different unions. Librarians were originally based in the National Library and the historians in the National Archives. For several decades the two agencies were housed in the same building and shared common administrative services. When merged into Library and Archives Canada in 2004 their operational units were integrated, but it has not been possible to combine the classification groups to reflect the convergence of their work. On the other hand, the $\mathrm{ClO}$, working primarily through ORO, has been able to update the Computer Sciences (CS) classification standard, which provides the core group of IT workers. Again, however, there are significant structural impediments to expanding it to include related technological specialists, much less information workers.
} 
public wants" along side the more traditional motive of "safeguarding of public interests at home and abroad." The result was the gradual evolution since Confederation of the "public service state" - largely unplanned, with a great deal of experimentation and improvisation, and very much influenced by federalism (Glassco 1962 3: 120).

From today's perspective, Glassco's list of services for the public ${ }^{120}$ appears quirky. The most important and extensive was the Post Office (report 17), as much a financial and social institution as the deliverer of mail and at the time still a, if not the, primary vehicle for communications among individuals, civil society organizations and the state. Three other reports addressed services provided by the federal government to specific client populations, in the areas of education (report 14 - Indians, children of service personnel and in the NWT), health (report 15 - veterans, Indians and Eskimos, service personnel and their families, inmates, crews of foreign ships and Canadian fishermen, and residents of the Territories), and a wide variety of lending, guaranteeing and insuring activities (report 16). Report 18 (miscellaneous services) comes closest to the current understanding of service to the public, briefly canvassing a list that included harbours, national parks, patents, passports, and free trees for shelter belts around prairie farms. Two major concerns were cost-recovery and efficient delivery of services, the commission arguing forcefully that in the spirit of make-or-buy the government should separate policy-making about services from modes of delivery. To that end - anticipating the Program Review checklist a generation later - the federal government should be open to cooperating with the "energetic and competent" provincial governments as well as municipalities, non-governmental organizations and the private sector $(121-124)$.

\footnotetext{
${ }^{120}$ The phrasing "service to the public," with its transactional connotations, is more recent and arguably represents a subtle shift (encouraged by ICTs) in an understanding of what services are about.
} 
The contemporary approach to the provision of services to the public builds on this foundation, augmented by official bilingualism and ATIP, early efforts at requiring government to put itself in the shoes of members of the public in organizing its services. From the outset, the delivery of services to minority language populations and the travelling public led to experimentation with technological aids such as telephone hot lines and information kiosks. In the 1970s and 1980s, the Department of Communications invested heavily in applying new telecommunications technologies to the delivery of services to homes and businesses, most visibly the Telidon technology which ultimately was stillborn but helped pave the way for the Internet (Gillies 1990). Much of this work built on principles of automation pioneered in $19^{\text {th }}$ century forerunners of $20^{\text {th }}$ century computers, later combined with self-service principles applied in the early $20^{\text {th }}$ century in areas such as food-dispensing automats and vending machines. The banking industry picked up these threads to develop Automated Teller Machines (ATMs), which by the 1980s had become a feature of daily life and became even more important with electronic networking. These developments had a major impact on government, leading to efforts in the 1980s both to automate funds transfers with and within government and also to harness the technologies with the client-centred focus advocated by the New Public Management (NPM) to develop a philosophy of and managerial approaches to citizencentred and self-service-based electronic service delivery. Meeting the citizen's needs and service to the public have come to be seen as primary roles and legitimizing characteristics of the public service, both from its perspective ${ }^{121}$ and from that of citizens

\footnotetext{
${ }^{121}$ Service was one of the four themes of Public Service 2000 when it was launched in 1989, and the 1990 White Paper endorsing its results lists "service to Canada and to Canadians" as the first among the values of Public Servants in a democratic government (Canada Government of Canada 1990 (Synopsis): 3). This
} 
who see a "value chain" between service and confidence and trust in government (Heintzman and Marson 2005).

Although the direct heir, beneficiary and frequently the agent of these developments, the CIO has had an ambivalent relationship with them. When the CIO position was established in 1993 it inherited work that had already begun in TBS on electronic funds transfer and IT-enabled service delivery (Canada TBS 1992), and its first major initiative was the draft Blueprint for renewing government services using Information Technology circulated in 1994 (Canada TBS 1994). Integrated with webbased technologies, including the introduction of the Canada Site in 1995, and prodded by Industry Canada's Connecting Canadians initiative, the Blueprint led to Government On-Line (GOL), which over a period of several years brought all the government's major transactional and information services on-line, under the CIO's leadership.

At the same time, the heterogeneity of services to the public, with a major role for non-electronic channels, led to the separation of service policy from the CIO from 19992002 and again from 2008-2010. The first time was so the CIO could concentrate on electronic service delivery while ensuring that separate attention was given to the wider context of service delivery and techniques for managing it, with the Service Improvement Initiative (SII) parallelling and even framing GOL. It also recognized that the government could not move exclusively to electronic service delivery, as this was a direction in which the Canadian public was not universally able or willing to go. However, the organizational separation of GOL and SII also ended because they were so closely related in practice, focusing on the same services and the same public. In the second separation reference to the Public Service mission of "excellence in service to Canadians" (Wouters 2010:1). 
of the $\mathrm{CIO}$ and service policy, service policy itself was re-defined to encompass services to government as well as to the public; it was also judged that they warranted attention on their own, independent of the technology or information context. While this could be seen as a maturing of service policy beyond the technology drivers that have shaped it for the past quarter century, it removed one of the CIO's major claims to be a force for modernization and renewal and left it to concentrate on managing IM and IT assets. This move was reversed, however, after a former CIO became Treasury Board Secretary.

The government's relationship with the citizen of course goes beyond the provision of services. Two dimensions deserve comment in the context of a discussion of the implications for the CIO and the IM/IT space. The first grows out of the central focus of the privacy regime: personal information that is provided by citizens to government that they might not be prepared to divulge to others. This information is obtained through the use of the coercive state powers and creates a reciprocal obligation on the part of government not to mis-use it and to protect it from access by others who should not see it. Privacy principles provide a basis for good information management practices within government, ${ }^{122}$ but of even greater significance is the implicit understanding that is created between government and governed - in its idealized form: citizens will be open and honest with government in meeting its information requests about themselves, and in return the government will only ask for what is necessary and will use that information judiciously and transparently. In that sense there is an analogy, as well as reinforcement, to voluntary-compliance-based payment of taxes. This gives a normative dimension to

\footnotetext{
${ }^{122}$ Privacy policy focuses on the provenance of personal information, the purpose for which it was collected, its sensitivity if compromised, and the primary and secondary uses to which it is put. These are all organizing principles for good information management and also provide a basis for decisions about what not to retain or link, which are important questions from an efficiency and economy perspective.
} 
the administration of the Privacy policy and Act that at times conflicts with the CIO's pursuit of the full potential of networked IT and IM.

The second dimension is even more complex. A central objective of both the Access to Information and Communications policies is promotion of liberal democratic values of openness, transparency and accountability in government and informed citizen participation in political debate and policy making. The Communications policy regulates government practices in publishing, advertising, public opinion research, and public consultation and engagement. These activities, especially the latter, have acquired an additional dimension with the movement of policy consultation on-line and a related new set of institutions and dynamics (Borins and Brown 2007a). At the same time, these goals and their administrative manifestations touch on some of the most politically sensitive areas of public administration and have the potential to draw the CIO into areas that risk being controversial. It also means that TBS is in practice less central to the administration of the two policies than it is in other policy areas, leaving a wide field of manoeuvre in both policy sectors to $\mathrm{PCO}$ and its alter ego PMO, especially in the case of the Communications policy. It is therefore not surprising that TBS was essentially not present during the events that became the sponsorship scandal - even though it was about the administration of a Treasury Board policy - nor that a CIO with experience in public communications chose not to seek the return of the Communications policy to CIOB when it was available. The challenges that these realities pose to the CIO and the IM/IT space are discussed in chapter 5 .

A different but associated sensitivity arises from the Government Security policy. Its orientation is towards the protection of sensitive government information, including 
information whose compromise poses risks to national interests in addition to personal information and information provided by commercial interests and other jurisdictions. This brings it into the realm of national security, with its many dimensions that begin with protection against leakage to and espionage by foreign powers (the original focus of the Official Secrets Act that has been carried over into the Security of Information Act). In an era of concerns about terrorism and politically-motivated violence against governments by non-state actors, this dimension draws the CIO into the wider security and intelligence community - again led by PCO, with most of its members also lead agencies under the Government Security policy - and the complex grey zone between subversion and legitimate dissent mapped out by the McDonald commission that led to the establishment of CSIS out of the ashes of the RCMP Security Service (Canada McDonald 1979 \& 1981a\&b).

The relationship with the citizen also highlights accountability issues. The CIO and related areas of TBS encounter challenges to the collective accountability model in a number of ways. PCO has a leading - and not simply a lead agency - role in several policies, which creates a more complex terrain for the $\mathrm{CIO}$ to navigate as a central agency. These include Access to Information (Cabinet Confidences and communications relating to ATI-related public controversies) and Communications (link to PMO in overall communications strategy, support to Cabinet Operations committee in overseeing government communications and their link to Parliamentary debate, direction to the advertising and public opinion research common services in PWGSC), but also aspects of the Government Security Policy (information security and leakage, with links to whistleblowing - in principle, a values-related human resources policy concern). The 
events that became the sponsorship scandal illustrate both the marginal role played by TBS, the ostensible policy holder, ${ }^{123}$ in an area of politically-sensitive public administration and the more generic difficulties of linking common service organizations (with their separation of policy and operations) into the accountability model. The challenges created by separating policy and operations are also found in the "front room" integrated service to the public model, although it has yet to be tested as severely as in the case of advertising and sponsorship common services.

A final accountability dilemma arises from another aspect of service to the public: the risk that those receiving services will consider that the public servant service providers are in some sense accountable to them - and that this view may be shared by the service providers themselves. While partly an understandable matter of human psychology, this raises questions about the traditional accountability model - does this new view "disintermediate" the ostensibly responsible Minister or even the entire parliamentary accountability chain? Combined with the question of ministerial accountability in the context of the "front room" - which Minister answers in Parliament when a service organization under one Minister is delivering a service on behalf of another? - it adds yet another eternal question to the collective accountability mix.

\section{The private sector}

Chapter 3 noted that a 2004 Expenditure Review study commissioned by Treasury Board found that the federal government's annual IT and IM spending totalled about $\$ 5 \mathrm{~B}$, roughly $10 \%$ of its core operating budget. Of this total, a little over $\$ 3.1 \mathrm{~B}$ was spent

\footnotetext{
${ }^{123}$ When the Gomery commission looked at TBS as a possible institutional counterweight to keep the administration of government advertising accountable they overlooked the CIO or the Communications policy centre and instead focused on the OCG. In the end, they recommended that it be PCO, apparently willing to accept that its role in supporting Cabinet policy decision-making about advertising risked placing it in a conflict of interest (Canada Gomery 2006: 166).
} 
on the purchase of IT goods and services from the private sector. A recent study of public service outsourcing (Macdonald 2011) found that three contracting areas with a major IT component - informatics services, management consulting and temporary help - alone totalled in the range of $\$ 1.4 \mathrm{~B}$ per year between 2006-07 and 2009-10 (10), creating a "shadow public service." The top ten areas of contracting out, which also included architectural and engineering services, computer equipment, telephone and voice services, and software, averaged just under $\$ 4 \mathrm{~B}$ per year in the same period (8). Interviews for this dissertation indicate that these global amounts and proportions are considered broadly accurate by both government officials and private sector observers. This profile of spending has many dimensions - generally ones that are not easy to quantify - and has created an array of relationships in both the federal government and the elements of the private sector that it deals with. In sheer scale, IT purchasing of goods and services from the private sector (outsourcing) exceeds internal IT spending (insourcing, mainly on staff and associated costs); it is more difficult to determine how federal government-related employment levels compare in the two sectors. ${ }^{124}$

It is fair to say that the private sector relationship in the IM/IT area is considerably more extensive than in other areas of public service management and is one of the IM/IT sector's defining characteristics. Academic observers give considerable weight to the procurement relationship in commenting on e-government performance (Kernaghan and Gunraj 2004, Dutil et al. 2005, Roy 2006, Borins 2007a) and even go as far as making it the most important factor (Dunleavy et al. 2006). The management of this relationship

\footnotetext{
${ }^{124}$ Macdonald found that outsourcing has grown more rapidly than payroll spending under the Harper government (2011: 15). Reasons include simpler procedures, avoidance of bilingualism and merit requirements, and lack of policing (16-18). To this list could be added, in the case of IM/IT spending, lack of focused data and of an expenditure role by the CIO.
} 
generates a number of Treasury Board policies and actors within the federal government. The CIO is a major stakeholder and plays a leading role in many respects but is in the end only one player among several in a crowded field.

The global procurement figures cover a wide range of goods and services that are purchased outright or leased. Hardware purchases include new computing equipment, from mainframes to desktop computers and hand-held devices, telecommunications equipment, and networking hardware. Software includes word processing and other commercial applications purchased under licence, often in bulk, but also numerous specialized and customized applications. A significant part of IT spending is for human resources, with a large number of contract IT specialists working for short or longer periods, often in jobs that elsewhere in government are filled by public servants. These are frequently hired as individuals but many also come from IT temporary help "body shops" or as sub-contractors. A key sub-set is individuals trained on obsolete programming languages who are hired to maintain and upgrade the mainframe computers that were installed in the 1960s and 1970s and continue to be the backbone of many programs - a situation described as problematic by both Dunleavy et al. (2006: 78) and the Auditor General (Canada Auditor General 2010). "High" end consulting includes diagnostic and strategic advice on IT requirements, design of next generation hardware, software and network architecture, and management of major IT projects. Another dimension involves advice on technology trends and management innovations as well as training of all kinds. On the other hand, the federal government makes only limited use of 
the private sector in areas such as data storage or the delivery of services to the public, which are contracted out in some provinces and even other national governments. ${ }^{125}$

IM/IT goods and services are at the heart of the "make or buy" principle that was one of the Glassco commission's major themes, in particular in report 10 (Canada Glassco 1962 2:310-359). Concerned that "secondary fields of activity" (318) increase the complexity of management and divert attention from the primary concerns of government, Glassco advocated using the private sector where possible, which also offered economies of scale and flexibility in adjusting to changing requirements. At the same time, not all requirements could or should be met from private enterprise, and where this was done the government would need to have the necessary organization, staff, procedures and training to play its part in a two-sided relationship. ${ }^{126}$ But, Glassco argued, the default position should lie with "buy" rather than "make," and decisions to do the latter "should only be taken on the basis of conclusive evidence of the unavailability on reasonable terms of the goods and services from outside the government" (319).

In practice, some IM/IT purchases are for goods and skills that can only be obtained from the private sector. The government does not develop its own hardware and is dependent on the marketplace, although as a major purchaser it can obtain tailored equipment and configurations. Similarly it makes little effort to generate its own software in areas such as word processing where Commercial Off-the Shelf (COTS) applications are available and can be obtained in bulk. In most other areas, practice varies, broadly along two axes. One is in the area of departmental programs and services, where there is

\footnotetext{
${ }^{125}$ In the extreme case, the British counterpart of Canada Revenue Agency and at least one Australian state government (South Australia) have contracted out their entire IT environment to the private sector.

${ }^{126}$ Langford and Harrison 2001 stress the importance of having the right organizational capacity to manage the government's side of major IT contracts. They are particularly concerned with realizing the "business value" of public-private partnerships - which the federal government has not engaged in to the same extent as provinces and local government - but their argument is relevant to all major IT projects.
} 
a general demarcation between larger departments with information-intensive activities and mainly medium and smaller-sized departments and agencies. The first group are primarily departments that obtained mainframe computers as early as the late 1950s, with a major wave of purchases in the 1960s and 1970s. Typically, they have built up their own in-house capacity to maintain these computers and to update their programs, especially in areas where there is regular revision of program requirements, for example annual changes to income tax or employment insurance premium rates. The half-dozen or so departments in this situation have extensive public service IT staffs, including program-related software application development and project management capabilities. Paradoxically, they are also the largest outsourcers (Macdonald 2011: 13-15), although mostly to complement permanent staff. Most other departments have more limited internal capability and rely on outsourcing for a wider range of services. Some also buy IT services from in-sourced departments - a practice encouraged by Glassco.

The second axis is technology related to departmental administration and internal services. Again the situation varies widely. In a well established area such as telecommunications the government has had a considerable degree of centralized contracting since the aftermath of the Glassco report, which devoted its report 8 to the subject - even so, some departments have developed specialized capabilities, such as DFAIT's global telecommunications environment. Equipment and services used by individual public servants present a more varied picture. Desktop computers were originally purchased individually, initially with considerable variation even within departments; it took some time to achieve uniform standards and procurement at the level of departments, and this has been under serious consideration at the government-wide 
level only in the past two or three years. The situation has been even more decentralized and fragmented with respect to the purchase of mobile equipment and applications.

A different picture emerges in the case of administrative systems. The rise of integrated administrative enterprise software came in the same period as the 1993 reorganization and Program Review. Departments devoted considerable energy to integrating their back offices ${ }^{127}$ and then to reconfiguring them to meet budget cuts, which were disproportionately weighted towards internal administration, at least in part in the expectation that significant savings would be achieved through a simultaneous investment in IT-based integrated environments. Some of the mainframe-based departments developed their own electronic administrative systems but most bought COTS applications, in some cases from multi-national suppliers and in others from Ottawa-based firms. The question soon arose whether departments should consolidate into a small number or even a single software application, in particular for financial and human resources management information systems, which operate under common Treasury Board rules. An initial move in this direction after the 1993 reorganization was dropped with Program Review, and instead CIOB brokered a voluntary progressive consolidation, leaving room for customization by departments. Opposition came both from departments wishing to retain control of their administrative systems and from software suppliers concerned about a winner-take-all single contract that favoured the large multinationals. ${ }^{128}$ A further concern has been that multinational-supplied software

\footnotetext{
${ }^{127}$ HRDC reportedly combined five IT environments from its predecessor departments. It can be speculated that the cost and difficulty of integrating the back rooms is an obstacle to future government restructuring. ${ }^{128}$ A major influence was Ottawa-based Corel's successful appeal in 1998 to the Canadian International Trade Tribunal against a move by Revenue Canada to award a department-wide contract for office automation software to Microsoft (Canada CITT 1998). There had also been a history, going back to the earliest mainframe contracts, of spreading major IT contracts around, partly to support the development of a competitive market, especially Canadian firms, but also to avoid over-reliance on a small number of
} 
suites are not designed with Canadian government rules and procedures in mind and adapting them, even at the enterprise level, entails additional costs. These debates have been a significant, although not the only, part of failed efforts to consolidate administrative services in 1994, 2002 and 2005 and were inherent in the recent administrative services review.

The federal government's relationship with the IT suppliers is shaped by the nature of the industry that has grown up around federal government procurement. The government is generally regarded as the largest purchaser of IT goods and services in the country and a major influence on the industry's health, making this an area where internal administrative policy is also de facto industrial policy. Interviews with senior private sector observers of the federal government indicate that there is no structured IT industry as such but there are at least three identifiable clusters of firms. At one end of the spectrum are large multinational firms, with various specializations but generally offering a range of consulting, design and project management services. The major hardware suppliers are also multinationals, and some firms - notably IBM - are both manufacturers and consultants. A particular niche is firms specializing in large-scale data storage and management, including EDS and ISM, an IBM affiliate. A middle group are Canadian firms - some, such as CGI, themselves multinationals - but most operating in specific niches, offering specialized consulting and applications development services. At the other end of the spectrum are the body shops and a large number of small firms and freelance individuals. Many of these are based in the Ottawa area although others deal with federal regional offices. Often firms will assemble consortia to bid on larger projects or

suppliers. As Dunleavy et al. note (2006: ch. 5), the ability to maintain a competitive IT market is one of the hallmarks of successful e-government. 
sub-contract work to other firms or individuals, even when they are the sole contractor of record. As a result there is a continually shifting set of relationships within the industry, many of them cutting across the various categories, which in any case are notional.

Another feature of the landscape is the IT industry associations that have a major government relations presence in Ottawa. The most visible are: the Industry Technology Association of Canada (ITAC), which includes most of the multinationals and some of the larger Canadian firms; the Canadian Advanced Technology Association (CATA), which is more oriented towards the Canadian firms; and the Canadian Business Information Technology Network (CABiNET), which represents medium and small firms, many of them in the Ottawa area or working in regional markets. ITAC and CATA in particular sponsor venues for private sector and government IT executives to meet and discuss common issues as well as technology trends. The government has used the associations, notably ITAC, as an administering vehicle for interchange agreements that allow private sector executives to be brought into IT positions in the public service for periods of up to five years while retaining private sector compensation packages. Four CIOs, including the current one, have been hired through ITAC interchanges.

The procurement relationship between government purchasers and private sector vendors is governed by the Treasury Board Policy Framework on Management of Assets and Acquired Services, especially policies on investment planning, management of projects, and contracting. The policy centre in all three cases is in OCG, although CIOB has units that work closely with OCG on IT investment planning and major projects. The common service agent is the Acquisitions Branch of PWGSC, which has the lead role in contracting for significant projects; projects beyond a certain financial and risk threshold 
are approved individually by Treasury Board ministers, and major projects have dedicated project offices. Most goods and services contracts, however, are let though MERX, a privately-owned electronic tendering service (MERX 2010) that originally dealt with federal contracts but has expanded to include tenders from all provinces except Quebec and British Columbia as well as US government contracts under NAFTA procurement agreements. ${ }^{129}$ Given the special requirements of IT procurement, there is an IT acquisitions sector within the PWGSC Acquisitions branch that works closely with both CIOB and PWGSC's IT Services Branch.

Although not directly responsible for IT procurement or the administration of major projects, the TBS CIO is the leading public service executive in this environment and is in regular communication with senior industry executives and the industry associations. This includes more concentrated contacts during the annual GTEC Week and Lac Carling conferences (see the next part of this section) as well as with IT industry research organizations such as Gartner, Forrester, and the Standish Group. The CIO can become informally involved in discussions with industry about IT projects with a major government-wide dimension, although formal negotiations are through PWGSC and the CIO needs to ensure that CIOB's role in monitoring major IT project management is not compromised. Perhaps a more important $\mathrm{CIO}$ role is to monitor the state of the industry and the direction that technology is taking. A challenge in this area, however, is that firms are understandably reluctant to reveal proprietary information about new product development either to the government, outside a negotiated contract or a tendering

${ }^{129}$ Chapter 10 of NAFTA, on Government Procurement (Canada DFAIT 2009), also requires that all government contracts above a certain threshold - which depending on the nature of the contract can be as low as US\$50,000 - be open to bidders from all three NAFTA countries. As a result, the Canadian International Trade Tribunal (CITT), the Canadian quasi-judicial tribunal for NAFTA and other trade agreements, is the appeal mechanism for all medium-sized and large IT contracts. 
process, or especially to their competitors. The process of consulting with vendors on more strategic issues can therefore be complicated (Brown and Brook 2001, Brown and Kourakos 2005). While the relationship with the private sector, including the CIO's involvement, generally operates below the political radar, there is periodic Parliamentary attention paid to IT procurement issues, notably when there is an Auditor General's report on the subject or there are apprehensions about changes that might affect the contracting process, especially as it affects small and medium-sized firms.

This web of relationships and inter-dependencies creates significant accountability challenges, and in this area accountability is both legal and political. Fundamentally, the relationship between government and the private sector is contractual, representing an allocation of liability (and related costs) between the contracting parties. This also brings in the CITT and the courts as dispute resolution bodies. It is therefore important to have well constructed and administered contracts, requiring specialized skills in both government and the private sector, as well extensive resort to lawyers. Closely related to the issue of liability is the allocation of risk, which takes many forms including the technology risks of choosing the right and most cost-effective and sustainable technologies when they are constantly changing. The assumption of risk sometimes has the features of a cat and mouse game where each side seeks to leave the residual risk in the hands of the other, but both sides know that ultimately the government has the deeper pockets. ${ }^{130}$ Political accountability is rooted in the internal dynamics of government, and the difficulties inherent in the Glassco management model have already been referred to.

\footnotetext{
${ }^{130}$ For private sector firms the bottom line is company survival, and there have been high profile corporate failures owing to failed IT projects. For government the issue is the financial cost of bailing out projects in difficulty or the disruption and political embarrassment of not having the project completed. Borins (2007a: 29-32) argues that the success rates of major IT projects has gradually improved, while Dunleavy et al. (2006: 72) state that Canada has been more successful than most governments in requiring companies to assume reputational costs for failed projects.
} 
Here again, there is a three-cornered relationship within government between the program department, the contract administrators in PWGSC and the overseers (but also the collective leaders) in TBS that is not always easy to present to Parliament.

\section{Other jurisdictions}

A set of relationships that is not regulated by Treasury Board policies but that is no less characteristic of the IM/IT space and the role of the CIO is with other jurisdictions, both internationally and within Canada. All have a dimension of mutual learning and moral support in the face of a common and constantly evolving external environment, while the domestic public sector relationships also entail an element of partnership that is new and distinct within Canadian public administration. This part of the chapter provides a brief overview of these relationships. Chapter 6 has a more detailed account of the Ontario Corporate $\mathrm{CIO}$, which represents both a key public sector collaborator and the most important alternative governance model to the federal CIO.

\section{International}

Dunleavy et al. (2006: 134) observe that the fact that the same multi-national consultants and vendors deal with most governments has not meant very much crossjurisdictional learning in how governments deal with them. There is, however, a global dimension to the $\mathrm{CIO}$ picture. Several interviewees working for multinationals commented that during GOL, which was seen to be at the international leading edge, their firms placed some of their best public sector-oriented staff in Canada and used Canadian experience to inform their own international learning. Since the end of GOL Canada has been perceived as less innovative and the top staff have gradually moved elsewhere. 
With less at stake, the dynamic has been a little different inside government. All public administrations in liberal democratic governments have faced the issue of responding to ICTs and integrating the institutional dimension of that response into their public sector governance. Most, if not all, have introduced some form of government CIO. In doing so, they have been aware of each others' experience and to at least some degree motivated by it. There have been a number of contributory factors. A general base for mutual awareness and experience-sharing has been through the Organisation for Economic Cooperation and Development (OECD). While its primary focus has been on collaboration and standard setting in economic and fiscal policy, this has led to cooperation in administrative areas as well. In the IM/IT sphere, the earliest example was the OECD's 1980 Guidelines on the Protection of Privacy and Transborder Flows of Personal Data (OECD 1980), a response to the growing automation of data in all OECD countries, combined with efforts to integrate the European market. Developed by an expert group chaired by the head of the Australian Law Reform Commission, the OECD guidelines have been widely used as the reference point for public sector privacy regimes, including by all levels of government in Canada. By the late 1980s, the OECD Technical Cooperation Committee (TECO) ${ }^{131}$ initiated consultations on the administration of IT and service to the public which have evolved into ongoing sharing of experience and development of guidelines in the area of e-government (OECD 2003), paralleling other work by the committee on budgeting, human resources management and top-level central government coordination - international networking by central agencies.

\footnotetext{
${ }^{131}$ Later the Public Management (PUMA) committee and now the Public Governance and Territorial Development committee.
} 
Canadian CIOs and their predecessors have participated in the OECD work. They have also been active in the International Council for Information Technology in Government Administration (ICA), ${ }^{132}$ a not-for-profit international organization founded in 1968 that has provided a venue for more technologically-oriented discussion and comparisons (ICA 2010). ${ }^{133}$ More intensive experience-sharing and collaboration has occurred with a more restricted group of countries, in particular the US, UK and to a lesser extent Australia and New Zealand. The five countries have long-standing intelligence sharing agreements; as the international security environment has become increasingly influenced by ICTs, this has led to the development of common secure telecommunications and data sharing arrangements, led by the various national communications security organizations, including the Canadian Communications Security Establishment (CSE), the lead agency for IT security under the Government Security policy. Several CIO incumbents interviewed for this dissertation commented on the importance of this relationship to their ability to stay current with technological developments. The web of communications flows across (and about) the common border makes the relationship with the US government the CIO's single most important bilateral relationship, notably with the Office of Management and Budget and, since the appointment of Vivek Kundra as the first US government CIO by President Obama, the White House. Given the similarities in governance environments, there have also been extensive contacts with British and Australian counterparts, including the recruitment of the first Canadian CIO, Andy Macdonald, to become the first Australian CIO in 1995.

\footnotetext{
${ }^{132}$ Not to be confused with the International Council of Archives (also ICA), which is the international association of national archivists and in which Canada has been an active member as well.

${ }^{133}$ Two Canadians have been President of ICA: John Riddle, former Health Canada CIO, and Peter Bruce, former Acting CIO and ICA President at the time of writing. Both were interviewed for the dissertation.
} 
A final influence, the impact of which has varied, has been international surveys comparing technology performance in national governments and even entire countries. Several are well established, although often asking slightly different questions. The International Telecommunications Union (ITU) has regularly conducted surveys on the expansion and use of the Internet as part of its Technology Watch (ITU 2011), while the United Nations Public Administration Program (UNPAN) conducts periodic egovernment surveys comparing all UN members, most recently in 2010 (UNPAN 2010) when countries were assessed on both the state of e-government and their use of it as leverage in addressing the economic crisis. The Economist Intelligence Unit, working with an IBM think tank, has issued periodic "E-Readiness" surveys, most recently in 2010 (Economist EIU 2010). Academic researchers have also prepared regular international comparative surveys of e-government (e.g., West 2008, Harvard 2010).

Canada generally does well in these surveys, usually ranking in the top half dozen countries where the focus is on public sector services, a little less well when the larger society and economy are taken into account. Canada does least well when broadband and mobile technologies are given a major weight; in the 2010 Economist survey of digital economies, for example, Canada is ranked $11^{\text {th }}$, down from $9^{\text {th }}$ in 2009 , reflecting a lower score in connectivity. The greatest Canadian success in the comparative studies was the consulting firm Accenture's annual e-government survey, mainly of OECD countries, that ranked Canada first for five years from 2001-05 (Accenture 2005). This was during the period of GOL and reflected the fact that what it was doing - bringing services on line, with design and implementation strategies driven by extensive user research resonated with the approach advocated by Accenture to bring about significant change in 
how governments serve the public. After 2005, Accenture began to evolve away from an e-government approach in its annual survey, concentrating increasingly on the results of citizen satisfaction surveys; although overall rankings have not been given, Canada has generally come near, but not at, the top in the individual components under review. ${ }^{134}$ Provinces, territories and municipalities

In introducing the subject of service for the public Glassco comments on the already extensive and growing range of federal-provincial cooperation, identifying four types (Glassco 1962 3: $124-130$ ): consultation, where there is concertation of plans and operations (with the example of pooling tourism promotion); joint programs, with shared costs and administration (construction of the Trans-Canada Highway, services to the blind and disabled); delegation of functions by one government to another (Indian agents given authority as provincial welfare officers); and contracting of service by one government to another (RCMP provincial policing). Glassco's immediate purpose was to make the case for greater central agency coordination of federal-provincial relations, but this categorization still applies in the world of networked citizen-centred services and the CIO's interjurisdictional agenda.

A comparative study of how the provinces organize their central agency and collective management functions, including the areas covered by the federal Treasury Board, is a separate research project. Some general similarities and differences can be noted, however. The character of provincial programs is somewhat different from the federal government's, with much less international orientation on the one hand and more points of connection with daily life on the other. In the municipal, university, schools and

\footnotetext{
${ }^{134}$ For example, the 2008 report (Accenture 2008) looks at shared responsibility between levels of government and with the private sector. One of the featured case studies is Service Ontario.
} 
hospitals (MUSH) sectors, provincial policy ministries work through a network of local and regional authorities that are outside the Westminster accountability model. ${ }^{135}$ Although many provinces have a significant land mass and a few operate in more than one time zone, broadly speaking provincial governments act in a more compact space than the federal government. The scale of population and therefore of provincial administration varies considerably among the provinces and so does the complexity of their collective management. That being said, they all work under the principles of the Westminster model, albeit in a less elaborate, unicameral version and one where the strong governor/weak assembly model holds sway - with executive councils tending to dominate legislatures (Docherty 2005) and premiers to dominate their Cabinets (White 2005) - to an even greater extent than is the case in Ottawa.

All provinces have a CIO or other senior public servant with whom the federal CIO deals as a counterpart. ${ }^{136}$ No provincial $\mathrm{CIO}$ has the same mandate as the federal $\mathrm{CIO}$ - in some cases it is narrower, in others quite different. The stronger Ontario model is discussed in Chapter 6. A common difference is that provincial governments do not have the same national security concerns as the federal government, which greatly reduces their activity in that area, focusing them on basic IT security and protection of material assets and buildings. The other areas of management policy addressed by the federal CIO, either currently or in the past, are all present in provincial administration, although they have rarely been combined to the extent they have been in the federal government, and most provinces do not have an equivalent of TBS that oversees all the major sectors

\footnotetext{
${ }^{135}$ Nevertheless, there is a kind of vertical integration between provincial and local administration that arguably was also envisaged for the federal-provincial relationship by the drafters of the British North America Act in 1867 but did not eventuate. The patchwork described by Glassco has filled the space.

${ }^{136}$ The generalizations in this paragraph about provincial administrative arrangements are based on a 2003 Public Policy Forum study on behalf of TBS of their provincial and territorial counterparts (Brown 2003).
} 
of public administration. Most if not all provincial governments have kept their public communications functions distinct and some have also kept their privacy and freedom of information administration regimes separate. Given their scale, provincial governments for the most part have a much more consolidated technology environment, building it around the Revenue ministry or an administrative services office, although increasingly the tax collection activities of the former have been contracted to the federal Canada Revenue Agency. ${ }^{137}$ Some have a single IT back office that provides services to the entire provincial government, helped by a greater physical concentration of provincial ministries - for example, Newfoundland, where a large part of the provincial public service is housed in a single building or complex. Others have even contracted much of their IM/IT work out to the private sector (Manitoba). Some provinces have positioned the CIO to cover the entire provincial public sector, including the MUSH sectors (Nova Scotia), another variant being to give the $\mathrm{CIO}$ a role with respect to provincial economic development and the provincial IT industry as well (Alberta).

The three rooms model is further advanced in provincial governments. In addition to more integrated back offices, all provinces have been influenced by NPM-based clientcentred service philosophies and have well developed consolidated networks of physical and virtual centres providing services to the public, frequently linked with municipal service centres. These make extensive use of ICTs, in some cases in partnership with the private sector, which can operate the IT environment (New Brunswick), or deliver services on behalf of the provincial government (British Columbia).

\footnotetext{
${ }^{137}$ In Nova Scotia, this was followed by turning the provincial taxation computer environment into the IT
} backbone for Service Nova Scotia (Brown 2010a: 528). 
The citizen-centred logic has also brought the provinces to collaborate with the federal government. Even before the advent of electronic single windows, there were experiments between the provincial and federal governments in providing integrated services to common clients, an early example being a federal-provincial-municipal business service centre that opened in Place Ville Marie in Montreal in the late 1980s. An early CIO project was promotion of a Canadian Governments On-Line project to provide a common electronic source of information about government services. Building on this experience, the first version of GOL gave a high priority to linking the services themselves, and the client-oriented electronic portals that were a central feature of the second generation of GOL were conceived as fully integrating services from all levels of government to a common client group- making considerable progress in that direction in cases such as the Seniors portal (www.seniors.gc.ca) and the associated Canadian Seniors Partnership. The federal and several provincial governments have also combined the processes for registering the birth of a newborn child and applying for a birth certificate and a Social Insurance Number. ${ }^{138}$

Lying behind this collaboration is an unusual degree of interjurisdictional institutionalization. Well before the establishment of the CIO in 1993 there was a network of federal and provincial computing and telecommunications officials that became the Association of Canadian Informatics in Government (ACIG), co-chaired by a federal and a provincial official. Meeting annually since the early 1980 s, ACIG began as a network among data centres and was largely an information exchange vehicle although it was able informally to address coordination issues and points of intersection among

\footnotetext{
${ }^{138}$ Service Canada Newborn Registration site: http://www.servicecanada.gc.ca/eng/sin/apply/newborn.shtml
} 
governments (Riddle interview). With a growing emphasis on service delivery, the first federal CIO from the private sector, Paul Rummell, decided to give a greater priority to the relationship with his provincial counterparts, and catalyzed the transformation of ACIG into the Public Sector CIO Council (PSCIOC) in the mid-1990s. In addition to the federal, provincial and territorial CIOs it added two representatives of the Municipal Information Systems Association (MISA), the network of local government CIOs.

At about the same time that ACIG evolved into the PSCIOC, a federal-provincialacademic network formed as the Citizen Centred Service Network (CCSN), ${ }^{139}$ working initially with the federal government's Canadian Centre for Management Development (now the Canada School for the Public Service). CCSN sponsored the first of the series of Citizens First surveys of the public's client service needs and preferences that have been the backbone of the approach taken in service initiatives in all levels of government, including GOL. ${ }^{140}$ This work spawned regular meetings of the heads of the provincial service-to-the-public agencies with their federal counterparts (initially from the TBS service sector and later also Service Canada), which by 2001 had been formalized as the Public Sector Service Delivery Council (PSSDC). In the same year the PSSDC established the Institute for Citizen-Centred Service (ICCS), based in Toronto, to be its research arm. The PSCIOC and PSSDC also began meeting together, and in 2002 they adopted ICCS as their joint secretariat and research agent, based in offices supplied by the Ontario government and with staff loaned by the federal and other governments. Both

\footnotetext{
${ }^{139}$ A more detailed account of these developments can be found in Marson and Heintzman 2009. See also Brown 2007: 44-45 and Kernaghan 2007a: 107.

${ }^{140}$ This research base was a major factor cited by Accenture in awarding Canada (essentially the federal government) its first place ranking for five years at the height of GOL.
} 
for financial reasons and because it began to attract international interest, the ICCS was incorporated as a not-for-profit organization in 2005.

Both Councils have a federal and rotating provincial co-chair (the CIO is the federal co-chair of the PSCIOC) and meet several times a year, in person and virtually. The PSCIOC addresses joint requirements and common concerns, which have included: coordinating collaboration on Year 2000 initiatives; developing common technology standards and management protocols for inter-jurisdictional information transfers, notably to address privacy and IT security concerns; and establishing a national register of public sector IT standards. Much of this effort has been to support the more substantively-oriented work of the PSSDC. In addition to the secretariat for the two Councils, ICCS activities have included conducting regular Citizens' First and Taking Care of Business surveys; developing and maintaining the Common Measurement Tool, a citizen survey instrument; a benchmarking database of service innovations in the public and private sectors in Canada and internationally; and supporting the professionalization of the service delivery functional community through curriculum development and certification programs. In recent years, the ICCS has also had a growing international program (ICCS 2010).

One other unusual feature of this interjurisdictional collaboration is the role played by a private sector media organization, ITWorld Canada, which has trade publications directed at both the public and private sector IT and CIO communities (ITWorld Canada 2011). In the early 1990s ITWorld Canada began to host conferences of public sector senior IT and service officials, together with senior executives from private sector vendors, consultants and researchers, at a resort centre at Lac Carling in the Laurentians. 
These conferences included both on and off the record discussions and were promoted as a major networking opportunity for the participants (apart from any benefits to ITWorld Canada). The early Lac Carling conferences played an important part in incubating both the PSCIOC and the PSSDC, and they have become an annual institution, retaining the name although not the location. Of continuing significance, the Lac Carling conferences have provided a venue for informal contacts and information-sharing between the public sector CIOs and their private sector suppliers, combining problem-solving with forward looking that, as discussed earlier, is more difficult to carry out in the context of any given jurisdiction's vendor-client and contracting relationships.

The logic of citizen-centred service - as the ICCS expresses it, of taking an outsidein approach to service improvement - has therefore created a set of interjurisdictional dynamics that are not found in other areas of management. The extent of collaboration is itself unprecedented, including the establishment of a network of institutional relationships to sustain it. By their nature, these activities go to the boundaries of federal, provincial, territorial and even municipal jurisdiction, in many areas blurring those boundaries in the image of the single citizen-taxpayer. Needless to say, there are associated accountability issues. The challenge of ministerial accountability for the frontoffice service delivery agent is common to all jurisdictions, ${ }^{141}$ so pooling service delivery across jurisdictional lines adds to the complexity. To a considerable degree, however, it is a matter of alignment. Each jurisdiction has its own internal and legislative regulatory and oversight machinery, and a useful test in any given circumstance is to ask whose information is in question, who is in control of it, whose privacy commissioner (or

\footnotetext{
${ }^{141}$ This is setting aside the fact that local government in Canada does not operate under the Westminster model and Nunavut and the NWT have made significant modifications to it.
} 
auditor general) has oversight, and ultimately, which minister and legislature provides the forum for addressing problems that arise? In many respects, these issues, which are practical ones given the large amount of information flowing between jurisdictions and the interlocking nature of their dealings with the public, are similar to those of sharing liability and risk that arise between the public and private sectors. Here again, however, there is a grey zone, which in the public sector is political, with the underlying currency being credit and blame, rather than financial cost and corporate survival. The potential for political controversy is very real, but in practice the risks have so far not been realized. This may be because politicians have not yet become fully engaged in the implications of citizen-centred federalism (Ambrose et al. 2006). It may also be due to a successful abundance of caution on the part of the CIOs and other senior officials involved - or because in the final analysis better service is generally considered to be good news.

\section{Conclusions}

The CIO is riding a tiger. The beast's form and characteristics are to a considerable extent historically determined - a combination of institutional nature and political and administrative nurture - and there is no question that the digital leadership provided by politicians, senior, middle and front-line public servants and especially by the CIOs (Borins and Brown 2007b) has also been an important factor. But if the tiger's physiology is important, so too is its ecology (Hodgetts 1973), which, to extend the metaphor, includes both the flora and fauna with which the CIO interacts and the underlying topography. This chapter has sought to explore and to explicate both the physiology and the ecology. It attaches considerable importance to the influence of the 
Treasury Board policy model, in terms both of the IM/IT space that it defines and of the roles and relationships that flow from the model within that space.

With a half generation of evolution since it was inaugurated, the CIO and related sector are well established as a public sector administrative institution. The CIO and CIOB have embraced the Glassco model for management of government as an entity/enterprise, with its core features of centralized, politically driven decision-making about administrative policies that are implemented through decentralized mechanisms overseen and led by the CIO as a senior TBS official. The resulting matrix is complex, not least because the leadership instruments available to the $\mathrm{CIO}$ are in many cases horizontal ones of convening and persuasion, working through others and vertical structures, rather than the kind of integrated command and control available in principle to managers of government programs and services directed at the Canadian public.

Taken together, the CIO-related Treasury Board policies define a distinct although still relatively new and in any case still evolving - terrain, with individual components and a combination of components that are important to modern governance. This terrain has some fixed elements: government policies with respect to management of the government's information and its information technology, public access to that information, protection of information that is personal to Canadians, security of government information and assets, and behavioural norms for use of the electronic environment by public servants. There are also some closely related substantive areas, notably government communications and branding and the wider set of norms to do with service to the public, in which information and technology play a central role. These have rotated in and out of the CIO's mandate in the past, and in any case share the IM/IT 
space. A second set of close CIO linkages relates to management procedures: instruments that are central to the IM/IT space, even if not defined by it, including with respect to investment planning, contracting and management of major projects, as well as several dimensions of human resources management.

In many respects the rise of the CIO reflects the rise of information and ICT-related hardware as major assets of government, as well as their becoming important building blocks in the "new" economy. This makes them the newcomer on the public administration block, taking their place along with people and money, the traditional primary concerns of central public sector management. While asset management is a longstanding feature of government, and in that sense relatively easy for central management agencies such as Treasury Board to absorb, the CIO brings new features and emphases that are not traditional and have posed a challenge to the Treasury Board model. One is the link to systemic change, even the potential - to the point of being an article of faith in the minds of many of its advocates - of IT and IM to transform public administration in directions that are often unprecedented, carry considerable risks but also offer significant pay-offs. This potential is reflected most clearly in the area of government services, both to the public and to government itself - two areas of considerable recent organizational and policy volatility.

The CIO's span of interests also brings into focus a number of relationships and linkages to other areas of society that in some cases are not altogether new for Treasury Board but assume greater importance in the IM/IT space. Information and technology bring into the mainstream a set of skills, many of them highly technical but in regular need of refreshing, with the result that a significant part of the CIO's work is in the realm 
of public service human resources leadership and management. Even more than in other sectors of public administration, there is a need for the general workforce to absorb basic IT skills but also to harness a diversity of professional orientations and especially to align technical and lay perspectives in high-level decision-making. The make-or-buy challenge that runs through all of public administration is particularly acute in the IM/IT space, raising questions about both the balance between insourcing and outsourcing and the management of the complex set of dynamics that outsourcing brings. Even more challenging are the implications of the focus on service, especially to the public, that comes with IT. These run in two principal directions, arising from the ethos of citizencentred services: issues of values and citizenship, with their links to the political process; and collaborative relationships with other jurisdictions, increasingly ignoring as opposed to cutting across jurisdictional boundaries. Interesting new institutions have emerged in the latter area in particular, but also unanswered questions about where they lead.

Many of the issues in the IM/IT space are being played out in the context of the Treasury Board model, which so far seems capable of absorbing them. Indeed they have shown the Treasury Board model working at its best. As portrayed by Dunleavy et al. (2006: 47) TBS and the CIO have been cheerleaders for e-government, and setting up the $\mathrm{CIO}$ "seems to have created a key political champion for e-government, sending an important message both domestically and internationally." In their view, this central initiative was reinforce by strong support from the Clerk in the formative period of GOL, highly effective cross-government coordination, a committee of Deputy Ministers in a leadership role, and a useful part by PWGSC, especially in the areas of procurement and the Secure Channel. 
There has, however, also been some fraying around the edges of the Treasury Board model, as well as pressure points on the Canadian Westminster model. The latter arise in at least two respects. One is the implications of a renewed emphasis on collective management, flowing from the logic of networked technologies, after a period where managerial philosophies have privileged decentralization, deregulation, and empowerment. Although the collective dimension of political accountability has never disappeared from the Westminster model, in particular its Canadian variant, it has been de-emphasized through the force of events and of administrative philosophies. That particular wheel appears to be turning, assisted by networked information and technology but also foreseeably by new financial stringencies. The other significant pressure is on the distribution of power embedded in the Westminster model and pressures to make the policy process more accessible to an informed public (Roy 2008).

The CIO, responsible for policies that demarcate the boundary between the public and the private spheres and that are designed both to promote democratic participation in public life but also to protect public information and space, is at the heart of these debates. The most potent set of forces relates to the substantive aspect of the IM/IT nexus, the information that government acquires and holds and that is an asset in itself. This is the source of the CIO's greatest potential and its greatest uncertainty. To date, the potential has not been realized - that is the subject of chapter 5 . 


\section{Chapter 5 - The Pivotal Role of Information Management}

Where is the wisdom we have lost in knowledge?

Where is the knowledge that we have lost in information?

(T.S. Eliot, "Choruses from The Rock" 1934)

Information is the cornerstone of a democratic, effective, and accountable government.

(Treasury Board Policy Framework for

Information and Technology

Canada TBS 2007b)

Information is the key to the longer-term success of the Chief Information Officer (CIO) and also its greatest challenge. It embodies a paradox: it is the lifeblood of modern public administration, lying at the heart of government decision-making and the relationship between government and the governed. The vision of knowledge-based government is based on the transformative power of information when harnessed with information and communications technologies (ICTs) in support of the knowledge-based society and economy. Information is also the government's most enduring asset, assuming a life of its own that can last decades or even centuries, and the management of information is one of the oldest disciplines of public administration. At the same time, information management (IM) has been one of the most volatile elements of the CIO's mandate, creating tensions between information and technology in the CIO's focus, between policy management and project leadership in its role, and between asset management and innovation in its orientation. An equilibrium has now been achieved, but one that constrains both the $\mathrm{CIO}$ and the potential for knowledge-based government. Chapter 3 describes the chequered history of the CIO's IM mandate, and chapter 4 surveys the IM space that has emerged in the past two decades and the CIO's role within it. This chapter explores in greater depth the nature of information and IM and the reasons why they are at the same time so central and yet so challenging to the CIO. 
In a technology-enabled environment information has been given new shape: it is given away, but it is also sold and has its own economic model (Tapscott 1996). Information is integral to the power of the modern state, with some authors (Braman 2006) arguing that the information state is replacing the Weberian bureaucratic state, itself anchored by written documentation. Information is also integral to democratic accountability: financial information is central to management of the executive branch of government and its relationship with Parliament. When introduced, Access to Information legislation was seen as a cornerstone of accountable and honest government (Robertson 1978), but the use of statutory mechanisms to gain access to information has become politically contentious (Roberts 2006, Pugliese 2010, Martin 2010). While the availability of information is central to exercising the rights and obligations of citizenship, control of the apparatus of government communications has become a critical tool of modern politics.

Over time, information has been held in a wide range of media and formats, although hand-written and printed paper records have prevailed for most of Canadian administrative history. With the advent in the past two decades of networked computing and databases, the Internet and related ICTs, there has been a growing recognition in governments across Canada and internationally that their knowledge base is a defining element of their role in the knowledge-based economy and society and therefore a critical resource (Lenihan et al. 2002). This also defines many of the services provided to the public and has given rise to a vision of knowledge-based government (Canada IHAC 1995, Tapscott 1997), linking the potential of ICTs to the skills and experience of public service staff and making fullest use of what government knows in support of more 
effective public policy and public administration (Bontis 2007b). As the largest holder of information in the country, the federal government's own information management practices and information-based services to the public are central to realizing the vision. In turn, IM is given greater prominence as a discipline of public administration.

Notwithstanding the power and potential of information, as discussed in chapters 3 and 4 its management has been one of the most vexed and challenging areas of responsibility for the CIO. In its earliest incarnation, the CIO was not assigned a significant role with respect to information and IM, in either the position's title or its mandate. While an array of information-related responsibilities was soon added and the CIO title was later rebranded to feature an information role, in practice these were largely sloughed off in the CIO's first decade. More recently they have been treated as a central, even a defining, feature of the CIO mandate and supporting organization; "leadership in implementing the Government of Canada Information Management Strategy" is listed first among the CIO's main activities and policy responsibilities (Canada TBS 2010a) and four of the six major organizational units within the TBS CIO Branch (CIOB) are defined wholly or substantially by information-related responsibilities. ${ }^{142}$

At best, the promise of information and of knowledge-based government is a work in progress, and deficiencies in the management of information have been a major concern among senior managers in all levels of government (Brown 2007: 60). ${ }^{143}$ In the

\footnotetext{
${ }^{142}$ Three major CIOB units reporting to the CIO are information-related: the Information and Privacy Policy, Information Management, and Security and Identity divisions. In addition, the Organizational Readiness Office (ORO) works with the IM and IT functional community in government departments. The two other major CIOB units are the IT Project and Oversight division and the recently-returned Service sector. In addition to the CIO, the CIOB's top management also includes a Deputy CIO (Canada TBS 2010a).

${ }^{143}$ The reference is to the results of three surveys of senior federal, provincial and municipal officials conducted by the Public Policy Forum on citizen-centred web-based service delivery (i.e., GOL and its counterparts in other levels of government). All groups identified IM as the area of greatest concern in
} 
federal government the $\mathrm{CIO}$ as an institution is firmly established as is IM as one of its top priorities. IM is also understood to be critical to the ultimate success of the CIO and to achieving the promise of ICT-enabled public administration. Nevertheless, even its most optimistic proponents agree that the IM agenda is highly ambitious and will take a long time to realize, both its individual aspects and as a defining characteristic of government.

This situation can be explained for a number of reasons, many of them rooted in the circumstances of the federal government's institutional response to the widespread introduction of ICTs in the 1990s that were discussed in earlier chapters. In considering the implications for the CIO and for realizing the potential of IM, five sets of factors provide both an explanation for the current situation and identify obstacles to overcome. These are: the historical neglect of information and records management in public administration before the CIO was established; tensions between the CIO's technological and IM roles; the lack of a unified understanding of what IM encompasses and tensions among the information policy areas; weak recognition and consequent undervaluing of information as a public resource; and vulnerabilities in the CIO's relationship to public service governance and reform, especially in information-related areas. The latter factor in particular has been compounded by uneven attention from the senior levels of the public service and ambivalence, at times hostility, at the political level.

The second half of this chapter addresses these reasons in turn. Individually each represents a significant challenge to effective management and use of the government's information holdings and therefore to the CIO's effectiveness. Cumulatively they have identifying IM as a - if not the - major unresolved area in ICT-shaped public administration. 
made it very difficult to realize the potential of information and knowledge-based government - and consequently of the CIO. In order to address these issues, however, it is important to understand the nature of information, the impact on it of modern ICTs, and the role of information in public administration. This is where the chapter begins.

The chapter draws primarily on secondary literature and on interviews. About a third of the interviews, in addition to the $11 \mathrm{CIOs}$ and Acting CIOs, were largely about or had useful insights to offer about information management. 10 of those interviewed had worked on IM policy-related issues in TBS, covering most of the information-related policies; 3 were interviewed due to their link to Library and Archives; and 4 others were involved in ATIP issues through the offices of the information and privacy commissioners and the Department of Justice. 4 had worked with IM policies as departmental CIOs and one as Deputy Minister of an information intensive department, while 7 had sightings of federal IM practices as private sector managers and consultants and in one case as a journalist.

\section{Information and Its Context}

Information and technology have been an integral part of public administration from the earliest forms of empire and social governance. Rulers have needed information about their territory in order to take decisions relating to it. Recorded decisions and laws are required both to guide their implementation by the agents of the state and so that subjects can be aware of their rights and obligations and act accordingly. Information lies at the heart of the modern bureaucratic state. More generally, information is central to a society's definition of itself and its presentation to others. These dynamics have been in 
play from earliest times. As discussed in chapter 2, they have also been characterized by an inextricable link between information and technology, and between content and medium, where advances in technology have driven changes in how information is collected and used and ultimately - through impacts on the dynamics of space and time in the nature of the state itself (Innis 1950).

This section begins with an operating definition of information and technology as a reference point for the balance of the chapter. It then considers the implications of the various formats in which information is recorded, held and used, followed by the hierarchy commonly assigned to information by information theory. This leads to a discussion of the information life cycle, a basic archival concept that has influenced government information management policies and practices. Much of the earlier discussion in the section is independent of the medium in which information is held or the technology shaping that medium, and the section continues with a brief analysis of the relationship between information and technology, in particular in the context of the dominant technologies of the past two decades. Finally, it reviews the role of information in public administration, in particular the sources of government information and the uses to which it is put - the building blocks of knowledge-based government.

Information and technology defined

There is no standard definition of information (Rowley 1998), either in general use or in government policy statements. The dictionary definition is not very precise, but sketches a territory: the Canadian Oxford Dictionary's primary definition is "something told, knowledge", followed by "items of knowledge, news." An additional meaning is "data as processed or stored etc. by a computer system." The Latin derivation of the root 
word "inform" means to "give shape to, fashion, describe," which adds a purposeful dimension. The definition of the singular "datum" is narrower: "a piece of information," but also "an assumption" or "fixed starting point", derived from the Latin for "thing given." Knowledge is a broader concept, including "awareness" and "a person's range of information" but extending to "the sum of what is known." Taken together, these definitions verge on the circular but they do indicate something with substantive content that lends itself to use and management. After a multidisciplinary survey of definitions of information, Rowley identifies five, as: subjective knowledge, useful data, resource, commodity, and constitutive force in society (243).

Technology is no less enigmatic. Political philosophers have described it as the society-shaping dynamic (Ellul 1964), while the Canadian Oxford Dictionary defines it as "the study or use of the mechanical arts or applied sciences," coming from a Greek word meaning "systematic treatment," rooted in the Greek word for art. Treasury Board's Policy Framework for Information and Technology (Canada TBS 2007b) defines information technology (IT) in terms of the medium that houses the content: "any equipment or system that is used in the automatic acquisition, storage, manipulation, management, movement, control, display, switching, interchange, transmission, or reception of data or information." The operative word is "automatic." The definition goes on to make a vital link to purpose-driven management: "It includes all matters concerned with the design, development, installation and implementation of information systems and applications to meet business requirements" (TBS 2007b: Appendix - Definitions). 


\section{Information format}

Information, especially to the extent that it is influencing behaviour, is in principle independent of its medium. At a given point in time and in the context of a particular event its most important existence is in the minds of the individuals who are acting on the basis of the information they have obtained and how they respond to it, influenced by the hardwiring of their brains, their accumulated experience, and the cultural context in which they are operating. It is not the purpose of this dissertation to enter into the realm of cognitive psychology, but the relevance of that discipline cannot be ignored. Similarly, oral culture (one might say, in the current IT metaphor, the cultural cloud) provides the basic medium for the organization and transmission of information at the societal level. This has always been the case, although since the development of the alphabet oral tradition has increasingly had to make room for the written. Each is inextricably linked to the other, however, and new communications technologies have been as much about broadening the reach and complexity of orally-transmitted information as about the written - increasingly about the two in combination.

In the context of the evolution of the modern state, however, and of contemporary public administration, the critical moving part is recorded information: information that is captured in an enduring medium and that can reliably be retrieved for later use. Information thereby assumes a life of its own, independent of its original production, with a distinct existence through space and time. Oral communication remains an important part of information production, conveyance and use, but in the context of public administration at least, retrievable recorded information is the reference point, 
especially over time. In this paper, therefore, information is discussed in its recorded context, but with the essential corollary that it swims in the sea of oral communication.

ICTs have simply multiplied the range of possible media in which information is held and conveyed, compounding but not creating the complexity of public sector information management. Tablets of stone as an enduring medium are as old as the Ten Commandments or Hammurabi's Code and can be found today in public monuments enshrining messages that society does not want to forget. The transition from wax tablets to papyrus to paper as the dominant medium of record-keeping and information dissemination is central to early accounts of the changing nature of empire and administration (Innis 1950). Public art ${ }^{144}$ and bronze plaques also have their place in the national political narrative. The two-row wampum belt (Gus-Wen-Tah) - made of coloured beads - exchanged between the British American Superintendent-General of Northern Indians, Sir William Johnson, and First Nations leaders in 1764 to cement the Royal Proclamation of 1763, provides a key link of constitutional legitimacy for contemporary land rights negotiations (Borrows 1997).

While few of these earlier forms have been totally eliminated as part of the public record, paper has been the primary medium for most of Canadian administrative history, and the management of paper documents has been the enduring focus of information management. Even paper has a number of dimensions: paper has long been a basic medium for conveying information to the public, but over time there have been variations both in how it is recorded and in the paper itself. Well into the $20^{\text {th }}$ century handwritten records were a major (until the invention of the typewriter in the late $19^{\text {th }}$ century, the

\footnotetext{
${ }^{144}$ See, for example, the paintings in the Senate chamber depicting World War I battles considered to be formative events in the assertion of Canadian political nationhood.
} 
only) format for internal record keeping. Even today handwritten notes made for transitory purposes are subject to the Access to Information Act. An important concern for librarians and archivists has been the durability and permanence of paper (Feather 2004) - for much of the $19^{\text {th }}$ and $20^{\text {th }}$ centuries government records and publications were kept on paper containing acidic chemicals that result in significant deterioration over time. This has led to the reintroduction of acid-free paper but also to a search for accessible and enduring digital media for long-term information preservation, including a major study of digitization sponsored by the Information Highway Advisory Council in the mid-1990s (Canada Federal Task Force on Digitization 1997). A different storage problem results from the rapid evolution of office automation software, with electronic records developed even a decade ago inaccessible in obsolete equipment and at risk of deterioration.

The government's approach to information management acknowledges this diversity of formats but also seeks to navigate around it by focusing on recorded information, broadly defined, which is presumed to be retrievable. The Access to Information Act applies to any recorded information, regardless of medium, but also establishes a core distinction between records "under the control of a government institution," to which the Act applies, and information in the public domain, notably government publications, which are outside its purview. The same limit applies to the Privacy Act. This distinction establishes the boundary between the Treasury Board Access to Information and Government Communications policies and also between public service archival and library functions, although both boundaries have been blurred in the electronic era. 


\section{Information hierarchy}

The dictionary definitions for data, information and knowledge can be loosely linked together in a continuum: a datum is an item of information, information is a collection of such items, and knowledge is an array of information. Information theorists have described an ascending hierarchy, often portrayed as a pyramid with a fourth level, wisdom, at the apex (Rowley 2007: 164). Some authors add embellishments, such as understanding as a level between knowledge and wisdom, or enlightenment as a state beyond wisdom. Often referred to as the DIKW hierarchy, its elements are assigned a wide range of definitions and usages (Zins 2007). Typically, each level is defined in terms of a value added or judgment applied to lower levels, often progressing from "raw" data to integrated knowledge, but "there is less consensus in the description of the processes that transform elements lower in the hierarchy into those above them, leading to a lack of definitional clarity" (Rowley ibid.)

The information hierarchy was first articulated in the 1980 s, coinciding with the accelerating automation of information holdings, although many authors point to T.S. Eliot's 1934 poem The Rock (Eliot 1934) as providing an early insight. It can also be speculated that inspiration has been provided by atomic theory's hierarchy from subatomic particles to complex materials in a dynamic relationship and similar models in the biological sciences. The information hierarchy does not have a specific application, and variants and debates can be found among related but not entirely similar schools of thought such as knowledge management. Although the inwardness of such distinctions can be important in some contexts, the general concept of a DIKW-based hierarchy provides a common "mental map" for public servants working on information and on 
technology issues and between them and service providers in the private sector. There is also resonance with similar hierarchical models in networked computing, providing yet another area of potential common ground. ${ }^{145}$

Information life cycle

A concept that has had a more direct influence on public sector information management is the information life cycle. Well established in the archival community, the information life cycle was incorporated into Treasury Board IM policies after passage of the Access to Information Act in 1983.

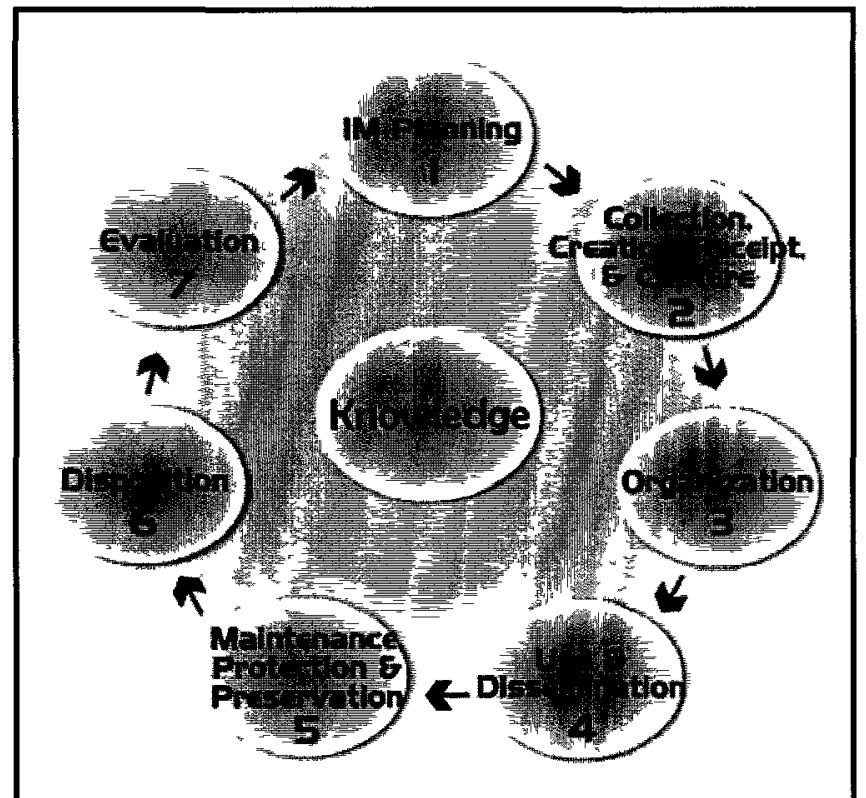

Figure 1: Records and Information Management Life Cycle (Canada LAC 2008:7)

Four stages are particularly important: acquisition of information, whether internally generated or obtained from external sources; its use; its maintenance, preservation and use beyond initial use; and its ultimate disposition, normally either permanent preservation or - in the majority of cases - destruction (see stages $2,4,5$ and

\footnotetext{
${ }^{145}$ For example, the service model for computer networking is based on horizontal layering of network protocols (which govern the exchange of messages within and among layers and the actions taken when messages are sent and received). A common version is the Internet Protocol stack, which has five layers, reflecting the architectural layers of a network, with each protocol layer providing the foundation for the one above: physical, link, network, transport, and application (Kurose and Ross 2008: 7-9, 45—51).
} 
6 in figure 1). The government's life cycle model includes three other stages intended to provide a more systematic IM approach: planning before collection, organization after acquisition, and evaluation after disposition - setting the stage for planning a new cycle (stages 1, 3 and 7).

This application of archival concepts to government information policy arose from the fact that under the Library and Archives Act Library and Archives Canada (LAC) is the ultimate repository for government records, and it serves its purposes to have as much discipline and uniformity as possible in government records management before files are turned over to them. It was also important to establish groundrules and a clear division of labour between departments and LAC for decisions about long-term retention and disposition of records after current "business" requirements have been met. An archival perspective has long been present in government, but the catalyst for developing an IM policy was the requirement under the Access to Information Act that government institutions produce records requested under the $A c t$ within 30 days - a requirement that continues to place considerable pressure on government information and records management practices.

The information life-cycle has been used to provide conceptual linkages and coherence among the various Treasury Board information management policies. ${ }^{146}$ Although these linkages have at times been honoured in the breach, there are several policies that build on the core information management policy, which embeds the cycle as a whole and promotes IM practices associated with it. The Access to Information

\footnotetext{
${ }^{146}$ An important contributory factor was that a number of archivists from the then National Archives participated in the task force that drafted the Treasury Board Access to Information and Privacy policies in the early 1980 s and then joined the TBS information policy centre. Some of the same group were later involved in drafting the original Government Security Policy and in integrating the Government Communications policy into the Treasury Board information policy suite.
} 
policy (Canada TBS 2008b), based on the $A c t$, is concerned with organization and dissemination - in response to requests under the $A c t$ - as well as protection in the case of exemptions. Its companion, the Privacy policy (Canada TBS 2008c) addresses the same concerns as Access to Information with respect to requests from individual Canadians for records held by the government about themselves. Based on the Privacy Act, the policy also regulates the collection, use and in particular the re-use of personal information, and has a general orientation towards information protection. The Government Security policy (Canada TBS 2009a), especially when first developed, is cast in terms of protecting government information, based on risk analysis, and ensuring appropriate protection to information deemed sensitive. An early concern was to align traditional security classification categories with the various exemptions and exclusions under the Access to Information and Privacy (ATIP) Acts. A greater challenge has been alignment with provisions in the Security of Information Act (which subsumed the moribund Official Secrets Act in 2001) concerning leakage of sensitive information and whistleblowing from within the public service and espionage from outside.

The reverse side of the coin is information dissemination. Complementing ATIP access provisions, the Government Communications policy (Canada TBS 2006) is designed to promote publications, advertising and other forms of public information dissemination, including establishing the framework for the long-standing Depository Libraries program (Canada PWGSC 2010) under which the government places master sets of its publications in public and university libraries across Canada. Through its regulation of public opinion and other forms of research, the policy is also concerned with information collection by the government. The Federal Identity Program (FIP - 
Canada TBS 1990), which is closely related to the Communications policy, establishes corporate identity standards for government institutions, with a view to enhancing the visibility of government activities and through that their accessibility and accountability. An extension of the FIP has been the establishment of a "common look and feel" for the federal presence on the Internet, including standards for web page design and navigation and for promoting on-line accessibility.

At the other end of the life cycle are regulations established by LAC governing the eventual disposition of government records (Canada LAC $\mathrm{n} / \mathrm{d}$ ), beginning with procedures for departments to screen out records not needed for current business purposes, leading to their transfer to LAC and decisions about destruction and long-term preservation. While only a minority of files are kept for the longer term, considerations supporting retention include providing evidence for the historical record, future business requirements of departments, and long-term accountability exercises - Indian residential schools are a recent case that has highlighted the importance of the historical record for commissions of inquiry and the courts. An incentive to keep the permanent record relatively small is the cost of long-term storage. Running against this has been the explosion in quantity and complexity of electronic records, with the associated challenge of keeping an inventory of outdated office automation equipment in order to access electronic records on word processing software versions that are no longer in current use.

\section{Information and technology}

Any consideration of information is never free from the role played by technology. The media in which information is recorded - even acid-free paper - are all shaped by technology, and to a great extent changes in the uses and impacts of information are 
driven by technological change. While this has always been the case, in the past generation there has been a sea change in the relationship between information and technology, shaped by the Internet and the related convergence between telecommunications, computing and broadcasting (Rowland 2006) - a process that, as discussed in earlier chapters, has been largely beyond the control of government.

Electronic databases facilitate consolidation of information well beyond the scope of paper-based filing systems, while networking greatly broadens access. By their nature, databases break information down into its data elements, making it possible to link and recombine information in an open-ended number of ways, according to the needs of users (within, of course, the limits of the extent and quality of the data and the design of the database). Networked databases increase the range of potential uses for information and also its value, both to government and as a service to the public. This puts particular pressure on personal information, much of it collected as a function of coercive state powers but requiring cooperation from those providing the information. As a result, government needs to maintain citizen trust, if only to maintain the continued flow of accurate personal information, while making best possible use of the information at its disposal. The new technologies increase by an order of magnitude both the amount of information in the hands of government and the speed with which it is acquired. They also increase the channels by which it is acquired and the media and locations in which it is held, creating a significantly more complex information management environment. By the same token, the government's ability to disseminate information is greatly increased. Compounded by 24-hour news media, information's importance has been increased as both an instrument of political action and a source of political risk. As discussed later in 
the chapter, it is this latter characteristic especially that poses a major challenge to the realization of the full potential of information management in the public sector.

\section{Information and public administration}

The information life cycle, as captured in government administrative policy, is intended to apply at a number of levels. At its most basic it addresses how individual documents and records are handled over time, and the intent of IM policy is to encourage their originators to give thought to what will happen to them after serving their original purpose. This in principle leads to the development of aligned institutional and personal filing systems - in practice with varying degrees of systematic organization and usually involving both paper and numerous electronic formats in some combination of mainframe, networked and desktop computer drives, memory disks and keys, and the memories of mobile phones, laptops and other portable devices. The effectiveness of government information management has always been sensitive to practices at the individual level. It has been heightened by the move towards electronic records - where to at least some degree everyone from the most junior clerk to the most senior manager has become their own stenographer and file clerk - compounded by reductions in clerical and secretarial staff justified by the wide availability and use of desktop computers and other electronic office equipment.

The actions of originators and recipients also shape the management of information at the level of the work unit, program, and government department or agency. At these higher levels of organizational aggregation, departmental and government-wide IMrelated policies and institutional capacities come into play, including specialized staff whose jobs are defined by aspects of the life-cycle and related Treasury Board policies. A 
major challenge is to ensure that record-keeping practices of individual public servants are integrated with those of the organization and in a way that facilitates finding records created by others and at other times. As a result, considerable effort has been devoted to developing and promoting government-wide standards for describing and organizing records and data and for "tagging" them so that they can be found electronically. ${ }^{147}$ In the first instance, this is with a view to making the full inventory of records and information accessible and useable at the level of a department, both so it is fully equipped to do its work as a knowledge organization and in order to meet the requirements of the Access to Information Act, which are imposed on government institutions and their ministerial Heads. In the larger vision, a single standard of access and utility, with enabling infrastructure, should apply to the management of information in the government as a whole. It is clear from interviews, however, that a common government-wide IM environment (in which a key test is whether information held by one department is accessible to another) is considered likely to occur in the medium to longer term, if ever. $^{148}$

\footnotetext{
${ }^{147}$ This includes government "metadata" standards for describing and cataloguing information, based on the international Dublin Core Metadata Initiative, and the use of controlled vocabularies for indexing and information retrieval purposes. Both aspects are governed by Treasury Board standards under the Policy on Information Management, with more detailed guidance provided by LAC and interdepartmental working groups of government librarians, records managers and webmasters.

${ }_{148}$ In contrast, major multi-national technology firms such as IBM or Cisco, which operate globally and on a scale that is comparable to that of the Government of Canada, have highly integrated information and technology environments, often with single desktop, office automation and financial management applications. Their establishment of a common information environment has been made easier by a smaller number of business lines and more integrated operations - a business line (even when headed by its own $\mathrm{CEO}$ ) generally has less administrative autonomy within a global corporation than does a government department headed by a politically visible and accountable Minister - as well as by the fact that these are corporations in the information and technology business. Nevertheless, many global firms have been able to drive through this level of integration, justified both by cost reduction and efficiency and by enhanced organizational effectiveness. (Kent interview, Ansari interview)
} 
Even though integrated government-wide information management largely remains an aspiration, ${ }^{149}$ the information life-cycle can also be seen at work at the level of the government, underlying the stages of the policy cycle, the array of policy instruments available to government, and the range of its activities. As an information-based organization, defined by what it knows, government obtains its information from a number of sources and uses it in a number of ways. Annex 10 provides a high level overview of the categories of information that the Government of Canada works with and of activities that its information holdings support.

The building blocks of knowledge-based government are provided by five broad categories of information that departments generate, collect and use, the precise mix depending on the nature of their program mandate, the policy instruments available to them and their role in government. As a first major source, a number of departments conduct large-scale in-house scientific research, both as a service to the public and sectors of the economy and in support of regulatory activities - this ranges from crop and oceanographic research to communications research and weather forecasting. These departments also collaborate with and commission research by universities and other non-governmental groups and sponsor the linkage of pure and applied research. A crosscutting support to government science is provided by the National Research Council. A second major source is regulatory and enforcement activities, which include information

\footnotetext{
${ }^{149}$ There are of course certain centrally-prescribed information management systems that are observed in common by all departments, usually linked to collective management and decision-making. These include: the Cabinet papers system (Canada PCO 2010b), supporting Cabinet decision-making, similar documentation systems for Treasury Board and Governor-in-Council submissions, and the expenditure management system (Canada TBS 1996), which structures information for internal and Parliamentary decision-making about departmental appropriations and then for accounting for the subsequent spending. It is also linked to the information system for tracking government revenues and assets. Another use is to track public service hiring and staff movement on a government-wide basis. Many Treasury Board policies have information collection and reporting requirements, but they vary considerably in the extent to which they result in common IM practices across government.
} 
provided by regulated organizations as well as that which is collected by government inspectors - related activities include tax collection, spectrum management, environmental and health regulation, and policing.

The third category - one that applies to all departments - is information obtained through the administration of departmental programs, which can include licensing and grant-giving activities, advice and support to economic and social groups, and the provision of information to the public in general. A fourth category, that in some ways complements in-house science as it represents an internal form of knowledge creation, is the collection and processing of foreign and domestic intelligence - in some cases this defines the organization's program mandate (e.g., the Canadian Security Intelligence Service (CSIS) in the Public Safety portfolio; the Communications Security Establishment (CSE) in the National Defence portfolio), in others it arises from broader program mandates (for example, diplomatic and military activities abroad, border security, airport and port security, criminal intelligence).

A fifth category of information sources is the specific and the aggregated information that is generated by central agency support to government decision-making and resource allocation. When brought to bear in ministerial decision-making, it includes political intelligence and partisan considerations that are not the purview of the public service but that define the role of the Prime Minister's Office and ministerial exempt staffs. ${ }^{150}$ In addition, all departments and policy sectors draw heavily on the information collection and processing work of Statistics Canada, the backbone of which is the

\footnotetext{
${ }^{150}$ This model for providing political intelligence and partisan support to Ministers is a distinctive feature of the Canadian version of the Westminster model, as compared, for example, to Britain where political and public advisors are combined in the Prime Minister's Office or Australia where senior public servants may identify themselves with political parties (which is also the case in most of Continental Europe). See also the discussion in earlier chapters of the Canadian Westminster model.
} 
Census. Other major external information sources that go into the mix include the media, scholarly publications, and interactions with the public. Internal sources include management information generated by internal administration and the considerable quantity of information and commentary generated by the processing and combining of all the other sources, including the government's accumulated inventory of records.

Once collected and organized, government information is put to a variety of uses. Common to all departments is the use of information in support of policy development and program operations within the individual policy sectors to which the departments are linked. A second category, which in some ways is a sub-set of the first, is informationbased programs. These were highlighted in the Government On-Line (GOL) initiative, which identified 63 information services in the 30 participating departments and agencies that were successfully brought on-line (Canada PWGSC 2006: 73-80). They include departmental and client-oriented information websites ${ }^{151}$ but also services such as weather forecasts, Estimates documents, statutes, information for small and medium businesses, and wait-time advisories at border land crossings. The $67 \mathrm{GOL}$ services listed as transactional also contain information to assist in applying for everything from licenses and patents to grants and campground spaces. In addition, information is provided for sale on some government websites, both in pre-processed form (such as government publications) and through access to databases, most prominently those of Statistics Canada, where users dos their own processing. A third category is information in support of defining and implementing the strategic direction of the government as a whole; this

\footnotetext{
${ }^{151}$ See, for example, the government's Seniors portal (http://www.seniors.gc.ca/h.4m.2@.jsp?lang=eng) and Aboriginal portal (http://www.aboriginalcanada.gc.ca/acp/site.nsf/eng/index.html), both of which contain information that is considered to be of interest to the client groups involved from sources at all levels of government as well non-governmental sources.
} 
includes the work of central agencies and two departments with quasi-central agency roles (Justice and Foreign Affairs and International Trade) but also information that is provided as a basis for Parliamentary accountability, such as the Budget and the expenditure Estimates. Again a cross-cutting category is internal administration, which is information-based in all departments.

\section{The Challenges to Effective Information Management and CIO Success}

Notwithstanding its contemporary importance, information and its management have received uneven attention in the past and are still not fully formed as an administrative discipline. Information has therefore not fully realized its potential as a defining, even transformative, element of modern government and indeed is unlikely to do so in the foreseeable future. These developments have at least partly been a consequence of the role played by the CIO, which has often been otherwise focused, especially in the earlier formative years. They have also reflected the structural weakness of the federal government's CIO model - discussed in chapter 3 - and have imposed limitations on the ability of the CIO to realize its potential, even within the terms of the role and authorities assigned to it. Individually and in combination they present daunting challenges. The reasons for this situation are discussed in the balance of this chapter.

Five sets of factors help to explain the current situation and to identify the issues that need to be addressed if the full potential of either government information or the CIO is to be realized. The vulnerability of IM and the CIO are rooted in the history of records and information management in the federal government, and the section begins with a summary of that background. A second reason is the effects of the ascendency of 
information technology on IM. A third factor is the internal dynamics of IM, including the relationship among the different spheres of information policy. A fourth source of weakness is inattention to information as a public resource. A final contributory set of factors - and in many ways the most significant - relates to the governance of information and its relationship to politicians and politics.

\section{Historical roots of records and information management}

When the CIO was established in 1993 in the context of the newly emerging Internet, IM had weak institutional roots in an administrative area that was marginal to government management. As late as the Glassco commission there was no government policy in this area and limited institutional capacity to deal with issues that had been flagged for some time. The following thirty years, leading up to the appointment of the TBS CIO, did see the development of a policy framework that by the end of the period was conceptually elegant and in many ways a model for collective management policy. Its implementation was uneven, however, driven primarily by the requirements of the Access to Information Act after it was enacted in 1983. This left the sector vulnerable to the pressures from the new ICTs, the subject of the following part of the discussion.

In describing the working conditions of rank and file clerks in the United Province of Canada (UPC), which formed the nucleus of the post-1867 federal civil service, Hodgetts states that in an era before any kind of office equipment their time was "taken up with making tedious entries in a vast number of clumsy ledgers, copying out letters or passing bulky files." As a result, "the written word became a living presence to which civil servants daily made their obeisance" (Hodgetts 1955: 54). The record of government activity was made less permanent by the hazards of fire (47) and of water 
travel associated with the system of "perambulating capitals" (58) during most of the lifetime of the UPC before the final move to Ottawa in 1865. The result was large gaps in the archives for this period (61). Two current institutions had their roots in the UPC - the Executive Council Office (now Privy Council Office)'s role in keeping the official record of the Governor-in-Council, and the Canada Gazette as the official publisher of statutes and other government notices. It is fair to say, however, that there was no systematic approach to information management in the pre-Confederation period, much less any thought that such a discipline was required.

This situation largely persisted for the next century. When the Public Archives was created in 1872, its director chose not to follow the model of the British Public Records Office or the American National Archives and to concentrate on documenting Canada's cultural record rather than that of government. By the early 1890 s, Joseph Pope (who after being Macdonald's Private Secretary was then Assistant Clerk of the Privy Council, responsible for the paperwork associated with the Governor in Council) was sufficiently concerned by generally poor record-keeping in the civil service, compounded by the recent introduction of the typewriter and telephone, to call for a commission of inquiry into public records. In the wake of a fire in the West Block that destroyed a number of important government records the new Laurier government appointed such a commission in 1897, with Pope as one of its three members. ${ }^{152}$ The commission lamented the state of public records and recommended that a systematic approach be taken to their handling

\footnotetext{
${ }^{152}$ Pope had been appointed Under-Secretary of State shortly before the 1896 election. Reflecting the seriousness of the situation (and also the then prevailing model for Commissions of Inquiry - see chapter 2), the other two commissioners were the Deputy Minister of Finance (presumably wearing his Treasury Board hat) and the Auditor General. There does not appear to have been a commission chair, but it is generally assumed that Pope spearheaded its work and wrote the report (Atherton 1979, Waite 2005).
} 
and long-term disposal, with the Public Archives as the final repository (Canada

Departmental Inquiry into Public Records 1898; Atherton 1979: 39-42).

A second commission of inquiry, this time chaired by Pope, was appointed by

Borden in 1912 after little was done about government records in response to the first report. ${ }^{153}$ It came to the same conclusion about public records, with much the same result (Canada Departmental Commission Pope 1914, Wilson 1982) ${ }^{154}$. Following the explosion of paper during and after World War I, the cost of file storage became a major concern, and Treasury Board finally authorized the building of a new records storage facility in 1938, notwithstanding Depression belt-tightening. The Canadian Historical Association (CHA) maintained pressure through the 1930s and 1940s for better management of government records in support of a growing national political selfawareness, but even in 1944 the CHA President was moved to criticize the Public Archives for refusing to assume a government records role, which he argued should be its primary mission (Brown 1944).

Matters improved marginally after World War II, with a new Dominion Archivist and under the prodding of the historians, the Massey Commission (Canada Massey

\footnotetext{
${ }^{153}$ Borden also enacted the first National Archives Act in 1912. The Laurier government did build a fireproof building to house the archives but it was filled up by World War I. It also followed the first commission's recommendation to combine the previously separate positions of Dominion Archivist, held by the head of the Archives Branch of the Department of Agriculture, and Keeper of the Records, held by the head of the Records Branch of the Department of the Secretary of State. This fault-line between records and archives has endured (e.g., Atherton 1985), reflected in periodic ambivalence about the proper orientation of Library and Archives Canada (as between the governmental and the national record) and its relationship with Treasury Board.

${ }^{154}$ Besides Pope, who was then Under-Secretary of State for External Affairs, the commission included the Secretary of the Department of Militia and Defence and the Dominion Archivist. Based on an exhaustive survey of government records holdings - even then housed in 438 rooms and 127,219 linear feet of shelving (Atherton 1979: 45) - the commission recommended the creation of a full-blown public records office on the British model and the establishment of procedures for the orderly disposition of older government records. At least part of the reason for later inaction was that for much of the period after World War I priority at both the political and senior official level was devoted to consolidating and publishing records relating to Canada's constitutional development and claims to full sovereignty rather than to organizing the more prosaic record of daily government business.
} 
$1951)^{155}$ and PCO, which had an interest from both a Governor in Council records perspective and in the context of national security in the early stages of the Cold War. In the wake of the Massey report, a separate National Library was created in 1953, for the first time institutionalizing the distinction between the government's records (Archives) and its publications (Library). Even so, the Glassco commission in 1962 painted a generally dismal picture of the state of records management and sounded a cautionary note about the effects of the newly emerging fields of automatic data processing and data transmission. The government had installed its first large computer in 1957 and other forms of office automation were well established. The commission found there was no policy guidance from Treasury Board in any of these areas or on encouraging collaboration among departments.

In the area of government record keeping, Glassco noted its importance in documenting both "the obligations of the citizens to their governments" and, in a democracy, the even greater importance "to record the obligations of a government to its people" (Glassco 1962 1: 486). Forms management, report preparation, correspondence processing, filing, and disposition of records were all criticized, citing costs and inefficiency of government operations. In the area of data transmission (well before this could be done over telephone lines - the key innovation of the Internet in the late 1980s), the commission expressed concern about the lack of compatible equipment and common coding, limiting the government's ability to realize "the benefits from integrating the flow of information ... by automatic handling throughout, which will facilitate the

\footnotetext{
${ }^{155}$ The research paper on archives that was prepared for the Massey commission (Stacey 1951) was by Col. C.P. Stacey, an academic historian who after World War II service became head of the historical research unit of the Department of National Defence, responsible for preparing the official Canadian war record. The CHA also had representatives on a post-war advisory committee to the Dominion Archivist on screening and retention of government records.
} 
exchange of common information through different systems (498)." In terms that still resonate, the commission concluded that, "The duplication and mistakes of the past, when automatic data processing was in its infancy, will be multiplied many times in the future unless concerted action is taken promptly to ensure skillful application of this new technology (498-499)."

In response to this criticism, the Pearson government in 1966 issued the first Public Records Order in Council, establishing groundrules for departments to deal with dormant files and identifying Public Archives as their ultimate custodian (Atherton 1979: 59). Acting on Glassco's recommendations to take a more managerial approach to government administration, records management was among the areas in which an Administrative Policy Branch (APB) was set up in the reconstituted Treasury Board Secretariat (TBS) in 1970 to provide central direction to departments. In the next decade it issued several Treasury Board directives governing IM and the management of information technology, although they were not linked to any degree, and the policies were oriented towards cost control and restraint (Paton and Dodge 1995), rather than promoting the use of management tools.

The situation changed in the course of the 1980 s, under the dual influence of the passage of the Access to Information Act in 1983 and a reorientation of Treasury Board administrative policies towards supporting program managers and outcomes, reflecting the influences of what later was termed by academic commentators the New Public Management (see chapter 2). This period also coincided with a conceptual shift from a focus on records to the broader but less tangible sphere of information, both as something to be managed in itself and as a means to the larger ends of government and society. 
From a records and information policy perspective, the late 1980s and early $1990 \mathrm{~s}$ represented a high water mark. After a long period of neglect, information was seen by Treasury Board as a corporate resource, with administrative policies designed to encourage departments to manage it in support of the move into the information society (Morton and Zink 1991). As discussed in chapter 4, Treasury Board ATIP policies developed in the mid-1980s were joined by the end of the decade by complementary policies on Government Security and Government Communications - in both areas addressing issues raised by royal commissions ${ }^{156}$ - and these were managed and presented by Treasury Board Secretariat (TBS) as an integrated policy suite. Under the influence of the Public Service 2000 initiative, there was a move to harness information with new ICTs in support of better service to both the public and government (Vision 2001 - Canada TBS 1992). Again, however, although the same TBS branch was responsible for both the suite of information, communication and security policies and the IT management policy, their administration was not linked to any degree and the integration of information and technology in government was more a matter of potential than of operational reality.

\footnotetext{
${ }^{156}$ The communications function had also received critical attention from Glassco (Canada Glassco 19623 Report 13) and by the 1980s had been the subject of the failed Information Canada experiment (Murray 1988 ) and efforts to centralize communications services in the national unity context. Security was the subject of three post-World War II Royal Commissions, the first at the beginning of the Cold War in the wake of the Gouzenko affair (Canada Taschereau/Kellock 1946), the second to look specifically at the Official Secrets Act (Canada Mackenzie 1969) and the third on the RCMP security service, leading to the establishment of the Canadian Security Intelligence Service (CSIS - Canada McDonald 1979, 1981a\&b). In all three cases a central concern was issues relating to information acquisition, retention, protection and dissemination about people and organizations posing threats to national security, in particular in the grey zone between political dissent and subversion in the context of national security. This was a key issue for the McDonald Commission and in their view defined the focus of CSIS as opposed to the criminal law orientation of the RCMP.
} 


\section{The CIO and information management in a technological context}

By the early 1990s the importance of IM was recognized and a comprehensive policy framework had been put in place. The situation then changed dramatically, shaping the current environment where the individual components of IM are more important than ever but the whole is less than the sum of the parts. Information policy has been blooded, engaging with technology and losing the more theoretical orientation that it was seen to have in the late 1980s (Morton and Zink 1991). It has become more central to public administration, but also less focused, its impact weakened by the lack of a unified understanding of what it constitutes or how its elements inter-relate, in turn weakening the CIO. The fragmentation of information has occurred under three pressures rooted in events that occurred in 1993: organizationally with the appointment of a Government of Canada CIO, technologically with the inauguration of the Internet (to which the CIO was at least in part a response), and financially with efforts to eliminate the federal deficit. These pressures are reviewed in this part of the chapter, with a particular focus on the tension between IM and the management of IT. The next looks at tensions among the information policies.

When a CIO was appointed in TBS in 1993 (see chapter 3 for the origins and evolution of the position), it was assigned responsibility for the Treasury Board management of IT policy and related initiatives to strengthen IT infrastructure and the use of technology in internal administration. An early priority was to launch the Blueprint for renewing government services using Information Technology (Canada TBS 1994), building on earlier work. The information policy suite was not at first included in the CIO's responsibilities and was only added 18 months later. Although an information- 
based approach fit well with the work of the Information Highway Advisory Council (IHAC), which encouraged government to be a model actor on the information highway (Canada IHAC 1995 \& 1997), the mid-1990s also saw severe Program Review-based cuts to the records management and other information-related functions, justified at least in part by the prospects of using automation of administrative functions to effect savings and a general suspicion of spending on administrative overheads. Some departments, notably Industry Canada and science-oriented departments such as Natural Resources Canada, adopted a strategy of using technology to turn themselves into knowledge organizations, ${ }^{157}$ but such initiatives were left to departments individually, with little effort at (or tolerance for) a government-wide approach (Giroux interview).

During this period, TBS's institutional focus on information policy gradually weakened. In 1998, after several re-organizations in the CIO branch (CIOB) and the appointment of a CIO with an IT orientation from the private sector, the informationrelated policy centres were separated organizationally within CIOB and in 1999, following the recruitment of a second $\mathrm{CIO}$ from the private sector, responsibility for most policy areas was transferred to other units in TBS, although the CIO retained the lead on policies and initiatives relating to electronic services to the public. The aim was to allow the CIO to focus on IT-related issues, including Year 2000 preparations, electronic service delivery, monitoring major IT projects and strengthening the IT function in general. The CIO continued to have IM policy responsibility, but this was given a lower priority until more pressing technology issues had been resolved (Harder interview). The reduced CIO policy role was also reflected in a weakened relationship with National

${ }^{157}$ Industry Canada responded to $40 \%$ cuts in its budget by making a major investment in Strategis, a data base which it offered to the private sector - especially small and medium business - as a substitute for grants, which were heavily reduced (Brown 1997: 102-103). 
Archives, which was largely left on its own to address issues relating to records management and disposal.

With this more focused mandate, later CIOs successfully addressed Year 2000 and launched Government On-Line (GOL), the public service-wide reform initiative that brought 130 commonly-used federal services to the public fully into the electronic environment (see chapter 3). IM was addressed largely on a care and maintenance basis. By 2002, with GOL well established, the ATIP and non-IT security policy functions, along with the service policy, were transferred back to the $\mathrm{CIO}$, in order to provide closer integration with CIO activities and in particular to strengthen IM in support of service to the public in the context of GOL (IM in support of internal administration was left on the back burner). The Communications policy and the related Federal Identity Program were combined with the TBS departmental communications office, however, weighting the operational concerns of the increasingly political communications function over its conceptual and administrative links to information policy.

Organizationally, the situation has been largely stable since 2002. A life cyclebased IM policy remains the centre-piece of a suite of information-related policies and management initiatives, but their administration is considerably less integrated than in the 1980s and early 1990s. The TBS CIO is responsible for the information management, ATIP and security policies as well as policy with respect to the management of IT. Within the CIO branch, information policy is housed organizationally with ATIP, but government-wide implementation initiatives in support of information policy are in a different unit, and security policy and related initiatives are in another area (see footnote 142 above). Yet another part of the branch deals with the concerns of the communities of 
practice that are the primary agents of the various IM policies. While in principle all of these groups report to the CIO, it makes a coherent approach to IM more difficult. This dispersion of effort is reflected in atomized administration of information policies in departments (see chapter 4). Housed in a different TBS branch and with strong operational links to PCO and through it to the PMO, the Communications policy centre is even less integrated with the other information-oriented policies, with a consequent loss of synergies. Service policy, which has close links to both the information and the communications policies, has been in and out of the CIO branch twice since 1993. This organizational dispersal at the centre of government both reflects and promotes an unfocused conceptual understanding of what constitutes IM in departments, adding to the constraints on government's ability to act as a knowledge organization.

The organizational fracturing of IM has been compounded by its intersection with the ICTs that have come into prominence in the past generation, notably the Internet and the networking and mobile technologies that have followed in its wake. These technological developments have expanded exponentially the contexts in which information may be held and transmitted, generally in an uneasy state of coexistence with older formats and methodologies. They have also contributed to the fragmentation - but potentially also the reinvention - of information management. There are several dimensions to this issue. Perhaps the most far-reaching is that information may be held and transmitted electronically in an ever expanding range of environments and devices, including databases, e-mails, computer mainframes, desk- and laptop hard-drives, floppy disks, memory keys, and a multiplicity of mobile devices. 
For the purposes of the Access to Information and Privacy Acts, information that is retrievable from any of these media "under the control of a government institution" (including of its employees individually) counts as a government record. Such information is carried on the devices in a wide range of computing programs and applications, often customized. Typically the information is moved frequently between environments, even within the context of a single transaction. It may have a diversity of uses and users and be used and transmitted both inside and outside the institution. Frequently individual data or units of information are combined and recombined to create new records based on the same content but for different purposes (although this can require careful navigation of Privacy policy guidelines on secondary use). Often information is held in more than one version, both of the content and of the applications and hardware, with obsolescent software and equipment rendering older information inaccessible. Many older mainframes, which continue to be the workhorses of government computing and electronic information storage, especially for government programs with wide application such as tax collection or employment insurance, have outlived an entire generation of programmers and have become a major source of risk (Canada Auditor General 2010). Other barriers to internal access and use include incompatible software and equipment, firewalls and other networking obstacles, and the isolation of records in e-mails, memory keys and off-network hand-held devices. The fact that the government lacks a common e-mail system simply compounds the issue.

The challenges to information policy and management are enormous in a context in which technologies and uses continue to multiply. While the desirability of establishing common standards and information management practices that promote 
interchangeability and information sharing is generally acknowledged, progress has been slow for a variety of reasons: the enormity of the task, its lack of immediate and obvious payback, the time and effort involved in the face of more pressing concerns, and cost. A different challenge is posed by the range of professions and skills that are brought together to address these issues: computer scientists, engineers, librarians and historians, to name a few, who need to overcome disciplinary barriers to working with each other and with lay managers and staff. The most serious challenge, however, is to overcome the natural resistance created by vertical accountability models in the public sector, reinforced by a generation of New Public Management-inspired emphasis on outcomes rather than inputs and the aftermath of the sponsorship scandal, to an inherently horizontal and homogenizing function such as networked information storage and transmission. ${ }^{158}$ The Glassco commission's warnings of nearly a half-century ago remain uncannily relevant.

\section{The internal dynamics of information management}

If the information life cycle provides a common thread for information management, it also creates a number of internal tensions and pressure points. These represent a third set of factors in explaining the challenges faced by IM before its potential as a component of public administration can be fully realized - some are independent of the CIO's role and mandate but all pose a challenge to its effectiveness. Variables can be grouped under three broad headings: the substantive focus of information policy, issues relating to information use, and perspectives of the actors in the IM process. A connecting thread is the influence of the Access to Information Act.

\footnotetext{
${ }^{158}$ See chapter 4 for a discussion of these accountability issues and the difficulties raised in this context by the Gomery Report (Canada Gomery 2006).
} 
The substance of IM - records and published material

Consideration of the nature of information begins with the three-cornered relationship between information, records and published material. The 1989 Treasury Board umbrella policy developed in the wake of the 1983 Access to Information and Privacy (ATIP) Acts was concerned with the management of government information holdings (MGIH) defined as either (internal) records, subject to the ATIP policies and later to the government security policy as well, or (external) published material, which was by definition beyond the purview of the ATIP and security policies and instead governed by the Government Communications policy. Although most holdings were in paper form, even at that stage it was recognized that electronically-held information did not fit these categories very well, and the ATIP legislation and related management policies were drafted to apply to records, independent of the medium in which they are held. With the expansion in the 1990s of electronic networks that reached across institutional boundaries within and outside government it was recognized that the same information - especially held electronically - could routinely be accessed and used for both internal and external purposes and used in either paper or electronic format, or both. This blurring of the distinction between records and published material made the umbrella concept of information holdings increasingly tenuous, compounded in practice by the administrative separation of the MGIH and Communications policies after 1998 . When the ATIP and Security policy centres returned to CIOB in 2002, the formal emphasis shifted from holdings to information more broadly (but within that to internally held information), and the MGIH policy was replaced by one on the Management of 
Government Information (MGI) in $2003 .{ }^{159}$ Records and published material remain core categories but no longer conceptually linked and part of a broader information universe that is not well defined. This blurring of boundaries was reflected in the merger in 2004 of the National Archives - the ultimate repository of government records - and the National Library - which houses the definitive collection of government publications - to form Library and Archives Canada, influenced by a similar convergence of information forms in society at large (English 2002). Ironically, this operational convergence was parallelled by the entrenchment of the separate administration of the two TBS policies (Communications and Management of Information) to which library and archival functions are linked.

\section{Tensions among information policies}

A number of tensions are built into the various information policies as well as into the dynamics among policies. In some cases these are consciously embedded in the statutory and policy structure, in others the effects are inadvertent. The Access to Information Act has a recurring influence, if only because it is the major piece of legislation affecting the management of information in government.

The most basic tension is between making information available and protecting it. Even availability has an inwardness: ATIP legislation facilitates access, but only at the initiative of a requester, while the Communications policy is oriented towards government taking the initiative to disseminate information to the public. Ideally the two should be administered in tandem - the more that government proactively disseminates,

\footnotetext{
${ }^{159}$ The MGI policy was in turn replaced by the current Policy on Information Management in 2007. Its basic orientation did not change, however, and the revisions were part of a wider Treasury Board policy renewal process. In that sense, they represented a closer integration of information policy with the broader Treasury Board approach to management, giving a new but perhaps unconscious emphasis to the Glassco model.
} 
in particular internally-held information, in principle the less need there is for recourse to ATIP procedures. This has been a recurring theme of successive Information Commissioners. The ATIP and Communications policies were originally drafted with this complementarity in mind, but it has proved difficult to achieve with the greater political sensitivity of the two functions and their increased isolation - both organizationally and operationally - from each other and from the rest of information policy. This has exacerbated the tendency for Access to Information to become a mechanism for controlling rather than facilitating access, the front line for information release rather than its intended role as a backstop.

A second tension can be found within the Access to Information (ATI) Act, between its general provisions for access and the specific exemptions and exclusions that limit access. Four pressure points are particularly significant. One that exists by design is with the Privacy Act, which is complementary to Access to Information, guaranteeing individuals access to information about themselves but establishing strong protections against access by third parties or even re-use of personal information within government beyond the purpose for which it was originally collected. Although the two regimes generally reinforce each other, they do have their points of conflict, exemplified by debates about whether to release information about convicted sexual offenders when they have moved into a new neighbourhood after completing their sentence.

A second major ATI pressure point is the relationship with national security. The injury-based tests for many ATIP exemptions had to be reconciled with traditional security-based information classification, which in turn determines levels of physical protection accorded to government information and other assets and the system of 
security clearances for government employees and contractors. The Access to

Information Act also highlighted the need to replace the Official Secrets Act, which had provided the statutory basis for security policy since World War I. Although some of the more controversial elements of the Security of Information Act which replaced it in 2001 resulted from the different kind of security threat posed by the $9 / 11$ events, ${ }^{160}$ many of its provisions dealt with issues that had been addressed in some detail by the Taschereau/Kellock and Mackenzie commissions in 1946 and 1969 as well as by the McDonald commission in 1979-81. The access-security tension continues to play out in very concrete terms, a recent example being the issue of Parliamentary access to information about Afghan detainees (Pugliese 2010).

The third ATI pressure point relates to the exemptions and exclusions under the ATIP legislation, in particular the Access to Information Act. The Act is structured under the general proposition that requested records are to be released subject only to limited and specific exemptions (s. 2). The list of exemptions is largely built around the government's relationship with outside bodies or sensitive areas of public policy; in many cases even those exemptions require the government to demonstrate that injury or prejudice will result from disclosure. The categories of exemptions (ss. 13-24) is wideranging: information provided in confidence by other Canadian and foreign governments and international organizations, the conduct of federal-provincial and international relations, law enforcement, safety of individuals, economic interests of Canada, personal information, trade secrets and information received from third parties, information

\footnotetext{
${ }^{160}$ The Official Secrets Act was originally developed with threats from other states and their agents in mind, linked to a larger context of state-based diplomacy and warfare. Since 9/11 there has been a shift in emphasis to an environment in which non-state actors are pursuing political aims mainly using criminal means. This has complicated traditional boundaries between policing and security, with implications for institutional mandates and (information-intensive) investigation procedures, illustrated by tensions between the RCMP and CSIS over the Air India disaster and more recent anti-terrorism investigations.
} 
relating to sensitive operations of government, tests and testing procedures, and information subject to solicitor-client privilege. Although there has been a gradual expansion and tightening of the list of exemptions over the years - much of it in the aftermath of $9 / 11$ - none of the exemptions is absolute, and the application of any is subject to judgment by the responsible minister and review by the Information Commissioner - ultimately to political debate. The outer perimeter of the Act is also contentious: Cabinet confidences are completely excluded for twenty years, raising questions about what the category includes and the temptation to hide behind it. Also, the limitation that the $A c t$ applies to information under the control of a government institution (s. 2 (1)) opens the question of whether it applies to ministerial private offices and in particular to the PMO. Even the exclusion for published material becomes a barrier to access when publication is through placement on a Website that is then taken down.

The fourth pressure point in the Access to Information Act arises from its positioning in the political process. When the Act was first contemplated in the 1970s a major argument in favour was that it would help provide more informed public debate and therefore better public policy (Canada Secretary of State 1977). It was considered important that the accountability structure and oversight mechanisms should reinforce rather than undermine the Westminster-based system of ministerial responsibility and Cabinet government (Robertson 1978). This led to several of the Act's distinctive features, including placing decision-making about exemptions in the hands of ministers (as Heads of their departments), minimizing the role of the courts, assigning an independent third-party information-gathering and publicity role to the Information Commissioner (in support of ministerial accountability to Parliament), and excluding the 
records of and direct policy inputs to Cabinet discussion from the coverage of the Act (but not, in principle although no longer in practice, the factual background, which was considered an important part of informed public discussion).

In some respects the $A c t$ has worked very well. Information released under it has become the lifeblood of Question Period and other aspects of parliamentary debate, ${ }^{161}$ and Parliament has become more vigilant in overseeing its implementation - although for many years Information Commissioners complained that their reports were being ignored. At the same time many departments have been found wanting in their performance in meeting requests (Canada Information Commissioner 2010), political vetting of sensitive requests has increased notwithstanding safeguards in the Act (Roberts 2005), the relationship between government officials and requesters has become more adversarial (Roberts 2006), policy making has become less open than envisaged (including ending the practice of releasing background papers to Cabinet discussions), and the Act itself has become a focus of contention rather than the handmaiden of public debate. Among the developed Westminster-system countries Canada is judged by at least one knowledgeable observer as having moved from being a leader in the introduction of freedom of information to a laggard (Hazell and Worthy 2010). All of these trends were compounded in recent years by the dynamics of acrimonious minority Parliaments.

\section{Perspectives and interests of actors in the IM process}

A third set of internal factors constraining the effectiveness of IM relates to the diversity of actors and interested parties. Some of these elements have already been

\footnotetext{
${ }^{161}$ A Gomery Commission study estimates that $25.6 \%$ of requests to nine major federal institutions were by the media and $13.3 \%$ were from partisan or Parliamentary sources. Academics represented $0.5 \%$ of requesters (rising to $3.1 \%$ for PCO records) and the general public was part of a $17.4 \%$ Other category. Over one third of requests were from lawyers and commercial interests; lobbyists were less clearly identified. (Roberts 2006: 153)
} 
mentioned. Politicians, abetted by journalists and private information researchers, have a major interest in gaining political advantage through disseminating information that is favourable to them (if the government) or getting access to information that will embarrass the government (if its critics), although both groups have demonstrated less interest in the systemic concerns of the Access to Information Act and information management more generally. ${ }^{162}$ The $A c t$ has also been extensively used by commercial and other interests but perhaps not as much by ordinary citizens (or university researchers) as its framers had hoped. These public uses of both the ATIP and Communications policies have had a major influence on their internal administration.

A more subtle tension exists between the originators of records in the context of immediate operational requirements, the interests of their larger organization in managing that information in the medium term, and the longer term interests of Library and Archives Canada and its users. Any interest that the government as a whole might have, as ordinarily expressed by TBS and the CIO, is superimposed on these other perspectives, which are largely driven by operational or programmatic concerns. The differing mandates and world-views of IM specialists and the IT specialists with whom they must work also come into play. Even within the Archives, which since 1985 have had a statutory role in determining what records to keep for the longer term (measured in

\footnotetext{
${ }^{162}$ There have been numerous reviews of the ATIP legislation commissioned by both Parliament (beginning with Canada House of Commons 1987, which identified many of the ongoing administrative issues) and the government (most recently, Canada ATI Review Task Force 2002) as well as continuing commentary and recommendations from the two Commissioners, including Canada Information Commissioner 2010. In his study for the Gomery Commission, Roberts, the most assiduous academic commentator on the Access to Information Act, includes "realistic" (as opposed to "idealistic") recommendations in half a dozen areas for constructing rules of engagement for processing politicallysensitive requests (Roberts 2006: 137-143). By and large proposals for strengthening the operations of the $A c t$ have not been taken up, and the major changes made in the Harper government's 2006 Federal Accountability Act were mainly focused on tightening exemptions. Those amendments did, however, act on recommendations by Roberts and Gomery to extend application of the ATI Act to Crown Corporations.
} 
decades and potentially centuries), there are longstanding debates about the role of the archival function, its relationship to historical research on the one hand and future but unforeseeable operational and accountability requirements on the other, and ultimately the criteria used for selecting the small proportion of documents that become part of the permanent record (Bearman and Lytle 1985, Cook 1997). These archival dilemmas have become even more complex with the addition of electronic records (Grimard 2005).

\section{Information as a public resource}

A fourth set of factors inhibiting effective information management in the federal government is a history of weak recognition and consequent undervaluing of information as a public resource. This is also a central characteristic of the weakness of the TBS CIO model. Harnessing the power of information has been identified as one of the keys to the information age (Lenihan et al. 2002) - both for government itself and in support of its socio-economic roles - and the management of information and technology is coming to be understood as a major discipline of public administration. The government has been slow to organize itself to move in this direction, however, beginning with how it values and manages its information assets.

It is generally agreed that in order to be managed well an asset must first be valued. Government bookkeeping assigns no value to its information holdings (Wilson interview), ${ }^{163}$ and indeed the dropping of the concept of "holdings" from the core information policy in 2003 can be seen as a step back from understanding information as a stock or inventory to be managed cost-effectively. The activities associated with IM information policy development and administration, IM-related communities of practice,

${ }^{163}$ This has been a recurrent theme by Ian Wilson, who was the National Archivist for ten years, (after holding a similar position in the Saskatchewan and Ontario governments and Queen's University). He was also the IM champion during GOL, although in many ways a lone voice. 
and information common services, supplies and storage - are individually treated as costs but the structure of the government's accounting system provides no means of aggregating them on a government-wide or even departmental basis. There has been a greater administrative focus on the IT that houses much of the government's information, but even it is treated as a cost in its acquisition and then as a depreciating asset - as well as the source of numerous administrative and political headaches. During the 1970s and 1980s the TBS Administrative Policy Branch published annual summaries of IT spending proposals identified in the Estimates, but this was discontinued with the establishment of the CIO. ${ }^{164}$ The CIO branch conducted a study of IT costs in 2003/04 in the context of an expenditure review exercise; this has not been repeated. Interviews for this dissertation indicate that more recently efforts have been made to estimate IT-related spending in support of moves to consolidate internal services to government, and in a speech in October 2010, the CIO referred to an effort to "develop a standardized departmental chart of accounts for IT-specific expenses" (Canada TBS 2010e), but there is little evidence that a comprehensive cost estimate of information management will also result.

Even without a clear understanding of costs, the government can still act to make effective use of its information resources. Because of its unmatched ability to collect, organize and analyze data, government information in many areas is prized by external users for its integrity and credibility. This is especially true of information products from public agencies that are in the business of collecting and generating information and

\footnotetext{
${ }^{164}$ See, for example, Canada TBS 1983, which was one of a series. After a hiatus, a final study (Canada TBS 1993) looked at IT expenditure trends and was released shortly before the establishment of the CIO. The expenditure studies were prepared by the TBS IT policy unit, which was included in the CIO's staff at the beginning, but this aspect of its work was not taken up by the new CIO.
} 
related knowledge, such as Statistics Canada ${ }^{165}$ or science-based organizations such as the Geomatics branch of Natural Resources Canada. Their IM practices are largely tied to the nature of their "business," however, and do not depend on central regulation or support; by the same token, their information is not necessarily much more readily available to the rest of government than to the public. The situation is even less clear-cut in other areas of the government, and the government-wide objectives first expressed in the Blueprint for renewing government services using Information Technology (Canada TBS 1994) still have an aspirational, even Utopian, aura: single collection and re-use of information from the public, information sharing and data mining within government, supported by common standards and infrastructure, with adequate security and protection of personal information and information integrity.

These latter objectives depend on an effective government-wide information management framework, supporting infrastructure and active IM practices to give them effect. Some of the obstacles have already been described, including neglect of records and information management until relatively recently, and tensions in the nature of information itself and in the objectives and interaction of the content of IM policies. A broader concern has been the government's desire and capacity to take a policy-driven "enterprise" approach to these matters. An underlying factor in the early churn in organizational arrangement for the Treasury Board IM policies was ambivalence for many years about the nature of central management policy administration in general and even, for a period, about the degree to which that should be part of the TBS vocation at all (see chapter 3 ). It was only after a decade that the CIO branch was mandated and

\footnotetext{
${ }^{165}$ It remains to be seen what impact the changes to the 2011 long form Census will have on the credibility of Statistics Canada data.
} 
organized itself to take a systematic approach to shaping and leading the IM function across government.

The earlier ambivalence about a policy management role is now gone. A Government of Canada Information Vision adopted in 2010 declares that: "In the Government of Canada, information is safeguarded as a public trust and managed as a strategic asset to maximize its value in the service of Canadians" (Canada TBS 2010d). Within this Vision and the intervening Policy Framework for Information and Technology (Canada TBS 2007b), the stated objectives of the renewed Policy on Information Management are concrete, even ambitious:

5.1 ...to achieve efficient and effective information management to support program and service delivery; foster informed decision making; facilitate accountability, transparency, and collaboration; and preserve and ensure access to information and records for the benefit of present and future generations. (Canada TBS 2007c)

These objectives are linked to an IM strategy, a supporting CIOB division and horizontal governance structure, and a planned policy framework with associated instruments drawn from the Treasury Board toolkit discussed in chapter 4 (figure 2, next page). ${ }^{166}$

On the face of it, the policy structure represents the most systematic attention accorded to IM by CIOB to date, and there is anecdotal evidence of a considerable interdepartmental effort linked to developing and implementing the policy-led approach. From an administrative point of view the IM Policy objective identifies essential concerns, and to the extent they are carried out will make a major difference (although it should be noted that they are also essentially the same goals that were expressed in policies written in the 1980s).

\footnotetext{
${ }^{166}$ The CIOB website notes that not all of the IM Policy instruments are currently in place (see Annex 6 for the current list). The titles in figure 2 for the most part give a clear indication of what is referred to. The two acronyms in the list of standards refer to Electronic Documents and Records Management Solutions (EDRMS) and Enterprise Resource Planning (ERP). Among the higher level instruments, the Data Stewardship Directive and the ERP Standard are not yet available.
} 


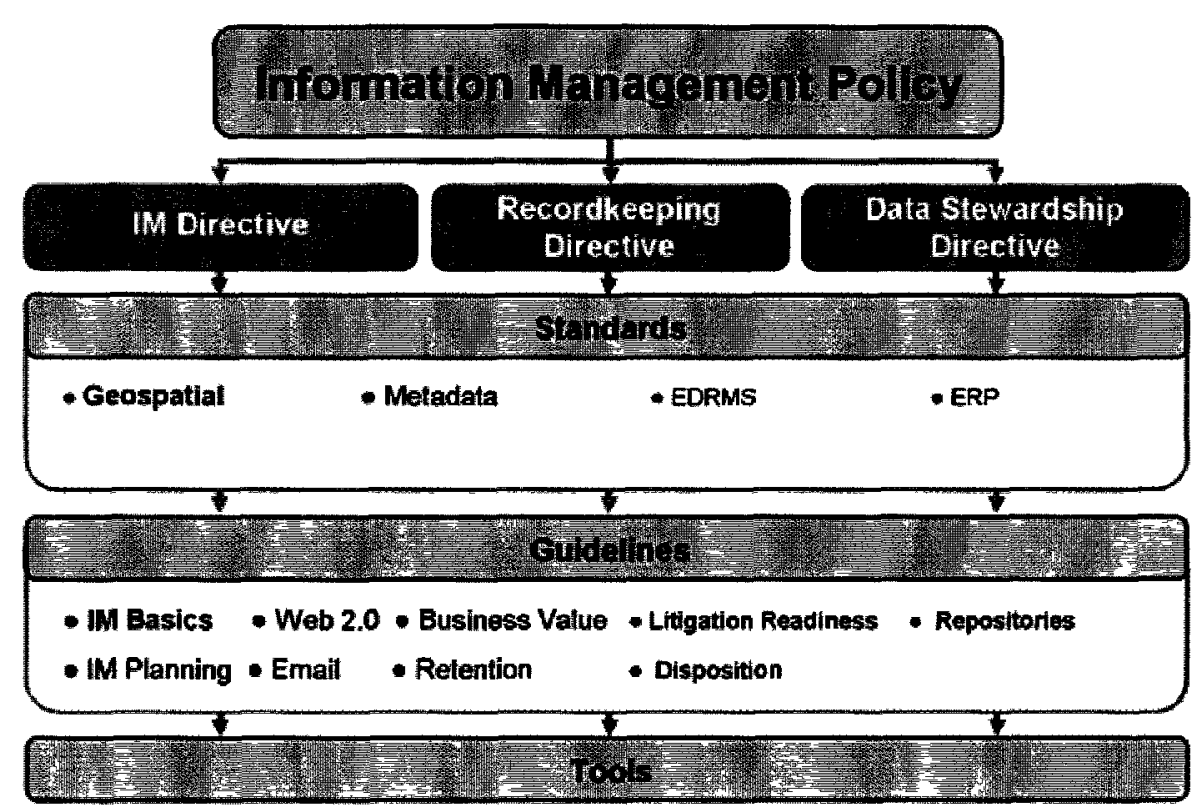

Figure 2: Planned Universe of Information Management Policy Instruments (CIOB Website http://www.tbs-sct.gc.ca/im-gi/imp-pgi/imp-pgi-eng.asp )

Even so, the complete array of instruments is not yet available and full implementation will take several years and considerable resources, at a time when funding for administrative overhead will be increasingly restricted in light of the postrecession deficit situation. While the paper and electronic IM practices are increasingly integrated in work units and physical premises with more than one unit, the interviews suggest that many departments are still struggling to achieve a comprehensive approach within the department and there is a considerable distance to go in this direction at the government-wide level, which lacks a number of basic building blocks.

Beyond implementation concerns, it is not clear what will be the longer term result. There is little overt linkage to a broader goal such as the Blueprint's vision of enterprisewide (in effect, cross-program and especially cross-departmental) information sharing or support to the ongoing process of public sector renewal, much less repositioning the government as a knowledge organization playing its part in the knowledge society. 
Similarly, the Management Accountability Framework, the template used by Treasury Board to assess departmental management performance since 2003, did not include information and IT management in its original version, and currently these are largely cast in process terms under the rubric of Stewardship, which is linked to the "departmental control regime." A major MAF IM concern is to meet the process requirements of the ATIP Acts (Canada TBS 2010c).

The question, then, is whether in the absence of a good handle on the inventory of records and information across government - in terms of its content and not just its architecture - and of meaningful metrics in financial and human resources terms it is possible to manage the government's information resources in any significant way. The development of such metrics is not an easy task and for reasons that are unclear earlier efforts, such as the 2005 exercise but also the pre-1993 experience, have not been sustained or built upon. ${ }^{167}$ In effect, CIOB is developing an array of instruments for managing the government's information resource, but there is still only a rudimentary understanding of the nature of the resource that is to be managed or what good management and use of that resource looks like. In that sense, the current situation can be regarded as meeting a necessary but insufficient condition for the full realization of the potential of the government's information assets. This is partly an issue for TBS but, as discussed in the next part of this section, it is also a matter for the senior levels of the government as a whole.

\footnotetext{
${ }^{167}$ Successive CIOs have played a generally limited role in TBS review of IT spending proposals. While they have frequently provided input to Treasury Board ministerial consideration of individual departmental IT projects, this has mainly been from a technical or project management point of view, leaving costing and efficiency concerns to the expenditure analysts in the TBS Program sectors. For practical purposes, no CIO input was asked for or given to the dramatic restructuring of the records management function during Program Review.
} 
Before turning to that part of the discussion, two other dimensions of the issue of information as a public resource should be noted: Crown copyright and the sale of government information. In common with British practice, the federal government asserts intellectual property rights for all the information and knowledge that it generates, and part 5 of the Communications policy governs licensing procedures. This policy pre-dates the Internet and has long been a factor in the sale of government publications and the diffusion of government statistical and scientific research. Building on the allencompassing nature of the Crown, it has also been based on the need to recuperate the costs of developing and organizing information that is provided to the public - especially specialized publics - and ensuring its quality and integrity. This has justified charging for information services such as access to Statistics Canada and weather forecasting databases. The federal government's approach contrasts with that of the United States where there is no assertion of over-riding government intellectual property rights. Instead, on the argument that they have already been paid for by the taxpayer, the US government has a general orientation towards making government data available to the public at no or minimal cost, especially where this can lead to the development of valueadded products and the generation of economic activity. There is periodic pressure on the Canadian government to adopt such an approach, or at least to accelerate efforts to "liberate" its data, ${ }^{168}$ but little indication that the overall policy orientation to government intellectual property is likely to change or to link it to more general approaches to the management of information as a public resource.

\footnotetext{
${ }^{168}$ See for example, Statistics Canada's Data Liberation Initiative, which gives post-secondary institutions access to Statistics Canada databases on a holistic basis rather than charging file by file: http://www.statcan.gc.ca/dli-ild/about-apropos-eng.htm [Accessed January 7, 2011]
} 


\section{The governance and politics of information management}

Governance, for the purposes of this discussion, refers to the mobilization of collective decision-making and supporting resources for the IM agenda. It includes both the high-level institutional deployment of IM-related agencies and senior officials and their linkage to the broader public service and political arenas. A central issue is the organizational location and relationships of the $\mathrm{CIO}$ and the implications that this has for the IM agenda. A review of the CIO's current arrangements in light of experience in the past twenty years suggests that at present governance supports incremental - and necessary - improvements in the state of IM as a component of internal administration but not a more fundamental harnessing of information as a driver of public sector reform or defining characteristic of modern government. The ultimate determinant is political attitudes and priorities, especially at the ministerial level but also in Parliament; this dimension, which is discussed at the end of this section, is also key to the CIO's success.

The ground-level dimension of governance is the role accorded to it in the Treasury Board IM policy, with a view to developing "A fully implemented set of policy instruments supporting information management outcomes, defined accountabilities, and enterprise information management governance" (Canada TBS 2007c). Specific objectives include alignment of departmental with government-wide IM policies and practices, better measurement of policy compliance, and less need for independent action, including training, by departments. The steering mechanism for these goals is a Policy and Governance Sub-committee of the Committee on Information Management in Business (CIMB), the CIO's senior IM committee, whose members are program ADMs in line departments. CIMB is the CIO's primary vehicle for influencing and obtaining 
input from departments, with associated sub-committees and working groups covering most significant areas of the CIO's IM domain, including internal services, enterprise architecture and ATIP. All departments are expected to participate, and supporting IM governance is a MAF assessment criterion. Interviews with both $\mathrm{CIOB}$ and senior departmental officials suggest that this machinery provides an effective mechanism for CIOs to mobilize their IM universe, supplemented by their work with IM functional specialists in departments, but it does not directly engage top public service management and is largely focused on strengthening the foundation of IM administrative procedures.

A second dimension of IM governance is the CIO's position in the central agency universe and in particular its standing within TBS. When the office was created in 1993 it was within the organizational model that grew out of the 1962 Glassco report. The model's essential feature was that TBS should combine the role of budget office with that of policy-based overseer of public service management practices, bringing together most areas of management policy but separating the central policy role played by TBS from the provision of common services to government pursuant to those policies; the latter was the domain of operational common service organizations, notably in today's context Public Works and Government Services Canada (PWGSC).

The application of this model to the CIO and IM has been tested in several ways. As already noted, at best a weak link has been established between the CIO and the TBS expenditure branches (this is generally the case for all three TBS management sectors). In addition, the Glassco model has not been followed with respect to IM common services. Unlike IT common services, which are concentrated in PWGSC's IT Services Branch, there is no single IM common service organization. Instead each policy area has an array 
of associated common services or lead agencies (see Annex 8). The Glassco common service model is most nearly followed in the two policy areas that have been on the margins of the CIO's responsibilities: the Consulting, Information and Shared Services Branch of PWGSC, which provides services under the Communications policy; and the two service agencies (Service Canada and Canada Business) that are loosely linked to the Service policy. More generally, the CIO's mandate has in the end fallen short of the full range of IM-related policies.

Chapter 3 discusses some of the other constraints on the CIO's weight in the system, adding up to a "weak" CIO model. These include: the CIO's standing within TBS below the Deputy Ministerial level accorded the senior comptrollership and human resources officers; the resulting lack of sponsorship by the Clerk of the Privy Council; the lack of a comprehensive legislative framework in the areas covered by the CIO (again unlike other areas of management); limited access to the structure of senior public service horizontal committees; and similarly limited access to the government-wide management reform agenda and related political support and financial resources. The fact that IT and IM come under the generic management authorities provided by s. 7 of the $F A A$, without being specifically mentioned in the $A c t$ is perhaps the most significant structural difference from other areas of management. There have been proposals in the IM area for a comprehensive public information act ${ }^{169}$ that would place in statute IM-related policy objectives - including those in the Communications and service policies - and provide a framework to situate the existing patchwork of ATIP, Archives and information security legislation. There is no evidence, however, that such a step is being considered.

\footnotetext{
${ }^{169}$ See, for example, Reid 2004, in which a former Information Commissioner argues for IM legislation.
} 
The greatest governance challenge relates particularly to IM and has major implications not only for realizing the potential of IM but for the CIO's success as well. This is the link to the political sphere, both within the executive and in Parliament. The level of support provided by the Prime Minister, prompted by the Clerk and less visibly by PMO, is an important contextual factor, especially in shaping the broad public service reform agenda. After 15 years when there was a succession of catalytic high level initiatives sponsored by the Clerk and endorsed by the Prime Minister, this kind of comprehensive approach has not been taken up by the Harper government and there has been no successor to GOL. Treasury Board Presidents have generally supported initiatives to promote information and technology in government, although this was most visible and enthusiastic during GOL. The most engaged was Reg Alcock, the Treasury Board President in the Martin government, who also took a greater interest in strengthening the internal management of IM (and IT) and using them to create greater efficiency in government. This might well have led to a successor to GOL, but his efforts were still-born with the fall of the Martin government in early 2006 .

The reality is that IM and IT are not vote-getters and are more likely to be seen as sources of political risk. Parliament has a chequered record in this sector, with consideration of IM and IT scattered across the committee system. Both areas are regularly the subject of reports by the Auditor General, often (although not always) critical, and less frequently of follow up hearings by the Public Accounts Committee (PAC). The House of Commons Standing Committee on Government Operations, especially with Alcock as chair before he entered Cabinet, also held hearings on GOL and other IM/IT topics and is currently the locus for discussion of IT projects and 
Treasury Board-related issues more generally. Several committees potentially deal with security policy issues, including the committee on Public Safety and National Security. Recently, the Standing Committee on Access to Information, Privacy and Ethics, which was set up during the Martin government, has begun to pay closer attention to the annual and special reports of the Information and Privacy commissioners. It remains to be seen whether this interest will translate into consideration of IM practices more generally, although these have been the subject of increasingly critical reports by the Information Commissioner (Canada Information Commissioner 2010).

If Parliament's interest in the administrative dimensions of IM-related issues has been atomized, reflecting the circumstances of IM policy administration in government, the political process has concentrated attention in two areas. The most direct is daily House of Commons Question Period, where virtually uniquely among liberal democracies - even in the Westminster system - oral questions may be posed without notice on any subject to any minister, with the Prime Minister as the default, on any day that Parliament is sitting. Played out on television and the Internet, these gladiatorial contests accentuate the inherently adversarial nature of Westminster parliamentary proceedings and place particular pressure on the Access to Information Act, which is the vehicle for much of the information gathering by the government's critics, leading to allegations of interference by political staff in the processing of information requests (Martin 2010) and considerable evidence that at a minimum such requests are given different handling in practice that is not always in the spirit of the Act (Roberts 2005 \& 
2006). ${ }^{170}$ Lying behind this has been the growing centrality of communications to the political process (Flanagan 2007). The result has been closer political oversight than ever of the communications function in government, compounding its isolation and that of Access to Information from each other and from other areas of information management.

\section{Conclusions}

The management of information has come a long way in recent years, and a modern Glassco Commission would probably be less critical of the basic state of affairs than its predecessor a half century ago. Both information and the technologies that carry it play a more central role in public administration, and the possible uses - and related issues that Glassco was just beginning to discern have become much more visible and in many ways realized. The role of ICTs in society has changed dramatically, and the pace of change continues to accelerate. This has placed considerable pressure on government to adapt, if only to keep pace with the various publics that it deals with. For reasons of historical legacy combined with strong political and public service leadership and public expectations, the federal government has at times done very well, especially in the first generation of bringing its services to the public on-line and in developing a robust conceptual framework for managing information. The fact that Canada, as a society and as a state, has traditionally depended on transportation, telecommunications and broadcasting also equipped the country with infrastructure and industrial capacity that positioned it to take full advantage of the combination of technologies represented by the Internet that were introduced in the final decades of the $20^{\text {th }}$ century.

\footnotetext{
${ }^{170}$ While the proposals by Conservative backbench MP Michael Chong to reform Question Period (Chong 2010) may improve its decorum it is unlikely that they will lessen the dependence on the Access to Information Act.
} 
The open-ended nature of technological change ensures that the situation facing the government is never static - at best this is a continuing incentive to innovate, at worst it creates instability and under any circumstance there is a continuing need to manage an increasingly complex administrative environment. Considerable progress has been made in understanding and managing ICTs. Networked desktops are the norm, for practical purposes all government services are available on-line, with growing integration among service channels, building on GOL, and automation is the norm for data holdings linked to major government programs. While there are still enormous issues and obstacles - and Glassco's warning about the weakness of data transmission in government rings eerily true - there is continuing movement in the direction of an integrated technological environment, including for internal administration, with many observers predicting the emergence of a "utility" model for basic IT and telecommunications services.

The TBS CIO has played an important role in promoting the orderly adoption of ICTs and their application to government infrastructure and major projects. While these will continue to require expert attention and leadership and there is still much to be done - if only because of continuing technological change - the CIO's attention has increasingly shifted to the content of the hardware and software and to the realm of information management. Here the agenda is in many ways less developed, even more open-ended, but also with more at stake. With an increasingly mature technology base, information content and its management are assuming a pivotal role in the government's response to ICTs as well as in the success of the CIO.

The task is considerable. Public administration as a discipline needs to develop its own understanding - both practical and conceptual - of information and information 
management. It is only beginning to come to terms with the multiplication of formats and media in which information can be held as well as the uses to which it can be put. The transition to individual new technological environments is daunting and cumulatively the challenge is formidable - observers have described the last decade as the worst documented in Canadian history, both notwithstanding and because of the proliferation of technologies (Wilson interview) - and the situation requires systematic and sustained action to get out of. In many ways, service delivery provides an analogy, where government needed to come to terms with the electronic environment but also to develop an integrated multi-channel approach that never completely abandoned traditional approaches and in some aspects even gave them new life.

Currently the $\mathrm{CIO}$ and CIOB appear to be comfortable with a policy management vocation and with $\mathrm{IM}$ as the substance of that vocation; they are also well integrated into the wider Treasury Board approach to management, no doubt encouraged by having a former CIO (Michelle d'Auray) - generally regarded as having been successful in the position - serving as Treasury Board Secretary. The policy framework and related instruments are still being fleshed out, however, and there is much to do to overcome ingrained structural and cultural obstacles.

Two challenges are particularly important. One is to determine - and to keep reinventing - a clear sense of what information-based government looks like and how far the federal government as an institution wishes to go in that direction. Current policy statements are focused on an administrative vision that is already a very tall order: aiming, in the words of the IM Policy, for better and more efficient program and service delivery, better decision making, and greater accountability, transparency and 
collaboration, now and for future generations. There has always been, however, an even more ambitious vision that challenges government to turn itself - as an entity, to return to the Glassco focus - into a knowledge organization, playing a full value-added role in the transition to a knowledge-based economy and society. Whether or not expressed in precisely these terms, this vision is one that ties an understanding of how government manages itself to its role in society - an updating of the IHAC concept of the government as a model actor on the information highway that provided much of the intellectual, political and administrative fuel for GOL. In concrete terms, it means that information held in one part of government is easily accessible and useable from another - across organizational and geographic boundaries - and that there are well developed information banks available as a common service to government. The was the Blueprint's vision.

Whether the more modest or the more ambitious vision is adopted - and it may be that government has to learn to walk with the former before running with the latter - the reality currently falls considerably short of the aspiration. This is for a number of reasons. There was no systematic approach to government records for the first century of Confederation, and it took another twenty years to develop a framework of administrative policies based on the information life cycle. The institutional response to new ICTs - the appointment of a $\mathrm{CIO}$ - at first represented a set-back to a systematic approach to information management and as recently as ten years ago IM was not treated as a core function of federal public administration, except in the important but relatively confined context of service to the public. As management of information and of technology have become better integrated, IM has been brought into the administrative mainstream, but its unity has also eroded both organizationally and conceptually, made worse by natural 
tensions within and among its various components. A further complication has been the lack of a systematic understanding of how to value information as a public resource, evoking the insight that what is not valued is not managed.

The greatest test facing IM (and the CIO as its institutional agent) and the greatest obstacle to realizing a vision of information-based public administration - much less knowledge-based government - is its centrality to the political process. The clearest progress in IM occurred during GOL from 1999-2006 - literally its seven fat years. The situation is leaner now, partly because many of the easier advances have been made, also because more difficult issues set aside during GOL are now being tackled. In addition, the kind of public policy "pull" that shaped GOL is not currently present, and it may be that the Harper government is philosophically not disposed to take such a holistic approach - this will be a measure of how it uses the majority it won in May 2011.

On the other hand, components of information policy have become core instruments of the Canadian political process in the maturing information society, in particular the use of Access to Information procedures to fuel public debate and accountability and of communications tools to conduct that debate. In many respects, that is precisely what they were intended to do, but - herein the paradox - in the short run at least this has had the effect of isolating these information disciplines from each other and from IM more generally. This has weakened the CIO and is also a symptom of the weakness of the TBS CIO model. In the short term these are setbacks. In the longer term, this very sensitivity to the political environment and to public policy leaves future prospects wide open. It also serves as a reference point for considering the main organizational alternative within Canada to the federal CIO, the Ontario Corporate CIO. This is the focus of chapter 6. 


\section{Chapter 6 - A Faster Lane on the Information Highway: The Ontario Corporate CIO}

Scotland Yard detective: "Is there any other point to which you would wish to draw my attention?"

Holmes: "To the curious incident of the dog in the night-time."

Detective: "The dog did nothing in the night-time."

Holmes: "That was the curious incident."

(Arthur Conan Doyle. "Silver Blaze" in

The Memoirs of Sherlock Holmes 1892)

All governments in the past two decades have invested heavily in office automation and information and communications technologies (ICTs) and have put in place institutional responses to those forces. Although there are no large-case comparative studies in this area of public administration, it can safely be assumed that governments in common with major corporations - have developed centres of expertise and common services within their central management structures that address the management of information and of technology and related issues of technology-enabled services to the public and to government. ${ }^{171}$ In Canada, all the provincial governments have appointed a senior public servant to play the role of a Chief Information Officer (CIO) and most have a position with that title. From the perspective of the federal CIO, the most interesting provincial case is the Corporate $\mathrm{CIO}(\mathrm{CCIO})$ in the Government of Ontario.

This chapter discusses the Ontario CCIO in light of the analysis of the federal CIO in earlier chapters. It begins by considering the relevance of the Ontario case to an understanding of its TBS counterpart and also the availability of research to support such an analysis. The second section looks at the institutional background to the CCIO,

\footnotetext{
${ }^{171}$ The OECD's annual survey of government performance includes three e-government indicators out of 31 covering all areas of management (OECD 2009). An OECD e-government working group (OECD 2003) concluded that leadership and commitment was a major factor in successful introduction of e-government. While the report does not discuss the institutional manifestation of such leadership, its tasks are described as including integration of e-government into government policy, inter-agency collaboration, accountability, and monitoring and evaluation: roles typically played by a central management agency CIO.
} 
including the salient features of the historical evolution of the Ontario Public Service (OPS) ${ }^{172}$ This provides the basis for discussing the creation of the Corporate CIO position in 1998 and its evolution since then, with four incumbents, providing an overview of the IM/IT space in the Government of Ontario. These two sections broadly parallel chapters 2, 3 and 4 in the dissertation. They highlight the numerous similarities between the federal and provincial CIO positions, which have developed in mutual awareness and in a real sense are variations on a common institutional model. Within the broad similarity, however, there are some important differences, with the more unified and directive Ontario approach part of the context of any discussion in the federal government about the CIO's role and mandate and - as discussed in chapter 3 - an alternative model that was seriously considered on at least one occasion.

The curious thing about the Ontario Corporate $\mathrm{CIO}$ is its notable institutional stability and its general lack of controversy, either at the time it was established or since. The chapter considers the reasons for the apparent ease with which the position was put in place and more generally the implications of the similarities and differences between the experiences in Toronto and Ottawa for an understanding both of the federal CIO and of the dynamics of institutional continuity and change.

\section{Relevance of the Ontario Case and Research Sources}

In chapter 1 it was stated that the dissertation is a single case study, seeking to provide an in-depth analysis of the federal CIO. In the nature of the subject matter there is ample scope for taking a comparative approach to the issue of public sector institutional responses to ICTs, but in the current state of scholarship it was considered to

${ }^{172}$ The acronym OPS is commonly used in the Ontario government. 
be more useful and straightforward to do a fuller exploration of a single institutional environment (the federal $\mathrm{CIO}$ ), both for the understanding that it provides of that case in its own terms and also to give more substance to the comparative work that should follow. Even so, parallels, relationships with and influences from other governments both internationally and in Canada - have been noted at a number of points in the dissertation. The Ontario mini-case sketched out in this chapter goes a little further in the direction of comparative research.

Ontario is relevant to the federal case substantively and methodologically and for both its similarities and its difference. The similarities help to validate - or at least to suggest - findings about the Treasury Board Secretariat (TBS) CIO that potentially can be generalized and that could serve as a basis for broader comparative study. They also provide additional insights to the Canadian variant on the Westminster model, which in fact has as many sub-variants as there are federal, provincial and territorial governments. ${ }^{173}$ The differences within the broad base of similarity are in many ways more significant. Contrasts between the Ontario and federal governments open up avenues for analyzing the approaches taken in Ottawa. As noted in chapter 3 in particular, they have also influenced debates in Ottawa (although this chapter demonstrates that the influence has gone in both directions).

Ontario provides a good basis for comparisons with the federal government. It is the most populous province (over one-third of the population of Canada), has the largest and

\footnotetext{
${ }^{173}$ A significant variable is the matter of size, which can amount to differences in kind and not just degree (White 1990). This is especially clear with the smaller jurisdictions - Prince Edward Island, for example, has roughly $1 \%$ of the population of Ontario and a correspondingly smaller land-mass, so its public institutions are significantly smaller and less complex. The smallest jurisdictions in population (but among the largest in size), the Northwest Territories and Nunavut, effectively have their own model of Cabinet and its relationship to the legislature (White 2005: 58-62).
} 
most complex provincial public sector, ${ }^{174}$ and shares many of the federal government's attributes of scale of operation over a large geographic space with distinct regions and even a multiplicity of time zones (albeit two rather than six). Ontario shares its preConfederation governance and administrative roots with the federal government (the United Province of Canada (UPC) and its forerunners) and is a creation of the same constitutional matrix (see next section). In the nature of the evolution of the Canadian Constitution since Confederation, Ontario, in common with the other provinces, has a wide degree of autonomy - even sovereignty - in its broad range of responsibilities and as a result its public service administers much the same range of governance instruments as the federal government and its central institutional structure has many of the same features. There are of course important differences, including a different (and arguably narrower) mix of policy sectors than the federal government, a requirement to operate in only one official language ${ }^{175}$ and a more vertically-integrated division of responsibilities with lower levels of the public sector, resulting in a wider range of public sector institutional forms under provincial jurisdiction.

There is a considerable amount of political science and public administration literature available both on intergovernmental comparisons within Canada and on Ontario. ${ }^{176}$ It is fair to say that much of the comparative literature has grown out of research on the institutions and operations of Canadian federalism, although in recent

\footnotetext{
${ }^{174}$ See, for example, White 1990: 543, which compares the federal and provincial public services. The data are out of date in their specifics but present a proportionate picture that almost certainly remains valid.

${ }^{175}$ The OPS does offer services in French in Eastern Ontario and other regions with significant demand. It also provides written material and some other services in a number of other languages. The administrative impact on the OPS, especially with respect to its internal operations, is considerably less, however, than the statutory requirements for institutional bilingualism in the federal and New Brunswick governments.

${ }^{176}$ The following discussion does not address the literature on public administration in individual provinces, which is extensive and continues to grow. This includes comparisons between selected provinces, in particular in Western Canada and the Maritimes.
} 
years there have been comparative analyses of provincial institutions and practices (many including studies of individual provinces) in areas linked to the common Westminsterbased constitutional model, which has resulted in considerable similarity or at least variations on a common theme among the provincial governments. Chandler and Chandler 1982 provide a comprehensive survey of literature to that date. Areas covered more recently include: legislatures (Docherty 2005), Cabinets and first ministers (Pal and Taras 1988, White 2005), executive styles (Bernier et al. 2005), top public service leadership (Evans et al. 2007, Dutil 2008), the impact of government restructuring on career public services (Lindquist 2000), and provincial politics generally (Dyck 1995, Brownsey and Howlett 2000, Dunn 2006). Bourgault et al. 1997 represents an effort to present Canadian public administration as a whole - including all three levels of government - to an international audience. ${ }^{177}$ There has, however, been relatively little comparative work on the public administration and central agency organizational models adopted by provincial governments, perhaps because these are more independent of constitutional structures and lend themselves to greater variation. ${ }^{178}$

There is also a literature on comparisons between the federal government and individual provinces. The largest part of this work is in French looking at the Quebec and

\footnotetext{
${ }^{177}$ This book was prepared in 1997 as a portrait of Canadian public administration for an international audience. It has eleven chapters on federal institutions, seven on Quebec, five on other provinces and territories (including Alberta and British Columbia case studies) and one on municipal government.

${ }^{178}$ Bernier et al. 2005 has a considerable amount of material about central agencies in the context of Cabinet structures, which is its main focus, but there are no direct comparisons. Brown 2003 was a study conducted by the Public Policy Forum on behalf of Treasury Board Secretariat of its provincial equivalents. It found that there are no exact counterparts to the federal TBS but all provinces have a Financial Administration Act or equivalent and a committee of ministers responsible for internal management, variously called a Treasury Board, Management Board or Financial Management Board. In most cases, more than one central agency supports the ministerial committee (not all make a central agency/common service organization distinction in the terms defined by the Glassco report). CIO functions are usually combined with either a Treasury/Management Board Secretariat or a consolidated government services agency, although Alberta and Nova Scotia linked the function to the ministry of economic development. (Brown 2003) The Nova Scotia CIO now reports to the Secretary to the Executive Council, a former CIO (Keefe interview). In many respects, the arrangements in most provinces resemble the federal government before the Glassco report.
} 
federal governments (e.g., Bernard 1992, Charih and Paquin 1993, Demers and Gow 2002). ${ }^{179}$ This is a more natural focus for francophone researchers and is probably also related to the fact that Quebec, among provincial governments, comes closest to the federal government in the breadth of its activities and in its self-image as a sovereign state. ${ }^{180}$ Anecdotally, Quebec is also the provincial government whose collective management mechanisms most closely resemble those of the federal government, although this is an area for further research. ${ }^{181}$

There is less comparative literature looking specifically at the Ontario and federal governments. One exception is Borins et al. 2007, which has individual chapters on the federal and Ontario governments (Brown 2007, Borins 2007b) and two chapters comparing the two (Borins and Brown 2007a\&b). ${ }^{182}$ An extensive literature addresses Ontario specifically, however. This includes an administrative history from Confederation to World War II by J.E. Hodgetts (Hodgetts 1995) and several textbooks and books of readings (Schindler 1969, MacDonald 1975, Bell and Pascoe 1988, White 1997). A number of authors have written about public service reform in Ontario, especially in the aftermath of the Committee on Government Productivity in the early 1970s (Fleck 1972 \& 1973 in support, Mallory 1973 and Bryden 1975 as critics) and a

\footnotetext{
${ }^{179}$ Jacques Bourgault has written extensively on the senior public service in both the federal and Quebec governments. See, for example, Bourgon and Dion 1991 and Bourgault and Tremblay 1994. Bourgault et al. 1997 provides a parallel treatment of the federal and Quebec governments and was published simultaneously in English and French (by the publishing arm of the Quebec government).

${ }^{180}$ One manifestation is that the provincial government and Quebec authors often refer to Quebec governance entities as a whole as the State (l'État - see, for example, Parenteau 1992). This largely fills the space assigned to the "Crown" in federally-oriented and anglophone writing generally, although it is undoubtedly a creative ambiguity in the context of debates about Quebec sovereignty that is also influenced by the more all-encompassing (European) French concept of l'Etat. That being said, the federal government also uses the term État; for example a federal Crown Corporation in French is a "Sociéte d'État."

${ }^{181}$ For example, the 2003 PPF study indicated that Quebec was one of the few provincial governments with a Treasury Board and Treasury Board Secretariat approximating the federal range of responsibilities.

${ }^{182}$ Schindler 1969 also makes use of comparisons with the federal government in looking at organization of the Ontario executive and legislative oversight. The book's current interest is primarily historical, however, as most of the institutional dynamics it presents have changed in both Ottawa and Queen's Park.
} 
generation later during the era influenced by New Public Management (NPM) thinking (Lindquist and White 1994, White 2002). The rise of NPM coincided with - and to a certain extent was bound up in - the succession of provincial governments formed by all three major Ontario political parties between the mid-1980s and late 1990s; this led to a number of studies, including of the transition process itself (Cameron and White 2000), reasons for change (Gagnon and Rath 1992) and the impact of change on the public service (Malloy $2001 \&$ 2003). Several authors have also written about information technology-related issues. Only Borins has written specifically about the Ontario Corporate CIO (Borins and Wolf 2000, Borins 2007b, Borins and Brown 2007a\&b), but a number of others have looked at related topics, including public private partnerships in Ontario (Bradford 2003), two problematic major IT projects (Jordan 1999, Whorley 2001), and a special task force appointed to look at the management of major IT projects (Dutil et al. 2005).

This chapter draws on these sources as well as Ontario government documents. Three of the four Ontario Corporate CIOs appointed since the position was created in 1998 were interviewed for the dissertation and the fourth was profiled in Borins 2007b and Borins and Brown 2007b. Four other interviews were with currently serving or former Ontario public servants now working in other organizations, and four were with individuals in intergovernmental or private sector organizations that support networking and collaboration among federal and provincial CIOs and have sightings of the Ontario CIO from that perspective. 


\section{Institutional Pathways (1867-1995)}

The Constitution (British North America) Act 1867 is the Ontario provincial as well as the federal Constitution. ${ }^{183}$ At Confederation, the UPC legislature and administrative institutions were largely based in Ottawa and became the nucleus of the federal government. It was therefore necessary to establish new Ontario (as well as Quebec) provincial institutions, largely from scratch. ${ }^{184}$ After an initial period of slow growth, the Ontario government has expanded steadily, developing a range of institutions and processes that in most respects are reminiscent of those in the federal government and often influenced by them. For the first century, however, this evolution was highly pragmatic, and unlike the federal government there were no commissions of inquiry on the civil service until the Commission on Government Productivity in the early 1970s (Hodgetts 1995: 2 fn 1). More recently, successive Premiers have taken a more systematic approach to issues of government organization and civil service reform. An important contextual factor in developments since Confederation has been long periods of single-party dominance, during which change was largely evolutionary and in response to personalities and external events, although a change of government in 1905 marked a turning point in the period before World War I, and the two World Wars

\footnotetext{
${ }^{183}$ There is no Ontario constitution as such, but sections $12,58-70,81-87,90,128,129$, and 134-143 of the Constitution Act 1867, taken together, establish Ontario executive and legislative institutions, largely paralleling similar provisions in other parts of the $A c t$ for the federal government and providing for the transition from the UPC, the governance matrix that spawned both the federal and Ontario public services. Various sections in part VIII of the Act (ss. 102-126) cover provincial and federal revenues, debts, and assets. The distribution of legislative powers in ss. 91-95 sets up a common interlocking division of legislative and taxation authorities that applies to both the federal and provincial governments.

${ }^{184}$ The first Ontario government was formed on July 22, 1867 but had limited scope for action until the first legislature was convened in December 1867. Two departments, Crown Lands, and Agriculture and Public Works, were based on previous Canada West-oriented units transferred from the UPC more or less intact. The former Canada West Education Office reported to a non-ministerial Council of Public Instruction and had never moved to Ottawa. In other cases, departments were built "from the ground up" (Hodgetts 1995: 6 ), and at the end of 1867 the combined headquarters staff of all Ontario departments numbered under 50, most in Crown Lands, with another 400 in the field (8).
} 
provoked significant growth in the provincial government's range of activities. Since 1985 there have been four changes of government party (five, if the Liberal-New Democratic Party (NDP) Accord from 1985-87 is counted separately), resulting in more attention to organizational and public sector reform issues. This latter period has also coincided with the global changes in ICTs and management thinking that affected all governments in Canada, however, so many of the developments could well have occurred even without change in government.

Hodgetts (1995) divides the evolution of the OPS into three periods: Confederation to 1905,1905 to 1940 (these two being the focus of his book), and World War II to the late 1970s/early 1980s. Developments since the mid-1980s suggest that that constitutes a fourth period. These are each discussed in the balance of this section, with a view to describing some of the key events in the institutional evolution of the OPS and factors that drove it. Where relevant, parallels to and influences from developments in the federal government are noted.

\section{Confederation to 1905}

In the first 40 years after 1867, the organizational environment was conditioned by provisions in s. 63 of the Constitution Act that specify five ministerial Offices to make up the provincial Executive Council; these served as omnibus portfolios that often included a number of disparate elements. This is in contrast to the federal government, where the profile of ministerial offices was left open (ss.11 and 131). The five Ontario BNA Offices - as Hodgetts terms them - were: the Attorney General, Commissioner of Crown Lands, Commissioner of Agriculture and Public Works, the Provincial Secretary and the Provincial Treasurer. Agriculture and Public Works were separated in 1874 and 
Education became a department headed by a minister in 1876 , so for most of the first 40 years there were seven ministerial portfolios. The Constitution Act does not specify an office of Premier (presumably to keep it in the realm of constitutional convention), and for most of the initial period the Premier held one of the BNA Offices as well, usually Attorney General. ${ }^{185}$

In the generation after Confederation, the functions of the provincial government were primarily at "arm's length" (to use Hodgetts' term) - enabling and regulating economic and social service activities and services that were mainly provided by local authorities or by provincially subsidized private entities, many of them affiliated with religious denominations. This was partly a matter of philosophy but also reflected the limitations of transportation and communications in the province at the time and consequently of span of control in the provincial (and federal) civil service. A major feature of this approach was data gathering through government inspectors and periodic commissions of inquiry. There was also "hands-on" direct provision of services but this was largely the exception.

\section{5 to World War II}

A second phase began with the election of the Conservative Whitney government in 1905, after continuous Liberal administration since just after Confederation. The earlier gradual expansion of hands-on government activity was accelerated by the adoption of new technologies - notably the telephone and typewriter - and the introduction of the automobile (Hodgetts 1995: ch. 5), all of which considerably expanded the demands on government as well as its capacities. By the early decades of the $20^{\text {th }}$ century, these new

${ }^{185}$ See also Hodgetts' discussion of the influence of the $18^{\text {th }}$ century British Place Acts on s. 63 and the related ss. 83 and 134 (Hodgetts 1995: 44 46)). 
elements were compounded by population growth and structural changes arising from territorial expansion in Northwestern Ontario (through several land transfers from the North West Territories up to 1912) and expansion of provincial jurisdiction through decisions by the courts and the Judicial Committee of the Privy Council. A number of shortcomings in the arm's length approach had also become apparent. The Whitney government began the process of restructuring the government on the more conventional departmental model as a basis for a more hands-on approach, moving away from the five BNA Offices; it also took steps to strengthen central management institutions, including setting up a separate Executive Council Office. ${ }^{186}$ These changes both reflected and contributed to significant change in the role of government and the growing sophistication of the OPS leading up to World War II. It is fair to say, however, that Ontario lagged behind the federal government in organizing the internal governance of the OPS and in particular in moving towards the merit principle. ${ }^{187}$

The Ontario government also lagged in its financial management practices. ${ }^{188} \mathrm{~A}$ Provincial Auditor was created by statute in 1869 , but its existence was for a long time

\footnotetext{
${ }^{186}$ Arm's length instruments were not abandoned, however, and another major development was the establishment in 1906 of the first major Ontario regulatory agency, the Railway and Municipal Board. ${ }^{187}$ Much of Hodgetts 1995 is an account of periodic efforts at administrative reform in Ontario - see in particular chapters 10 and 11 . The Ontario government was aware of changes in Ottawa, in particular the wholesale move towards a merit-based system of job classification and appointment after World War I. These were rejected for a variety of reasons, and while there were nods in the direction of merit, during much of this period debates focused on the distinction between a system based on "spoils," which was regarded as American and bad, and "patronage," which was the "perfectly proper exercise of personal discretion to choose your trusted advisors" (185). In practice, until well after World War I there was rampant patronage in the field (in effect, a spoils system) but a good deal of continuity in headquarters, even after changes in government - especially in the most senior positions. (This was not dissimilar to the federal government's experience.) The full adoption of the ethic of a professional, merit-based politically neutral civil service came after World War II and was still being tested in the 1990s (see, for example, the account in Cameron and White 2000 of controversy about the NDP Rae government's senior public service appointments). Even today, the OPS has less of the apparatus of a merit system than does the federal government (Brown 2003, Hodgetts 1995: 244-246), with, for example, the Ontario Public Service Commission coming under the authority of the Management Board.

${ }^{188}$ Hodgetts 1995's chapter 12 provides an account that goes beyond the timeframe of the rest of his book; it provides the highlights in this paragraph. The struggle to establish an independent legislative oversight of
} 
entangled with that of the provincial Treasurer, and its position as an independent officer of the legislature auditing comprehensive public accounts prepared by the government was only fully confirmed in 1977 . Scandals about misappropriation of funds led to the creation of a Treasury Board in 1886, although its role was more to keep an eye on the Provincial Auditor on behalf of the Executive Council than to oversee internal management or spending. Accordingly, the Provincial Auditor was widely considered to report to the Treasurer until after World War II, to the extent of attending Cabinet meetings and helping Leslie Frost, then the Treasurer, draft the Budget speech in the late 1940s (Hodgetts 1995: 221). The Treasury department was one of the weakest in government until well into the $20^{\text {th }}$ century, reflecting and no doubt contributing to general weaknesses in financial management - exemplified by the fact that there was no full audit of government revenues before 1924. This came in the wake of another misappropriation scandal, which brought down the post-World War I United Farmers government. Provincial revenue collection continued to be a problem and was only consolidated in response to the rapid expansion of retail sales tax revenues in the early 1960s and a critical report from the Ontario Committee on Taxation in 1967 (Ontario Smith 1967), finally leading to the creation of a Department of Revenue in 1968.

World War II to 1985

Hodgetts and other historians (e.g., Rae 1985) have described World War II and the generation that followed it - for the purposes of this discussion, until the end of the 40- 
year Conservative regime in the mid-1980s - as Ontario's prosperous years. ${ }^{189}$ This can be seen as the third phase of the evolution of the OPS and the one in which the current institutional environment began to mature. Building on the staff support to the Premier and the office of the Clerk of the Executive Council, a Cabinet Secretariat was established in 1948, following the federal and British examples; ${ }^{190}$ until 1953, its head also served as Secretary of Treasury Board (which at the time met infrequently). In 1954, on the advice of Walter Gordon, a Toronto-based management consultant who had earlier chaired a federal Commission of Inquiry on Administrative Classification (Canada Gordon 1946), Ontario passed its first Financial Administration Act (FAA), ${ }^{191}$ which assigned an expenditure and general administrative oversight role to Treasury Board and an allied Budget committee, which often met together (Schindler 1969: 59).

In June 1958, Gordon (who had just concluded a Royal Commission on Canada's economic prospects for the federal government) was asked by Premier Frost to chair a Committee on the Organization of the Government of Ontario. Although the committee was appointed two years ahead of the federal Royal Commission on the same topic, the government's primary concern was more limited: to address criticisms from the increasingly independent Provincial Auditor of the uneven ministerial and legislative oversight of non-departmental boards and commissions, which had proliferated since the

\footnotetext{
${ }^{189}$ Rae's book starts in 1939. Ian Drummond entitled his book (in the same series) about Ontario's economic history from Confederation to World War II, Progress without Planning (Toronto: University of Toronto Press 1987). This sums up the situation in (and role of) the provincial government as well. ${ }^{190}$ Until after World War II, such structure as there was in Cabinet decision-making was the responsibility of the Premier personally and the Provincial Secretary, a Cabinet member (one of the BNA Offices) but a position carried over from UPC models when the distinction between ministers and senior officials was not always clear. Roland Michener, who became Provincial Secretary in 1946 (and later moved into the federal sphere), is credited with sending the future Cabinet Secretary to London and Ottawa on a fact-finding mission that led to a Cabinet secretariat in Ontario staffed by public servants (Schindeler 1969: 44-45).

${ }^{191}$ See Revised Statutes of Ontario 1990 c. F-12 for the current version.
} 
end of World War II. This had also been the subject of the recent Franks Committee in the United Kingdom and a concern of the Hoover Commission in the United States.

In its report (Ontario Gordon 1959), the Gordon Committee recommended measures to strengthen financial and ministerial responsibility of both departments and non-departmental bodies, including a more central role for Treasury Board in all aspects of budgeting and expenditure control and the establishment of a permanent Treasury Board secretariat. ${ }^{192}$ Although Gordon later complained that many of the report's recommendations were never implemented (Gordon 1977: 69—70), the government did hire his management consulting firm, Woods Gordon \& Company, to advise on the organization of the new secretariat. The new structures were incorporated in an amended FAA in 1962. The Treasury Board secretariat was located in the Treasury Department and was made up of two branches, one to provide staff support to the Board and the other the Organization and Methods Services Branch - to advise departments, boards and commissions on management issues (Schindler 1969: 60).

Institutional development in the OPS was given a new impetus - and greater discipline - with the appointment of a Committee on Government Productivity (COGP) by Premier John Robarts in late 1969, after he had implemented a number of incremental changes during eight years in office. ${ }^{193}$ Chaired by a senior private sector executive, the

\footnotetext{
${ }^{192}$ Gordon also recommended integrating Treasury Board and the Budget committee. Notwithstanding the similarity in their titles, the Gordon committee did not cast its net as widely as the federal Glassco commission (Canada Glassco 1961-63), which was appointed the year after Gordon reported; Gordon's recommendations with respect to management in general were much more limited in scope than Glassco's. It can be assumed, however, that the two men were aware of each other's work: Glassco was a partner in Gordon's family firm of chartered accountants, Clarkson and Gordon, and conducted a taxation study for Gordon's Royal Commission on Economic Prospects. In 1944 Clarkson and Gordon and its sister management consulting firm, Woods Gordon, affiliated with Arthur Young (Edwin O. Griffenhagen's original firm), which has since merged into the global firm Ernst \& Young. For a brief corporate history

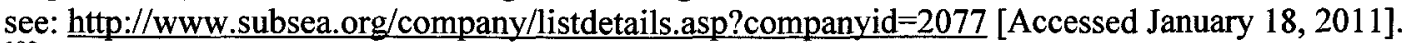

${ }^{193}$ Evans (2008: 125 - 127) offers several reasons why Robarts took this step, an important one (echoing Drummond - see fn. 187 above) being that the OPS's rapid growth in the post-War era had been generally
} 
COGP had ten members, five from the private sector and five deputy ministers. It submitted ten interim and final reports between 1970 and 1973 (Ontario Cronyn 19701973), with the government response largely left to Bill Davis, who became Premier in 1971. The committee's Executive Secretary was later at pains to emphasize that this was not another Glassco report - citing a more balanced involvement by "insiders" as well as Glassco's "outsiders," a focus on implementation, and greater participation by those affected (Fleck 1972) - but the report echoed Glassco in calling for more comprehensive government-wide mechanisms for both policy development and internal administration. ${ }^{194}$ This included new Cabinet committee structures, featuring a Policy and Priorities Board and a Management Board. In addition, the COGP proposed grouping departmental programs and activities into three policy fields (social development, resource development, and justice), each overseen by a Cabinet committee and a ministerial chair. A consolidated Ministry of Treasury, Economics and Intergovernmental Affairs (TEIGA) was proposed to manage the economy and expenditure allocation, with a new Management Board of Cabinet to oversee internal administration and a Ministry of Government Services to provide consolidated support to government, including in areas such as office accommodation and data processing. ${ }^{195}$

undisciplined and led by individual departments rather than guided by any central direction. Robarts, perhaps encouraged by a new Cabinet Secretary, felt that improvements were required in Cabinet decisionmaking and the supporting machinery (see also White 2002), if only to contain costs and improve efficiency. At the same time he felt that the OPS could not solve all its problems itself and needed outside help. Robarts and his advisors would have been aware of the post-Glassco ferment in Ottawa, spurred on by the recent arrival of Trudeau and his emphasis on public sector modernization. Another source of inspiration was the greater attention being paid in the United States and in public sector management generally to techniques such as Program Budgeting, which were influenced by the two Hoover Commissions and the US private sector.

${ }^{194}$ Chandler and Chandler 1982 (595: fn 43) note that in addition to the COGP at least three other provinces commissioned similar studies in the wake of Glassco: Saskatchewan, Manitoba and Quebec. ${ }^{195}$ The major structural proposals were advanced in report 2 (Ontario Cronyn 1971a) and supplemented in report 9 (Ontario Cronyn 1973a). Fleck 1972: 383-384 provides a useful summary. 
The COGP proposed Management Board as a replacement for the earlier Treasury Board, with a full-time chair (Ontario Cronyn 1971a) and a mandate to set management policy and standards to guide both departments and Government Services (Ontario Cronyn 1971b). This was reminiscent of the Glassco model of decentralized management policy administration, with the Board's remit also extending to most aspects of human resources management (the subject of the sixth committee report - Ontario Cronyn 1972b). Following up Gordon's earlier report, the COGP recommended that departments be restructured on a more policy-oriented ministry model that took account of their nondepartmental relationships (Ontario Cronyn 1973a). The committee's fifth interim report was on Automatic Data Processing (ADP - Ontario Cronyn 1972a) and the seventh on Communications and Information Services (Ontario Cronyn 1972c), the latter supported by several academic studies, including one on the potential for new communications technologies to enhance citizen participation and increase program effectiveness (Axworthy 1971).

The ADP study, echoed by the $9^{\text {th }}$ report, recommended a single common information system for the use of both program managers in ministries and central management agencies; a task force was recommended to design such a system, to be located in TEIGA and advised by a committee of users (Ontario Cronyn 1973a: 80-81). The one other major computing environment would be in the Revenue ministry, under the policy direction of TEIGA. Again echoing Glassco, the committee recommended that a common ADP approach should include steps to develop common coding for internal data transmission and sharing, and greater attention to records management. The COGP's final report (Ontario Cronyn 1973b) concluded with a call for developing a stronger 
relationship between citizens and government on the one hand and more productive use of common services on the other.

The COGP was a watershed in Ontario's development, variously characterized as marking the beginning of the institutionalization of the provincial Cabinet (Glenn 2005: 157), "formative" (Evans 2008: 121) and "forward looking" (126). Describing it as the "touchstone" for all more recent developments, Lindquist and White (1995: 270) note that its emphasis on structure and process was also the result of coming to terms with Ontario's "embarrassment of riches" in the sustained good economic times of the 1960s, when the OPS effectively doubled in size (275). The COGP's recommendations were largely implemented (Fleck 1973), although not without criticism at the time. ${ }^{196}$ Implementation began with a major government reorganization in 1972 - even before the COGP final report - to introduce the machinery recommended by COGP, including more formalized Cabinet decision-making procedures and more centralized budgeting.

Another major step was introduction of public sector unionization, with the passage of the Crown Employees Collective Bargaining Act (CECBA) in 1972 and the recognition of the Ontario Public Service Employees Union (OPSEU) as the main public service union, although it was not given the right to strike. The adoption of COGP's proposals was undoubtedly hastened by the entry into office of a new Premier wanting to put a fresh face on a government that had been in power for nearly 30 years. The prospects were only improved when, after the last report was submitted in 1973, the

\footnotetext{
${ }^{196}$ One criticism at the time was whether the proposed ministerial coordinating roles would work (Mallory 1973 - this aspect of the model was dropped by the Peterson government.) Another was that the report's solutions were too technocratic, with insufficient attention to linking executive and legislative reform (Bryden 1975) - arguably still an issue. Evans 2008 (154) argues that the initial COGP implementation focused on its structural proposals but other important themes such as service to the public and managerial reform were left "untouched" until after the return of the Conservatives in 1995. While this helps to support Evans' arguments for the importance of the Cabinet Secretaries under Harris, the developments between COGP and Harris discussed in the balance of this section suggest that his generalization is too sweeping.
} 
COGP executive secretary, Jim Fleck, ${ }^{197}$ became the head of the Prime Minister's Office - with the title of Chief Executive Officer - and then Cabinet Secretary.

Once the COGP report was put in place, Davis made few changes during the rest of his 14-year term, apart from some restructuring of the Cabinet policy committees and their secretariats. In addition, Inter-Governmental Affairs was separated from Treasury and Economics in 1978 in response to the growing demands of the national constitutional agenda. The general stability was presumably because the original model suited the requirements of Davis' government, but no doubt a six year period of minority government (1975-81) reduced the incentive for further innovation. In any case, much like the aftermath of Glassco in Ottawa, there was time to put a new administrative matrix in place following the COGP report and it continues to provide the basic framework for the development of Ontario administrative institutions.

The COGP model since 1985

The fourth phase in the OPS's institutional development is most simply demarcated by the change of government in 1985 , after the Conservatives had been in power for 42 years and six Premiers. This ushered in a period of considerable political flux - which can also be understood as Ontario coming closer to the Westminster model's implicit assumption of a regular alternation of the party in power. In the past 25 years there have been five Premiers, from the three main political parties, with all but one in office for at

\footnotetext{
${ }^{197}$ Before going to work for the COGP, Fleck, who had a Harvard Doctorate in Business Administration, had been a successful businessman and then an academic administrator at York University.
} 
least five years. ${ }^{198}$ Apart from the first two years of the Liberal Peterson government, this has also been a period of continuous majority government.

Ontario has been subject to many of the same external influences as the federal government and has often responded in similar ways, with the federal responses seen as providing both positive and negative examples. ${ }^{199}$ Economically, Ontario did well for most of the 1980s, but it faced a gradual and then a precipitate economic downturn in the early 1990s - compounded in the province's case by reductions in federal fiscal transfers and downloading of program responsibilities as a result of Ottawa's Program Review exercise in the mid-1990s - followed by renewed economic growth in the 2000s and the economic downturn of 2008. The economic crisis of the mid-1990s was the Achilles' heel of the NDP Rae government (1990-95), a major contributor to its defeat after one term in office, and was also the catalyst for the dramatic changes made by the Progressive Conservative Harris government in the late 1990s. These economic difficulties, in tandem with ICT-driven social and economic changes and prevailing ideas about public sector modernization that also shaped events during the same period in Ottawa, provided the context for the establishment of the Corporate CIO in 1998. The discussion that follows looks at the Peterson and Rae governments, while the Harris/Eves and McGuinty governments are discussed in the next section.

\footnotetext{
${ }^{198}$ The Premiers since 1985 have been: David Peterson (Liberal 1985-1990), Bob Rae (NDP 1990-95), Mike Harris (Progressive Conservative 1995-2002), Ernie Eves (Progressive Conservative 2002-2003), and Dalton McGuinty (Liberal 2003-present).

${ }^{199}$ Lindquist and White 1995 give a number of examples of how modernization efforts in Ottawa, notably Public Service 2000, were monitored by senior Ontario officials during the Peterson and Rae governments, although as with the COGP's view of the Glassco commission they were often seen as too elaborate and top-down in their approach.
} 


\section{Peterson government (1985-1990)}

The Liberal government of David Peterson had two phases: a minority government in alliance (but not coalition) with the NDP (1985-87), ${ }^{200}$ followed by three years of majority government (1987-90). Especially in its early years, the Peterson government devoted its attention primarily to policy issues, retaining the inherited COGP system with few changes apart from adjustments to the mandates and composition of Cabinet policy committees and secretariats. The introduction of a Human Resources Secretariat, reporting to Management Board, led to efforts to introduce cultural changes in the public service in order to strengthen leadership and innovation (Lindquist and White 1995: 275-277). Peterson also separated the Cabinet Office and the Premier's Office on a public service/partisan distinction similar to the arrangement in the federal government (Cameron and White 2000: 26). Later, in 1989, the Cabinet Office launched an OPS-wide Tomorrow Project, to some extent at least inspired by the federal Public Service 2000 exercise, that included three projects to look at the role and structure of the key central agencies, improve customer-oriented service to the public, and improve productivity and internal services. This work was still under way, however, when the government changed in October 1990.

\section{Rae government (1990-1995)}

Although it entered office with a clear majority, the Rae government had not seriously expected to form a government (Rae 1996) and was under-prepared either for the transition (Cameron and White 2000) or to govern. The government's primary focus was on policy and responding to social movement pressures (Lindquist and White 1995:

\footnotetext{
${ }^{200}$ The Liberal-NDP Accord related to an agreed policy agenda and groundrules for confidence votes in the legislature (Rae 1996: 95-96). It did not impose limitations on Peterson's management of the OPS.
} 
285), paying limited attention to internal management issues. The Tomorrow Project continued within the public service, and its work had an influence on early fine-tuning to the central machinery: a Treasury Board of Cabinet, with a supporting Treasury Board Secretariat, was established to counter perceived fragmentation of Cabinet's financial decision-making (Glenn 2005: 158), and the MBS Program and Estimates division was transferred to Treasury and Economics to provide an integrated approach to the revenue and expenditure budgets. MBS retained its role with respect to information and technology but was re-oriented towards human resources and employer issues, ${ }^{201}$ while the Cabinet Office's policy capacity was strengthened.

The Rae government faced a deteriorating economic and fiscal situation from the time it came to office, compounded by suspicion of its motives by the business community and later by federal downloading. ${ }^{202}$ After mid-1992, these issues increasingly dominated the government's agenda, and Rae took two steps in anticipation of having to take difficult and unpopular measures. In September 1993 he gave his closest political advisor, the head of the Premier's Office, a dual appointment as head of the Cabinet Office; this led to criticism that the senior OPS was being politicized, ${ }^{203}$ although pragmatically it also meant that the government began to take greater interest in public service reform, if only to strengthen its ability to deal with the fiscal crisis. In a

${ }^{201}$ OPSEU was given the right to strike and a number of previously excluded public servants were moved into the unionized sector - the latter move in particular faced internal resistance, further complicating the already uneasy relationship between the Rae government and the OPS.

${ }^{202}$ Lindquist and White 1995 (294) suggest that the Ontario government was aware of the deCotret study that paved the way to the major federal government reorganization in June 1993 by incoming Prime Minister Campbell and that it anticipated that this would lead to major federal spending cuts.

${ }^{203}$ The two positions had in fact been combined from 1948-1971. Davis initially separated them but in 1976 combined them again, which they remained until 1985 when Peterson split the posts for the duration of his government (Evans 2008). Both Lindquist and White 1995 and Cameron and White 2000 conclude that while some Rae appointments to the senior ranks of the OPS had overtly partisan connections many others had in fact been recruited by Peterson or even earlier. They also have some sympathy for the view that the OPS had become more politicized than it recognized under the long period of Conservative government (or to put it differently, that the non-partisan ideal was not as well established as was thought). 
second preparatory step, Rae made a more substantial reorganization in February 1993, reorganizing Cabinet committees and decision-making, restructuring a number of line ministries, creating a Ministry of Finance (by combining Treasury and Economics, Financial Institutions, and Revenue), and merging MBS with Government Services. This machinery was used to approve and carry out a far-reaching expenditure control plan, which included major cuts to government spending and wage rollbacks in the OPS and the wider public sector. The resulting confrontations with public sector unions and other NDP constituencies were a major factor in Rae's defeat in the June 1995 election.

Management of information and technology in the Peterson and Rae governments

Within the OPS, the management of information and technology continued to take shape during the Peterson government in particular, driven by both internal and external dynamics. Although not an issue addressed by the COGP, freedom of information and privacy had come onto the public agenda by the late 1970 s, and major changes were made in this area under Peterson and extended by Rae. In addition, institutional structures began to develop in the centre of government for the various aspects of information and technology management, generally in line with the COGP's recommendations. These were not as unified as their federal counterparts during the same period, however, either conceptually or organizationally, although in the nature of the OPS they may well have been more integrated in their effect. ${ }^{204}$

\footnotetext{
${ }^{204}$ Any discussion of integration within the OPS should take account of its smaller scale and the more compact physical arrangement of headquarters offices. The agencies and ministries in the organizational centre of government are also centrally located physically, in a complex of buildings across from the provincial legislature. Although the organizational boundaries of the Cabinet and Premier's offices, the Treasury, Management Board Secretariat and Ministry of Government Services have all moved more than once since World War II their offices have remained in close proximity to each other. A "whole-ofgovernment" approach flows naturally from this physical proximity, which is more concentrated than in Ottawa. Arguably it also contributes to the OPS's generally more pragmatic attention to formal structures and the emphasis instead on organizational culture in the OPS's approach to public sector modernization.
} 
In 1977, Davis appointed a Commission on Freedom of Information and Individual Privacy, chaired by D.C. Williams, at the same time as possible legislation in the same areas was beginning to be discussed in the federal government as well as internationally. After three years of deliberation, the commission delivered a comprehensive threevolume report (Ontario Williams 1980) supported by seventeen research studies ${ }^{205}$ that thoroughly canvassed both dimensions of its mandate and recommended a unified provincial Freedom of Information and Privacy (FOIP) regime. In the context of a discussion of the balance between secrecy and the public's right to know (ch. 7), the report included in the scope of information practices (ch. 8) information in the context of: the formulation of public policy, administrative activity, adjudication, government statistics, communication of government policies and programs, records management, archives, and information in local government institutions. The report also included discussions of the emerging international consensus on fair information practices and of the effects of computers on privacy (ch. 26).

Davis did not act on the Williams report, even though in many ways it parallelled proposals considered by the Progressive Conservative Clark government (1979-80) in Ottawa. Peterson did, however, and established a unified FOIP regime based on the Williams report that came into effect on January 1, 1988. This featured a single governing statute (now the Freedom of Information and Protection of Privacy ActFIPPA) and an officer of the Legislative Assembly, the Information and Privacy Commissioner (IPC), to receive complaints and conduct research on implementation of the $A c t$. From the beginning, FIPPA had a broader (as well as more integrated) remit than

\footnotetext{
${ }^{205}$ Lindquist and White 1995 state that the report's research volumes "constitute most of the academic research published on public administration in Ontario." (273: fn 6).
} 
its federal counterparts, applying to a wide range of provincial boards and commissions as well as to post-secondary institutions. It was supplemented by legislation extending FOIP to municipal institutions and school boards (introduced by the Rae government) in 1991 and creating a personal health information regime within the health care system in 2004 (McGuinty government). In both cases the IPC has an oversight role, which is reinforced by order-making powers - a contrast with the federal Information and Privacy commissioners, who only have powers of investigation and publicity. ${ }^{206}$

Oversight of the FOIP regime and of related information management (IM) and information technology (IT) issues was originally dispersed across the centre of government. Under Peterson, Management Board was given responsibility for establishing administrative policies and procedures for implementing FOIP within the OPS, and Management Board Secretariat (MBS)'s Management Policy Division ${ }^{207}$ (one of three reporting to the Secretary of MBS ${ }^{208}$ had a FOIP policy branch to work with FOIP coordinators in ministries and with the IPC. Information technology had a full division on its own, with responsibility for developing a corporate strategy for government-wide management of IT, advice on IT aspects of program proposals from ministries to Cabinet, policy development and implementation of IT-related management policies, and support to the IT functional community across government. Two of the four divisions of the Ministry of Government Services provided services to or on behalf of

\footnotetext{
${ }^{206}$ The Ontario regime is often a point of reference in discussions about reform of the federal legislation. Three Ontario differences that have attracted particular attention in Ottawa are the combined information and privacy legislation and Commissioner, the IPC's order-making authority, and the IPC's wider mandate - with supporting resources - for research and promotion of the three FOIP-related Acts.

${ }^{207}$ The Management Policy division also administered the Management Board's consolidated directives manual. During this period, the third major MBS unit was the Program and Estimates Division which had policy-sector units responsible for the expenditure-estimates process and corporate expenditure control. ${ }^{208}$ Organizational details in this paragraph are drawn from Bell and Pascoe 1988, in particular pp. 324, $335-343$ and $353-355$.
} 
government within the policy framework administered by MBS. The Computer and Telecommunications Services provided a common environment for government departments, including telephones, data transmission and audio and visual technology; three computer centres handled approximately 80 percent of the government's computing, with most of the rest housed in the Ministry of Revenue at its decentralized offices in Oshawa. The Supply and Service division delivered a range of common services to government as well as services to the general public, including information services, in both its Information Services Branch (databases and directories for access to government, government records centres, publications services) and the General Services Branch (notably a section managing Ontario official documents ranging from land patents to certificates of appointments under the provincial Great Seal).

During the Rae government, information and technology policy were combined in a single division in MBS, with Government Services providing information and technology services to government and to the public. IT strategic planning was begun and there was some early interest in IT in support of customer service. With the worsening fiscal situation, there was growing interest in the potential of information and technology along several lines - notably support for service delivery, re-engineering line ministry operations, and improvements in cross-ministerial collaboration - all in order to gain savings and a greater focus in government spending on programs. It was also recognized, however, that a limiting factor to using technology in these ways was the major front-end investment needed (Lindquist and White 1995: 296-297). This was the situation in June 1995 when the incoming Harris government revisited organizational arrangements at the centre of the OPS. 


\section{Establishment and Evolution of the Corporate CIO}

The creation of the Corporate Chief Information Officer position in Management Board Secretariat was a function of the circumstances of the Harris government (19952002). At the same time it built squarely on the earlier institutional evolution of the OPS generally and its management of information and technology specifically. Once established, the position has been remarkably stable, with its mandate and internal organizational model virtually unchanged in thirteen years' existence - a marked contrast with the federal CIO's experience described in chapter 3 . This stability has been maintained through four incumbent CIOs and three Premiers as well as several changes in Cabinet Secretary and in the CIO's more direct reporting relationships. On the face of it, the designers of the Corporate CIO model "got it right the first time" - the mantra of the quality movement - and instituted a position that has taken root and matured in the evolving circumstances of the OPS since 1998. This section discusses these developments. It begins with an account of the evolution of the Ontario Cabinet machinery and central agencies under Premiers Harris, Eves and McGuinty and then looks at the decision to introduce the Corporate CIO model, followed by a summary of its features and more recent development.

\section{Cabinet and central management agencies under Harris, Eves and McGuinty}

As Premier, Harris paid more attention to the design of the machinery of government as an instrument of public policy than most, if not all, of his predecessors, leading to the paradox of a smaller but more centralized provincial state (Evans 2008: 142). Glenn 2005 identifies four distinct stages in his approach to the structure and 
operations of Cabinet and its supporting institutions. On coming into office (159-160) with a mandate to implement the Common Sense Revolution - aiming to bring down the size of government and balance the government's books - Harris was focused on implementation, not policy debate. In a move towards what amounted to a pre-COGP Cabinet structure, ${ }^{209}$ the Cabinet policy committees were all wound up, as was Treasury Board, leaving Policy and Priorities (P\&P - chaired by the Premier) as the decisionmaking committee and Management Board in charge of in-year expenditure management (this is reminiscent of the hands-on approach adopted by R.B. Bennett when he became federal Prime Minister at the height of the Great Depression in 1930 - see chapter 2). Financial decision-making was centralized through an increasingly comprehensive system of business planning which, by its third year (1998-99), included planning for the administrative inputs to government programs, including human resources and information technology.

After a year (160 - 162), the relatively straightforward elements of the Common Sense Revolution had been implemented (including a 15 percent reduction in the OPS), leaving a more complex restructuring agenda in the major sectors of education, health, welfare and local government. P\&P sub-committees were set up to flesh out the second wave of initiatives. The growing public communications challenges posed by the government's often hard-edged changes led to measures to centralize the public communications function, with a deputy minister position established to lead it in the Cabinet Office in 1997. In 1998, a communications organizational model was introduced whereby communications directors in ministries were given a formal dual reporting

${ }^{209}$ Glenn (2005: 156) describes the pre-COGP Cabinet as "unaided," drawing on Christopher Dunn's terminology in writing about the institutionalized Cabinet (e.g., Dunn 1996). 
relationship to both the communications deputy minister in Cabinet Office and the deputy minister of their own ministry $(161){ }^{210}$

The third phase of Harris' Cabinet (162 - 165) came after the 1999 election, when he campaigned on a platform that was more directional than specific, in a context in which fiscal pressures were becoming less urgent. A more comprehensive Cabinet decision-making system was introduced, with Policy and Priorities reconstituted as the Policy, Priorities and Communications Board (PPCB - chaired by the Premier), four policy committees (a fifth was later added), ${ }^{211}$ and a committee on Privatization and Superbuild to drive infrastructure initiatives involving public-private partnerships. The final phase (165-166) began when Harris announced his retirement in October 2001, with effect the following Spring. Focused on personal legacy projects and some recurring fiscal constraints, he suspended the activities of Cabinet policy committees for his last six months in office. The (phase three) Harris Cabinet model was continued for the nineteen months of the Eves government, with the policy committees reactivated. His main modification was the introduction of an outer perimeter to Cabinet, appointing several Associate Ministers and including Parliamentary Assistants on all Cabinet committees except PPCB. ${ }^{212}$

When the Liberal Dalton McGuinty was elected with a majority government in October 2003, he carried over much the same structure, renaming PPCB to become Planning and Priorities Board (a centralized communications function was kept in the Cabinet Office), retaining Management Board and adding a sixth policy committee.

\footnotetext{
${ }^{210}$ In 2001, the deputy minister position became an Associate Secretary to Cabinet, which it remains (Glenn 2005: $161 \mathrm{fn} 27$ ).

${ }^{211}$ The vice-chairs of the policy committees all sat on Management Board to ensure integration of policy and financial decision-making.

${ }^{212}$ This was a modified version of efforts to involve government caucus members in Cabinet decisionmaking that had been introduced in Alberta and British Columbia. See also White 2005: 125-129.
} 
McGuinty also continued the trend towards greater participation by backbenchers in Cabinet discussion, appointing a parliamentary assistant and a backbencher to chair and co-chair each of the policy committees (170). In $2005 \mathrm{McGuinty}$ reorganized the centre of government, creating a combined Treasury Board/Management Board of Cabinet and also combining the ministerial positions of Minister of Finance and Chair of Management Board. MBS was wound up, and its management policy oversight functions - including the Corporate $\mathrm{CIO}$ - were transferred to the Ministry of Government Services (echoing Rae's approach), as was the human resources management policy secretariat, which earlier in the McGuinty government had reported to the Premier and at other times had been linked to Management Board. While this could be seen as blurring the boundary between central agency and common service organization roles, a link to collective decision-making was provided by the dual appointment of the Deputy Minister of Government Services as Associate Secretary to Cabinet. ${ }^{213}$

Underpinning the Cabinet machinery has been an ongoing effort to continue the process of reforming the OPS and keeping it up to date. The course was set when Harris, on coming into office, chose to engage with the senior public service rather than marginalize it (Evans 2008: 142ff). Based on extensive pre-election planning, Harris moved quickly to remove five deputy ministers deemed too close to the previous administration and to select a new Cabinet Secretary, Rita Burak, from the OPS. She then proceeded to put the OPS to work on implementing the government's agenda, both in policy terms and organizationally through an OPS Restructuring Secretariat in the

\footnotetext{
${ }^{213}$ More detail on the McGuinty Cabinet and related structures can be found on the Premier's web site: http://www.premier.gov.on.ca/team/default.asp?Lang=EN [Accessed January 26, 2011]. Details of the organization reporting to the Corporate CIO can be found in the Info-GO telephone directory: http://www.infogo.gov.on.ca/infogo/office.do?actionType=servicedirectory\&infoType $=$ service\&unitId $=\mathrm{U}$ NT0003723\&locale $=$ en
} 
Cabinet Office. Building on the business planning process, the Restructuring Secretariat during the lifetime of the Harris/Eves government produced an annual "Framework for Action" to guide a variety of organizational and cultural change initiatives in the OPS (OPS Restructuring Secretariat 1997-2002). ${ }^{214}$ With the support of Harris, Burak took steps to strengthen the horizontal coordination (and later on, policy development) capacity in the OPS and to strengthen management and development of its senior ranks. Later Cabinet Secretaries continued to push for greater integration within the OPS and to "expand the role of deputy ministers as corporate rather than ministry leaders" (Evans 2008: 152). These initiatives were continued under McGuinty, who on coming into office in 2003 saw the OPS as part of the solution (149), in contrast to the perception held by his Liberal predecessor, Peterson, in 1983.

\section{Establishment of the Corporate CIO}

The decision to create an Ontario Corporate CIO (CCIO) grew out of the implementation of the Common Sense Revolution. It was understood within the OPS that major savings were called for in the operations of government and there was an awareness of the promise of information technology to perform the feat of simultaneously improving government services and operations while producing significant savings. A key change agent was Scott Campbell, a career Ontario public servant, who became the head of the Services Division in Management Board Secretariat in 1996, giving him

\footnotetext{
${ }^{214}$ There is an interesting contrast with the annual reports to the federal Prime Minister prepared by the Clerk of the Privy Council. The latter contain a combination of "speaking truth to power" (although not always very bluntly) and signaling to the public service as well as the public. The Frameworks for Action were clearly intended as direction to the OPS, with signals to the Premier and the public. On the face of it, the Framework approach was at least potentially more effective in mobilizing the public service, although it did not survive the departure of Harris for very long. The Frameworks also assumed a systematic modernization agenda, which has not been the case in the federal government in recent years.
} 
responsibility for IT policy. ${ }^{215}$ In the context of the government's new emphasis on business planning, Campbell was given a mandate to develop an IT strategy for the government as a whole. A key part of the strategy was to create a new corporate IT organization with effective leverage that would avoid the mistakes of the federal CIO, which Campbell has described as "a toothless tiger, relying on moral suasion" (Borins and Brown 2007b: 285). ${ }^{216}$ Having lined up support for his proposal from the Cabinet and MBS Secretaries as well as his own minister, Campbell's IT strategy and the related organizational structure were approved by Cabinet in Spring 1998 , along with $\$ 110 \mathrm{M}$ in new funding (bringing to mind the NDP concerns about the up-front costs in the transformation to e-government). Campbell was then appointed Corporate $\mathrm{CIO}$ with a mandate to implement the strategy. Once it was well established, he retired from the OPS in 2001, going on to serve a term as the British Columbia government CIO.

The Corporate CIO model introduced in 1998 is in fact an integrated model for the organization of the entire information and technology function across the OPS, building on an IM/IT functional space that had already been substantially integrated by Peterson and Rae, rooted in COGP's recommendation to adopt a unified approach for the entire OPS. Its foundation is a group of Cluster CIOs, each of whom is responsible for providing IT and IM services to a group of related ministries (for example, the Central Agencies cluster supports Cabinet Office and Finance). Each Cluster CIO has a line

\footnotetext{
${ }^{215}$ Campbell was a political science graduate, who earlier in his career had been director of organizational policy in MBS. He later gained experience in managing IT units, including as chief administrative officer in the Ministry of Health. Campbell's background and role in establishing the Corporate CIO are described in Borins and Brown 2007b (284-286) and were elaborated in an interview for this dissertation.

${ }^{216}$ In preparing his proposal, Campbell talked to senior private sector IT executives and also to the then federal CIO, Paul Rummell. Rummell, who was the first federal CIO with either an IT or a private sector background, encouraged him to develop an Ontario CIO model with more clout in the system (Rummell interview). In working out the CIO organizational design Campbell also drew on his earlier experience with COGP implementation.
} 
reporting relationship both to the deputy ministers of the ministries they support and to the Corporate $\mathrm{CIO}$ - much like the dual reporting model for communications directors that was also introduced in $1998 .{ }^{217}$ While this was an ambitious use of the concept of clusters, precedent for them could be found in past groupings of similar departments under Cabinet policy committees, going back to the COGP reforms, and even the groupings of often-unrelated departments in the original BNA Offices.

In addition to having the senior ministry CIOs at its management table, the Corporate CIO was given a comprehensive package of IT-related responsibilities, including: IT policy, standards and strategic planning; a mandate to assess IT implications of submissions to Management Board; oversight of IT and IT infrastructure projects; and control of senior IT appointments in ministries. Three key IT areas brought under the CCIO's direction were the major OPS computing environments (apart from the Revenue ministry), telecommunications and networking infrastructure, and control of IT purchasing. In addition, the Corporate CIO was given policy responsibility for information management and the implementation within the OPS of freedom of information and privacy legislation. The functions reporting to the $\mathrm{CCIO}$ have not changed significantly since 1998 , and today the Corporate CIO is supported by a Corporate Chief Strategist and a Chief Information and Privacy Officer, as well as Corporate Security and Infrastructure Technology units. Information and technologyintensive common service organizations operating under CCIO policy leadership such as

\footnotetext{
${ }^{217}$ There is some indication that Cabinet Secretary Burak intended to introduce the cluster concept in a number of areas across the OPS with a view to making productive use of government resources. A key application of clusters was in the area of integrated service delivery to the public. (See, for example, Covelli and Cece n/d: 2 fn 3: "Working in clusters means formalizing natural working relationships of ministries that have common interests and customers. Working collaboratively in clusters allows the OPS to do better planning, and connect or integrate policies and programs. Clusters will result in more accessible and responsive services through more opportunities for one window service delivery.")
} 
Service Ontario and Archives Ontario report to the Deputy Minister of Government Services alongside the CCIO, as does Ontario Shared Services, which provides common back office services to Ontario ministries using the CCIO's computing facilities. ${ }^{218}$

The OPS communications function has never been directly linked to the CCIO, but there have been indirect connections. The CIO departmental clusters are parallelled by a structure of communications clusters, and the two functional communities have a joint stake in Service Ontario. Additional connections are provided by the fact that both the corporate communications leadership and the $\mathrm{CCIO}$ are in the same headquarters complex of offices and the Deputy Minister of Government Services - the CCIO's supervisor - is at the Cabinet Office management table along with the senior communications officer.

The Corporate CIO since 1998

For practical purposes, the Corporate CIO model that was introduced in 1998 has been fully implemented and remains in place. Its organizational location changed in 2005 with its transfer to Government Services, although the effects of the separation from the central agency environment were attenuated by a closer formal relationship between Government Services and Cabinet Office. In practice, all the key players have remained in the same physical offices, in close proximity to each other in the OPS precinct across from Queen's Park. The model has passed the test of political and internal controversy, including an external review and the firing of a Corporate CIO. Its survival has also been helped by stability at both the political and the top public service levels, notably

${ }^{218}$ An Integrated Financial Information System project, led by the Ministry of Finance, was launched in 1997-98 and provides a unified financial management application for all OPS ministries. Although it had early difficulties, it was successfully implemented through collaboration between Cluster CIOs and a lead Assistant Deputy Minister of Finance (Sékaly interview). 
continuous majority government and a succession of Cabinet Secretaries who have enjoyed the confidence of their Premiers - including a smooth transition between Premiers on two occasions and once between parties. The OPS top leadership have been actively engaged in a continuous process of public service modernization, with information and technology understood to play an integral part, along with human resources management and cultural change.

Since Campbell's retirement there have been three Corporate CIOs: Greg Georgeff (2001-2005); Ron McKerlie (2005-2008); and David Nicholl (2008-present). Unlike Campbell, all three had an IT professional background. Georgeff and Nicholl both worked in the OPS as IT specialists early in their careers; they returned to the OPS as Cluster CIOs after gaining experience in the private sector and then were promoted to Corporate CIO when the position became vacant. McKerlie had spent all his earlier career in the private sector, rising to become a senior IT executive at Rogers before being recruited as Corporate CIO when Georgeff was fired in 2005 (a rare turbulent incident in a generally placid institutional story). ${ }^{219}$ McKerlie's departure was under very different circumstances, when he was promoted to Deputy Minister of Government Services and Associate Secretary to the Cabinet in 2008.

Based on a year as a visiting scholar embedded in the office of the CCIO, Borins (2007b) has provided a portrait of the CCIO's agenda - what "keeps a CIO awake." Two sets of relationships are represented as particularly important. The first was with the politicians in the recently elected McGuinty government, which was enthusiastic about the use of IT (PowerPoint had not until then been used in Cabinet discussions) but also

\footnotetext{
${ }^{219}$ Georgeff was a casualty of the 2005 reorganization. By Borins' account, he came out on the losing end of a clash of personalities with his new Deputy Minister at Government Services, a victim of bureaucratic politics rather than ministerial disapproval (Borins 2007b: 96 - 97).
} 
critical of some of the previous government's IT-related practices. In addition the government faced a renewed deficit situation. The second key relationship for the CCIO was with the committee of executives under his direct managerial authority (the combined group of Cluster CIOs and senior managers in the office of the $\mathrm{CCIO}$ ) - what Borins refers to as the IT organization - which together directly controlled half of the government's IT spending (71). (The very different composition of their respective management tables and agendas is a good illustration of the difference between the federal CIO and Ontario CCIO.)

The IT organization was called upon to respond to the government in three areas. Echoing OPSEU concerns, the Liberals were critical of the heavy use of consultants in the OPS, 80 percent of whom were in the IT area; the IT organization came up with changes that reduced spending on consultants while doing more permanent staffing (in effect they adopted an insourcing strategy). The CCIO also met an early request from the government to find $\$ 100 \mathrm{M}$ in annual savings in the overall IT budget, much of it through efficiencies and consolidation in IT operations across government. ${ }^{220}$ The third and most challenging area in the CCIO and IT organization's relationship with the McGuinty government was the management of major IT projects, which Borins argues are the most difficult procurement area for any government (Borins 2007a: 30). Two projects were particularly problematic: the Integrated Justice Project (IJP), and the Business Transformation Project (BTP) at the Ministry of Community and Social Services (known as ComSoc). Both were launched in 1997, before the CCIO was set up, as "common

\footnotetext{
${ }^{220}$ Total IT spending in 2003-04 was estimated at $\$ 926 \mathrm{M}$, i.e., $\$ 71$ per capita or 1.25 percent of total government spending (Borins 2007b: 75-76). It is noteworthy that the CCIO had these cost figures available on an annual basis, produced by an Information and Information Technology Controllership Branch in the CCIO's Office of the Corporate Chief Strategist. The federal CIO does not have such a capacity to track information and technology spending.
} 
purpose procurement" projects based on a model of government partnership with a private firm or consortium involving shared risk, costs and benefits, as opposed to a more traditional contract based on lowest cost arrived at through competitive tendering. Both projects ran into major difficulty, with the IJP ending in litigation and BTP well over expected costs and under considerable controversy. ${ }^{221}$

The experience of dealing with IJP and BTP provoked a wider discussion in the public and legislature about IT initiatives and led the new McGuinty government in 2004 to appoint an external task force to review the management of large scale IT projects, led by Denis Desautels, a former federal Auditor General. ${ }^{222}$ In its report (Ontario Desautels 2005) the task force recommended a number of measures for strengthening IT projects, in particular large ones, which it argued should be limited in number and supported by improvements in business case development and project management, monitoring and review. The task force endorsed the $\mathrm{CCIO}$ and cluster model (if somewhat weakly), stating that it worked "reasonably well" (17) and assuming its continued existence. At the same time the task force was clearly concerned about the CCIO's clout in the system and the recommendation to which it gave highest priority was that a Deputy Minister for business transformation and public service modernization should be established to oversee major projects (18), with enough stature to work as a peer with ministry deputy ministers. (How the CCIO would relate to this person was not addressed.) The report,

${ }^{221}$ These projects and the challenge of this kind of public-private partnership were the subject of two Canadian Public Administration articles: Jordan 1999 wrote about the administrative challenges of setting up the IJP partnership, before the problems emerged; and Whorley 2001 discussed the ComSoc BTP after it had been criticized by the Provincial Auditor. The political difficulties created by these two projects are reportedly one of the reasons why the Harper government, which includes several former Harris ministers, has been cautious about major IT initiatives, in particular John Baird (who became ComSoc minister after the BTP project ran into trouble) when he was federal Treasury Board President.

${ }^{222}$ Another of the four members was David Johnston, then President of the University of Waterloo, who in the mid-1990s had chaired the federal Information Highway Advisory Council and later a Broadband task force on behalf of Industry Canada (and is now the Governor General). 
which was consistent with thinking in the wider public sector IT community (Dutil et al. 2005), was accepted by the government. It was followed by the transfer of the CCIO to Government Services and the designation of the Deputy Minister of that department to play the role recommended by the task force - thereby resolving any tension between that role and the CCIO (although it led to the departure of an established CCIO, who was expected to make room for his new supervisor). If anything, the $\mathrm{CCIO} /$ cluster model was reinforced shortly thereafter when the newly appointed CCIO, Ron McKerlie, became the Deputy Minister of Government Services and was replaced by a Cluster CIO whom he had recruited.

Borins' account of the topics discussed at the CCIO's management committee (2007b: 88-96) provides an indication of the span of policy attention created by the Ontario organizational model. In addition to the politically sensitive issues mentioned above, their agenda included a range of procurement issues, providing policy direction to the CCIO's Procurement Policy Branch: whether to lease or buy "commodity" hardware such as laptops; renewal of a government-wide licensing agreement with Microsoft; evaluation of open-source software to balance the Microsoft monopoly; and strategies to reuse software, especially when developed by the OPS itself. Other topics of concern to senior IT managers included strategies for keeping OPS IT services operational in the event that negotiations with OPSEU led to a strike, dealing with emerging technologies (Blackberries were coming into the mainstream at that time), and a range of security issues including hackers and viruses, security aspects of public servants working on-line from home, and unacceptable personal use of IT facilities by public servants. By way of contrast, the federal CIO has a lead role or is closely involved in the same set of security 
issues (as well as a broader set relating to national security) but is well away from being able to orchestrate a management discussion, much less operational decisions, about IT procurement issues. The federal government is also still some distance short of a common environment for basic office automation or administrative applications, and recent steps to develop a common desktop, for example, have met with stout resistance from the IT industry and in Parliament.

The more subtle, but in many ways more important over the longer term, effects of the CCIO model relate to organizational integration and maturity. From the time of the COGP, the OPS has taken an integrated, government-wide, approach to developing its mainframe computing environment and related infrastructure and software applications. For a number of years the CCIO included a Chief Services Officer, responsible for developing a common approach to service delivery, both to the general public and to businesses. Its task was facilitated by having a unified technology and data management environment in the OPS. Since the 2005 reorganization, Service policy and Service Ontario have been part of the Ministry of Government Services, linked to the CCIO by a common reporting relationship to the Deputy Minister (who is a former CCIO). Policy and operational responsibilities for shared services to government have gone through a similar evolution. With a single ministry housing both the policy and the operational direction for integrated OPS "front" and "back" offices, ${ }^{223}$ as well as the policy centres for the management of information and technology in line ministries and a senior official (the CCIO) who has line authority over the ICT-enabled environment in ministries, including a substantial portion of the IT budget, the Ontario government has put in place

${ }^{223}$ See chapter 4 for a discussion of these two organizational concepts in the e-government context. 
well-integrated institutional environment for harnessing information and technology effectively in government operations.

A different form of integration has been with other jurisdictions. In a summary of OPS IT projects in the Desautels report (Ontario Desautels 2005: 8), the first one listed is the Seniors Portal which was developed jointly with the federal and municipal governments and is maintained by the Government of Ontario. ${ }^{224}$ This grew out of collaborative work that began in the early 1990s and has continued to be sponsored by the Public Sector CIO Council (PSCIOC) and the Public Sector Service Delivery Council (PSSDC), two federal-provincial-territorial bodies which the Ontario CCIOs helped to establish and in which they have played an active part. The two Councils jointly sponsor the Institute for Citizen-Centred Service (ICCS), which provides them with research and secretariat support and helps to prepare for the annual Lac Carling conference, which brings together the councils and senior private sector IT executives. Now a not-for-profit organization, the ICCS is housed in Ontario government offices in the same complex as the $\mathrm{CCIO}$ and other OPS central management agencies. ${ }^{225}$

The CCIO has also matured institutionally since it was established in 1998. This is not just a matter of evolving organizationally or surviving the test of external events, which have included change in technology and government, political controversy and a blue ribbon external review. Indeed, in each of these critical moments (to use Lindquist's terminology - see Lindquist 2006) the CCIO organizational model has been re-affirmed and steps taken to strengthen it and its effectiveness within the OPS. An important reinforcing factor is that it has enjoyed continuous political support at the level of both

\footnotetext{
${ }^{224}$ See http://www.seniorsinfo.ca/en/welcome [Accessed January 28, 2011]

${ }^{225}$ Chapter 4 has a more detailed discussion of the PSCIOC, ICCS and Lac Carling conference.
} 
the Premier and the ministers of MBS and Government Services. The result has been a virtuous circle of sustained self-renewal in the OPS, building on and deepening its roles in government policy making and business planning on the one hand and internal management and external service delivery on the other. The growing degrees of integration and support within the OPS are one measure of the CCIO's institutional maturity. The evolving nature of its agenda is another. The CCIO's early focus was containing IT costs and the political as well as administrative risks of major IT projects. There was an aspiration to link information and technology and to harness them strategically and innovatively in support of internal management and external service delivery. After over a decade the spaces on the Ontario IM/IT map are much the same as they were when the CCIO was established, but the role it has assumed and the nature of its agenda represent a second or even third generation fulfilment of the aspiration, consolidating and broadening an established base and realizing the payoffs of earlier work (McKerlie interview) ${ }^{226}$ In Ontario, the wheel has not only turned but it has moved forward.

\section{Conclusions}

The Ontario Corporate Chief Information Officer case is important at several levels. It is a valid case study in its own right, but apart from Borins it has received little scholarly attention, either as a CIO or as an actor in the Ontario Public Service. ${ }^{227}$ This

\footnotetext{
${ }^{226}$ A number of the interviews, including with organizers of the annual Lac Carling conference and with federal and other participants in interjurisdictional discussions, commented on the degree of integration and the consistently innovative use of technology in the OPS. This is attributed to the CClO model, reinforced by the establishment of a Corporate Chief Strategist, and to the quality of the appointments to those jobs (e.g., Annan interview).

${ }^{227}$ The CCIO receives no mention in recent works on the OPS (e.g., Glenn 2005, Evans 2008) even though efforts to harness technology are described as an important part of OPS modernization.
} 
chapter is not intended to be a complete case study, but it does provide ample evidence that more attention is warranted. The CCIO also has a multi-faceted relationship with the federal Chief Information Officer, the focus of this dissertation. The two CIOs grew out of and are situated in a broadly similar institutional model, representing variants rather than distinct categories. There are numerous points of comparison, but some even more revealing contrasts. The two CIOs interact with each other and work together in dealing with the broader environment. Each institutional model (and CIO model within it) has influenced the development of the other - the federal has had a more sustained influence on Ontario, but the Ontario CIO experience, at least, likely has more profound implications for the federal. This raises the question of whether the Ontario model offers insights of more general application, with respect both to public sector institutional responses to information and communications technologies and to collective management, especially within the Westminster model. There is also the question of what insights the Ontario case offers to theories of institutional stability and change. This concluding section addresses these points.

The CCIO is very much a product of its environment and history. More than most public sectors, Ontario began with an institutional clean slate in 1867 , and it took until after World War II for recognizable collective management mechanisms to begin to emerge and effectively until the Committee on Government Productivity (COGP) in the early 1970 s - more than a century after Confederation - for a structured system of politically-sensitive central management agencies in support of an institutionalized Cabinet to be put in place. Administrative historians such as Hodgetts and Schindeler have variously characterized the first century of institutional development in Ontario as 
casual, expedient and ad hoc, and an ethos of pragmatism remains part of the OPS culture.

Even so, in the past 40 years the structure of the OPS has regularly been seen as a policy instrument, as evidenced by the work of the COGP under Robarts and Davis and the Cabinet Office Restructuring Secretariat in the Harris Cabinet Office. There may not have been a consistent institutionalized voice for organizational adjustment based on constitutional doctrine akin to the Machinery of Government unit in the federal Privy Council Office, but successive Ontario Cabinet Secretaries have taken an active interest in organizational means of harnessing the OPS to the agenda of the government of the day. This kind of instrumental pragmatism, combined with the more compact nature of the OPS (in particular its headquarters operation), has probably had a great deal to do with the more integrated approach taken over the years to OPS management, including the CCIO model, with its combination of ministerial clusters, formal dual reporting relationships, and integration between policy and operations.

An important consideration in making comparisons with the federal government about institutional responses to ICTs is scale and complexity. Ontario ministries have had fewer of the large-scale computing requirements that federal departments have faced, especially at the time of the move to mainframe computing in the 1950 s. There were, for example, no OPS requirements equivalent to data-heavy federal scientific and statistical undertakings such as weather forecasting or the census, for which in any case the OPS was a client. Nor were there OPS administrative systems that were big enough to stand on their own, such as the Army payroll, the first major federal mainframe purchase, in 1957. (At the time, the Army was several time larger than the OPS and even today the Canadian 
Armed Forces are roughly double the size of the OPS but only one of several major federal administrative environments). The OPS came to large-scale computing after the federal government and has from the beginning given weight to the possible efficiencies of consolidated hardware and software purchasing over arguments in favour of diversification in support of the Canadian IT industry.

In the event, the only OPS environment that developed a separate computing capability was revenue collection - the COGP endorsed its continued separate existence within a wider government policy framework but also recommended that all other computing needs be administered centrally, making the Ministry of Revenue the exception that has proved the rule. More recently, moves towards electronic health records led to the establishment of a separate agency, e-Health Ontario, which has however had its own teething problems (Howlett 2009); it would appear the project was considered to be too large and complex to be undertaken by the $\mathrm{CCIO}$ structure, which does provide other computing services to the Ministry of Health.

More important than scale, however, and a feature that does offer insights for the federal government, is the fact that the introduction of the $\mathrm{CCIO}$ was a product of central decision-making in response to the Premier's political priorities, building on 25 years of institutional consolidation of IT and IM responsibilities. This was in contrast to its federal counterpart which was established essentially as a by-product of high-level institutional change (somewhat ironically, given the institutionalized approach to continuous review of the machinery of government in Ottawa). While the CCIO model has been tested at various points since its inception, these have had the effect of reinforcing the position and maintaining its centrality, even through changes in government, top OPS leadership and 
central agency structures. Its mandate has from the outset been shaped by OPS strategic business planning goals and has included a wide set of policy instruments, connecting policy management, budgeting and procurement, and combining the management of information and technology as well as of IT-enabled restructuring of services to the public and to government. The cluster model has given the CCIO access to every ministerial management committee and their budgets, and the role of the CCIO's supervisor - the Deputy Minister of Government Services - as the overseer of major IT projects (as well as being responsible for OPS corporate human resources management policy) has provided a voice for the CCIO's concerns in the deputy ministerial community. These all represent differences from the federal CIO and ones that have looked attractive from Ottawa. ${ }^{228}$

The relationship to the federal government is a thread that has run through the entire history of the OPS, including the CCIO. An important aspect has been the demands of working with the federal government, both as policy compartments in the ship of state have become increasingly porous, and to meet the administrative requirements of fiscal federalism. ${ }^{229}$ The federal public service has also been a major continuing influence on thinking about the organization and modernization of the OPS, starting with the units that were patriated from Ottawa in 1867. At just about every stage in the development of the OPS, the federal government had already put in place a response of its own to the same functional requirements and external pressures - whether the demands of wartime,

\footnotetext{
${ }^{228}$ A space to watch is whether having a federal Treasury Board Secretary who is also a former CIO will have some of the same effects in Ottawa, notwithstanding the weaker CIO model in place there.

${ }^{229}$ A research project on its own would be to look at the impact on public sector financial management practices (comptrollership in the federal government, controllership in the OPS and other provincial governments) of federal fiscal transfers to the provinces and the highly-integrated nature of tax collection on behalf of both levels of government since World War II. The latter has also been one of the major pressures for the harmonization of federal and provincial privacy regimes.
} 
economic growth, ICTs or ideas about public sector efficiency. The most important of these was the COGP, which like the earlier federal Glassco commission marked a permanent turning point - amounting to a critical juncture - in the evolution of provincial administrative institutions. Federal solutions have rarely been adopted holistically (and have often been seen as too elaborate and theoretical by the OPS) but in most cases something similar but adapted to its circumstances was put in place in Ontario.

The influence of federal thinking and practices was also true of the $\mathrm{CCIO}$, which was introduced five years after the federal CIO and structured in a way that was intended to avoid the perceived inherent weakness of the Ottawa model. The influence has been on-going and in both directions. Chapter 3 discusses debates in the federal government over organizational alternatives to both Treasury Board and the CIO. In 2004-2005 serious consideration was given to introducing the Ontario CCIO model to the federal government and, as part of such a move, even to appointing the first CCIO, Scott Campbell, as federal CIO. While this did not happen, the interviews for this dissertation indicate that the Ontario model continues to be widely seen in the federal government as the main alternative to the current arrangement (always allowing for differences in size, complexity and corporate culture).

At least as interesting is that the adjustment made to the CCIO in 2005, when it was transferred to Government Services, closely resembled another alternative looked at in the federal government. In 1997, consideration was given to combining Treasury Board Secretariat management policy units with the common service organizations that operated under the same policies - most of the latter being housed in the Department of Public 
Works and Government Services (PWGSC). ${ }^{230}$ The proposal, which was turned down at the political level, involved winding up the PWGSC ministerial portfolio (which, probably not incidentally, has pre-Confederation roots), creating a galaxy of Special Operating Agencies under the Treasury Board portfolio. The 2005 Ontario reorganization was based on the same idea of combining the policy and common service operational roles in the same organization, but with the important difference of placing all such combined units in the Ministry of Government Services. This has had the effect of creating a strong ministerial voice for management issues - and considerable leverage within the OPS, which was less likely to be the case with the changes considered in Ottawa.

A fair question is whether the Ontario CCIO case has wider implications. Within Canada it is well known among public sector CIOs and presumably offers an alternative to the models in place in other jurisdictions, allowing again for differences in scale, complexity and culture, which are as real between the Ontario and smaller provincial governments as they are between Queen's Park and Ottawa. Although more integrated than the federal approach, the Ontario CCIO model is in some respects not as radical as arrangements in some of the other provinces, which have, for example, gone further than Ontario in outsourcing services to government and the public (British Columbia) and in integrating the government $\mathrm{CIO}$ function with broader economic and social policy instruments (Nova Scotia). There are undoubtedly useful comparisons and contrasts to be made with versions of the Westminster model outside Canada as well.

${ }^{230}$ As discussed in chapter 3, this also is the essence of the British model. The Ontario Cabinet Secretary in 2005 was Tony Dean, who was originally British and had participated in international networking through the Commonwealth Association of Public Administration and Management (CAPAM - see, for example, Dean 2006). It seems likely that he and the OPS Restructuring Secretariat were aware of British practice. 
Theoretically, the Ontario case sheds additional light on the dynamics of institutional continuity and change. Historically derived and reinforced pathways have played a central role in shaping the emergence and development of political and administrative institutions in Ontario, which, like the rest of Canada, has enjoyed continuous, virtually linear, evolution in institutional development without the disruption of revolution and wartime attack that has marked most countries in continental Europe and in most of the rest of the World as well. In the absence of such profound systemic shocks, the seeds of current arrangements can be discerned in Ontario's earliest institutional incarnations and the edifice builds firmly on structural foundations laid in the 1970s and reinforced in the following quarter century.

At the same time, forward movement has not been deterministic. In common with the federal and indeed all Canadian and OECD governments, Ontario has had to respond to unforeseen external drivers and secular trends in society, including economic growth (and set-backs), demographic and technological forces, and ideas, whether in good currency or seasoning in the primeval policy soup. These in turn have led to a major rethinking of the role of the state. In-built decision-making mechanisms, triggered by windows created by changes in government and top public service leadership, and laced with the reality check of daily events, have also been important factors in making the CCIO what it is today. Much the same can be said of the federal ClO, and these considerations are an important part of chapter 7 , the concluding chapter. 


\section{Chapter 7 - Conclusions}

Men at some time are masters of their fates.

(Cassius - William Shakespeare.

Julius Caesar Act I Scene 2: 146)

This dissertation brings together several threads of analysis. Its larger canvas is the Government of Canada's institutional response to the information and communications technologies (ICTs) that came into prominence in the final decades of the Twentieth Century, in particular the effects they have had on the internal machinery concerned with the management of the government as an entity. Its specific focus is a single senior public service position, the Chief Information Officer (CIO) in Treasury Board Secretariat (TBS), the government's lead central management agency. The CIO was set up in June 1993 at the same time as broader organizational changes designed to position the government to respond to ICTs in the sectors of public policy most directly affected by them; even though the CIO was not formally part of those changes, it was complementary and has been influenced by them at several stages in its development.

The CIO is a senior official supporting the Treasury Board, the committee of Ministers that oversees most functional areas of federal government administration, based on a highly developed and formal internal collective governance model. Through the application of that model, the CIO's responsibilities have come to define an administrative domain - which can also be understood as a management policy sector linked by various aspects of the management of information and communications technologies (ICTs) as well as by their information content. This sector has introduced new skills and instruments to federal public administration and linked them with others that were not previously connected. The pervasive nature and potential of the ICTs argued to be transformative by their advocates - has also led the CIO into roles not 
previously played by TBS in modernizing the structure and delivery of government programs and services and into new working relationships both inside and outside government. These changes have been in response to pressures faced by all governments (as well as all private sector and voluntary organizations of any size), but they are particularly interesting and visible in the federal government, which is the largest and most sophisticated institutional environment in Canada.

The changes brought about in the Government of Canada by ICTs, as seen through the lens of the CIO position, are the subject of four chapters of this dissertation and are looked at from a comparative perspective in a fifth. Much of the discussion is from an historical and what might be termed a spatial perspective. While there is a substantial descriptive component to these five chapters, they also address the research questions outlined in chapter 1 , which by and large cut across the substantive chapters. This concluding chapter begins with a short summary of each of the substantive chapters as a basis for a more extensive discussion of the findings with respect to the research questions. The third section discusses the utility of broader theories of policy and institutional stability, continuity and change as a theoretical lens for analyzing the CIO case study. The final section considers some areas for further research.

\section{The narrative thread of the dissertation}

In his framework for designing social research (Blaikie 2000), Blaikie states there are five objectives for basic social science research, which includes this dissertation: to explore, describe, explain, understand and predict. The first two generate research questions in the nature of "what?" while explanation and understanding are "why?" 
questions. Prediction is a form of "what - what is likely to happen?" ("How?" questions are, in Blaikie's framework, linked to applied research, which is more policy oriented and outside the scope of the dissertation.) Basic research questions are addressed through a research strategy, which provides a logic of enquiry and, flowing from that, a research design which provides the methodology for collecting data to support the analysis and conclusions and sets boundaries for the research project. This dissertation is organized as a case study, which Yin considers to be a form of research strategy (Yin 2003); it focuses on a single case - the $\mathrm{CIO}$ - although providing a comparative mini-case (the Ontario Corporate $\mathrm{CIO}$ ) as a source of additional insight to the main case.

The empirical data for the dissertation are presented in chapters 2 through 6 . They are drawn from three main sources: government documents and reports, key informant interviews, and academic and other secondary literature. The research methodology, together with the dissertation's research questions and the theoretical models that it draws on in considering them, are discussed in chapter 1 and Annex 2. The balance of this section summarizes the broad lines of the discussion in each chapter and notes any additional theoretical context in the chapter. This perspective emphasizes exploration and description - basic "what?" questions - which are a central part of a topic that has not received very much scholarly attention to date. It also provides a reference point for revisiting the dissertation's research questions in the following section; there the focus is on explanation, understanding and prediction - "why?" and "what is likely to happen?"

\section{Chapters 2-6 summarized}

The CIO and its associated environment is the most recent of the federal government's major collective administrative institutions to take shape, coming after the 
positions that are currently the Comptroller General and the Chief Human Resources Officer. It arises from the same institutional matrix, however. Chapter 2 describes the development of the Canadian Westminster collective management model, which is the product of a continuous process of evolution and testing that stretches in recognizable form back to the first half of the Nineteenth Century, with even earlier roots in both Canadian and British governance. A major focus of the chapter is the development of the Treasury Board as a uniquely Canadian entity. Among several critical junctures in this evolution, the one with the greatest continuing influence was the wholesale adoption in the 1960s of the spirit and most of the individual elements of the Glassco Report on government organization (Canada Glassco 1961-1963). This was followed by a quarter century of policy-driven organizational change in the federal government that had the effect of consolidating and refining the Glassco organizational model. A parallel track was the evolution of a number of strands of information and communications technologies that eventually converged by the early 1990 s to create the networked environment embodied in the Internet. These ICTs had a growing influence both on public policy and related institutions and on the concerns and structure of public administration. At first this influence was peripheral but it became increasingly central over time and by the early 1990 s had paradigm-shifting implications.

Chapter 3 discusses the creation, evolution and gradual entrenchment of the $\mathrm{CIO}$ as an institutional response to networked ICTs, within the Treasury Board model of collective management. As a reference point, it begins by reviewing academic literature on electronic government, including three earlier sightings of the federal CIO, one in an international comparative context. It then discusses the Campbell government 
reorganization in June 1993 that was a conscious effort to equip government institutionally to address the new economic and social environment created by the Internet and related ICTs. The CIO position and its supporting office in TBS were initially a secondary element of this larger set of changes. Both it and the wider reorganization were solidified, however, by the Chrétien government, which came to power in November 1993 and during its ten-year tenure launched a number of ICTrelated initiatives. The most important for the $\mathrm{CIO}$ was the Information Highway Advisory Council (IHAC), which created a comprehensive public policy framework for addressing ICTs, including identifying a role for government administration as a model actor on the information highway.

In its first few years, the CIO's existence was highly tenuous, but over time it came to be well established and to play a high profile role in government modernization, notably preparations for the Year 2000 date change followed by the Government On-Line (GOL) initiative, which brought the main government services to the public into the networked environment. GOL was widely seen as a success and remained the dominant CIO activity through to the beginning of the Harper government in 2006. The CIO had considerably less success, however, in reforming administrative services to government. In addition, through most of the Chrétien government there was considerable churn in the CIO's mandate, in particular with respect to Treasury Board policy roles and information management. Its role was even more limited with respect to technology spending in government, although it did have some oversight of major technology projects. Against this backdrop, the chapter also looks at some of the organizational alternatives to the CIO 
model that were considered but not adopted and at the strengths and limitations of the CIO's authority within the federal government.

Chapter 4 builds on chapter 3 to discuss the cumulative effects of the CIO's experience over half a generation, seven CIO incumbents and four Prime Ministers on the substance of the CIO's role and the Treasury Board instruments that it administers. The chapter begins with a review of the theory and practice of collective responsibility in the Canadian version of the Westminster model and in that context summarizes the Treasury Board policy model, which shapes management practices within the federal public service. It then considers the "three rooms" organizational model that reflects the influence of ICTs on large organizations and is beginning to take hold in the federal government, placing new pressure on its accountability model.

The core of the chapter is a discussion of a new Information Management (IM)/Information Technology (IT) public administration "space" that has resulted from the CIO's Treasury Board policy role. This space is defined in two ways. One is by the range of Treasury Board IT, information and security management policies for which the CIO is currently responsible, following the evolution described in chapter 3; in addition, the chapter argues that the space should be seen as including policies for which the CIO has been responsible in the past but is not at present, notably government communications, as well as the provision of ICT-enabled services to the public and to government, for which the $\mathrm{CIO}$ has had fluctuating responsibility. There is also an outer perimeter of administrative policies managed by other areas of TBS where the CIO has an important role and which are often administered by the CIO in other jurisdictions (notably, for the purposes of this discussion, Ontario). A second way in which the chapter 
defines the IM/IT space is by the policy instruments that the CIO administers and the functional roles that it plays by virtue of the Treasury Board model. Operating within this space, and by its nature, the CIO has developed a series of relationships, internally with the agents in government departments of the IM/IT-related policies and externally with the citizen, the private sector and other jurisdictions. The external relationships, in particular the one with the citizen, bring the CIO into roles and activities that have not traditionally been a major feature of Treasury Board and other functional areas of public administration such as financial and human resources management.

The most problematic aspect of the CIO's role in the federal government and the greatest challenge to its long-term effectiveness has been the need to reconcile the twin management demands of technology (IT) and information (IM) - of medium and content - in the environment created by networked ICTs. Chapter 5 explores this tension, arguing that the CIO will only be fully successful when it moves beyond its initial preoccupation with IT and the elements of IM are integrated with each other and with the management of IT. The chapter begins with a discussion of the nature of information in a public administration context and some of the concepts in information theory, notably the information life-cycle, which influence IM. Information can be held in a wide range of formats, calling for a diversity of management responses. The situation was already complex in the era dominated by paper records but has been made exponentially more challenging with the widespread addition of networked ICTs, a set of pressures that if anything is accelerating with the expanding use of mobile technologies. Although it is still evolving, there have already been major implications for public administration, 
including both a vision of knowledge-based government and a reality of an IM environment that is widely regarded as unsatisfactory.

The second half of the chapter reviews explanations for the current situation and identifies obstacles that will need to be overcome in the future if it is to improve. Historically, records management - the form in which IM is most easily internalized in public administration - was neglected until the Glassco report and only attracted serious Treasury Board attention with the passage of the Access to Information Act in 1983. Even now there are unresolved issues about the respective roles of the CIO and Library and Archives Canada. The marginalization of records management has been compounded by the explosion in ways of holding, transmitting and linking information that has resulted from networked and mobile ICTs. A third set of pressures arises from the nature of information and the information life-cycle, including tensions between the imperatives of information dissemination and protection and between concrete current and potential future uses. In a public administration context, a major obstacle is the failure to attach value - or even surrogate metrics - to information as a public resource, with the result that IM tends to be treated only as a cost rather than as an asset or investment. A final set of challenges arises from the CIO's shifting relationship, as the central agent for IM, to the governance structures of the public service and the government's public service modernization agenda; as illustrated by GOL, the CIO can play a leading role but this requires a congruence of "winning conditions" that need to be continuously refreshed. The most elusive of these is support at the political level, where the greatest challenge of all is the growing political sensitivity of information and political centrality of government communications - yet another impact of ICTs. 
Chapters 2 through 5 are about the CIO case. An additional, indirect, sighting is provided in chapter 6 , about the Ontario government's Corporate $\mathrm{CIO}$ (CCIO). In many respects the chapter is a case study in its own right, but its primary purpose is to provide additional insights to the federal case. Like the federal CIO, the CCIO grew out of the institutional matrix of collective management in the Ontario government, and there are many similarities between the two environments, to the extent that they can be seen as variations on the same institutional model rather than as distinct models. At the same time there are important differences, some reflecting differences in scale and in organizational culture but also growing out of policy choices at critical moments.

Like the federal CIO, the CCIO was set up (in 1998) in response to networked ICTs in a well-established central agency that had been in place for the better part of a generation. Similarly, its responsibilities combined existing units and roles, many of them previously unconnected, with functions arising from the new technological and fiscal circumstances, defining a similar IM/IT space. In contrast to the federal CIO, however, the establishment of the CCIO was supported by the Premier and Cabinet Secretary and directly linked to implementation of the government's agenda. Coming five years after the federal $\mathrm{CIO}$, its role and mandate were structured to avoid perceived weaknesses in the federal model, including giving the CCIO line oversight of the Cluster CIOs supporting departmental deputy ministers, policy responsibility for both IT and IM, and an active role in IT procurement, major project management and budgeting. The CCIO has also had more direct and consistent responsibility than its federal counterpart with respect to both services to government - based on a significantly more unified computing environment than in Ottawa - and service to the public. Although the organizational 
location of the CCIO has changed, the position remains closely linked to the government's agenda and there has been a high degree of continuity in its role and mandate as an agent of collective management. The Ontario model has generally been seen as the main organizational alternative for the federal CIO, which is considered by observers to be weaker within its own environment than its provincial counterpart.

\section{Research questions}

This dissertation provides an account of a sector of public administration that less than twenty years ago did not exist, although many of its elements were present. The CIO has served as the catalyst for the emergence and entrenchment of this sector and, in the nature of the federal government's collective management model, defines it - even though it does not have complete authority over it. Very little of the role that the CIO has played in these developments has been tidy and it has not always been self-evident at the time, there are many loose ends, and the dynamics looking ahead are open-ended and uncertain. At the same time, there is no question of going back to some form of pre-1993 status quo ante - the IM/IT space is too well developed and pervasive to be undone.

Chapter 1 sets out three research questions that run through the dissertation. Working as it does in a new area of study, the foundation of the research project is exploration and description, a common thread in all the questions. Building on that base, the research also focuses on explanation and understanding, the "why?" questions of causality. Because the $\mathrm{CIO}$ is a functioning organic case, its story is unfinished, however. There is some evidence that in the nature of the current political situation in the federal government the $\mathrm{CIO}$ has reached a stage of relative stability, which permits more rounded 
conclusions, but in the nature both of its substantive concerns and of the larger institutional environment in which it operates, the $\mathrm{CIO}$ will go through many further changes in the future. The research questions therefore also have a predictive dimension, partly in terms of "what is likely to happen?" but especially (and more usefully) in terms of "what are the moving parts?"

This section is organized around the three core research questions as well as a fourth that is implicit in them. Chapter 1 evoked the imagery of an irresistible force meeting an immovable object, and the discussion begins with the irresistible force: networked information and communications technologies and their impact on the Canadian public sector. This was described as an implicit research question in chapter 1 , but ICTs are clearly an independent variable and the findings in this area provide the over-all context. The immovable object is the subject of two questions. The one in sharpest focus is the balance sheet of the CIO itself: how successful has it been; what are its essential characteristics; what are its strengths and limitations; and how can these characteristics be explained and understood? The CIO is very much a creature of its institutional environment, however, and the following question therefore relates to the impact of ICTs and the CIO on the Treasury Board model and the Canadian Westminster model within which it operates. Here, the underlying question is how immovable the object actually is. The final question takes the discussion into a disciplinary realm: the implications of the $\mathrm{CIO}$ and related dynamics for an understanding of Canadian public administration, specifically whether they amount to the creation of a new and distinct sector that warrants further attention. It also considers the relevance of the emerging egovernment literature. 


\section{The impact of networked information and communications technologies}

Technologies of all kinds have always been an integral part of governance and public administration, shaping everything from the tools and methods of operation to the concerns and reach of government. Many individual strands of the networked ICTs that came into prominence in the early 1990 s were already well established and having an impact, notably the telephone from as early as the late 1890 s and computing from the 1950s. These were absorbed as working tools and administrative concerns (and costs) and they did help to extend government's geographic reach - but they were not regarded as determining factors in how it did its work. The situation changed more dramatically with the convergence of computing and telecommunications, combined with the development of equipment and software applications that brought networked computing to every desk in the public service in a form that did not require specialized training and was mirrored in - and connected to - the private lives of public servants. While these changes did not occur overnight, they began to accelerate in the early 1990s in a way that led the architects of the 1993 reorganization - including the establishment of the CIO - to regard them as a key reference point for restructuring the institutions of government in anticipation of medium to longer term requirements.

Since that time, networked ICTs have influenced every aspect of federal activity. They have reshaped the public policy landscape, bringing to the fore new forms of wealth creation and economic activity to support and new industries to regulate, transforming the substance and context of cultural policy, and defining new skills to introduce to the workforce and the population at large. These dynamics alone have changed the relationship of the federal government to the economy and society as the largest single 
holder of knowledge and ICT-related skills in the country. They have also changed the policy process, greatly expanding the ability of government to provide information about its programs and policy choices, both to the public in general and to targeted audiences. At the same time, ICTs have widened the channels and techniques available to government in consulting the public on the need for policy or regulatory change and in considering policy choices. This has, however, also contributed to the heightened political sensitivity of government information, which as discussed below has imposed limitations on the extent to which the potential of ICTs has been fully realized.

Networked ICTs have if anything had a greater continuing impact on public administration. Internally, a common communications and information network has had a centralizing effect, within organizational units, departments and increasingly across the public service, creating a new emphasis on "whole of government" and "enterprise" approaches and going some distance towards reversing the decentralizing pressures of the preceding era of New Public Management. Harnessed with client-centred service concepts, networked technologies have also permitted the introduction of organizational models that consolidate the delivery of services to the public and to government, putting pressure on the traditional departmental model in which policy making, service delivery and supporting administrative infrastructure are all under the authority of a single Minister and Deputy Minister. This shift in government organization is by no means complete, but it has begun the process of breaking down increasingly entrenched individual accountability models and, when linked to a whole-of-government approach, creates a renewed emphasis on collective accountability. The situation is further complicated when services are provided collaboratively with other jurisdictions. 
In addition to these organizational effects, ICTs have also added to the substance of public administration and related public service skills. Building and operating the computing and telecommunications environments of contemporary government are major undertakings, requiring specialized and often highly technical capabilities to manage and execute. They also compound the challenge of linking technical expertise to program management and lay decision-making, especially at senior public service and political levels. As well as bringing new skills and combinations of skills into the public service, there has also been a major expansion in contracting for services from a diverse and unstructured private sector consulting industry, adding a requirement for skills to manage those relationships.

The most profound impact of ICTs is their effect on the role and management of information in government. Although the process is by no means complete, government is increasingly defining itself in terms of what it knows, as a knowledge organization. This has major implications for what kind of information it acquires and uses, giving particular prominence to personal information about Canadian citizens and residents and raising questions about its use and protection. Networked data bases and a multiplicity of means of holding and transmitting information have had the effect of separating information - as such - from the records in which it has traditionally been held. A major challenge has arisen from the need to bring together the skills and cultures involved in the management of information and of technology, while tensions among the components of information management have made it difficult to develop a unified information discipline. These tensions have been compounded by the political sensitivity of much of the information that enters into the public domain, especially when this is done through 
Access to Information procedures or through political communications conditioned by the around-the-clock news cycle tied to the daily Parliamentary Question Period.

All of these effects are only partial, however, and still playing out. Government is heavily networked in its internal communications, but paper records are still ubiquitous and record-keeping practices are uneven, perennially playing catch-up with technological advances and some distance from capturing the diversity of forms in which information is held. While communications and policy direction are increasingly unified in the networked environment within the public service, the management of information and knowledge assets is not and unlikely to be so in the foreseeable future. Similarly, ICTs have reconfigured the relationship between government and the public, but in the nature of Canadian society those relationships are by no means all conducted through networked channels. Again, they are unlikely to be in the foreseeable future, if only because the public also want access to telephone and in-person service channels, and a sizeable minority still do not have access to or do not wish to use electronic channels at all.

The challenge is partly one of scale; even Ontario, the largest of the provincial governments, is considerably more compact than its federal counterpart and has faced substantially fewer difficulties in unifying its information management environment (helped as well by a more unified approach to management in general and to mainframe computing in particular). It is also a matter of political will: the Harper government has shown little inclination to take a public policy-driven approach to develop further the potential of ICTs - they have not, for example, launched their own successors to the Chrétien government's IHAC and GOL initiatives - and efforts to address outstanding ICT-related issues in the public service and to work through the implications of the 
newest technologies such as mobile communications and social networking have been incremental and have demonstrated a limited appetite for tackling more difficult structural issues. As discussed in the next section, political will also colours the balance sheet for assessing the impact of the CIO, the most important institutional effect of networked ICTs.

\section{The CIO balance sheet}

When the CIO was set up in Treasury Board Secretariat (TBS) in June 1993 it was not at all clear that it would become a permanent feature of the federal government's central agency landscape: the focus was on the change agenda that the CIO carried with it rather than on longer-term institution building. The establishment of a CIO was the product of bureaucratic entrepreneurship, based on a judgment formed by senior TBS officials that new ICTs deserved more systematic attention, within the Treasury Boardbased model of government management, rather than on intentional government policy or a view of how the government was to be run. This contrasts with Ontario, where the Corporate CIO was introduced on the initiative of the Cabinet Secretary as part of efforts to strengthen government-wide IT strategic planning in support of the government's political agenda. The federal CIO's early role was shaped by the units and files assigned to it more than by a guiding philosophy. Its strength was the energy and enthusiasm of those involved and the fact that it was both linked to but outside the established bureaucratic order; in the first decade this also proved to be its greatest vulnerability.

A half generation later, the $\mathrm{CIO}$ is well established in the mainstream of federal government collective management. It has defined a space in federal and Canadian public administration, even if one with boundaries that have not been entirely stable. Early 
sightings suggested that the federal government had introduced a "weak" CIO model (Borins and Wolf 2000), reflecting the position's rank below the DM level and its weak mandate and limited resources in relation to departments. At the time that this judgment was formed (in the late 1990s, before Year 2000 and GOL had come to the fore), the CIO was not well integrated into the Treasury Board model, a situation that has changed, especially in recent years. On the other hand, this characterization of the CIO's inherent structural position remains valid in many important respects: the CIO was not established as an overt agent of government policy and is not well placed in relation to departmental Deputy Ministers; its Treasury Board policy authority does not extend to all the areas of management defined by ICTs (notably leaving out communications and IT procurement); and it has a limited and inconsistent role in IT-related resource allocation. Here again there are instructive contrasts with the Ontario CCIO, which has combined significant responsibilities in all these areas from the time of its establishment and to good effect.

On the other hand, the CIO has been able to achieve some strong results. The Year 2000 date change was successfully addressed, and GOL was widely seen as a leadingedge change initiative, both in Canada and internationally. Less tangibly, there is a general view that the federal government's IT function is healthy and its major IT projects are well managed, even if as the Auditor General has observed there is room for improvement in the management of older "legacy" systems. This suggests that even a weak institutional model can be successful if supported by "winning conditions." There is no magic formula, but several factors have improved the CIO's effectiveness. Perhaps the most important is senior level support within the public service - this has taken several forms. One is the role played by the Treasury Board Secretary and in particular the Clerk 
of the Privy Council. The CIO position was created at the initiative of a technologyoriented Treasury Board Secretary (Clark) and all of his successors have supported it, although the intensity and form of that support has varied - the one who took the greatest interest (Harder) at the same time strengthened the position (by focusing it on IT management and what became GOL) and weakened it (by pushing information management to the side and breaking it up as a policy concern).

Arguably a more decisive role has been played - at what might be called a strategic level - by the Clerk, who as Head of the Public Service has both a practical and a symbolic role in public service management. More than anyone else, the Clerk affects the IT governance environment, which in a comparative context has been identified as a key factor in the success of government in the "digital era" (Dunleavy et al. 2006). The CIO position was created with the acquiescence of the Clerk at the time of the 1993 reorganization (Shortliffe), who then put in place a mechanism designed to harness the $\mathrm{CIO}$ in restructuring the government-wide administrative back office using IT and thereby to realize significant savings. This survived a change in government but not the change in Clerk that followed (Bourgon), and the CIO was largely marginalized during the Program Review exercise, entrenching the weak CIO model. The following Clerk (Cappe) was instrumental in giving GOL a prominent role and in mobilizing departmental deputy ministers to support it. His successors - all of whom had previously worked closely with TBS CIOs and were regarded as sympathetic to the use of IT in government - saw GOL through but did not link it to efforts to modernize the public service personnel system (Himelfarb) and were either unwilling or unable to put a successor initiative in place (Lynch and Wouters). 
A closely related way in which the Clerks have shaped the environment has been the positioning of the ClO in relation to the Deputy Ministerial community. Even before the CIO was created - indeed one of the major factors that led to its creation - was the existence of a committee of line departmental deputy ministers (for most of the period in question, TIMS) appointed by the Clerk and mandated as part of the individual performance expectations of its members to work with the CIO to promote the expanded use of IT in government. For a while, one of the TIMS members was also the designated government-wide IM Champion. This dedicated top-level horizontal support has been seen by external observers (e.g., Culbertson 2004) as a critical part of the success of GOL but noticeably has been stood down since the end of GOL in 2006. By the same token, successive Clerks have chosen not to appoint the CIOs after the first one to a personal rank of Deputy Minister, unlike their TBS counterparts in the comptrollership and human resources management areas, thereby limiting their standing in relation to senior management in departments. In this respect, it is noteworthy that an Ontario blue ribbon panel that was also familiar with the federal government situation had as its primary recommendation that there be a Deputy Ministerial voice for the IT/IM agenda at the centre of government (Ontario Desautels 2005).

The other decisive role played by successive Clerks has been as the gatekeepers to the Prime Minister and the government's political and administrative agenda. At its highest level, this is reflected in what is taken on board politically as a government priority, reflected in Speech From the Throne references and allocations in the annual Budget, which require the support of Cabinet in general and the Minister of Finance in particular. An important part of the success of GOL was its link to the government's 
economic development agenda that followed from the IHAC report, which in turn created ownership in PMO, PCO, and the departments of Industry and Finance. More recently, the Clerk has placed ICT-related issues somewhere between the middle and the back burner, as reflected in the annual report to the Prime Minister on the public service (e.g., Wouters 2010).

Another key piece of the puzzle is political attitudes. Prime Ministers and Treasury Board Presidents have generally ranged from mildly supportive to benignly neutral in their view of the CIO and the IM/IT agenda, leaving the Clerk and other senior public servants to do most of the running. Only Paul Martin and Reg Alcock have had a demonstrated active interest in ICTs and created a demand for the CIO's services. The Martin government was too brief and concerned with its survival, however, to take major initiatives in this area; it was also constrained by coming towards the end of GOL but before a window opened for a successor initiative. The government's political position in Parliament has therefore been a significant factor. Institutional and longer-term administrative issues are more likely to receive attention either at a change in government or at the beginning of a majority Parliament - a condition that prevailed for the first decade of the CIO - while the permanent second-half-of-mandate circumstances between 2004 and 2011 made it less likely that they would be given much financial or political capital. Having Ministers who have experienced political costs from major IT projects (former Harris ministers in the Harper government) simply exacerbates the situation. A final element in the CIO balance sheet is the CIOs themselves. It is fair to say that all have had a legitimate claim to the job by virtue of their training and professional experience, but some have been better equipped, personally and contextually, and more 
successful than others. The most successful have enjoyed a virtuous circle in which they have had a clear mandate and strong backing, both politically and within the public service. In the circumstances where the CIO has been responsible for delivering a government priority, experience indicates that - in light of the underlying weak institutional model - the CIO needs foremost to be knowledgeable about the public service environment and how it works, although capable of mobilizing and making the most of technical expertise. These individuals are most likely to be found from within the career public service. Where information and technology initiatives and instruments have a lower priority on the government agenda, then the ongoing and very real demands of managing the government's IT and IM assets strengthen the case for bringing in an IT expert from the private sector - although there is also scope in the future for the government to appoint one of its home-grown IT specialists. (The current situation, where an experienced technically-oriented CIO reports to a generalist TBS Secretary who is also a former $\mathrm{CIO}$, offers another combination that might work to achieve low-profile but important gains, essentially operating below the political radar - this is an area to monitor.) The underlying issue is whether the CIO is simply an asset manager or also an innovator, catalyzing the government to re-think and improve all that it does. The evidence is that the former is the default position, conditioned by the CIO's organizational position and authority, while its ability to be the latter depends on larger public service and political priorities, to which the CIO does not have ready direct access.

Although there have been genuine successes in the sector led by the CIO, the approach taken to date has also created hostages to fortune. These have occurred in three areas in particular. The most visible has been the effort to establish a consolidated "back 
office" for the government as an enterprise, in providing both IT services to government and IT-enabled services in comptrollership, human resources management and other areas of public administration. This has not been for lack of trying - there have been significant moves in this direction in 1993-4, 2001, during the Martin government, and in the past two years. The first three were stillborn, each in different circumstances but having in common that the "winning conditions" described earlier in the context of GOL did not align themselves to overcome significant systemic inertia and even hostility from departments, especially those with legacy mainframe computing environments. This has left the federal government the odd one out when compared with provincial governments and major IT corporations but also, and more importantly, unable to realize the potential of ICTs in terms of both operational efficiency and program effectiveness. A contemporary Glassco commission would be highly critical of the situation.

A second area of endemic weakness is the continued inability to fully value the government's IT assets or to value its information assets at all, further limiting its ability to manage them effectively. This is compounded by the weak role played by the $\mathrm{CIO}$ in government decision-making about information and technology spending, an area where the Glassco model of linking program and administrative management is not being followed. Cumulatively (the third hostage to fortune), the federal government's ability to develop its potential as a knowledge organization - to privilege what it knows over the media in which information is held and transmitted - is severely limited, to the detriment of the government's own effectiveness but also of its ability to play a continuing role as a model actor in Canadian economic and social development. 
Looking ahead, there are as many question marks as certainties. The CIO is well established and the unremitting development of new ICTs will ensure that there is a continuing requirement for related central agency expertise. Under something like current conditions the weak CIO model is likely to remain, but still as one of the major sectors of Treasury Board Secretariat and of public service administration. These factors also point to the CIO being largely focused on management of IT projects, infrastructure and assets and on incremental improvements in information management and compliance with IM policies and procedures in areas such as Access to Information and Privacy.

More significant change, if and when it occurs, will probably come in one of two ways. The more likely is that a majority government wishing to take a major governmentwide modernization initiative will work with the current organizational model to lead change in the public service, especially if this is linked to broader public policy initiatives in economic and social policy. The less likely, in light of current variables, is that a future government will revisit the CIO organizational model, either to strengthen its role and mandate - perhaps bringing it closer to the Ontario model - or conceivably even to wind it up and recombine it with other areas of administration. This kind of more radical rethinking has been seriously contemplated at least twice in the CIO's history, in 1997 and 2004, provoked by a TBS Secretary on the one hand and a Treasury Board President on the other, and there is no reason to believe that it will not eventually recur. Experience to date suggests, however, that interventions by these actors on their own are insufficient and some greater shock to the system is required - most likely a government reorganization in the context of a larger political and social sea change. The prudent forecaster would conclude that that is unlikely until the current generation of technology 
change has played out and is replaced or some larger set of forces have taken hold to revisit the federal government's more fundamental institutional assumptions. If the 1993 reorganization is seen as a once-in-a-generation reconfiguration of government, then the arc of its lifecycle is still only half complete.

\section{Insights to the Canadian Westminster model}

The CIO is a creature of the Canadian Westminster model and of the Treasury Board model within it and offers insights into the nature and state of both. To begin with, the CIO was the brainchild of senior Treasury Board Secretariat officials and was set up under the authority of Treasury Board Ministers within established TBS organizational assumptions. It was understood to be a response to changing environmental circumstances: at one level, to change in the larger society and economy; more prosaically to supplement a policy-driven restructuring of the machinery of government. Together these changes demonstrate the in-built capacity of the federal government to adjust to new circumstances and priorities - a general sign of systemic health.

Lying behind these developments is the deeply entrenched nature of the Canadian Westminster model and Treasury Board as a collective management mechanism. European scholars have commented on the "civic culture" that prevails in Westminstermodel systems, in which the public service meets the national interest and requirements of constitutional legitimacy by serving the government of the day, within the framework of whatever electoral mandate it has. Civic culture countries, including Canada, are, for most purposes and most of the time, able to combine their concepts of the State, the public interest and the government of the day because of their long tradition of institutional and constitutional continuity, unbroken by war, revolution or dictatorship. 
Continental European administrations have not had this luxury and have been forced by experience to establish structural buffers and checks and balances among these institutional actors and forces (Mitchell and Sutherland 1999).

The Canadian Westminster model grew out of the requirements of $18^{\text {th }}$ and $19^{\text {th }}$ century colonial administration, within which the Treasury Board as its collective management arm has pre-Confederation roots that have been broadened and deepened at several points since but only once - the Murray Report in 1912 (Canada Murray 1912) fundamentally challenged. The Treasury Board's bias towards collective approaches to management, supported by a sophisticated taxonomy for government organization, was confirmed by the Glassco commission in the 1960s (Canada Glassco 1961-63), reinforced by later efforts to fine-tune specific components without touching the larger system (Canada Lambert 1979, Canada Gomery 2006). Even the most dramatic organizational options considered in the aftermath of the mid-1990s Program Review, which would have combined most of the CIO's responsibilities with related common services in the Department of Public Works and Government Services (PWGSC), assumed the continued existence of Treasury Board and related collective legislative and policy instruments.

The strengths of the Canadian Westminster model have included its ability to keep organizational arrangements within the executive under review over a long period of time and the mechanisms that have been built into it to keep those arrangements and related practices responsive to changing circumstances and government priorities. Notable among the latter is the Privy Council Office's capacity to advise the Prime Minister on the structure and operations of the machinery of government and to oversee 
implementation of the resulting decisions. Experience since the Glassco Commission suggests that this is a capacity that needs to be kept current, both in terms of technical expertise but also in terms of the willingness of Prime Ministers and their Clerks to engage in significant organizational change. Government reorganizations require considerable effort to implement and can encounter both institutional forces of inertia and active resistance among Ministers and within the public service. It is noteworthy that there have been no major machinery of government changes since 1993, which at the very least raises questions about whether this policy instrument is likely to atrophy through disuse. Implementation of the 1993 reorganization also demonstrated the complexity of integrating organizational units with differing computing and telecommunications environments, suggesting that the continued lack of a unified back office represents an obstacle to future organizational flexibility.

The CIO case highlights other pressures on the Canadian Westminster model. One, which is not restricted to Canada, is the accumulating importance of political communications in a media and Parliamentary environment that feeds on scandal and the daily quest for headlines. The particularly open daily Question Period in the Canadian Parliament compounds the sensitivity of potentially controversial government information, putting considerable pressure on the government's public relations functions and turning Access to Information procedures into mechanisms for information control rather than of more open government, as its framers had hoped. This has also had the effect of isolating the administration of these two areas from each other and from the rest of information management within the public service. A second pressure point has been the weakness of Parliamentary oversight mechanisms other than Question Period, 
especially standing committees, in monitoring the implementation of Access to Information, Privacy and related areas - at least in part because of the distorting effects of Question Period on the incentive structures for non-Ministerial Members of Parliament. One consequence is that Parliament has paid very little attention to the shift that ICTs have fostered in the direction of more complex Ministerial responsibility and an increase in requirements for collective accountability.

While the Canadian Westminster model, and Treasury Board in particular, have been able to absorb ICTs in the short and even the medium run, there is a real question as to whether they will nevertheless be changed by them in the longer term. In the limited academic debate on the subject to date, McNutt and Carey (2008) have pointed to the fact that Canadian institutions have successfully introduced electronic service delivery without profoundly changing their assumptions, while Roy (2008) has made the case that a networked public will be increasingly unwilling to accept the elitism and secrecy in Westminster-based decision-making. The difference may be one of timeframe. ICTs have already begun to affect the organizational structure of government through the application of the three "rooms" model, which most visibly includes services to the public but increasingly is extending to other areas of government administration as well. Arguably these are compatible with the Glassco organizational taxonomy but they do raise questions about accountability. Roy is looking at a different aspect of the governance environment: whether the policy process will become more accessible to non-elected interests and individual members of the public. Technological mechanisms already exist for widening the circle of participants in policy-making, and there has been some experience with electronic consultations. In recent years the use of these 
mechanisms has been restricted, another reflection of the political sensitivity of government communications and information. In the longer term, however, it is difficult to believe that the pressure for more open decision-making and information access will not increase, although in the light of past experience it will probably take some kind of political crisis for the current pattern to change significantly.

Implications for the study of Canadian public administration

The CIO position and the IM/IT space have implications for Canadian public administration, as a field of study. They have come into focus in a relatively short time; some of the CIO's roles and concerns are new, many are older but in a combination that is new. Some version of the position and functional space exists in all the provincial and territorial governments as well as in the federal. All are involved in similar relationships with the citizen, the private sector and other jurisdictions. Most of the provinces and territories are more advanced in adopting the "three rooms" model than is the federal government, and several have been considerably more aggressive in the use of IT outsourcing than their federal counterparts. All have Access to Information and Privacy legislation, facing the same sensitivities, and all are wrestling with the same tension between information and technology. These are dynamics that deserve attention for a complete understanding of what the contemporary public sector does and how it goes about its work. In the nature of the subject matter, it is also an area that will only continue to grow and evolve.

The institutional impact of ICTs, including the CIO, has received relatively little attention in either Canadian public administration literature or teaching. This may simply reflect their status as relative newcomers but does point to an area that warrants more 
research and writing. Greater attention has been paid, however, to the delivery of services to the public, looking both at electronic services specifically and at integrated services across the range of available service channels. A second area that has attracted interest is procurement - in which IT procurement figures large - and the issues raised by the relationship with the private sector in managing government and delivering its services. Considerably less attention has been paid, however, to information and information management in their own right and very little to knitting these threads together. As discussed in the final section, this situation points to a need for further research and reflection on the components of the discipline.

At the same time, there is what amounts to a parallel universe under the rubric of egovernment. Inspired by e-commerce - the impact of ICTs on the operations of business - e-government as an area of study has not made explicit linkages to public administration, or for that matter any traditional academic discipline, even though it addresses many of the same issues. To a considerable extent it is a preserve of consultants and practitioners; where academics have become involved it is often in a context of international comparisons rather than of the Canadian or any other individual administrative system (Roy 2006 is a significant effort at looking at Canadian experience from an e-government perspective - his focus, however, is thematic rather than institutional). This is not to suggest that e-government is illegitimate as a field of study but rather that more effort is needed to link its agenda and analytical lens with those of public administration, potentially to the advantage of both. Public administration work on service to the public and procurement owes a good deal to e-government studies, which also have insights to offer in areas such as knowledge management. On the other hand, e- 
government has paid relatively little attention to the institutional context in which it operates, including public sector CIOs - an area where it could usefully draw on public administration. The dissertation seeks in particular to contribute to this aspect of the egovernment/public administration relationship.

\section{A theoretical lens on the continuity of change}

The dissertation is primarily a case study based on an inductive research approach, but it does draw on established theory in assessing its findings, focusing on theory testing rather than theory development. Ultimately it is framed by mid-range theories about policy and institutional stability, continuity and change. Most of the dissertation's theoretical discussion, however, is of a substantive nature, a consideration of the impacts both of and on the Canadian Westminster constitutional model and, embedded in it, the Treasury Board model of collective management that provide the context for the establishment and evolution of the federal CIO. The discussion also draws on the emerging body of theory - best described as empirical generalization in Blaikie's categorization (Blaikie 2000: 155-156) - under the heading of e-government, which seeks to identify and analyze some of the universal dynamics of ICTs in the public sector, focusing on a sub-set of functional concerns (notably service to the public and procurement) while largely taking their institutional context as an unexamined given.

Chapter 1 did, however, set out some important higher-level (i.e., mid-range) theoretical issues to which the dissertation offers some insights. The CIO represents the introduction of a new public sector institution within a larger, well developed, institutional environment and in response to societal forces that mostly have been 
independent of government policy. Questions about how and why the CIO was introduced, what has driven its development - including why it has survived at all - and what are its prospects have been discussed earlier in this chapter in the context of the characteristics of the Canadian system of governance. The CIO case also provokes the same questions at a more conceptual level. Chapter 1 suggested that theories of policy continuity, stability and change and of institutional continuity, stability and change can be harnessed in considering the CIO case, the former to look at individual decisions and events affecting the $\mathrm{CIO}$ and the latter for analyzing the decision-making environment. This working assumption was largely borne out in the balance of the dissertation.

The best starting point is with institutional theory. The first question is whether an entity such as the CIO, combined with the IM/IT space, counts as an institution; the evidence is that it does. The CIO fits a classic view of an institution. It is an organizational arrangement that over time has been established administratively within a statutory and constitutional framework. It is physically present, housed in government offices, has a visible staff, hierarchy and set of relationships, and has an articulated mandate creating an assigned role within the executive branch of government that is subject to political and Parliamentary oversight and accountability.

At the same time, its institutional existence is in more than just the material and historical terms of traditional political science. New institutionalism has also borrowed from economics and sociology to define an institution as a set of rules of the game and as a set of cultural assumptions that affect behaviour (Lecours 2005). These dimensions can be found in the CIO's institutional environment. Central agencies such as the CIO quintessentially operate within a set of rules of the game that are at work at several levels: 
constitutional conventions that define the role of the Prime Minister, Cabinet and the central agencies that support them; management rules and procedures that are embedded in Treasury Board policies; and organizational culture that structures working relationships within the public service, in particular among the interlocking organizational forms - central agencies, common service organizations and line departments - that have been in place since the Glassco report. The capacity that has been built into Canadian governance to keep the machinery of government under systematic review and to adjust the structural assumptions of the federal government in response to the priorities of the government of the day provides a mechanism both to implement the rules of the game within federal institutions and to adjust them from time to time. Similarly, the public service is influenced by societal values and behaviours, including society's adoption of networked ICTs and more recently of social networking.

If the public service is an institution, it follows that a major administrative sector within the public service with defined organizational features, actors, rules of the game, prevailing ideas and culture also counts as an institution (or perhaps more accurately as a sub-institution) and that its evolution can be analyzed through the lens of theories of institutional stability, continuity and change. Chapter 1 proposed that historical institutionalism provided a useful tool for explaining and understanding the CIO case, and this turns out to be the case. Historical explanations are generally most readily applied to institutional stability and continuity. This is especially so in a case like the federal government where there has been a large measure of continuity over an extended period of time, with most changes building on what has gone before rather than introducing a radical new dimension. Stability and continuity do not mean stasis, 
however. New institutions and policies are implemented and tested over time, nurtured by a process of learning by the actors within the organization, both individually and collectively. In principle this leads to greater effectiveness within established assumptions and a more systematic basis for keeping those assumptions under review and self-renewing.

Within the continuity of federal institutions there have been major turning points and significant choices. The conservation of Treasury Board as a collective mechanism at Confederation and its preservation in the face of advice to the contrary by the Murray report in 1912, the wholesale introduction of Griffenhagen-inspired scientific management after World War I, and the fleshing out and entrenchment of a collective management model after the Glassco report were all points at which significant new elements were introduced to the federal system and combined with others that were already well established. These did not ordain the creation of the CIO in 1993, but they did ensure a fertile environment when it was introduced on the margins of a broader restructuring as well as providing many of the required components for re-assembly. In retrospect, these can all be seen as critical junctures: turning points that represented roads not taken as much as positive decisions but that proved to set a new course - a pathway that channelled subsequent events. In each case, new and existing elements were brought together in new combinations, reflecting an injection of ideas, personalities, new technology and (at least indirectly) political will and priorities. These same dynamics can be seen at work on a more modest scale in the evolution of the CIO after 1993: for much of the time less stability but over-all continuity and maturation. 
A characteristic of the evolution of the federal government has been the extent to which there have been regular conscious efforts to review its structure and operations in light of contemporary circumstances. The dissertation has discussed nearly two dozen such reviews by external bodies including legislative committees, Commissions of Inquiry, Royal Commissions and various kinds of external and internal task forces since the 1830s that have looked at the organization and management of the public service. These have been supplemented in recent years by the work of the Auditor General, and to a lesser extent the other Parliamentary commissioners and even at times Parliamentary committees. This reflective capacity can even be seen as an inherent feature of the rules of the game of the Canadian Westminster model. It also provides a link to the application of public policy-based theories of stability, continuity and change, which are concerned with the taking and implementation of decisions.

Policy-making with respect to an institution such as the CIO arises at two levels. The more prosaic but more common is that much of its evolution occurs through the accretion of day-to-day events, activities and operational decisions. Less frequently, but more visibly, there are also higher level and strategically more significant decisions - to appoint a CIO of a particular background, to approve a major IT project, to allocate new funds in a particular direction, to change the policy mandate of the $\mathrm{CIO}$ or to change significantly the substance of a policy that the CIO administers. These decisions typically engage the government at both the political and top public service levels and put into play the factors discussed earlier in this chapter affecting the CIO's effectiveness. In sum, policy theory provides the more useful lens for considering day-to-day or even medium term decisions about the $\mathrm{CIO}$ and its responsibilities. Institutional theories are helpful in 
looking at the evolution of the environment in which the decisions are taken, especially when viewed over time. The Canadian Westminster model provides a set of policy instruments that are specifically concerned with institutional design. These provide a connection between the two bodies of theory, which are probably best seen as two ends of the same microscope.

In the final analysis, these theoretical issues are reminiscent of classic debates about free will and determinism, or nurture and nature. Historically derived institutional dynamics, external forces such as ICTs but also the business cycle, the weather and other factors that government cannot control, individual personalities and human nature will all contrive to encourage some tendencies within a complex environment such as the federal government and discourage others, often in unpredictable and seemingly random ways. At the same time, in any politically responsive administrative system there are forces for rationalism and intent, compounded in the case of the federal government by the presence of collective management mechanisms that are designed, and have regularly been made to work, as active instruments of political will. The CIO case makes clear that when fully deployed these are powerful instruments indeed.

\section{Further research}

The CIO case is neither static nor a closed story. It is also part of a larger institutional environment, one that has parallels in all public sectors, each of which faces similar pressures from changing ICTs and has responded institutionally with some version of a government-wide $\mathrm{CIO}$. While all the research questions discussed in the 
dissertation have an open-ended dimension to them, those related to the CIO case in particular point to areas for follow up research.

The most basic is to monitor the future progress of the CIO. It is likely to continue in something like its current form, but there are a number of variables at work that warrant attention, including its role and mandate, organizational location, and leadership. A critical variable will be how the government of the day chooses to use the capacity for public service innovation and modernization that the CIO represents, as well as what relationship it sees between the CIO's internal management concerns and broader economic development initiatives. A related set of variables will be the nature and future effects of technological and political change.

In addition to broadening and deepening the CIO case, there is also considerable scope to pursue the numerous comparative dimensions that it presents. This dissertation has provided a sighting of the Ontario case, but primarily from the perspective of the insights it provides to the federal case. Again this aspect can usefully be pursued, but there is also scope for a more extensive treatment of the Ontario $\mathrm{CCIO}$ as well as the $\mathrm{CIO}$ counterparts in the other provinces and territories, both individually and in pursuit of a broader understanding of the multiple variations on the Canadian Westminster model.

A related research vein is to flesh out comparisons with other national governments, linking to the relatively limited work that has already been done. These include an inner circle of countries with which Canada has close ties (the US) and similar institutions (Australia and the UK) but also a larger group of OECD countries that face similar tensions between administrative rationalism and political responsiveness. A wider perimeter still is the countries and administrative systems in varying stages of economic 
and institutional development, both for the expected comparative insights but also with a view to transfer of learning and support for governance reform - which to be really effective needs to be two-way. In many respects, the rethinking and retooling of public administration that ICTs provoke echo the open-ended challenges faced by developing countries, placing Canada in that category perhaps more than it recognizes.

The dissertation has also argued that the public administration discipline as practiced in Canada has been affected by ICTs and by the emergence of public sector CIOs and - in the dissertation's most prescriptive dimension - that this reality needs to be recognized and internalized more systematically by the discipline. This suggests research to help flesh out the required understandings. Another fruitful line of enquiry is to develop a more explicit link between public administration and e-government, which at present overlap to a considerable degree but largely without acknowledging that this is the case. The emergence of mobile government adds an additional boundary to explore, and ongoing technological change will in due course provide others.

Finally, the linkage between theories of policy and institutional stability, continuity and change lends itself to continuing reflection. Their development in recent years has not particularly had public sector institutions in mind, yet these are a major element of both public policy and public administration and, like the CIO, are not static. Public institutions represent some of the most basic and straightforward testing grounds for these theoretical lenses, especially in the face of forces that are largely external to governments. They may also, however, be the most enigmatic: political men (and women) may indeed at times be masters of their fates, but no theory to date has been able to provide an adequate explanation as to precisely when and how that is so. 


\section{Bibliography}

Works cited

6, Perri (P6 2002). Towards Holistic Governance. New York: Palgrave MacMillan.

Accenture (2002). eGovernment Leadership: Realizing the Vision. London: Accenture, The Executive Series.

Accenture (2005). Leadership in Customer Service: New Expectations, New Service. London: Accenture, The Executive Series.

Accenture (2008). Leadership in Customer Service: Creating Shared Responsibility for Better Outcomes. Available at http://www.accenture.com/NR/rdonlyres/14E4340B4D2B-4147-9291-8FA94D8218E7/0/LCS08Report012109.pdf [Accessed December 3, 2010]

Alexander, Cynthia J. and Leslie A. Pal, editors (1998). Digital Democracy: Policy and Politics in the Wired World. Don Mills: Oxford University Press.

Ambrose, Rona, Don Lenihan and John Milloy (Ambrose et al. 2006). "What is CitizenCentred Federalism and Why Does it Matter?" in Rona Ambrose, Don Lenihan and John Milloy. Managing the Federation: a Citizen-Centred Approach. Ottawa, Crossing Boundaries Volume 7.

Andersen, Kim Viborg (1999). "Reengineering public sector organizations using information technology" in Richard Heeks, editor., Reinventing Government in the Information Age: International practice in IT-enabled public sector reform. London: Routledge.

Atherton, Jay E. (1979). "The Origins of the Public Archives Records Centre, 18971956." Archivaria 8 (Summer 1979): 35-59.

Atherton, Jay (1985). "From Life Cycle to Continuum: Some Thoughts on the Records Management-Archives Relationship" in Archivaria 21 (Winter 1985-86): 43-51.

Aucoin, Peter and Herman Bakvis (1988). The Centralization-Decentralization Conundrum: Organization and Management in the Canadian Government. Montreal: Institute for Research on Public Policy

Aucoin, Peter and Mark D. Jarvis (2005). Modernizing Accountability: A Framework for Action. Ottawa: Canada School of Public Service.

Axworthy, Lloyd assisted by J. Cassidy, Jocelyn O'Hara and John Badertscher (1971). "A Public Communications System: A Study of the Use of New Communications Technology by Government to Enhance Citizen Participation and Increase Program Effectiveness." Paper Prepared for the Ontario Committee on Government Productivity. Winnipeg: University of Manitoba and Toronto: Queen's Printer for Ontario.

Bagehot, Walter (1928). The English Constitution. London: Humphrey Milford for Oxford University Press.

Bakvis, Herman and Luc Juillet (2004). The Horizontal Challenge: Line Departments, Central Agencies and Leadership. Ottawa: Canada School of Public Service.

Barker, Paul (2008). Public Administration in Canada: Brief Edition. Toronto: Thomson Nelson.

Barney, Darin (2005). Communication Technology. Vancouver: UBC Press.

Baumgartner, Frank R. and Bryan D. Jones (1993). Agendas and instability in American politics. Chicago: University of Chicago Press. 
Bearman, David A. and Richard H. Lytle (1985). "The Power of the Principle of Provenance" in Archivaria 21 (Winter 1985-86): 14-27.

Bell, George B. and Andrew D. Pascoe (1988). The Ontario Government: Structure and Functions. Toronto: Wall \& Thompson.

Bernard, André (1992). Politique et gestion des finances publiques. Québec et Canada. Montréal, Presses de l'Université du Québec.

Bernier, Luc, Keith Brownsey and Michael Howlett, editors. (Bernier et al. 2005). Executive Styles in Canada: Cabinet Structure and Leadership Practices in Canadian Government. Toronto: University of Toronto Press.

Blaikie, Norman (2000). Designing Social Research: The Logic of Anticipation. Cambridge: Polity Press.

Blakely, Arthur (1963). "PM Adds His Voice to Rising Opposition to Glassco Reforms" The Gazette, Montreal. January 9, 1963, pg. 1.

Bontis, Nick (2007a). "Citizen Relationship Management in Canadian Cities: Starting to Dial 311" chapter 5 in Sandford Borins, Kenneth Kernaghan, David Brown, Nick Bontis, Perri 6 and Fred Thompson Digital State at the Leading Edge. Toronto: University of Toronto Press, pp. 137-154.

Bontis, Nick (2007b). "Mining the Nation's Intellectual Capital: Knowledge Management in Government" chapter 6 in Sandford Borins, Kenneth Kernaghan, David Brown, Nick Bontis, Perri 6 and Fred Thompson Digital State at the Leading Edge. Toronto: University of Toronto Press, pp. 155-182.

Borins, Sandford (2002). "Information Technology in the Public Sector" in Christopher Dunn, editor. The Handbook of Canadian Public Administration. Toronto: Oxford University Press, pp. 450-465.

Borins, Sandford (2007a). "Conceptual Framework" chapter 1 in Sandford Borins, Kenneth Kernaghan, David Brown, Nick Bontis, Perri 6 and Fred Thompson. Digital State at the Leading Edge. Toronto: University of Toronto Press, pp. 14 36.

Borins, Sandford (2007b). "What Keeps a CIO Awake at Night? Evidence from the Ontario Government" chapter 3 in Sandford Borins, Kenneth Kernaghan, David Brown, Nick Bontis, Perri 6 and Fred Thompson. Digital State at the Leading Edge. Toronto: University of Toronto Press, pp. 69-101.

Borins, Sandford and David Brown (2007a). "E-Consultation: Technology at the Interface between Civil Society and Government," chapter 9 in Sandford Borins, Kenneth Kernaghan, David Brown, Nick Bontis, Perri 6 and Fred Thompson. Digital State at the Leading Edge. Toronto: University of Toronto Press, pp. 253276.

Borins, Sandford and David Brown (2007b). "Digital Leadership: The Human Face of IT" chapter 10 in Sandford Borins, Kenneth Kernaghan, David Brown, Nick Bontis, Perri 6 and Fred Thompson. Digital State at the Leading Edge. Toronto: University of Toronto Press, pp. 277-301.

Borins, Sandford, Kenneth Kernaghan, David Brown, Perri 6 and Fred Thompson (Borins et al. 2007). Digital State at the Leading Edge. Toronto: University of Toronto Press.

Borins, Sandford F. and David Wolf (2000). "Realizing the Potential of Public Sector Technology: An Organizational Challenge" in David Zussman and Garry Sears, 
editors. Change, Governance and Public Management: Alternative Service Delivery and Information Technology. Ottawa: Public Policy Forum, pp. 159-277.

Borrows, John (1997). "Wampum at Niagara: The Royal Proclamation, Canadian Legal History, and Self-Government" in Michael Asch, editor. Aboriginal and Treaty Rights in Canada: Essays on Law, Equality and Respect for Difference. Vancouver: UBC Press, pp. 155-172.

Bourgault, Jacques (2005). "The Deputy Minister's Role in the Government of Canada:

His Responsibility and His Accountability" in Canada, Commission of Inquiry into the Sponsorship Program and Advertising Activities, II. Research Studies. Ottawa:

Public Works and Government Services Canada, pp. 253-296.

Bourgault, Jacques, Maurice Demers and Cynthia Williams (Bourgault et al. 1997).

Public Administration and Public Management Experiences in Canada. Sainte-Foy:

Les Publications du Québec.

Bourgault, Jacques and Stéphane Dion (1990). "The Whitehall model as seen from

Ottawa: Canadian senior civil servants and transitions of government" in

International Review of Administrative Sciences vol. 56, no. 1 (March 1990): 149_69.

Bourgault, Jacques and Stéphane Dion (1991). The Changing Profile of Federal Deputy

Ministers 1867 - 1988. Ottawa: Canadian Centre for Management Development, March 1991.

Bourgault, Jacques and Yvon Tremblay (1994). "La gestion du rendement à la croisée des chemins : entre la rigueur et le laxisme" in Canadian Public Administration, vol. 37 no. 4 (Winter 1994): 547-572.

Bourgon, Jocelyne (1997). Fourth Annual Report to the Prime Minister on the Public Service of Canada. Ottawa: Privy Council Office.

Bourgon, Jocelyne (2009). Program Review: The Government of Canada's Experience Eliminating the Deficit, 1994-99 - A Canadian Case Study. Waterloo, ON: The Centre for International Governance Innovation.

Bradford, Neil (2003). "Public-Private Partnership? Shifting Paradigms of Economic Governance in Ontario" in Canadian Journal of Political Science, vol. 36, no. 5 (December 2003): 1005-1033.

Braibant, Guy, editor. (1977). Informatics and Administration. Brussels: International Institute of Administrative Sciences.

Braman, Sandra (2006). Change of State: Information, Policy, and Power. Cambridge MA: The MIT Press.

Brown, David (1997). "New Information Technologies in Canadian Public Administration" in Mohamed Charih and Arthur Daniels, editors, New Public Management and Public Administration in Canada Toronto: Institute of Public Administration of Canada, pp. 93-112.

Brown, David (2001a). The Governance of Government On-Line, Report to the Treasury Board Secretariat Chief Information Officer. Public Policy Forum, March 2001.

Brown, David (2001b). Study of Government On-Line Committees. Ottawa: Public Policy Forum.

Brown, David (2003). Treasury Board Policy Review: Comparative Study of Provincial and Territorial Practices. Unpublished study by the Public Policy Forum, Ottawa on behalf of Treasury Board Secretariat. 
Brown, David (2005a). "Gateways and Clusters: the Government of Canada's Experience with Client-Oriented Single-Window Electronic Service Delivery" in Giorgio Petroni and Fanie Cloete, editors, New Technology in Public Administration. Amsterdam, IOS Press, pp. 38-59.

Brown, David (2005b). "Electronic Government and Public Administration" International Review of Administrative Sciences, vol. 71, no. 2 (June 2005): 241254.

Brown, David (2007). "The Government of Canada: Government On-Line and CitizenCentred Service," chapter 2 in Sandford Borins, Kenneth Kernaghan, David Brown, Nick Bontis, Perri 6 and Fred Thompson. Digital State at the Leading Edge. Toronto: University of Toronto Press, pp. 37-68.

Brown, David C.G. (2009a). "Coming to Terms with Information and Communications Technologies: the Role of the Chief Information Officer of the Government of Canada." Paper presented to the annual meeting of the Canadian Political Science Association, Ottawa, May 27, 2009.

Brown, David C.G. (2009b). "The Canada Revenue Agency as separate employer: Anomaly or model for the future?" in Canadian Public Administration, vol. 52, no. 4 (December 2009): 569-590.

Brown, David C.G. (2010a). "Information, Technology and Canadian Public Administration" in Dunn, Christopher, editor. The Handbook of Canadian Public Administration, 2nd Edition. Don Mills, Ontario: Oxford University Press Canada, pp. 521-537.

Brown, David C.G. (2010b). "The unfulfilled promise of information management." Paper presented to the annual meeting of the Canadian Political Science Association, Montreal, June 2010.

Brown, David C.G. (2011). "Accountability in a collectivized environment." Paper presented to the annual meeting of the Canadian Political Science Association, Waterloo, Ontario, May 2011.

Brown, David and David Brook (2001). Making Government Procurement Work in Support of Government On-Line. Ottawa: Public Policy Forum.

Brown, David and George Kourakos (2005). Vendor Engagement Strategy Consultation. Ottawa: Public Policy Forum.

Brown, George W. (1944). "The Problem of Public and Historical Records in Canada," Canadian Historical Review, vol. 25, no. 1 (March 1944): 1-5.

Brownsey, Keith and Michael Howlett, editor. (2000). The Provincial State: Politics in Canada's Provinces and Territories. Toronto: Broadview Press.

Bryden, Kenneth (1975). "Executive and legislature in Ontario: a case study on governmental reform" in Canadian Public Administration, vol. 18, no. 2 (Summer 1975): $235-252$.

Cameron, David and Graham White (2000). Cycling into Saigon: The Conservative Transition in Ontario. Vancouver: University of British Columbia Press.

Campbell, Colin and George J. Szablowski (1979). The Superbureaucrats: Structure and Behaviour in Central Agencies. Toronto: Macmillan of Canada.

Campbell, Kim (1996). Time and Chance: The Political Memoirs of Canada's First Woman Prime Minister. Toronto: Doubleday Canada Limited. 
Canada. Access to Information Review Task Force (2002). Access to Information: Making it Work for Canadians: Report of the Access to Information Review Task Force. Ottawa: Public Works and Government Services Canada.

Canada. Auditor General (1997). Report of the Auditor General of Canada to the House of Commons, October 1997, chapter 12. "Information Technology - Preparedness for Year 2000." Ottawa: Minister of Public Works and Government Services.

Canada. Auditor General (1998). Report of the Auditor General of Canada to the House of Commons, December 1998, chapter 20. "Preparedness for Year 2000:

Government-Wide Mission Critical Systems." Ottawa: Minister of Public Works and Government Services.

Canada. Auditor General of Canada (2001). Report of the Auditor General to the House of Commons, December 2001, chapter 4. "Voted Grants and Contributions Government-Wide Management." Ottawa: Minister of Public Works and Government Services Canada

Canada. Auditor General of Canada (2003a). Report of the Auditor General to the House of Commons, May 2003, chapter 6. "Reform of Classification and Job Evaluation in the Federal Public Service." Ottawa: Minister of Public Works and Government Services Canada

Canada. Auditor General (2003b). Report of the Auditor General to the House of Commons, November 2003, chapter 1. "Information Technology: Government OnLine." Ottawa: Minister of Public Works and Government Services.

Canada. Auditor General of Canada (2004). Report of the Auditor General to the House of Commons, March 2004, chapter 7. "Managing Government: a Study of the Role of the Treasury Board and its Secretariat." Ottawa: Minister of Public Works and Government Services Canada

Canada. Auditor General (2010). Report of the Auditor General of Canada to the House of Commons, April 2010, chapter 1. "Aging Information Technology Systems" Ottawa: Minister of Public Works and Government Services.

Canada. Canadian International Trade Tribunal (CITT 1998). Determination: Corel Corporation, File Nos.: PR-98-012 and PR-98-014, October 26, 1998. Available on webpage http://www.citt.gc.ca/procure/determin/pr98012_e.asp [Accessed December 3, 2010]

Canada. Civil Service Commission (Heeney 1959). Personnel Administration in the Public Service: A Review of Civil Service Legislation (Heeney Report). Ottawa: Queen's Printer.

Canada. Commission Appointed to Enquire Into Certain Matters Relating to the Civil Service of the Dominion (Hague Commission) (Hague 1892). Report of the Commissioners. Can. Sess. Pap. 55 Victoria. (1892), no. 16c.

Canada. Commission to Consider the Needs and Conditions of the Civil Service of the Dominion (McInnes Commission) (McInnes $1881 \&$ 1882). First Report of the Commissioners. Can. Sess. Pap. 44 Victoria (1881), no. 113. Second Report of the Commissioners. Can. Sess. Pap. 45 Victoria (1882), no. 32.

Canada. Commission to Enquire into All Matters Connected with or Affecting the Administration of the Various Departments of the Government and the Conduct of the Public Business Therein, 1911-12 (Morine Commission) (Morine 1913). Report 
of the Commissioner. Canada. House of Commons. Sessional Papers (1913), No. 57.

Canada. Commission to Enquire into the Present State and Probable Requirements of the Civil Service (Langton Commission) (Langton 1869 \& 1870). First Report of the Civil Service Commission and Second Report of the Civil Service Commission. Canada, House of Commons, Sessional Papers (1869), No. 19; Final Report of the Civil Service Commission. Canada. House of Commons. Sessional Papers (1870), No. 64.

Canada. Commission to Enquire into and Report Upon the Civil Service Act and Kindred Legislation 1907-08 (Courtney Commission) (Courtney 1908). Report of the Commissioners. Can. Sess. Pap. 7 Edward VII (1908), no. 29a.

Canada. Commission to Inquire into Certain Matters Affecting the Operation of the Civil Service Acts, the Organization of the Public Service and the Methods of Administration under which the Public Business of Canada is Carried On, 1912 (Murray Commission) (Murray 1912). Report on the Organization of the Public Service of Canada. By Sir George Murray. Ottawa: King's Printer, 1912.

Canada. Commission of Inquiry Concerning Certain Activities of the Royal Canadian Mounted Police, David C. McDonald, Chairman (McDonald 1979). First Report: Security and Information. Ottawa: Minister of Supply and Services.

Canada. Commission of Inquiry Concerning Certain Activities of the Royal Canadian Mounted Police, David C. McDonald, Chairman (McDonald 1981a). Second Report: Freedom and Security under the Law, Volumes $1 \& 2$. Ottawa: Minister of Supply and Services.

Canada. Commission of Inquiry Concerning Certain Activities of the Royal Canadian Mounted Police, David C. McDonald, Chairman (McDonald 1981b). Third Report: Certain RCMP Activities and the Question of Governmental Knowledge. Ottawa: Minister of Supply and Services.

Canada. Commission of Inquiry into the Sponsorship Program and Advertising Activities, Report from Justice John Gomery, February 1, 2006 (Gomery 2006). Restoring Accountability: Recommendations. Ottawa: Public Works and Government Services Canada.

Canada. Department of Foreign Affairs and International Trade (2009). North American Free Trade Agreement: Text of the Agreement. Available at http://www.international.gc.ca/trade-agreements-accords-commerciaux/agracc/nafta-alena/texte/index.aspx?lang=en\&menu $\mathrm{id}=34 \& \mathrm{menu}=\mathrm{R}[$ Accessed December 3, 2010]

Canada. Departmental Commission Appointed to Inquire into and Report upon the State of Public Records, 1897 (1898). Report of the Commissioners. Ottawa.

Canada. Departmental Commission Appointed to Inquire into the State of the Records of the Public Departments, Sir Joseph Pope, Chairman (Pope 1914). Report. Ottawa.

Canada. Federal Task Force on Digitization (1997). Final Report - Towards a Learning Nation: the Digital Contribution. Ottawa: National Library of Canada. Available at http://www.collectionscanada.gc.ca/8/3/r3-407-e.html [Accessed on January 7, 2011] 
Canada. Finance (2011). Budget 2011 - Chapter 5: Plan for Returning to Balanced Budgets. Available at: http://www.budget.gc.ca/2011/plan/chap5-eng.html [Accessed on April 6, 2011]

Canada. Government of Canada (PCO 1990). Public Service 2000: The Renewal of the Public Service of Canada. Ottawa: Minister of Supply and Services.

Canada. Government on-Line Advisory Panel (2002a). Letter to the President of the Treasury Board, April 12, 2002. Preliminary Report of the Government on-Line Advisory Panel

Canada. Government On-Line Advisory Panel (2002b). Transforming Government to Service Canadians Better, Report of the GOL Advisory Panel

Canada. Government on-Line Advisory Panel (2003). Connecting with Canadians: Pursuing Service Transformation. Final Report of the GOL Advisory Panel.

Canada. Governor General (1997). Speech from the Throne to open the first session, thirty-sixth Parliament of Canada. 23 September, 1997. http://www.pcobcp.gc.ca/index.asp?lang $=$ eng\&page $=$ information\&sub $=$ publications\&doc $=$ sftddt/1997-eng.htm [Accessed November 1, 2010]

Canada. Governor General (1999). Speech from the Throne to open the second session, thirty-sixth Parliament of Canada. 12 October, 1999. http://www.pcobcp.gc.ca/index.asp?lang $=$ eng\&page $=$ information \&sub $=$ publications\&doc $=$ sftddt/1999-eng.htm [Accessed November 1, 2010]

Canada. House of Commons. Select Committee Appointed to Inquire into the Present Conditions of the Civil Service, 1877 (Casey Committee) (Casey 1877). Report in Journals (1877), Appendix No. 7.

Canada. House of Commons. Standing Committee on Government Operations and Estimates (2009). In Pursuit of Balance: Assisting Small and Medium Enterprises in Accessing Federal Procurement. Committee Report, June 2009, 40 ${ }^{\text {th }}$ Parliament, $2^{\text {nd }}$ Session.

Canada. House of Commons. Standing Committee on Justice and Solicitor General (1987). Open and Shut: Enhancing the Right to Know and the Right to Privacy. Ottawa: House of Commons.

Canada. Industry Canada (1996). Building the Information Society: Moving Canada into the $21^{\text {st }}$ Century. Ottawa, Supply and Services Canada.

Canada, Industry Canada (2004). The New National Dream: Networking the Nation for Broadband Access, Report of the National Broadband Taskforce. Ottawa: Industry Canada.

Canada. Information Canada (1970). The Organization of the Government of Canada. Ottawa: Queen's Printer.

Canada. Information Commissioner (2010). Out of Time: 2008-09 Report Cards/Systemic Issues Affecting Access to Information in Canada - A Special Report to Parliament by the Interim Information Commissioner of Canada, April 2010. Ottawa: Minister of Public Works and Government Services.

Canada. Information Highway Advisory Council (IHAC 1995). Connection, community, content: the challenge of the information highway. Ottawa: Minister of Supply and Services.

Canada. Information Highway Advisory Council (IHAC 1997). Preparing Canada for a Digital World. Ottawa: Industry Canada. 
Canada. Info Source (2009a). Sources of Federal Government and Employee Information 2009 page on Info Source website http://www.infosource.gc.ca/emp/emp01eng.asp\#foreword [Accessed November 24, 2010].

Canada. Info Source (2009b). Access to Information Act and Privacy Act Bulletins page on Info Source website http://www.infosource.gc.ca/bulletin/bulletin-eng.asp [Accessed November 24, 2010].

Canada. Library and Archives Canada. Government Records Branch. (LAC 2008). Email Management Guidelines - Roadmap. Available at http://collectionscanada.ca/obj/007001/f2/007001-6306-e.pdf [Accessed 7 May, 2010]

Canada. Library and Archives Canada (LAC n/d). "Government Records Appraisal and Disposition Program" on Library and Archives Canada Website http://www.collectionscanada.gc.ca/government/disposition/007007-1034-e.html [Accessed 7 May, 2010]

Canada. Office of the Prime Minister (PMO 1989). "Announcement of the launch of Public Service 2000" Press Release, 12 December 1989.

Canada. Office of the Prime Minister (PMO 1993). Press Release, 25 June 1993.

Canada. Prime Minister's Advisory Committee on the Public Service (Tellier/Emerson Committee) (2010). Fourth Report to the Prime Minister, February 2010. Ottawa: Privy Council Office.

Canada. Prime Minister's Advisory Committee on the Public Service (Tellier/Emerson Committee) (2011). Fifth Report to the Prime Minister, March 2011: A Public Service for Challenging Times. Ottawa: Privy Council Office.

Canada. Privy Council Office (PCO 1977). Responsibility in the Constitution. A Submission to the Royal Commission on Financial Management and Accountability. Ottawa: the Privy Council Office.

Canada. Privy Council Office (PCO 1993). Responsibility in the Constitution. Ottawa: the Privy Council Office. Available at: http://www.pcobcp.gc.ca/index.asp?lang=eng\&page $=$ information\&sub $=$ publications\&doc $=$ constitu tion/table-eng.htm [Accessed July 5, 2010)

Canada. Privy Council Office (PCO 2003). Guidance for Deputy Ministers. Available at http://www.pco-

bcp.gc.ca/index.asp?lang=eng\&page $=$ information $\& s u b=$ publications $\& d o c=g d m-$ gsm/doc-eng.htm [Accessed November 23, 2010].

Canada. Privy Council Office (PCO 2010a). "The Role and Structure of the Privy Council Office." PCO Website: http://www.pco-

bcp.gc.ca/index.asp?lang $=$ eng \&Page $=$ information $\& S u b=$ publications \&Doc $=$ role $/$ ro le2010-eng.htm\#7.2 [Accessed July 5, 2010]

Canada. Privy Council Office (PCO 2010b). "Memorandum to Cabinet" on the Privy Council Office Website: http://www.pcobcp.gc.ca/index.asp?lang $=$ eng\&page $=$ information \&sub $=$ publications \&doc $=\mathrm{mc} / \mathrm{mc}-$ eng.htm [Accessed January 9, 2011]

Canada. Privy Council Office (2011). Accountable Government: A Guide for Ministers and Ministers of State. Ottawa: Privy Council Office. Available at http://pcobcp.gc.ca/docs/information/publications/ag-gr/2011/docs/ag-gr-eng.pdf [Accessed 10 September, 2011]. 
Canada. Public Works and Government Services Canada (PWGSC 2006). Government On-Line 2006. Ottawa: Public Works and Government Services Canada. Available on

http://www.collectionscanada.gc.ca/webarchives/20061210154748/http://www.gedgol.gc.ca/rpt2006/rpt/rpt e.pdf [Accessed January 6, 2011]

Canada. Public Works and Government Services (PWGSC 2010). Depository Services Program. page on PWGSC website http://publications.gc.ca/site/eng/programs/dsp.html [Accessed November 24, 2010]

Canada. Royal Commission on Administrative Classification in the Public Service, Walter Gordon, Chairman (Gordon 1946). Report of the Royal Commission. Ottawa: King's Printer.

Canada. Royal Commission on Broadcasting, Robert Fowler, Chairman (Fowler 1957). Report. Ottawa: Queen's Printer.

Canada. Royal Commission on Financial Management and Accountability, Allan Lambert Chairman (Lambert 1979). Final Report. Hull: Supply and Services Canada.

Canada. Royal Commission on Government Organization, J. Grant Glassco, Chairman. (Glassco) (1961). Interim Report; (1962). Vol. 1, Management of the Public Service; (1962). Vol. 2, Supporting Services for Government; (1962). Vol. 3, Supporting Services for Government Cont'd. Services for the Public; (1963). Vol. 4, Special Areas of Administration; (1963). Vol. 5, The Organization of the Government of Canada. Ottawa: The Queen's Printer.

Canada. Royal Commission to Investigate the Facts Relating to the Circumstances Surrounding the Communication by Public Officials and Other Persons in Positions of Trust of Secret and Confidential Information to Agents of a Foreign Power (Taschereau/Kellock 1946). Report. Ottawa: King's Printer.

Canada. Royal Commission on National Development in the Arts, Letters and Sciences, Vincent Massey, Chairman (Massey 1951). Report. Ottawa: King's Printer.

Canada. Royal Commission on Publications, Grattan O'Leary, Chairman (O'Leary 1961). Report. Ottawa: Queen's Printer.

Canada. Royal Commission on Radio Broadcasting, Sir John Aird, Chairman, (Aird 1929). Report. Ottawa: King's Printer.

Canada. Royal Commission on Security (Mackenzie 1969). Report. Ottawa: Queen's Printer.

Canada. Royal Commission on Technical and Professional Services, Edward W. Beatty, Chairman (Beatty 1930). Report. Ottawa: King's Printer.

Canada. Secretary of State (1977). Green Paper: Legislation on Public Access to Government Documents. Ottawa: Queen's Printer.

Canada. Senate. Special Senate Committee on the Desirability of Betterment in the Machinery of Government, 1919 (Senate 1919). Report. Journals of the Senate of the Dominion of Canada, 1867 - 1970, vol. 55, 2 July 1919.

Canada. Task Force on Government Information (1969). To Know and Be Known, Report of the Task Force on Government Information, volume I: Report; volume II: Research Papers. Ottawa: Queen's Printer. 
Canada. Treasury Board Secretariat. Administrative Policy Branch. Information Systems Division (TBS 1983). Review of EDP and Telecommunications in the Government of Canada, 1983.

Canada. Treasury Board Secretariat (TBS 1990). "Federal Identity Program Policy" page on TBS website http://www.tbs-sct.gc.ca/pol/doc-eng.aspx?id=12314 [Accessed November 23, 2010]

Canada. Treasury Board Secretariat (TBS 1992). Administrative Policy Branch. Enhancing Services Through the Innovative Use of Information Technology: Strategic Direction for the 90s. Ottawa: Minister of Supply and Services Canada.

Canada. Treasury Board Secretariat. Administrative Policy Branch (TBS 1993). Powering Up: A Review and Analysis of Information Technology Expenditure Trends in the Canadian Federal Government. Ottawa: Supply and Services Canada.

Canada. Treasury Board Secretariat (TBS 1994). Blueprint for renewing government services using Information Technology. Ottawa: Supply and Services Canada.

Canada. Treasury Board Secretariat (TBS 1996). "Expenditure Management System of the Government of Canada" on page Treasury Board of Canada (TBS) website: http://www.tbs-sct.gc.ca/Pubs_pol/opepubs/TB_H/exma-eng.asp [Accessed January $8,2011]$.

Canada. Treasury Board Secretariat (TBS 1998). "Policy on the Use of Electronic Networks" page on TBS website http://www.tbs-sct.gc.ca/pol/doceng.aspx?id=12419\&section=79 [Accessed November 24, 2010]

Canada. Treasury Board Secretariat (TBS 2000). "A Policy Framework for Service Improvement in the Government of Canada" page on TBS website http://www.tbssct.gc.ca/pol/doc-eng.aspx?id=13879 [Accessed November 23, 2010]

Canada. Treasury Board Secretariat (TBS 2006). "Communications Policy of the Government of Canada" page on TBS website http://www.tbs-sct.gc.ca/pol/doceng.aspx?id=12316 [Accessed November 23, 2010]

Canada. Treasury Board Secretariat (TBS 2007a). "Proposed Set of Treasury Board Policy Instruments" page on TBS website http://www.tbs-sct.gc.ca/prp-pep/ffgtcpgt-eng.asp\#Text [Accessed November 22, 2010]

Canada. Treasury Board Secretariat (TBS 2007b). "Policy Framework for Information and Technology" page on TBS website http://www.tbs-sct.gc.ca/pol/doceng.aspx?id=12452 [Accessed November 23, 2010]

Canada. Treasury Board Secretariat (TBS 2007c). "Policy on Information Management" page on TBS website http://www.tbs-sct.gc.ca/pol/doc-eng.aspx?id=12742 [Accessed November 23, 2010]

Canada. Treasury Board Secretariat (TBS 2007d). "Policy on Management of Information Technology" page on TBS website http://www.tbs-sct.gc.ca/pol/doceng.aspx?id $=12755$ [Accessed November 23, 2010]

Canada. Treasury Board Secretariat (TBS 2008a). "Foundation Framework for Treasury Board Policies" page on TBS website http://www.tbs-sct.gc.ca/pol/doceng.aspx?id=13616 [Accessed November 23, 2010]

Canada. Treasury Board Secretariat (TBS 2008b). "Policy on Access to Information" page on TBS website http://www.tbs-sct.gc.ca/pol/doc-eng.aspx?id=12453 [Accessed November 23, 2010] 
Canada. Treasury Board Secretariat (TBS 2008c). "Policy on Privacy Protection" page on TBS website http://www.tbs-sct.gc.ca/pol/doc-eng.aspx?id=12510 [Accessed November 23, 2010]

Canada. Treasury Board Secretariat (TBS 2008d). "Occupational Group Structure" page on TBS website at http://www.tbs-sct.gc.ca/cla/occst-eng.asp [Accessed November $28,2008]$

Canada. Treasury Board Secretariat (TBS 2008e). "Government of Canada Profile of Information Technology (IT) Services" page on TBS website http://www.tbssct.gc.ca/cio-dpi/webapps/technology/profil/profiltb-eng.asp [Accessed December 2, 2010]

Canada. Treasury Board Secretariat (2009a). "Policy on Government Security" page on TBS website http://www.tbs-sct.gc.ca/pol/doc-eng.aspx?id=16578 [Accessed November 23, 2010]

Canada. Treasury Board Secretariat (TBS 2009b). "Chief Information Officer: Corinne Charette" page on TBS website. http://www.tbs-sct.gc.ca/cio-dpi/org-eng.asp [Accessed February 3, 2010]

Canada. Treasury Board Secretariat (TBS 2010a). “About Us: Chief Information Officer Branch" page on TBS website http://www.tbs-sct.gc.ca/cio-dpi/abu-ans/abu-anseng.asp [Accessed February 8, 2010]

Canada. Treasury Board Secretariat (TBS 2010b). "Standard for Organizational Project Management Capacity" page on TBS website http://www.tbs-sct.gc.ca/pol/doceng.aspx?id=12078\&section=text\#cha4 [Accessed March 1, 2010]

Canada. Treasury Board Secretariat (TBS 2010c). "TB Management Accountability Framework" page on TBS website http://www.tbs-sct.gc.ca/maf-crg/index-eng.asp [Accessed November 1, 2010]

Canada. Treasury Board Secretariat (TBS 2010d). "Information Management" page on TBS website: http://www.tbs-sct.gc.ca/im-gi/index-eng.asp [Accessed January 10, 2011]

Canada. Treasury Board Secretariat. (TBS 2010e). "GTEC 2010 Keynote" page on TBS Chief Information Officer Website http://www.tbs-sct.gc.ca/cio-dpi/gtec/ks-do2010-eng.asp [Accessed 2011.06.02]

Carroll, Barbara Wake and Michael Whyte Kpessa (2007). "Enduring, ephemeral and emerging issues in public administration in Canada: Trends in Canadian Public Administration over fifty years (1958-2007)"' in Canadian Public Administration, vol. 50, no. 4 (December 2007): 477-491.

Carroll, Barbara Wake, David Siegel and Mark Sproule-Jones, editors (Carroll et al. 2005). Classic Readings in Canadian Public Administration. Don Mills, Ontario: Oxford University Press.

Chandler, Marsha and William Chandler (1982). "Public administration in the provinces" in Canadian Public Administration, vol. 25 no. 4 (Winter 1982): 580-602.

Charih, Mohamed (1989). "Le Plan financier de la Commission Lambert : évaluation et mise en oeuvre par le gouvernement fédéral" in Canadian Public Administration, vol. 32, no. 3 (Fall 1989): $367-381$.

Charih, Mohamed (1991). "Les facteurs qui ont affecté la mise en oeuvre du plan de Gestion Lambert" in Canadian Public Administration, vol. 34, no. 1 (Spring 1991): $203-222$. 
Charih, Mohamed and Arthur Daniels, editors. (1997). New Public Management and Public Administration in Canada. Toronto: Institute of Public Administration of Canada and Hull: École nationale d'administration publique.

Charih, Mohamed and Michel Paquin (1993). "La planification stratégique à Ottawa et à Québec: une comparaison de quelque ministères" in Canadian Public Administration, vol. 36 no. 2 (Summer 1992): 175-189.

Charih, Mohamed and Jacynthe Robert (2004). "Government On-line in the federal government of Canada: the organizational issues" in International Review of Administrative Sciences, vol. 70, no. 2 (June 2004): 373-384.

Charland, Maurice (1986). "Technological Nationalism" in Canadian Journal of Political and Social Theory, vol. 10, no. 1-2 (1986): 196-220.

Chong, Michael (2010). "Time to Reform Question Period." May 20, 2010 posting on Michael Chong, MP, Website: http://michaelchong.ca/articles.asp?ID=135 [Accessed January 10, 2011]

Churchill, Jason Lemoine (2006). The Limits to Influence: The Club of Rome and Canada 1968-1988. PhD Thesis, Department of History, University of Waterloo.

Clark, Dora Mae (1960). The Rise of the British Treasury: Colonial Administration of the Eighteenth Century. Newton-Abbott: David \& Charles (Publishers) Limited.

Clark, Ian D (1994). "Restraint, renewal, and the Treasury Board Secretariat" in Canadian Public Administration, vol. 37 no. 2 (Summer 1994): 209-248.

Cook, Terry (1997). "What is Past is Prologue: A History of Archival Ideas Since 1898, and the Future Paradigm Shift" in Archivaria 43 (Spring 1997): 17-63.

Courchesne, Thomas J. (2004). "The Changing Nature of Quebec-Canada Relations: From the 1980 Referendum to the Summit of the Canadas" in Institute of Intergovernmental Relations, Queen's University, Working Paper 2004 (2), Montreal, Institute of Research on Public Policy.

Covelli, Mary Anne and Maria Cece (n/d). "Ontario Delivers Innovation." Toronto: Ontario Public Service Restructuring Secretariat, Cabinet Office, Ontario.

Cross, William (1998). "Teledemocracy: Canadian political parties listening to their constituents," in Cynthia Alexander and Leslie Pal, editors., Digital democracy: Policy and politics in the wired world. Don Mills: Oxford University Press, pp. $132-148$.

Culbertson, Stuart (2004). "Building E-Government: Organizational and Cultural Change in Public Administration" in E. Lynn Oliver and Larry Sanders, editors. EGovernment Reconsidered: Renewal of Governance for the Knowledge Age. Regina, Canadian Plains Centre and the Saskatchewan Institute of Public Policy: $59-75$.

Dean, Tony (2006). "Lessons Learned: What Has Worked and What to Avoid?" Notes for an address to the biennial conference of the Commonwealth Association for Public Administration and Management, Sydney, Australia. Available on the CAPAM website: http://www.capam.org/documents/dean.tony.speakingnotes.pdf [Accessed January 28, 2011]

Demers, Jacynthe and James Iain Gow (2002). "Gestion des resources humaines et Nouveau Management Public : Opinions de gestionnaires fédéraux et québecois" in Canadian Public Administration, vol. 45 no. 4 (Winter 2002): 512-537.

Docherty, David C. (2005). Legislatures. Vancouver: UBC Press. 
Doern, G. Bruce and Brian W. Tomlin (1996). "Trade-Industrial Policy" in G. Bruce Doern, Leslie A. Pal and Brian W. Tomlin, editors. Border Crossings: The Internationalization of Canadian Public Policy. Toronto, Oxford University Press: $167-187$.

Doerr, Audrey D. (1981). The Machinery of Government of Canada. Toronto: Methuen Publications.

D'Ombrain, Nicholas (2000). “Alternative Service Delivery: Governance, Management and Practice" in David Zussman and Garry Sears, editors. Change, Governance and Public Management: Alternative Service Delivery and Information Technology. Ottawa: Public Policy Forum, pp. 83-157.

D'Ombrain, Nicholas (2001). "Managing Transitions of Power in Canada", in Peter E. Larson, editor. Passing the Baton: Effective Management of Transitions in Government. Ottawa: Public Policy Forum, pp. 27-47.

D'Ombrain, Nicholas (2007). "Ministerial responsibility and the machinery of government" in Canadian Public Administration, vol. 50, no. 2 (Summer 2007): $195-217$.

Dunleavy, Patrick, Helen Margetts, Simon Bastow and Jane Tinkler (Dunleavy et al. 2004). "Government IT Performance and the power of the IT industry: a crossnational analysis." Paper presented at the 2004 American Political Science Association annual conference.

Dunleavy Patrick, Helen Margetts, Simon Bastow and Jane Tinkler (Dunleavy et al. 2006). Digital Era Governance: IT Corporations, the State and E-government. Oxford: Oxford University Press, 2006.

Dunn, Christopher, editor. (1996). Provinces: Canadian Provincial Politics $\left(2^{\text {nd }}\right.$ edition 2006). Peterborough: Broadview Press.

Dunn, Christopher, editor (2002). The Handbook of Canadian Public Administration (2 ${ }^{\text {nd }}$ edition 2010). Don Mills: Oxford University Press.

Dutil, Patrice, editor (2008). Searching for Leadership: Secretaries to Cabinet in Canada. IPAC Series in Public Management and Governance. Toronto: University of Toronto Press.

Dutil, Patrick, John Langford and Jeffrey Roy (Dutil et al. 2005). E-Government and Service Transformation Relationships Between Government and Industry: Developing Best Practices. New Directions Series No. 17. Toronto: Institute of Public Administration of Canada.

Dyck, Rand (1995). Provincial politics in Canada: towards the turn of the century. $3^{\text {rd }}$ edition. Scarborough, ON: Prentice Hall Canada.

Economist Intelligence Unit (EIU 2010). Digital economy rankings 2010: Beyond ereadiness. Available at http://graphics.eiu.com/upload/EIU_Digital_economy_rankings_2010_FINAL_WE B.pdf [Accessed December 3, 2010]

Eisenstein, Elizabeth (2005). The Printing Revolution in Early Modern Europe, $2^{\text {nd }}$ edition. New York: Cambridge University Press.

Eliot, T.S. (1934). The Rock. London: Faber \& Faber.

Ellul, Jacques (1964). The Technology Society. New York: Vintage Books. 
English, John (2002). The Role of the National Archives of Canada and the National Library of Canada. Report Submitted to the Honourable Sheila Copps. Ottawa: Department of Canadian Heritage.

Evans, Bryan (2008). "Capacity, Complexity and Leadership: Secretaries to Cabinet and Ontario's Project of Modernization at the Centre" in Patrice Dutil, editor. Searching for Leadership: Secretaries to Cabinet in Canada. Toronto: University of Toronto Press and Institute of Public Administration of Canada, pp. 121-160.

Evans, Bryan, Janet Lum and John Shields (Evans et al. 2007). "Research Note: Profiling of the public-service élite: A demographic and career trajectory survey of deputy and assistant deputy ministers in Canada" in Canadian Public Administration, vol. 50 no. 4 (Winter 2007): 609-634.

Feather, John, editor (2004). Managing Preservation for Libraries and Archives: Current Practice and Future Developments. Aldershot, England: Ashgate Publishing Limited.

Flanagan, Tom (2007). Harper's Team: Behind the Scenes in the Conservative Rise to Power. Montreal and Kingston: McGill-Queen's University Press.

Fleck, James D. (1972). "Recent developments in public administration: Reorganization of the Ontario government" in Canadian Public Administration, vol. 15, no. 2 (June 1972): $383-385$.

Fleck, James D. (1973). "Restructuring the Ontario Government" in Canadian Public Administration, vol. 16, no. 1 (June 1973): 55-68.

Flumian, Maryantonett, Amanda Coe and Kenneth Kernaghan (Flumian et al. 2007). "Transforming service to Canadians: the Service Canada model" International Review of Administrative Sciences, vol. 73, no. 4 (December 2007): 557-568.

Forster, Ben (1990). "Donald McInnes (MacInnes)" in Dictionary of Canadian Biography, vol. XII, 1891-1900: 631-634. Toronto: University of Toronto Press.

Fountain, Jane E. (2001). Building the Virtual State: Information Technology and Institutional Change. Washington, D.C.: Brookings Institute Press.

Franks, C.E.S. (2009). "The Unfortunate Experience of the Duelling Protocols: A Chapter in the Continuing Quest for Responsible Government in Canada" in O.P. Dwivedi, Tim A. Mau and Byron Sheldrick, editors. The Evolving Physiology of Government: Canadian Public Administration in Transition. Ottawa: University of Ottawa Press, pp. 118-150.

French, Richard D. (1980). How Ottawa Decides: Planning and Industrial PolicyMaking 1968-1980. Toronto: James Lorimer and Co.

Fyfe, Toby, Michael McConkey and Patrice Dutil (Fyfe et al. 2004). Reinventing Service: Processes and Prospects for Municipal Alternative Service Delivery. IPAC New Directions Series No. 14. Toronto: Institute of Public Administration of Canada.

Gagnon, Georgette and Dan Rath (1992). Not Without Cause: David Peterson's Fall From Grace. Toronto: Harper Perennial.

Gallouedec-Genuys, Françoise (1977). "The Influence of Informatics on the Centralization/Decentralization of the Administration" in Guy Braibant, editor. (1977). Informatics and Administration. Brussels: International Institute of Administrative Sciences. 
Gillies, Donald (1990). "Technological Determinism in Canadian Telecommunications: Telidon Technology, Industry and Government." in Canadian Journal of Communication, vol. 15, no. 2: 1-15.

Glassco, J. Grant (1956). "Certain Aspects of Taxation Relating to Investment in Canada by Non-Residents." Study prepared for the Royal Commission on Canada's Economic Prospects (Gordon Commission). Ottawa: Queen's Printer.

Glenn, Ted (2005). "Politics, Personality and History in Ontario's Administrative Style" in Luc Bernier, Keith Brownsey and Michael Howlett, editors. Executive Styles in Canada: Cabinet Structures and Leadership Practices in Canadian Government. Toronto: University of Toronto Press: 155-170.

Goldenberg, Eddie (2006). The Way It Works: Inside Ottawa. Toronto: McLelland \& Stewart.

Good, David A. (2003). The Politics of Public Management: The HRDC Audit of Grants and Contributions. Toronto: University of Toronto Press.

Good, David A. (2007). The Politics of Public Money: Spenders, Guardians, Priority Setters, and Financial Watchdogs. Toronto: University of Toronto Press.

Gordon, Walter L. (1977). Walter Gordon: A Political Memoir. Toronto: McClelland \& Stewart.

Gow, James Iain and J.E. Hodgetts (2003). "Where are we coming from? Are there any useful lessons from our administrative history?" in Canadian Public Administration, vol. 46 no. 2 (Summer 2003): 178-201.

Graham, Andrew (2007). Canadian Public-Sector Financial Management. Montreal and Kingston: McGill-Queen's University Press

Granatstein, J.L. (1982). The Ottawa Men: The Civil Service Mandarins 1935-1957. Toronto: Oxford University Press.

Grimard, Jacques (2005). "Managing the Long-term Preservation of Electronic Archives or Preserving the Medium and the Message" in Archivaria 59 (Spring 2005): 153167.

GTEC (2010). GTEC Website at http://www.gtec.ca/ [Accessed December 6, 2010]

Hartle, Douglas G. (1973). "A proposed system of program and policy evaluation" in Canadian Public Administration, vol.16, no. 2 (June 1973): 243-266

Hartle, Douglas G. (1983). "An open letter to Richard Van Loon (with a copy to Richard French)" in Canadian Public Administration, vol. 26, no. 1 (March 1983): 84 -94.

Harvard University. Berkman Centre for Internet and Society (2010). Next Generation Connectivity: A review of broadband Internet transitions and policy from around the world. Available at http://cyber.law.harvard.edu/sites/cyber.law.harvard.edu/files/Berkman_Center_Bro adband_Final_Report_15Feb2010.pdf [Accessed December 3, 2010]

Havelock, Eric A. (1982). The Literate Revolution in Greece and Its Cultural Consequences. Princeton: Princeton University Press.

Hazell, Robert and Ben Worthy (2010). "Assessing the performance of freedom of information" in Government Information Quarterly, vol. 27, no. 4 (October 2010): $352-359$.

Heeney, A.D.P. (1946). "Cabinet Government in Canada: Some Recent Developments in the Machinery of the Central Executive" in Canadian Journal of Economics and Political Science, vol. 12 (Aug. 1946): 282-301. 
Heintzman, Ralph and Brian Marson (2005). "People, service and trust: is there a public sector service value chain?" International Review of Administrative Sciences, vol. 71, no. 4 (December 2005): 549-575.

Hicks, Michael (1973). "The Treasury Board of Canada and its clients: five years of change and administrative reform 1966-71" in Canadian Public Administration, vol. 16, no. 2, (Summer 1973): 182-205

Hodgetts, J.E. (1955). Pioneer Public Service: the administrative history of the United Canadas. Toronto: University of Toronto Press.

Hodgetts, J.E. (1973). The Canadian Public Service: A Physiology of Government, 1867-1970. Toronto: University of Toronto Press.

Hodgetts, J.E. (1995). From Arm's Length to Hands-on: the Formative Years of Ontario's Public Service, 1967-1940. Toronto: University of Toronto Press.

Hodgetts, J.E., William McCloskey, Reginald Whittaker and V. Seymour Wilson (Hodgetts et al. 1972). The Biography of an Institution: The Civil Service Commission of Canada 1908-1967. Montréal and Kingston: McGill-Queen's University Press.

Hogan, John (2006). "Remoulding the Critical Junctures Approach" in Canadian Journal of Political Science, vol. 39, no. 3 (September 2006): 657-679.

Hogan, John and David Doyle (2007). "The Importance of Ideas: An A Priori Critical Juncture Framework" Canadian Journal of Political Science, vol. 40, no.4 (December 2007): 883-910.

Howlett, Karen (2009). " $\$ 30,000$ for 78 hours: Scandal grows at eHealth Ontario" in Toronto Globe and Mail, June 8, 2009.

Howlett, Michael, M. Ramesh and Anthony Perl (Howlett et al. 2009). Studying Public Policy: Policy Cycles \& Policy Subsystems, Third Edition. Don Mills: Oxford University Press.

Hume, L. J. (1958). "The Origins of the Haldane Report" in Australian Journal of Public Administration, vol. 17, no. 4 (December 1958): 344-352.

Innis, Harold A. (1950). Empire and Communications. Toronto: Oxford University Press.

Institute for Citizen Centred Service (ICCS 2010). Website at http://www.iccsisac.org/en/ [Accessed December 4, 2010]

International Council for Information Technology in Government Administration (ICA 2010). Website at http://www.ica-it.org/ [Accessed December 3, 2010].

International Telecommunications Union (ITU 2011). Technology Watch. Webpage at http://www.itu.int/en/ITU-T/techwatch/Pages/default.aspx [Accessed 18 April 2011]

Inwood, Gregory J. (2009). Understanding Canadian Public Administration: An Introduction to Theory and Practice, Third Edition. Toronto: Pearson Prentice Hall.

IT World Canada (2011). Website at: http://www.itworldcanada.com/ [Accessed April 19, 2011]

John, Peter (1998). Analysing Public Policy. London: Continuum.

John, Peter (2003). "Is there life after policy streams, advocacy coalitions, and punctuations: using evolutionary theory to explain policy change" Policy Studies Journal, vol. 31, no. 4 (November 2003): $481-498$.

Johnson, A.W. (1971). "Management theory and cabinet government" in Canadian Public Administration, vol. 14, no. 1, (Spring 1971): 73-81. 
Johnson, A.W. (1973). "The Treasury Board of Canada and the Machinery of Government of the 1970s" in Canadian Journal of Political Science, vol. 4, no. 3 (September 1971): 346-366.

Johnson, David (2011). Thinking Government: Public Administration and Politics in Canada, $3^{\text {rd }}$ Edition. Toronto: University of Toronto Press.

Johnson, J.K and P.B. Waits (1990). "Sir John Alexander Macdonald" in Dictionary of Canadian Biography, vol. XII 1891-1900. Toronto: University of Toronto Press and Québec: Les Presses de l'Université Laval, pp. 591-612.

Jordan, Michael (1999). “Ontario's Integrated Justice Project: profile of a complex partnership agreement" in Canadian Public Administration, vol. 42 no. 1 (Spring 1999): $26-41$.

Juillet, Luc and Ken Rasmussen (2008). Defending a Contested Ideal: Merit and the PSC of Canada 1908-2008. Ottawa: University of Ottawa Press.

Kennedy, Carole and Martha Foote (2001). 160 Years of the Canada Gazette, Ottawa, Public Works and Government Services. Available at http://www.gazette.gc.ca/cggc/book-livre/toc-tdm-eng.html [Accessed July 5, 2010]

Kernaghan, Kenneth (1991). "Career Public Service 2000: Road to renewal or impractical vision?" in Canadian Public Administration vol. 34 no. 4 (Winter 1991): $551-572$.

Kernaghan, Kenneth (1994). "The emerging public service culture: values, ethics, and reforms" in Canadian Public Administration, vol. 37 no. 4 (Winter 1994): 614 630.

Kernaghan, Kenneth (2005). "Moving Toward the Virtual State: Integrating Services and Service Channels for Citizen-Centred Service Delivery" in International Review of Administrative Sciences, vol. 71, no. 1 (March 2005): 119-131.

Kernaghan, Kenneth (2007a). "Beyond Bubble Gum and Goodwill: Integrating Service Delivery" chapter 4 in Sandford Borins, Ken Kernaghan, David Brown, Perri 6 and Fred Thompson (Borins et al. 2007). Digital State at the Leading Edge. Toronto: University of Toronto Press, pp. 102-136.

Kernaghan, Kenneth (2007b). "Moving Beyond Politics as Usual? Online Campaigning" chapter 7 in Sandford Borins, Ken Kernaghan, David Brown, Perri 6 and Fred Thompson (Borins et al. 2007). Digital State at the Leading Edge. Toronto: University of Toronto Press, pp. 183-223.

Kernaghan, Kenneth (2007c). "Making Political Connections: IT and Political Life" chapter 8 in Sandford Borins, Ken Kernaghan, David Brown, Perri 6 and Fred Thompson (Borins et al. 2007). Digital State at the Leading Edge. Toronto: University of Toronto Press, pp. $224-252$.

Kernaghan, Kenneth and Justin Gunraj (2004). "Integrating information technology into public administration: Conceptual and practical considerations" in Canadian Public Administration, vol. 47, no. 4 (Winter 2004): 525-46.

Kernaghan, Kenneth and David Siegel (1999). Public Administration in Canada: A Text, $4^{\text {th }}$ Edition. Scarborough, Ontario: ITP Nelson.

Kingdon, John (1995). Agendas, Alternatives and Public Policies, $2^{\text {nd }}$ ed., New York: Harper Collins.

Kurose, James F. and Keith W. Ross (2008). Computer Networking: A Top-Down Approach, $4^{\text {th }}$ Edition. Boston: Pearson Addison-Wesley. 
Kushchu, Ibrahim, editor (2007). Mobile Government: An Emerging Direction in EGovernment. Hershey PA: IGI Global. Pp. 429.

Kushchu, Ibrahim and M. Halid Kuscu (2003). "From E-government to M-government: Facing the Inevitable" in Frank Bannister and Dan Remenyi, editors. Proceedings of the Third European Conference on e-Government, 3-4 July 2003, Trinity College, Dublin Ireland. Available on Mobile Government Website: http://www.mgovernment.org/resources/ [Accessed March 21, 2011]

Langford, John and Yvonne Harrison (2001). "Partnering for e-government: Challenges for public administrators" in Canadian Public Administration, vol. 44 no. 4 (Winter 2001): $393-416$.

Lecours, André (2005). "New Institutionalism: Issues and Questions" in André Lecours, editor. New Institutionalism: Theory and Analysis. Toronto: University of Toronto Press, pp. 3-25.

Lenihan, Don, Tony Valeri and David Hume (Lenihan et al. 2002). Information as a Public Resource: Leading Canadians in the Information Age. Ottawa: Centre for Collaborative Government.

Liberal Party of Canada (1993). Creating Opportunity: The Liberal Plan for Canada (Red Book). Ottawa: Liberal Party of Canada.

Lindquist, Evert, editor (2000). Government Restructuring and Career Public Services. Toronto: Institute of Public Administration.

Lindquist, Evert (2004). "Strategy, Capacity and Horizontal Governance: Perspectives from Australia and Canada" in Policy Options, Vol. 34, Issue 4 (December 2004): $2-12$.

Lindquist, Evert (2006). A Critical Moment: Capturing and Conveying the Evolution of the Canadian Public Service. Ottawa: Canada School of Public Service.

Lindquist, Evert A. and Graham White (1994). "Streams, springs and stones: Ontario public service reform in the 1980s and the 1990s" in Canadian Public Administration, vol. 37 no. 2 (Summer 1994): 267-301.

Macdonald, David (2011). The Shadow Public Service: The swelling ranks of federal government outsourced workers. Ottawa: Canadian Centre for Policy Alternatives.

MacDonald, Donald C., editor (1975). Government and Politics of Ontario. Toronto: The Macmillan Company of Canada Limited.

Mallory, J.R. (1971). The Structure of Canadian Government. Toronto: Macmillan of Canada, Ltd.

Mallory, J. R. (1973). "Restructuring the Government of Ontario: a comment" in Canadian Public Administration, vol. 16, no. 1 (Spring 1973): 69-72.

Malloy, Jonathan (2001). "Double Identities: Aboriginal Policy Agencies in Ontario and British Columbia" in Canadian Journal of Political Science, vol. 34, no. 1, (March 2001): $131-155$

Malloy, Jonathan (2003a). Between Colliding Worlds: The Ambiguous Existence of Government Agencies for Aboriginal and Women's Issues. Toronto: University of Toronto Press Institute of Public Administration of Canada Series in Public Management and Governance.

Malloy, Jonathan (2003b). To better serve Canadians: How technology is changing the relationship between members of Parliament and public servants. New Directions No. 9. Toronto: Institute of Public Administration of Canada. 
Mancke, Elizabeth (1999). "Early Modern Imperial Governance and the Origins of Canadian Political Culture" in Canadian Journal of Political Science, vol. 32, no. 1 (March 1999): 3-20.

Marson, Brian (2005). “Organizational Alzheimer's: A Quiet Crisis?” in Canadian Government Executive, vol. 11, no. 4 (2005): 16-18.

Marson, Brian and Ralph Heintzman (2009). Research to Results: A Decade of ResultsBased Service Improvement in Canada. Toronto: Institution of Public Administration of Canada.

Martin, Don (2010). "Defending access, if not practising it" in The Ottawa Citizen, April 14, 2010.

May, Catherine (2009). "Tech firms at war over federal plan" in The Ottawa Citizen, 20 April, 2009, pg. A-1.

McConkey, Michael and Patrice Dutil (2006). The Top Ten Topics in Public Administration Scholarship: An International Perspective. New Directions No. 19. Toronto: Institute of Public Administration of Canada.

McDonald, John (2002). The Financial Capability Model and the Records Management Function: An Assessment. Ottawa: Public Policy Forum.

McIntosh, Robert J. (1991). "Note: Public Service 2000: the employee perspective" in Canadian Public Administration vol. 34 no. 3 (Fall 1991): 503-511.

McNutt, Kathleen (2006). "Research Note: Do Virtual Policy Networks Matter? Tracing Network Structure Online" in Canadian Journal of Political Science, vol. 39, no. 2 (June 2006): 391 - 405.

McNutt, Kathleen and Meaghan Carey (2008). Canadian Digital Government. Public Policy Paper 57. Regina: The Saskatchewan Institute of Public Policy.

MERX (2010). "Canadian Public Tenders: Federal, Provincial and Municipal." Website at: http://www.merx.com/ [Accessed 3 December, 2010]

Mitchell, James R. (2002). "Changing the Machinery of Government" on Sussex Circle webpage Ideas at Sussex Circle. http://www.sussexcircle.com/pdf/002MachineryofGovt.pdf [Accessed 28 February 2010]

Mitchell, James R. and Sharon Sutherland (1999). "Ministerial Responsibility: The Submission of Politics and Administration to the Electorate" in Martin Westmacott and Hugh Mellon, editors. Public Administration and Policy: Governing in Challenging Times. Scarborough: Prentice Hall, 1999, pp. 21-37.

Morton, Bruce and Steven D. Zink (1991). "Contemporary Canadian federal information policy" in Canadian Public Administration, vol. 34, no. 2 (June 1991): 312-338.

Murray, Jean-Paul (1988). Information Canada 1970-76. Carleton University MA thesis (unpublished).

Negroponte, Nicholas (1995). being digital. New York: Vintage Books.

Oliver, E. Lynn and Larry Sanders, editors (2004). E-Government Reconsidered:

Renewal of Governance for the Knowledge Age. Regina, Canadian Plains Centre and the Saskatchewan Institute of Public Policy.

O'Neal, Brian R. (2004). "A Summary of Evidence Related to Chapter 3 (the Sponsorship Program), Chapter 4 (Advertising Activities), and Chapter 5 (Management of Public Opinion Research) of the November 2003 Report of the Auditor General of Canada for the Period up to 2 April, 2004 Prepared for the House 
of Commons Standing Committee on Public Accounts" Ottawa: Library of Parliament Parliamentary Research Branch.

Ontario. Commission on Freedom of Information and Individual Privacy (Williams Commission) (1980) Public Government for the People: Vol. 1, Report; Vol. 2 Freedom of Information; Vol. 3 Protection of Privacy. Toronto: Queen's Printer for Ontario.

Ontario. Committee on the Organization of Government in Ontario, Walter L. Gordon, Chair (Gordon 1959). Report of the Committee. Toronto: Queen's Printer for Ontario.

Ontario. Committee on Government Productivity (Cronyn). Toronto: Queen's Printer for Ontario.

(1970). Interim Report Number 1: Progress Report and Interim Recommendations. (1971a). Interim Report Number 2: A Progress Report and Interim Recommendations to Executive Council.

(1971b). Interim Report Number 3: Report on the Structure of Government: Interim Recommendations to Executive Council.

(1971c). Interim Report Number 4: Progress Report to Executive Council.

(1972a). Interim Report Number 5: Report to Executive Council on Automatic Data Processing.

(1972b). Interim Report Number 6: Report to Executive Council on the Utilization of Human Resources in the Ontario Public Service.

(1972c). Report Number 7: Report to Executive Council on Communications and Information Services.

(1972d). Working Paper: Citizen Involvement.

(1972e). Report Number 8: Report to Executive Council on Real Property Management.

(1973a). Report Number 9: Report to the Executive Council of the Government of Ontario.

(1973b). Report Number 10: A Summary.

Ontario Committee on Taxation (Smith 1967). Report: vol. 1 Approach, Background and Conclusions; vol. 2 The Local Revenue System; vol. 3, The Provincial Revenue System. Toronto: the Queen's Printer for Ontario.

Ontario Public Service Restructuring Secretariat. Toronto: Ontario Public Service

Restructuring Secretariat.

(1997). Framework for Action 1997: Building the OPS for the Future.

(1998). A Quality Service Organization, Framework for Action 1998: Building the Ontario Public Service for the Future.

(1999). A Learning Organization, Framework for Action 1999: Building the

Ontario Public Service for the Future.

(2000a). Transforming Public Service for the $21^{\text {st }}$ Century: An Ontario Perspective. (2000b). An Integrated Organization, Framework for Action 2000: Building the

Ontario Public Service for the Future.

(2001). Good People Doing Great Jobs, Framework for Action 2001: Building the Ontario Public Service for the Future.

(2002). The Innovation Culture: Framework for Action 2002: Building the Ontario Public Service for the Future. 
Ontario. Special Task Force on the Management of Large-Scale Information and Information Technology Projects, Denis Desautels, chair (Desautels 2005). Report of Ontario's Special Task Force on the Management of Large-Scale Information \& Information Technology Projects. Toronto: Queen's Printer for Ontario.

Organisation for Economic Cooperation and Development (OECD 1980). OECD Guidelines on the Protection of Privacy and Transborder Flows of Personal Data. Available at http://www.oecd.org/document/18/0,3343,en_2649 $34255 \quad 1815186 \quad 1 \quad 1 \quad 1 \quad 1,00 . h$ tml [Accessed November 25, 2010]

Organisation for Economic Cooperation and Development (OECD 2003). The egovernment imperative: main findings. Report of the E-Government Working Group. Paris: OECD Publishing.

Organisation for Economic Cooperation and Development (OECD 2009). Government at a Glance. Paris: OECD Publishing. Available at http://www.oecd.org/document/33/0,3746,en_2649 $37405 \quad 43714657 \quad 1 \quad 1 \quad 1 \quad 3740$ 5,00.html [Accessed January 12, 2011]

Osbaldeston, Gordon F. (1989). Keeping Deputy Ministers Accountable. Toronto \& Montreal: McGraw-Hill Ryerson.

Osbaldeston, Gordon F. (1992). Organizing to Govern, vol. 2. Toronto: McGraw-Hill Ryerson.

Osborne, Brian S. and Robert M. Pike (1994). "Lowering the Walls of Oblivion: The Revolution in Postal Communications in Central Canada: 1851-1911" in Donald H. Akenson, editor. Canadian Papers in Rural History, vol. 4: 200-225.

Pal, Leslie A. (2006). Beyond Policy Analysis: Public Issue Management in Turbulent Times, $3^{\text {rd }}$ edition. Thomson Nelson.

Pal, Leslie A. and David Taras, editors (1988). Prime Ministers and Premiers: Political Leadership and Public Policy in Canada. Scarborough, ON: Prentice-Hall Canada, Inc.

Parenteau, Roland (1992). Le management public: comprendre et gérer les institutions de l'État. Québec, Presses de l'Université du Québec.

Paton, Richard and Christiane Dodge (1995). "Reinventing administrative policies for the 1990s: Administrative policy reform in Canada" in International Journal of Public Sector Management, Vol. 8, Issue 2: 6-18.

Paulk, Mark C., Bill Curtis, Mary Beth Chrissis and Charles V. Weber (Paulk et al. 1993). Capability Maturity Model for Software, version 1.1. Pittsburgh: Software Engineering Institute, Carnegie-Mellon University.

Pearson, Lester B. (1975). Mike: The Memoirs of the Rt. Hon. Lester B. Pearson, Volume Three 1957-1968. Edited by John A. Munro and Alex I. Inglis. Toronto and Buffalo: University of Toronto Press.

Phillips, Susan D. and Karine Levasseur (2004). "The snakes and ladders of accountability: Contradictions between contracting and collaboration for Canada's voluntary sector" in Canadian Public Administration vol. 47 no. 4 (Winter 2004): $451-475$.

Pollitt, Christopher (1990). Managerialism and the Public Services: The Anglo-American Experience ( $2^{\text {nd }}$ ed.). Oxford: Basil Blackwell, Inc. 
Pollitt, Christopher (1998). "Managerialism Revisited" in Guy B. Peters and Donald J. Savoie, editors. Taking Stock: Assessing Public Sector Management Reforms. Ottawa: Canadian Centre for Management Development.

Pross, A. Paul (2009). "Law and Innovation: The Incremental Development of Canadian Lobby Regulation" in O.P. Dwivedi, Tim A. Mau and Byron Sheldrick, editors. The Evolving Physiology of Government: Canadian Public Administration in Transition. Ottawa: University of Ottawa Press, pp. 151-188.

Pugliese, David (2010). "(No) Access to information: Stephen Harper promised to lift the cloak of secrecy from government. Five years on, critics say we know less about it than ever" in The Ottawa Citizen, May 8, 2010.

Rae, Bob (1996). From Protest to Power: Personal Reflections on a Life in Politics. Toronto: Viking.

Rae, K.J. (1985). The Prosperous Years: The Economic History of Ontario, 1939-1975. The Ontario Historical Studies Series. Toronto: University of Toronto Press.

Rasmussen, Ken (1994). "Administrative Reform and the Quest for Bureaucratic Autonomy: 1867-1918," Journal of Canadian Studies, vol. 29, Issue 3 (Fall 1994): $45-62$.

Rasmussen, Ken (2009). "Robert Borden and the Rise of the Managerial Prime Minister in Canada." Paper presented at the annual meeting of the Canadian Political Science Association, Ottawa, May 2009.

Rasmussen, Ken and Luc Juillet (2009). "The Origins of Merit in Canada" in O.P. Dwivedi, Tim A. Mau and Byron Sheldrick, editors. The Evolving Physiology of Government: Canadian Public Administration in Transition. Ottawa: University of Ottawa Press, pp. $74-96$.

Rawson, Bruce (1991). "Public Service 2000 Service to the Public Task Force: findings and implications" in Canadian Public Administration vol. 34 no. 3 (Fall 1991): $490-500$.

Reid, John M. (2004). "Holding Governments Accountable by Strengthening Access to Information Laws and Information Management Practices" in E. Lynn Oliver and Larry Sanders, editors. E-Government Reconsidered: Renewal of Governance for the Knowledge Age. Regina, Canadian Plains Centre and the Saskatchewan Institute of Public Policy: 79-88.

Roberts, Alasdair (1995). So-called experts: How American Consultants Remade the Canadian Civil Service 1918-21. Toronto: Institute of Public Administration of Canada.

Roberts, Alasdair S. (2005). "Spin Control and Freedom of Information: Lessons from the United Kingdom and Canada" in Public Administration, vol. 83, no. 1 (March 2005): 1 - 23 .

Roberts, Alasdair (2006). "Two Challenges in the Administration of the Access to Information Act" in Canada, Commission of Inquiry into the Sponsorship Program and Advertising Activities, II. Research Studies. Ottawa: Public Works and Government Services Canada, pp. 115-162.

Roberts, Alasdair (2010). "A Fragile State: Federal Public Administration in the Twentieth Century" in Christopher Dunn, editor. The Handbook of Canadian Public Administration, $2^{\text {nd }}$ Edition. Don Mills: Oxford University Press, pp. 21934. 
Robertson, R. Gordon (1978). "Confidentiality in Government" in Archivaria 6 (Summer 1978): 3-11.

Robertson, R. Gordon (2000). Memoirs of a Very Civil Servant: Mackenzie King to Pierre Trudeau. Toronto: University of Toronto Press.

Rose, Jonathan W. (2000). Making "pictures in our heads:" Government advertising in Canada. Westport, CT: Praeger.

Rosell, Steven A. et al. (1993). Governing in an Information Society. Montreal: Institute for Research on Public Policy.

Rosell, Steven A. et al. (1995). Changing Maps: Governing in a World of Rapid Change. Don Mills: Oxford University Press Canada.

Rowland, Wade (2006). Spirit of the Web: The Age of Information from Telegraph to Internet. Toronto: Thomas Allen Publishers.

Rowley, Jennifer (1998). "What is information?" in Information Services \& Use, Vol. 18, Issue 4 (1998): 243-54.

Rowley, Jennifer (2007). "The wisdom hierarchy: representations of the DIKW hierarchy" in Journal of Information Science, vol. 33, no. 2 (April 2007): 163180.

Roy, Jeffrey (2006). E-Government in Canada: Transformation for the Digital Age. Ottawa: University of Ottawa Press.

Roy, Jeffrey (2008). "Beyond Westminster governance: Bringing politics and public service into the networked era" in Canadian Public Administration, vol. 51, no. 4 (December 2008): 541-568.

Russell, Peter H., editor (1965). Leading Constitutional Decisions: Cases on the British North America Act. Toronto: McClelland and Stewart.

Sabatier, Paul and Jenkins-Smith H.C., editors (1993). Policy Change and Learning. Boulder, Col.: Westview.

Saint-Martin, Denis (2000). Building the New Managerialist State: Consultants and the Politics of Public Sector Reform in Comparative Perspective. Oxford, New York: Oxford University Press.

Saul, John Ralston (2008). A Fair Country: Telling Truths About Canada. Toronto: Viking Canada

Savoie, Donald J. (1993). Taking Power: Managing Government Transition. Toronto: Institute of Public Administration of Canada.

Savoie, Donald J. (1999). Governing from the centre: the concentration of power in Canadian politics. Toronto: University of Toronto Press.

Savoie, Donald J. (2003). Breaking the Bargain: Public Servants, Ministers and Parliament. Toronto: University of Toronto Press.

Savoie, Donald J. (2008). Court Government and the Collapse of Accountability in Canada and the United Kingdom. Toronto: University of Toronto Press.

Schacter, Harvey (1999). Crossing Boundaries: Privacy, Policy, and Information Technology. IPAC New Directions Series No. 5. Toronto: Institute of Public Administration of Canada.

Schaffer, B. B. (1958). "Theory and Practice in the Machinery of Government" in Australian Journal of Public Administration, vol. 17, no. 4 (December 1958): 353-368. 
Schindeler, F.F. (1969). Responsible Government in Ontario. Toronto: University of Toronto Press.

Schindeler, Fred (1971). "The Prime Minister and the Cabinet: History and Development" in Thomas A. Hockin, editor. Apex of Power: The Prime Minister and Political Leadership in Canada. Scarborough, Ont.: Prentice-Hall of Canada Ltd., pp. $22-49$.

Schmitz, Gerald (1994). "Reorganizing Government: The Reform Debate in Perspective." Ottawa: Library of Parliament, Political and Social Affairs Division, January 1994.

Schultz, Richard J. and Mark R. Brawley (1996). "Telecommunications Policy" in G. Bruce Doern, Leslie A. Pal and Brian W. Tomlin, editors. Border Crossings: The Internationalization of Canadian Public Policy. Toronto, Oxford University Press: 82-107.

Simpson, Richard (1997). "Making government a "model user' of the Information Highway - Canada's progress to date" in Public Administration and Development, vol. 17: 103-107. London, John Wiley \& Sons.

Smith, David E. (2005). "Clarifying the Doctrine of Ministerial Responsibility as it Applies to the Government and Parliament of Canada" in Canada. Commission of Inquiry into the Sponsorship Program and Advertising Activities, II. Research Studies. Ottawa: Public Works and Government Services Canada, pp. 101-143.

Snellen, I.Th.M. and W.B.H.J. van de Donk (1998). Public Administration in an Information Age: A Handbook. Amsterdam: IOS Press.

Stacey, C.P. (1951). "Canadian Archives." Royal Commission Studies; A Selection of Essays Prepared for the Royal Commission on National Development in the Arts, Letters and Sciences. Ottawa: King's Printer, pp. 231-248.

Steele, I.K. (1968). Politics of Colonial Policy: The Board of Trade in Colonial Administration 1696-1720. Oxford: Clarendon Press.

Subramaniam, V. (1968). "Machinery of Government Investigations: Fifty Years After the Haldane Report" in Australian Journal of Public Administration, vol. 27, no. 3 (September 1968): 268-273.

Sutherland, S.L. (1980). "On the audit trail of the Auditor General: Parliament's servant, 1973-1980" in Canadian Public Administration, vol. 23 no. 4 (Winter 1980): 616644.

Sutherland, Sharon (1993). "The Public Service and Policy Development" in Michael Atkinson, editor., Governing Canada: Institutions and Public Policy. Toronto: Harcourt Brace Jovanovich Canada Inc., pp. 81-113.

Tait, John (1997). "A Strong Foundation: Report of the Task Force on Public Service Values and Ethics (the summary)" in Canadian Public Administration, vol. 40, no. 1 (Spring 1997): 1 -22.

Tapscott, Don (1996). The Digital Economy: Promise and Peril in the Age of Networked Intelligence. New York: McGraw-Hill.

Tapscott, Don (1997). "The digital media and the reinvention of government" in Canadian Public Administration, vol. 40 no. 2 (Summer 1997): 328-345.

Tapscott, Don and Art Caston (1993). Paradigm Shift: The New Promise of Information Technology. New York, McGraw-Hill. 
Tapscott, Don and Anthony D. Williams (2006). Wikinomics: How Mass Collaboration Changes Everything. New York and Toronto: Portfolio.

Tellier, Paul M. (1990). "Public Service 2000: the renewal of the public service" in Canadian Public Administration vol. 33 no. 2 (Summer 1990): 123-132.

Tellier, Paul M. (1992). Public Service 2000: A Report on Progress. Ottawa: Minister of Supply and Services.

Thelen, Kathleen and Sven Steinmo (1992). "Historical Institutionalism in Comparative Perspective" in Sven Steinmo, editor. Structuring Politics: Historical Institutionalism in Comparative Analysis. Cambridge: Cambridge University Press.

Thomas, Paul (2009). "Trust, Leadership, and Accountability in Canada's Public Sector" in O.P. Dwivedi, Tim A. Mau and Byron Sheldrick, editors. The Evolving Physiology of Government: Canadian Public Administration in Transition. Ottawa: University of Ottawa Press, pp. 215-248.

Tunnoch, G.V. (1964). "The Glassco Commission: Did it cost more than it was worth?" in Canadian Public Administration, vol. 7 no. 3 (September 1964): 389-397.

Tunnoch, G.V. (1965). "The Bureau of Government Organization: Improvement by Order-in-Council, Committee and Anomaly" in Canadian Public Administration, vol. 8 no. 4 (Winter 1965): 558-568.

United Kingdom. HM Treasury (UK HMT n/d). "The Treasury Board" on HM Treasury Website: http://www.hm-treasury.gov.uk/about treasury board.htm [Accessed April 17, 2010]

United Kingdom. Ministry of Reconstruction. Machinery of Government Committee, Viscount Haldane, Chairman (Haldane 1918). Report of the Machinery of Government Committee, Cmd 9230. London: HMSO.

United Nations Organization. UN Public Administration Programme (UNPAN 2010). United Nations E-Government Survey 2010. Available at http://www2.unpan.org/egovkb/global_reports/10report.htm [Accessed December 3, 2010].

Veilleux, Gérard and Donald J. Savoie (1988). "Kafka's Castle: The Treasury Board of Canada revisited" in Canadian Public Administration, vol. 31 no. 4 (Winter 1988): 517-538.

Waite, P.B. (2005). "Sir Joseph Pope" in Dictionary of Canadian Biography, vol. XV (1921-1930). Toronto: University of Toronto Press, pp. 842-846.

West, Darrell M. (2008). Improving Technology Utilization in Electronic Government Around the World, 2008. Washington: The Brookings Institution. Available at http://www.brookings.edu/ /media/Files/rc/reports/2008/0817_egovernment_west/ 0817 egovernment_west.pdf [Accessed December 3, 2010]

White, Graham (1990). "Big is different from little: on taking size seriously in the analysis of Canadian governmental institutions" in Canadian Public Administration, vol. 33 no. 4 (Winter 1990): 526-550.

White, Graham, editor (1997). The Government and Politics of Ontario, 5th edition. Toronto: University of Toronto Press.

White, Graham (2002). "Change in the Ontario State." Paper presented to the Role of Government Panel, October 2002.

White, Graham (2005). Cabinets and First Ministers. Vancouver: UBC Press. 
White, Walter L. (1965). The Treasury Board in Canada. $\mathrm{PhD}$ dissertation. Ann Arbor: University of Michigan.

White, Walter L. (1967). "The Treasury Board in Nineteenth Century Canada" in Queen's Quarterly, vol. 74 (Autumn 1967): 492-505.

White, W.L. and J.C. Strick (1970). Policy, Politics and the Treasury Board in Canadian Government. Don Mills, Ontario: Science Research Associates (Canada) Limited.

Whorley, David (2001). "The Anderson-Comsoc affair: Partnerships and the public interest" in Canadian Public Administration, vol. 44 no. 3 (Fall 2001): 320-345.

Wilson, Ian E. (1982). "“A Noble Dream'? The Origins of the Public Archives of Canada" Archivaria, vol. 15 (Winter 1982-83): 16-35.

Wouters, Wayne G. (2010). Seventeenth Annual Report to the Prime Minister on the Public Service of Canada for the Year Ending March 31, 2010. Ottawa: Privy Council Office.

Yin, Robert K. (2003). Case Study Research: Design and Methods, Third Edition. Thousand Oaks, Calif:: Sage Publications.

Zins, Chaim (2007). "Conceptual Approaches for Defining Data, Information, and Knowledge" in Journal of the American Society for Information Science and Technology, vol. 58, no. 4 (February 2007): 479-493.

\section{Interviews cited}

Annan, Fawn (2009).Vice President and Chief Strategist, ITWorld Canada. Interview 6 March, 2009.

Ansari, Terry (2009). Vice President, Business Solutions Group, Cisco Systems Canada. Interview 8 May, 2009

Binder, Michael (2008). Former Assistant Deputy Minister Spectrum Information Technology and Telecommunications, Industry Canada. Interview 24 November, 2008.

Campbell, Scott (2009). Ontario Corporate Chief Information Officer 1998-2002; later British Columbia Chief Information Officer. Interview 1 May, 2009.

Clark, Ian D. (2008). Secretary of Treasury Board 1989-94. Interview 13 November, 2008.

Claydon, Frank (2009). Secretary of Treasury Board, 2000-2002. Interview 26 March, 2009.

Darling, Alan J. (2010). Assistant Secretary, Machinery of Government, Privy Council Office 1976-1979. Interview 30 March, 2010.

Flumian, Maryantonnett (2009) - Former Chief Operating Officer, Service Canada; former Executive Director, Firearms Registry. Interview 8 April 2009.

Giroux, Robert (2009). Secretary of Treasury Board 1994-96. Interview 13 January, 2009.

Harder, Peter (2009). Secretary of Treasury Board 1996-2000. Former Deputy Minister of Citizenship and Immigration, of Industry and of Foreign Affairs and International Trade and Chair of TIMS. Interview 15 January 2009.

Judd, Jim (2009). Secretary of Treasury Board 2002-05. Interview 26 February, 2009. Keefe, Greg (2009). Deputy Minister, Treasury Board and Chief Information Officer, Government of Nova Scotia. Interview 9 July, 2009. 
Kent, Oliver (2009). Former National Partner, e-government, IBM/PriceWaterhouseCoopers. Interview 3 February, 2009.

Krupka, Ivo (2010). Officer, Privy Council Office, 1966-1972. Interview 21 April, 2010. Little, Bob (2008). Deputy Secretary Financial and Information Management Branch (Chief Information Officer), Treasury Board Secretariat 1995-97. Interview 7 November, 2008.

Macdonald, Andy (2008). Comptroller-General of Canada and Chair of TIMS 19911993, Chief Informatics Officer, Treasury Board Secretariat 1993-1995. Interview 22 October, 2008.

McKerlie, Ron (2008). Government of Ontario: Deputy Minister of Management Board Secretariat; Corporate Chief Information Officer, Management Board Secretariat 2005-2008. Interview 12 November, 2008.

Mitchell, Jim (2008). Managing Partner, Sussex Circle. Assistant Secretary, Machinery of Government, Privy Council Office 1988-94. Interview 19 November, 2008.

Paton, Richard (2008). Deputy Secretary, Administrative Policy Branch, Treasury Board Secretariat 1989-1994. Interview 18 September, 2008.

Richard, Elisabeth (2009). Information Technology Services Branch, Public Works and Government Services Canada. Interview 22 April, 2009.

Riddle, John (2009). Director, Information Technology Policy, Administrative Policy Branch, Treasury Board Secretariat 1991-1994. Interview 25 March, 2009.

Rummell, Paul (2008). Chief Information Officer Treasury Board Secretariat 1997-98. Interview 28 November, 2008.

Sékaly, Gabriel (2008). Chief Executive Officer, Institute of Public Administration of Canada; former Associate Deputy Minister of Finance, Government of Ontario. Interview 13 November, 2008.

Senior official, Treasury Board Secretariat (2009). Interview 24 June, 2009.

Sinclair, Ian (2009). Senior Director, Information Policy, CIO Branch, Treasury Board Secretariat 1998-2006. Interview 28 January, 2009.

Smith, Gordon S. (2010). Director, Government Organization 1972-75, Senior Assistant Secretary, Machinery of Government 1975-1977, Deputy Secretary, Plans 1977-79, Privy Council Office. Interview 13 April, 2010.

Steinsky-Schwartz, Georgina (2008). Deputy Minister, Supply and Services Canada 1989-92 and Chair of TIMS. Interview 14 November, 2008.

Wilson, Ian E. (2009). National Archivist 1999-2004. Head, Library and Archives Canada 2004-2009. Former Provincial Archivist of Saskatchewan (1976-1986) and of Ontario (1986-1999). Interview 13 January, 2009.

Wouters, Wayne (2009). Secretary of Treasury Board 2005-09. Interview 29 January, 2009.

Yeomans, D.R. (2009). Director, Organization Research, Glassco Commission 19601963, Director, Bureau of Government Organization, 1963-1966, Deputy Secretary, Management Improvement Branch, Treasury Board Secretariat, 1966-1970. Interview 25 May, 2009.

Zussman, David (2008). Assistant Secretary, Program Review and Machinery of Government, Privy Council Office. Interview 25 November, 2008. 


\section{Annex 1: Treasury Board Chief Information Officers and Acting Chief Information Officers}

Since June 1993, seven individuals have held the Chief Information Officer (CIO) or an equivalent position and four others on an extended acting basis. All eleven have been organizationally located within the Treasury Board Secretariat, reporting directly to the Secretary of the Treasury Board.

The CIOs and Acting CIOs are listed below. Information is provided on their dates in the position, title, by whom they were appointed, previous position and where they went after leaving the CIO position.

1. Andy Macdonald (June 1993-January 1995) - Chief Informatics Officer

- Appointed by Ian Clark (TB Secretary 1989-1994)

- Previously Comptroller General of Canada

- Subsequently Chief Information Officer, Commonwealth of Australia

2. W.E.R. (Bob) Little (January 1995-November 1996) - Deputy Secretary, Financial and Information Management Branch

- Appointed by Robert Giroux (TB Secretary 1994-1996)

- Previously Assistant Deputy Minister, Finance and Administration, Human Resources Development Canada and Chair, Council on Administrative Renewal

- Retired in 1996, independent consultant

a. Bernard A. Gorman (November 1996-April 1997) - Assistant Secretary, Information Management Systems and Technology Sector

- Appointed by Peter Harder (TB Secretary 1996-2000)

- De facto Chief Information Officer while the position of Deputy Secretary, Financial and Information Management Branch was vacant

- Became Deputy Chief Information Officer with the establishment of the Chief Information Officer Branch in April 1997

- Retired in 1998, independent consultant

3. Paul Rummell (March 1997-late 1998) - Chief Information Officer, Chief Information Officer Branch

- Appointed by Peter Harder

- Interchange through the Information Technology Association of Canada

- Previously Partner, Thorne Riddell management consultants

- Returned to the private sector (currently UniSys)

4. Linda Lizotte-Macpherson (late 1998-June 2000) - Chief Information Officer

- Appointed by Peter Harder 
- Interchange through the Information Technology Association of Canada

- Previously senior executive in the private sector

- Subsequently Chief Executive Officer, Canada Health InfoWay

- Later returned as consultant to PWGSC, Associate Secretary of Treasury Board, head of Service Canada, and Commissioner, Canada Revenue Agency.

5. Michelle d'Auray (June 2000-June 2004) - Chief Information Officer

- Appointed by Frank Claydon (TB Secretary 2000-2002)

- Previously Executive Director, e-Commerce, Industry Canada

- Subsequently Deputy Minister, Economic Development Canada

- Later Deputy Minister, Fisheries and Oceans, Chief Human Resources Officer, Treasury Board Secretariat, and Secretary, Treasury Board Secretariat

b. Helen McDonald (June 2004-November 2005) - Acting Chief Information Officer

- Appointed by Jim Judd (TB Secretary 2002-2005)

- Previously Assistant Secretary, Government On-Line, Chief Information Officer Branch, TBS

- Subsequently Assistant Secretary, Economic Development Sector, Treasury Board Secretariat

- Later, Assistant Deputy Minister, Spectrum, Information Technology and Telecommunications, Industry Canada

c. Jim Alexander (November 2005-June 2006) - Acting Chief Information Officer

- Appointed by Wayne Wouters (TB Secretary 2005-2009)

- Previously Director, Chief Information Officer Branch, TBS

- Retired in 2006, Vice-President, Chartwell

6. Ken Cochrane (July 2006-December 2008) - Chief Information Officer

- Appointed by Wayne Wouters

- Interchange through the Information Technology Association of Canada

- Previously Assistant Commissioner, Information Technology Branch, Canada Revenue Agency, and CEO, Information Technology Services Branch, PWGSC (both on ITAC interchange)

- Independent consultant

d. Peter Bruce (January-May 2009) - Acting Chief Information Officer

- Appointed by Wayne Wouters

- Previously Deputy Chief Information Officer, Chief Information Officer Branch (appointed in September 2008, previously Chief Information Officer, Library and Archives Canada)

- Returned to position as Deputy Chief Information Officer

7. Corinne Charette (May 2009-present) - Chief Information Officer

- Appointed by Wayne Wouters

- Interchange through the Information Technology Association of Canada

- Previously Chief Information Officer, Air Transat 


\section{Annex 2: Dissertation Methodology}

This Annex has four sections. It begins with a discussion of the over-all research methodology adopted in the dissertation, based on Blaikie's understanding (Blaikie 2000) of empirical, qualitative research as a basis for data collection and processing. Blaikie's model is used to provide the context for a discussion, in the second section, of Yin's approach (Yin 2003) to a case study as a research strategy. The third section describes the data sources for the CIO case study. The final section notes the administrative aspects of the dissertation project.

\section{General research methodology}

The major research methodology issues relate to data sources and selection, and methods of data collection, reduction and analysis. The goal is to provide a basis for drawing inferences and conclusions; case studies, which are well suited to qualitative research, lend themselves to analytic generalization (Yin 2003: 31-33) and can provide the context for detailed ("thick") description of social processes and theory testing.

Blaikie starts with the social setting of the data collection (Blaikie 2000: 187-197). Three settings are relevant to the dissertation project: natural and semi-natural settings and social artefacts. Natural social settings include meso-social phenomena such as organizations and communities with a relatively enduring structure of relations and forms of authority and leadership. While their dynamics are an important part of the context for a phenomenon such as the CIO-defined environment, they are difficult to address directly and probably require the use of anthropological field research methods. The dissertation research instead draws on the other two approaches. 
In semi-natural settings, individuals are asked to "report either on their own or other people's activities, attitudes and motives, or on social processes and institutionalized practices" (191). This can include focusing on individuals: their demographic characteristics, orientation to the world and reported behaviour. More importantly, for the purposes of this discussion, individuals can be studied as "special persons," as representatives of a particular type of social actor, as an informant to report on beliefs, values, norms, social activities and possibly motives of participants in a larger group and as a non-probability sample from a population. Even individuals can be case studies, looking at their perceptions of the social world and reporting on their social experiences (192). The means of reporting can include both quantitative and qualitative methods, but the latter can include semi-structured interviews that, combined with other sources, allow the interviewer to get close to social meaning (234).

Social artefacts are traces of social activities left behind by research participants. These include both public records and private records of various kinds, the latter defined as records where there is no legal obligation to provide open access to them (196) - they are particularly important in historical research but can add useful detail to any description. Documents in any form provide an additional form of qualitative data and are useful in "indentifying phenomena among which patterns of relationships are established" (235).

Blaikie comments that an ontological dilemma in using any such sources is distinguishing between the social actor's (social) construction of reality and the researcher's (sociological) construction, recognizing that social actors and researchers do not necessarily see the world in the same way $(197-198)$. For the purposes of this 
dissertation, this is not treated as a major issue, however, as the institutions being looked at are largely visible and in the State realm, providing a common frame of reference for researcher and participant.

The goal of data collection is to provide a reliable understanding of events (203), based on a small population - such as the universe of CIO appointees - or a nonprobability sample of a larger population - for example, senior federal public servants. The question is therefore whether the data provided by such sources provide an adequate basis for data reduction, which in a project such as this one involves developing themes and constructing typologies with a view to description and theory generating (236-241). The test is whether the range of sources can be considered to provide a representative picture of the social phenomenon and the basis for drawing a range of possible generalizations and conclusions, which can, when applied to the CIO, be about: the phenomenon itself (e.g., the CIO and related universe); closely related phenomena (other areas of TBS responsibility and the Canadian Westminster system); similar positions elsewhere; other administrative systems; and institutions in general (203-206). Generalizations can also be across time, ranging from a view of what is to what may be (is likely to happen) and what could be (whether a goal is achievable) (255).

\section{Case studies}

While not confined to qualitative research, case studies are well suited to such an approach. At a minimum, they are, in Blaikie's view, a way of organizing social data so as to preserve the unitary character of the social object being studied - they regard the social unit as a whole, including its development over time, relationships and processes, 
focusing on the characteristics which are relevant to the scientific problem being investigated (215).

Yin goes further and treats a case study as a research strategy, an empirical enquiry involving an investigation with three characteristics: a contemporary phenomenon within its real-life context; when boundaries between phenomenon and context are not clearly evident (i.e., variables cannot easily be isolated for data collection and analysis purposes); and when multiple sources of evidence are used (Yin 2003: 13). Yin suggests three purposes for case studies: exploratory, descriptive and explanatory (3), while other authors add theory generation and testing and initiating change (Blaikie 2000: 213). Case studies can be either single or multiple - structured to permit comparative analysis - and they can be holistic (looking at a single unit of analysis) or embedded (looking at forces at more than one level although within a larger whole - the CIO, for example, is best understood as embedded in the Canadian Westminster and Treasury Board models). Single case studies can look at a critical case, to corroborate or challenge theory; at an extreme case as a test of the boundaries of theory; at a representative or typical case; at a phenomenon not studied before - a revelatory case; or at a case over time - a longitudinal case. They can also serve more than one goal (Yin 2003: 39-46). The ClO case has elements of all of these goals, although in the first instance it is a revelatory case of a phenomenon that has not been studied before in any depth.

The ability to generalize from a case study depends on its appropriateness and reliability in relation to the research objectives - on whether there is a basis for "analytical generalization" (Yin) or "replication logic" (Blaikie). This depends on having 
an adequate description of both the context of the case and of the theory that is being used to evaluate the conclusions (Blaikie 2000: 223-225).

\section{Data collection for the CIO case study}

The primary objective of the dissertation case study is to describe and analyze and, to the extent possible, explain - the introduction and evolution of the TBS CIO in the context of the collective governance of the Government of Canada. This has required assembling an appropriately detailed description of the position and related responsibilities, policies, horizontal mechanisms, functional communities and internal and external relationships, over time. A contextual account also needs to look at external and internal events, as well as personalities and ideas, both management and political.

In the nature of a case study, much of the empirical research is descriptive, seeking to provide an account of decision-making processes, policy implementation, and statements of goals and activities to provide evidence for the conclusions reached. An effort has also been made to record relevant organizational, personnel and policy changes. The descriptive material is primarily from government sources, including both material in the public domain and internal documents. The tertiary literature about the CIO and TBS also has a good deal of useful descriptive material, in particular with respect to historical developments leading up to the 1993 reorganization but also to developments since then, notably the CIO's first decade.

Primary research for the dissertation is drawn from two main sources: government documents, and elite key-informant interviews with participants in the events under discussion and with informed observers. As much as possible, documents and 
publications provide the basis for constructing a picture of what happened, while interviews were used to gauge perceptions and motivations. One of the minor themes of the dissertation, however, is the deterioration of records management in the federal government during the period in question, so in some cases the interviews have been relied upon for factual descriptions as well for more subjective commentary. The dimensions of the various types of data sources are discussed in greater detail below.

The dissertation is a single case study. While there is reference to experience in other comparable jurisdictions, as well as an exploration of the federal CIO's relationship with those counterparts, the case study is not comparative in nature. The one partial exception is that chapter 6 is a mini-case study of the Government of Ontario's experience with a Corporate $\mathrm{CIO}$, both because of the light it sheds on the federal approach and because of its influence on developments in the federal government. Jurisdictional comparisons are based primarily on published government material and academic commentary. Four interviews focused specifically on the Ontario experience, it was a major component of four others and it was discussed in varying degrees of detail in several other interviews.

\section{Government documents}

Federal government documents took two forms, internal records and material in the public domain. Internal records include memoranda and other material relating to decision-making and to internal administration; they also include internal communications material such as PowerPoint presentations, which came into prominence in the same period in the early 1990s that saw the emergence of the Internet. Internal records in the possession of government institutions are subject to the procedures (and 
costs) of the Access to Information Act and, in the case of material deemed to be of a personal nature, to the Privacy Act. Some documents have been obtained under Access to Information and Privacy (ATIP) procedures; others have also been obtained informally through interviewees or previous research projects on related subjects.

Apart from general problems with records management in the government that have been alluded to (and that are also discussed in chapter 5) there is a particular challenge with respect to records of high-level government decision-making, including Prime Ministerial decisions with respect to the machinery of government and Treasury Board decisions. Records with respect to all the government transitions in 1993 and since are currently under embargo at Library and Archives Canada. This is most problematic with respect to the June 1993 Campbell reorganization as even files containing material that is ostensibly in the public domain, such as press releases, are embargoed; this is a limitation on the account provided of the reorganization.

There is a great deal of government material available in the public domain. This includes a wide range of reports, speeches, publications and, after the late $1990 \mathrm{~s}$, website material. The one difficulty with respect to the latter is that government websites have gone through repeated updating, and not all web-published material has been adequately archived, especially when it relates to material posted under previous governments.

\section{Interviews}

Key informant interviews were conducted with 88 individuals, ${ }^{231}$ primarily between the Fall of 2008 and late Spring 2009. A list of the interviewees is in Annex 3. The interviews were semi-structured, based on an interview protocol but allowing for follow-

\footnotetext{
${ }^{231}$ An $89^{\text {th }}$ interview that was conducted by telephone has not been included as the respondent never submitted a consent form. No information from that interview has been included in the dissertation.
} 
up and supplementary questions. A standard protocol with ten questions, several with related secondary questions, was sent in advance to all respondents (see Annex 4). In most cases additional questions were included, tailored to the interviewee's experience and perspective.

All interviews were oral, although in some cases supplementary responses were provided in writing. In some cases, the respondent provided additional written material, including copies of reports and personal notes. Almost all interviews were conducted one-on-one and in person. Four were conducted by telephone. In one case, three individuals representing an industry association were interviewed together and a second interview brought together two senior officers of the Office of the Privacy Commissioner of Canada. Four individuals were interviewed in two sessions and one in three sessions. Most interviews lasted between one hour and an hour and half; the shortest was half an hour and the longest over three hours.

Interviews were not recorded electronically; respondents were given the opportunity to ask that their comments be recorded in this way but none did. Interview responses were noted long-hand in dedicated notebooks and later summarized in electronic Word files for each interview, which also recorded the date and location of the interview and the respondent's preferences with respect to being listed in the dissertation and attribution of responses. The electronic versions of the interview notes were then tagged and combined thematically in a master file of interview responses as a basis for analysis of response content and patterns. Key word electronic search tools have also been used to identify relevant responses. 
Each respondent was sent a consent form (see Annex 4) that they were asked to sign and return at the beginning of the interview. The same form also asked for an indication of preference with respect to being named as having been interviewed in an annex to the dissertation (i.e., Annex 3) and in any subsequent publication. A second question asked for a similar indication with respect to attribution of responses by name in the dissertation and in any future publication. Five respondents agreed to be interviewed but asked that they not be named or have their comments attributed. They are listed generically at the end of Annex 3. Another 18 agreed to be listed but asked that their responses not be attributed to them by name. On the other hand, 45 gave unqualified agreement to have their responses attributed. The remaining 20 asked to be consulted on any attributions by name in the dissertation. The tagging of the electronic record of the interview responses included notations on anonymity and attribution with respect to each response.

Interview participants were selected according to a number of criteria, with a view to providing a range of perspectives on the work of the $\mathrm{CIO}$ and on the related issues and decision-making. An effort was also made to cover the entire time period since 1993 as well as provide insights into earlier periods. It is considered that most of the key individuals involved with successive CIOs have been interviewed. The one categorical exception is that none of the interviews was with current or former elected politicians, although the relationship with the political level was an important part of interviews with the CIOs, Treasury Board Secretaries and other senior officials.

All seven current and former CIOs were interviewed, as were the four individuals who have been Acting CIO for periods of four months or more and two former Deputy Secretaries of the Administrative Policy Branch, which was responsible for information 
and IT policy in the Treasury Board Secretariat (TBS) before the CIO position was created. All seven of the Secretaries of Treasury Board to whom the CIOs have reported have been interviewed, as have six of the seven chairs of TIMS, the committee of Deputy Ministers that worked with the $\mathrm{CIO}$ in the first dozen years of the position.

Most interviewees had more than one perspective on the work of the CIO, in either their current or previous positions. Ten interviewees were current or former managers or employees in the CIO Branch of TBS and nine had experience in other areas of TBS (in addition to the current and former Secretaries). Seventeen were or had been Deputy Ministers and two had been Clerk of the Privy Council (both former chairs of TIMS) another later become the Clerk. Eight had worked in PCO or Justice, while five more worked for Parliamentary agents when they were interviewed. Nine were or had been departmental CIOs, and twenty worked or had worked in organizations with common service roles under CIO leadership, notably PWGSC, Service Canada and Library and Archives Canada.

In addition to experience inside the federal government, respondents had a wide range of external perspectives on the CIO. Twenty-nine respondents had experience in the private sector, all but six of those with both public and private sector experience. Eight worked or had worked for industry or professional associations and there were two journalists specializing in IT issues, three individuals working in think tanks and five former senior public servants now in universities. Ten respondents had worked in provincial governments, including four current or former provincial CIOs; one respondent had been the $\mathrm{CIO}$ for the Australian government, another for a large 
municipality and five had experience with secretariats to intergovernmental networking among Canadian public sector CIOs.

While demographic variables were not part of the research focus, it bears noting that the essentially functional approach to selecting potential interviewees resulted in seventeen - just under one fifth - of the respondents being women. This included the four women among the eleven CIOs and Acting CIOs since 1993. At the same time, this same selection approach resulted in just one visible minority (who had no government background) among the 88 interviewees.

\section{Secondary and tertiary sources}

The dissertation draws on a variety of sources in the academic literature, essentially along two lines. Scholarly books and articles discussed in the literature review and in later chapters provide commentary and background on many of the developments discussed in the dissertation. In particular they are the source of much of the historical background, although there are also government reports and publications available and a number of the interviews provide sightings of developments between the Glassco report and 1993. Scholarly literature also provides the material for theoretical discussions.

In addition, there is a trade press addressed at the IT community in Canada and government CIOs within that. One of the most active, ITWorld Canada, is also one of the actors in the story of the CIO's relationship with provincial governments and the private sector; its current head was among those interviewed. 


\section{Administrative aspects of the dissertation research project}

The dissertation project was conducted under the supervision of Professor Jonathan Malloy of the Department of Political Science at Carleton University. Professors Leslie Pal of the School of Public Policy and Administration and Scott Bennett of the Department of Political Science were also members of the dissertation advisory committee. All three have conducted research on e-government, public policy and political and administrative institutions in Canada.

A dissertation research proposal was approved in October 2007. Because the research involved human sources, approval was obtained from the Carleton University Research Ethics Committee in December 2007 for the research approach in general and specifically for the interview recruitment procedures, the proposed interview protocol, and the interview consent form (including protocols with respect to anonymity and attribution). Annual progress reports were submitted to the Research Ethics Committee in January 2009 and again in May 2009 (due to a change in committee procedures), May 2010 and May 2011. Ethics approval was extended to May 2012 based on the latter report.

No financial support was applied for or received in conducting the dissertation research. A paper summarizing the issues raised in the dissertation and initial conclusions (Brown 2009a) was presented at the 2009 annual meeting of the Canadian Political Science Association (CPSA). A paper based on chapter 5 of the dissertation (Brown 2010b) was presented at the 2010 CPSA annual meeting and one drawing on chapter 4 at the 2011 CPSA annual meeting (Brown 2011). 


\section{Annex 3: Interviews}

The following 88 individuals have been interviewed using the interview protocol in Annex 4, with tailored supplementary questions in most cases (see Annex 2 for details). Unless otherwise indicated, departmental affiliations are with the Government of Canada.

All individuals listed have signed a consent form in accordance with procedures approved by the Carleton University Research Ethics Committee. Five individuals requested that they not be listed by name in an annex to the dissertation; all others have agreed. The five interviews are listed chronologically at the end of this list with a descriptor that is used in any references in the dissertation text.

All individuals who have statements or information attributed to them by name in the dissertation either consented to give their interview on a "for attribution" basis or gave their consent to the specific attribution.

The interviewees are listed alphabetically. The listing also indicates the date of the interview and the interviewee's position at the time of the interview. Previous, or in some cases later, positions that are relevant to the dissertation topic are also listed.

1. Achimov, Donna (2008.12.16) - Vice-President, Canada School of the Public Service

2. Alexander, Jim (2008.11.10) - Vice-President Public Sector, Chartwell Group; Acting Chief Information Officer Treasury Board Secretariat 2005-06

3. Annan, Fawn (2009.03.06) - Vice President and Chief Strategist, ITWorld Canada

4. Ansari, Terry (2009.05.08) - Vice President, Business Solutions Group, Cisco Systems Canada

5. Bhumgara, Noel (2009.05.21) - Partner CFN Consultants; former Director General, IT Acquisitions, Acquisitions Branch, Public Works and Government Services Canada

6. Binder, Michael - (2008.11.24) Chair, Canadian Nuclear Safety Commission; former Assistant Deputy Minister Spectrum Information Technology and Telecommunications, Industry Canada

7. Brisebois, Richard (2009.05.20) - Principal, Information Technology Audits, Office of the Auditor General of Canada 
8. Bruce, Peter (2008.09.18) - Deputy Chief Information Officer Treasury Board Secretariat; former Chief Information Officer Library and Archives Canada and sector Chief Information Officer Government of Ontario

9. Campbell, Scott (2009.05.01) - Private consultant; Ontario Corporate Chief Information Officer 1998-2002; later British Columbia Chief Information Officer

10. Capello, Gerry (2009.04.16) - Consultant, NCR; former Deputy Minister of Labour; Deputy Secretary Administrative Policy Branch Treasury Board Secretariat 1985-87

11. Cappe, Mel (2009.05.11) - President, Institute for Research on Public Policy; former Secretary to the Cabinet and Clerk of the Privy Council; former chair of TIMS and Deputy Minister of Environment; former Deputy Secretary Program Branch Treasury Board Secretariat

12. Caron, Daniel (2009.01.06) - Senior Assistant Deputy Minister, Library and Archives Canada

13. Charette, Corinne (2009.05.19) - Treasury Board Secretariat Chief Information Officer 2009-present; former Chief Information Officer Air Transat and FINTRAC

14. Clark, Ian D. (2008.11.13) - Professor, School of Public Policy and Governance, University of Toronto; Secretary of Treasury Board 1989-94

15. Claydon, Frank (2009.03.26) - Secretary of Treasury Board (2000-2002); former Deputy Minister of Agriculture

16. Cochrane, Ken (2009.02.10 \& 2009.03.19) - Chief Information Officer Treasury Board Secretariat 2006-08; former Chief Executive Officer, Information Technology Services Branch, Public Works and Government Services Canada and Assistant Commissioner Information Technology Branch Canada Revenue Agency

17. Danek, Jirka (2009.03.05, 2009.06.25) - Chief Technology Officer, Information Technology Services Branch, Public Works and Government Services Canada; formerly Partner, CGI

18. d'Auray, Michelle (2008.12.17) - Deputy Minister, Fisheries and Oceans Canada; Treasury Board Secretariat Chief Information Officer 2000-2004

19. Darling, Allan J. (2010.03.20) - Assistant Secretary, Machinery of Government, Privy Council Office 1976-79, later Secretary General, Canadian Radio-television and Telecommunications Commission.

20. Davies, Eric (2009.02.11) - former Executive Director, GTEC Week; former Director General, IT services, Employment Insurance Commission

21. Devooght, Kim (2009.03.11) - Vice-President, Public Sector, IBM Canada

22. Dorigo, Nancy (2008.12.02) - Organizer, Lac Carling conference; former Director of Strategy, Chief Information Officer Branch Treasury Board Secretariat (1993-9)

23. Duffett, Charles (2009.02.12) - Senior Vice President \& CIO Advisor, Canadian Advanced Technology Alliance

24. Fellegi, Ivan (2009.02.24) - Chief Statistician Emeritus, Statistics Canada, chair of TIMS

25. Fine, Ed (2008.11.27) - President, Fineworks; former Executive Director, Organizational Readiness Office, Chief Information Officer Branch Treasury Board Secretariat 
26. Florakas, Nik (2008.11.26) - Executive Director, Organizational Readiness Office, Chief Information Officer Branch Treasury Board Secretariat; former Chief Information Officer, Agriculture and Agri-Food Canada)

27. Flumian, Maryantonnett (2009.04.08) - University of Ottawa School of Public and International Affairs; former Chief Operating Officer, Service Canada; former Executive Director, Firearms Registry

28. Giroux, Bob (2009.01.13) - Retired; Secretary of Treasury Board 1994-96; former President of the Public Service Commission and Deputy Minister National Revenue (Customs and Excise); former President Association of Universities and Colleges of Canada

29. Glen, Ian (2009.02.03) - Retired; former Chief, Communications Security Establishment; Chair of TIMS, 1997-99; former Deputy Minister of Environment

30. Goldmann, Nahum (2008.11.26) - President, Array Technologies

31. Gorman, Bernie (2008.11.25) - Retired; former Assistant Secretary, Information Management Systems and Technology, Chief Information Officer Branch, Treasury Board Secretariat 1993-1999

32. Grosse, Jason (2009.02.19) - Communications Manager Industry Technology Association of Canada

33. Harder, Peter (2009.01.15) - Retired; Secretary of Treasury Board 1996-2000; former Chair of TIMS; former Deputy Minister of Public Security, Citizenship and Immigration, Industry, and Foreign Affairs and International Trade

34. Heintzman, Ralph (2009.01.22) - Research Fellow, University of Ottawa; former Assistant Secretary, Services Sector, Treasury Board Secretariat; former VicePresident, Canadian Centre for Management Development

35. Henry, Chuck (2009.03.17) - Chief Technology Officer, Chief Information Officer Branch Treasury Board Secretariat (Interchange assignment)

36. Hession, Paul (2008.12.08) - Director General, Real Property Technology, Information Technology Services Branch, Public Works and Government Services Canada; former Vice-President, Canada Health InfoWay; former Chief Information Officer, Fisheries and Oceans Canada

37. Himelfarb, Alex (2009.05.04) - Canadian Ambassador to Italy; Secretary to the Cabinet Secretary and Clerk of the Privy Council 2002-06; former Deputy Minister of Canadian Heritage 1999-2002 and chair of TIMS; Associate Secretary TBS 1997-99

38. Hodgins, Ross (2008.12.03) - Senior Advisory, Office of the Information Commissioner; Former; Director of Privacy, Health Canada and Senior Analyst, Information Policy Division, Chief Information Officer Branch Treasury Board Secretariat

39. Hurcomb, Philip (2009.04.15) - Assistant Secretary, Strategic Communications and Ministerial Affairs, Treasury Board Secretariat

40. Judd, Jim (2009.02.26) - Director, Canadian Security Intelligence Service; Secretary of Treasury Board 2002-05; former Deputy Minister of National Defence

41. Keefe, Greg (2009.07.09) - Deputy Minister, Treasury Board and Chief Information Officer, Government of Nova Scotia 
42. Kent, Oliver (2009.02.03) - former National Partner, e-government, IBM/PriceWaterhouseCoopers

43. Kieley, Barbara (2009.04.04) - Partner, DeLoitte's; former Assistant Secretary Transformation Alignment Office Chief Information Officer Branch Treasury Board Secretariat (Interchange assignment)

44. Krupka, Ivo (2010.04.21) - Plans Secretariat, Privy Council Office 1966-72, later Executive Director, Pest Control Agency

45. Lahey, Jim (2009.03.19) - Retired; former Deputy Secretary, Public Service Renewal Privy Council Office

46. Lebel-Ducharme, Monique (2009.06.08) - Director-General, Strategic Communications, Media and Parliamentary Relations, Treasury Board Secretariat; former secretary to TIMS

47. Legault, Suzanne (2009.04.23) - Assistant Information Commissioner of Canada (appointed Information Commissioner in 2010)

48. Lenihan, Don (2008.11.24) - Director, Crossing Boundaries

49. Little, Bob (2008.11.07) - Consultant; Deputy Secretary Financial and Information Management Branch (Chief Information Officer) Treasury Board Secretariat 199597; former chair, Council for Administrative Renewal and Assistant Deputy Minister, Finance, Human Resources Development Canada

50. Lizotte-Macpherson, Linda (2009.04.15) - Senior Associate Deputy Minister, Human Resources and Social Development Canada and Chief Operating Officer, Service Canada; Associate Secretary, Treasury Board Secretariat 2006-2008; Chief Information Officer Treasury Board Secretariat 1998-2000; former Chief Executive Officer Canada Health InfoWay

51. Macdonald, Andy (2008.10.22) - Consultant World Bank; former Chief Information Officer Treasury Board Secretariat 1993-95; former Comptroller General of Canada; former Chief Information Officer Government of Australia

52. MacLennan, Chuck (2009.05.21) - Associate Consultant CFN Consultants; former Chief Information Officer, Citizenship and Immigration; former Director General Infrastructure Engineering Royal Canadian Mounted Police

53. Manicom, Richard (2008.12.16) - consultant; formerly Assistant Deputy Minister, Information Technology Branch, Revenue Canada

54. Marson, Brian (2008.09.19) - Senior Advisor, Services Sector Treasury Board Secretariat, formerly Chief Information Officer Branch; former Deputy Principal, Canadian Centre for Management Development; former Comptroller-General of British Columbia

55. McDonald, Helen (2008.11.17) - Assistant Deputy Minister, Spectrum Management, Industry Canada; Acting Chief Information Officer Treasury Board Secretariat 200405; Assistant Secretary Government On-Line Chief Information Officer Branch Treasury Board Secretariat 2000-2004

56. McDonald, John (2008.12.09, 2009.01.14) - Consultant; former Director, Government Electronic Records, Archives Canada 
57. McKay, Colin (2009.09.17) - Director of Communications, Office of the Privacy Commissioner of Canada

58. McKerlie, Ron (2008.11.12) - Government of Ontario: Deputy Minister of Management Board Secretariat; Corporate Chief Information Officer, Management Board Secretariat 2005-2008

59. McLeod, Michèle (2009.03.24) - Manager, Acquisitions Branch, Public Works and Government Services Canada; Manager, Gateways and Clusters, Chief Information Officer Branch Treasury Board Secretariat

60. Mitchell, James R. (2008.11.19) - Managing Partner, Sussex Circle; Assistant Secretary, Machinery of Government, Privy Council Office 1988-94

61. Nicholl, David (2008.11.12) - Government of Ontario: Corporate Chief Information Officer, Management Board Secretariat

62. Oliver, Linda (2009.02.19) - Vice-President, Information Technology Association of Canada

63. Parkins, Bob (2008.11.18) - Editorial Director, Canadian Government Executive

64. Paton, Richard (2008.09.18) - Chief Executive Officer, Canadian Chemical Producers Association; Deputy Secretary, Administrative Policy Branch Treasury Board Secretariat 1989-94

65. Richard, Elisabeth (2009.04.22, 2009.06.23) - Director, Client Services, Information Technology Services Branch, Public Works and Government Services Canada; former senior advisor, Canadian Policy Research Networks

66. Riddle, John (2008.11.03, 2009.02.11, 2009.03.25) - former Chief Information Officer Health Canada; former Director, Information Technology Policy Directorate Administrative Policy Branch and Chief Information Officer Branch, Treasury Board Secretariat; former Director General, Applications, Government Telecommunications and Informatics Services, Public Works and Government Services Canada

67. Rummell, Paul (2008.11.28) - Partner, Infosys; Chief Information Officer Treasury Board Secretariat 1997-99

68. Savoie, Louis (2009.02.19) - Regional Vice-President, Enterprise Accounts, Bell Canada and Chair, Information Technology Association Canada government relations committee

69. Sékaly, Gabriel (2008.11.13) - Chief Executive Officer, Institute of Public Administration of Canada; former Associate Deputy Minister of Finance, Government of Ontario

70. Sinclair, Ian (2009.01.28) - Senior Director, Information Policy, Treasury Board Secretariat Chief Information Officer Branch 1998-2006

71. Smith, Gordon S. (85 - 2010.04.13) - Director, Government Organization Division 1972-75, Senior Assistant Secretary, Machinery of Government 1975-77, Deputy Secretary, Plans 1977-79, Privy Council Office, later Associate Secretary, Privy Council Office and Deputy Minister, Foreign Affairs and International Trade.

72. Steinsky-Schwartz, Georgina (2008.11.14) - Chief Executive Officer, Imagine Canada; Deputy Minister, Supply and Services Canada 1989-92 and Chair of TIMS; former Chief Human Resources Officer, Bell Canada 
73. Thauvette, Jérôme (2009.03.04) - Director General, Information Technology Acquisitions, Acquisitions Branch, Public Works and Government Services Canada

74. Thompson, Dave (2009.05.20) - Director General Web Channel Office, Service Canada

75. Turner, Michael (2008.10.30) - Strategic Advisor, Wesley Clover; former Assistant Deputy Minister, Government Telecommunications and Informatics Services and Information Technology Services Branch, Public Works and Government Services Canada

76. Vincent, Charles (2009.04.15) - Portfolio Director, Program Sector, Treasury Board Secretariat; former Director Institute for Citizen-Centred Service, Toronto (secondment from Treasury Board Secretariat Chief Information Officer Branch

77. Westcott, Grant (2008.11.14) - CIBC Executive Vice President, Technology Infrastructure (Administration, Technology \& Operations); former Chief Information Officer Industry Canada

78. Wilson, Ian (2009.01.13) - National Archivist 1999-2004. Head, Library and Archives Canada 2004-2009. Former Provincial Archivist of Saskatchewan (19761986) and of Ontario (1986-1999)

79. Wood, Donna (2008.12.16) - Assistant Deputy Minister, Corporate Services, Heritage Canada

80. Wouters, Wayne (2009.01.29) - Secretary of Treasury Board 2005-2009; former Deputy Minister, Human Resources and Social Development; appointed Secretary to the Cabinet and Clerk of the Privy Council in June 2009

81. Wutti, Valerie (2009.03.10) - Executive Director, IT Project Review and Oversight, Chief Information Officer Branch

82. Yeomans, Don (2009.05.25) - Director, Organization Research, Glassco Commission 1960-1963, Director, Bureau of Government Organization, 1963-1966, Deputy Secretary, Management Improvement Branch, Treasury Board Secretariat, 19661970. Later former Assistant Deputy Minister, Supply, Department of Supply and Services and Commissioner, Correctional Services of Canada

83. Zussman, David (2008.11.25) - Jarislowsky Professor of Public Sector Management, University of Ottawa and Public Service Commissioner; former President, Public Policy Forum; former Assistant Secretary, Program Review and Machinery of Government, Privy Council Office.

\section{Individuals requesting not to be listed in an annex to the dissertation}

84. Former departmental Corporate Affairs Assistant Deputy Minister and senior Privy Council Office official (2008.12.08)

85. Former senior municipal and intergovernmental official (2008.11.14)

86. Senior official, Department of Justice (2009.04.09)

87. Senior official, Office of the Privacy Commissioner (2009.09.17)

88. Senior official, Treasury Board Secretariat (2009.06.24) 


\section{Annex 4: Interview Protocol and Consent Form Interview protocol - Government of Canada Chief Information Officer}

The following questions are intended to provide a common framework for all the interviews conducted as part of this research project. It is expected that the emphasis will vary in each interview and not all questions will be covered to the same extent. It is also expected that each interview will cover additional issues with which the interview participant is personally familiar.

\section{Your background}

1. What role have you played with respect to the Government of Canada's information and technology agenda?

- What was your relationship to the Treasury Board Secretariat's Chief Information Officer (CIO)?

- What time period are you most comfortable discussing?

- What is your academic and professional background?

\section{Impact of information and communications technologies}

2. What has been the impact of information and communications technologies on public policy and public administration in the federal government?

- What have been the most successful uses of these technologies?

- The most problematic uses/greatest failures?

3. How do you explain this impact?

- How much control has the government had over the introduction of new information and communication technologies (both in society and within government)?

- What have been the key factors/who have been the key governmental actors?

- What role has been played by politics and politicians?

- What has been the role of outside actors and ideas?

- How important has been the relationship with the private sector?

\section{Establishment and Evolution of the CIO position}

4. Why do you think the CIO position was established?

- What is your understanding of the ClO's mandate and role within government?

- Is this the right one? What adjustments would you make?

- In your view, what have been the most important factors influencing the evolution of the office?

\section{Creation of a new sector of public administration}

5. Would you agree that the CIO's "territory" defines a new sector of public administration that is on a par with financial and human resources management?

- What are the sector's defining elements?

- Are these the right ones?

- How does it compare with other administrative sectors?

\section{Institutional maturity}

6. In your view, how institutionally "mature" are the sector and the office of CIO within it?

- What are the factors that will influence its evolution?

- What would a fully mature sector look like?

- How likely is that to occur? What is required? 


\section{Impact of the CIO}

7. How successful has the CIO been?

- What are the standards for judgment?

- What have been the most successful roles and initiatives?

- Where are the greatest challenges/limitations?

- How do you assess the CIO's influence in the following areas of activity within the federal government?

- Information and technology policy and standards

- Infrastructure development and major projects

- Procurement of information and technology goods and services

- Budgeting and resource allocation for information and technology

- Professional development of IT/IM workers

- Using technology to promote reform of public sector management and work practices.

- Shared and common services to government and to its employees

- Service to the public

- How do you explain these results?

8. What have been the effects of the issues we have been discussing on Canadian governance and public administration?

- Decision-making and implementation within the federal government?

- Accountability within government, to Ministers and to Parliament?

- Relationships with other levels of government?

- Relationships with the public?

\section{General}

9. Do you think Accenture's top international rating for Canada was merited? Is that level of performance sustainable?

10. Do you have suggestions about additional research sources?

- Academic or trade literature?

- Government documents and publications?

- People to interview?

Supplementary interview questions 


\section{Interview Consent Form}

I have read the attached description of the research being conducted by David C.G. Brown as a basis for his $\mathrm{PhD}$ dissertation, "Coming to terms with information and communications technologies: the role of the Chief Information Officer in the Government of Canada". I understand that I am participating in a research project and I voluntarily agree to participate.

In this context, I request that my responses and information about my participation be treated in the manner indicated below.

\section{Please indicate your preference to each of the following pairs of statements:}

I agree to have my name listed in an annex to the dissertation

I do not agree to have my name listed in an annex to the dissertation

I agree to have my name listed in any publication based on this research

I do not agree to have my name listed in any publication based on this research

$\square$ I agree to have my replies to the interview questions attributed by name in the dissertation

$\square \quad$ I do not agree to have my replies to the interview questions attributed by name in the dissertation

I agree to have my replies to the interview questions attributed by name in any publications based on this research

I do not agree to have my replies to the interview questions attributed by name in any publications based on this research

(signature) (date)

\footnotetext{
(name-please print)
}

Attachment: Information Annex to Interview Consent Form 


\title{
Annex to Interview Consent Form: Information About the PhD Dissertation Research Project Conducted by David C.G. Brown
}

\section{Contact information}

Researcher: David C.G. Brown

Department of Political Science

Carleton University

B-640 Loeb Building

1125 Colonel By Drive

Ottawa, Ontario

K1S 5B6

Tel. (613)

Supervisor: Prof. Jonathan Malloy

Department of Political Science

Carleton University

B-640 Loeb Building

1125 Colonel By Drive

Ottawa, Ontario

K1S 5B6

Tel. (613) 520-2600 ext. 1189

\section{Ethics review and contact}

This research project has been reviewed and received ethics clearance from the Carleton University Research Ethics Committee. Questions and concerns about participants' involvement in the project may be directed to the ethics committee chair:

\author{
Prof. Nino Gualtieri, Chair \\ Carleton University Research Ethics Committee \\ Carleton University \\ 1125 Colonel By Drive \\ Ottawa, Ontario \\ K1S 5B6 \\ E-mail: ethics@carleton.ca
}

\section{Brief description of the research project}

Interviews are being conducted as a research source for a $\mathrm{PhD}$ dissertation being prepared by David C.G. Brown under the supervision of Professor Jonathan Malloy in the Department of Political Science, Carleton University. The dissertation topic is: "Coming to Terms with Information and Communications Technologies: the Role of the Chief Information Officer in the Government of Canada." The subject of the dissertation is the office of Chief Information Officer (CIO), which was established in the federal government's Treasury Board Secretariat (TBS) when Prime Minister Kim Campbell came into office in June 1993. While the research is primarily focused on the evolution of the office during the Chrétien and Martin governments, it is also taking into account developments under the Harper government. 
The research project has two main components, documentary research and interviews. The interviews are being conducted with individuals who have served as the federal CIO, with others who have worked closely with them and with knowledgeable observers. The project is focused on three sets of issues in particular:

1. The decision to establish the office of CIO in Treasury Board Secretariat and factors that have shaped its subsequent evolution;

2. The sub-discipline (sector) of public administration defined by the office's mandate and working relationships; and

3. Institutional maturity of the sector and of the office of $\mathrm{CIO}$ within it and influences on future development.

\section{Interviews}

In general, participants in the research project are being interviewed once, although by mutual agreement there may be follow up. The interviews are expected to last approximately one hour, but the length can vary according to the participant's interest and availability. Should a participant decide to withdraw, they may at that time decide whether the researcher may use the information provided in the interview or they may request that it be destroyed. They may also be asked to be briefed on how the information was used when the dissertation is completed.

Interviews follow an interview schedule sent to the participant in advance. Participants may decline to answer any of the questions, but they are also free to comment on other points they consider relevant. The interviews are not audio- or video- recorded. Interview notes will remain in the sole custody of the researcher. Participants are asked to confirm in writing, before the interview begins, to confirm their preferences about whether they wish to be included in a list of interview participants in an annex to the dissertation and any publication which might result from it and whether their responses may to be treated on a for-attribution basis in the dissertation and in any resulting publication. 


\section{Annex 5: Glassco Report}

Canada. Royal Commission on Government Organization (Glassco Commission). 1962 \& 1963. Ottawa: Queen's Printer.

1961. First Report on Progress. Pp. 20.

1962. Vol 1. Management of the Public Service. Pp. 646. (Abridged Edition Pp. 228)

Report 1. A Plan for Management, pp. 17-77 (Abridged Edition, pp. 17-77).

Report 2. Financial Management, pp. 83-230 (Abridged Edition, pp. 83-117).

Report 3. Personnel Management, pp. 235-466 (Abridged Edition, pp. 123-183).

Report 4. Paperwork and Systems Management, pp. 477-629 (Abridged Edition, pp. 189-228).

1962. Vol. 2. Supporting Services for Government. Pp. 436.

General Introduction, pp. 13-16.

Report 5. Real Property, pp. 23-68.

Report 6. Purchasing and Supply, pp. 73-142.

Report 7. Transportation, pp. 147-207.

Report 8. Telecommunications, pp. 213-268.

Report 9. Printing and Publishing, pp. 273-307.

Report 10. The "Make or Buy" Problem, pp. 313-359.

Report 11. Legal Services, pp. 365-421.

1962. Vol. 3. Supporting Services for Government Cont'd. Services for the Public. Pp. 399.

Supporting Services for Government Cont'd.

Report 12. Economic and Statistical Services, pp. 17-51.

Report 13. Public Information Services, pp. 57-114.

Services for the Public

General Introduction, pp. 119-131.

Report 14. Education Services, pp. 139-171.

Report 15. Health Services, pp. 177-241.

Report 16. Lending, Guaranteeing and Insuring Activities, pp. 247-297.

Report 17. The Post Office, pp. 303-351.

Report 18. Miscellaneous Services, pp. 357-384.

1963. Vol. 4. Special Areas of Administration. Pp. 333.

Report 19. Canadian Broadcasting Corporation, pp. 17-51.

Report 20. Department of National Defence, pp. 59-92.

Report 21. Department of External Affairs, pp. 97-143.

Report 22. Northern Affairs, pp. 151-180.

Report 23. Scientific Research and Development, pp. 185-322.

1963. Vol. 5. The Organization of the Government of Canada. Pp. 184.

Report 24. The Organization of the Government of Canada, Pp. 23-121. Includes

Annex: Summary of Proposals for Reorganization, pp. 105-121. 


\section{Annex 6: CIO and CIO-related Treasury Board Policies}

This list is structured around the Foundation Framework for Treasury Board Policies, which was introduced in 2008 and on the basis of which the universe of Treasury Board Policies is being reviewed and updated. Related directives, standards and guidelines are indicated under each policy. All of the listed instruments are in the inventory of Treasury Board policies maintained on the Treasury Board website (www.tbs-sct.gc.ca). Not all, however, have been reviewed in the most recent exercise and their allocation to specific policies or policy frameworks is in some cases for illustrative purposes only. Policies for which the CIO is currently responsible are indicated in bold and those for which the CIO has been responsible in the past but not at present are indicated in italics.

Foundation Framework for Treasury Board Policies

- Policy on Management, Resources and Results Structure

- Management Accountability Framework (MAF)

- Portfolio Coordination Guideline: MAF Considerations \& Overview of Practices

- Policy on Government Security

- Directive on Departmental Security Management

- Directive on Identity Management

- Controlled Goods Directive

- Operational Security Standard - Business Continuity Planning (BCP) Program

- Operational Security Standard - Readiness Levels for Federal Government Facilities

- Operational Security Standard: Management of Information Technology Security (MITS)

- Operational Security Standard on Physical Security

- Operational Standard for the Security of Information Act

- Personnel Security Standard

- Security and Contracting Management Standard

- Security Organization and Administration Standard

- Policy on Use of Electronic Networks

- Guidelines to Acceptable Use of Internet Wikis and Blogs Within the Government of Canada

- Communications Policy of the Government of Canada 
- Communications Policy of the Government of Canada: Procedures

- Planning Information Products: Effective, No-Frills Publishing

- Practices Procedures for Planning and Contracting Public Opinion Research

- Federal Identity Program Policy

- Federal Identity Program Manual

- Collaborative Arrangements: Federal Identity Program Identifiers

- Collaborative Arrangements: Symbols And Hyperlinks

Framework for the Management of Compliance

- Policy on Internal Control

Framework for the Management of Risk

Policy Framework for Information and Technology

- Policy on Access to Information

- Directive on the Administration of the Access to Information Act

- Policy on Service Standards for External Fees

- Policy on Learning, Training and Development

- Access to Information Guidelines

- Preparation of a Certificate for the Commissioner Requests

- Third-Party Exemption and Notification

- Treatment of Access to Information Requests for Audit Information (PIN) - July 1, 1984

- Right of Access - Access to Information and Privacy

- Policy on Information Management

- Directive on Information Management Roles and Responsibilities

- Directive on Recordkeeping

- Standard on Geospatial Data

- Standard on Metadata

- Standard for Electronic Documents and Records Management Solutions (EDRMS)

- TBITS 39: Treasury Board Information Management Standard, Part 1: Government On-Line Metadata Standard

- TBITS 39: Treasury Board Information Management Standard, Part 2: Controlled Vocabulary Standard

- Guideline for Employees of the Government of Canada: Information Management (IM) Basics

- Policy on Management of Information Technology

- Directive on Management of Information Technology

- TBITS 3: Coded Character Set for Information Interchange Implementation Criteria

- TBITS 5 : Canadian Government Keyboard Standard for Information Technology Equipment - Implementation Criteria

- TBITS 6.11: Naming and Addressing for Government Handling Applications - Implementation Criteria 
- Canadian Open Systems Application Criteria (COSAC), TBITS 6.9: Canadian Open Systems Application Criteria (COSAC), Telecommunications wiring system in Government-Owned and leased buildings - Implementation Criteria

- TBITS 12: Codes for the Representation of Currencies and Funds Implementation Criteria

- TBITS 23: Information Technology Vocabulary - Implementation Criteria

- TBITS 25: Materiel Coding - Implementation Criteria

- TBITS 26: Software Product Evaluation, Quality Characteristics and Guidelines for their Use - Implementation Criteria

- TBITS 30: Business Number - Implementation Criteria

- TBITS 36: All-Numeric Representation of Dates and Times Implementation Criteria

- TBITS 38: Advanced card technologies - Physical parameters and appearance of the Government of Canada employee technology card - Implementation Criteria

- TBITS 39: Treasury Board Information Management Standard Part 2: Controlled Vocabulary Standard

- TBITS 39: Treasury Board Information Management Standard, Part 1: Government On-Line Metadata Standard

- Common Look and Feel Standards for the Internet, Part 1: Standard on Web Addresses

- Common Look and Feel Standards for the Internet, Part 2: Standard on the Accessibility, Interoperability and Usability of Web Sites

- Common Look and Feel Standards for the Internet, Part 3: Standard on Common Web Page Formats

- Common Look and Feel Standards for the Internet, Part 4: Standard on Email

- An Enhanced Framework for the Management of Information Technology Projects

- Policy on Privacy Protection

- Directive on the Social Insurance Number

- Directive on Privacy Impact Assessment

- Directive on Privacy Practices

- Directive on Privacy Requests and Correction of Personal Information

- Privacy Impact Assessment Guidelines: A Framework to Manage Privacy Risks

- Guidance Document: Taking Privacy into Account Before Making Contracting Decisions

A Policy Framework for Service Improvement in the Government of Canada

- Service Standards: a Guide to the Initiative

- Enhancing Services Through the Innovative Use of Information and Technology

Official Languages Policy Framework 
- Policy on the Use of Official Languages for Communications with and Services to the Public

- Directive on the Use of Official Languages on Web Sites

- Directive on the Use of Official Languages in Electronic Communications

- Directives for Implementing the Official Languages (Communications with and Services to the Public) Regulations, 1991

Policy Framework for the Management of Assets and Acquired Services

- Policy on Investment Planning - Assets and Acquired Services

- Policy on Management of Materiel

- Directive on Disposal of Surplus Materiel

- Policy on Management of Real Property

- Accessibility Standard for Real Property

- Policy on the Management of Projects

- Standard for Organizational Project Management Capacity

- Standard for Project Complexity and Risk

- Policy on Long-term Capital Plans

- Management of Major Crown Projects

- Project Approval Policy

- Project Management Policy

- Systems Under Development (Audit Guide) - March 1, 1991

- Policy on Contracting

- Procedures for Liaison with Private Contractors

- Policy on Title to Intellectual Property Arising Under Crown Procurement Contracts Retention of Royalties, Fees from Licensing of Crown-Owned Intellectual Property

- Common Services Policy

Policy Framework for Financial Management

- Policy on Financial Resource Management, Information and Reporting

- Policy on Stewardship of Financial Management Systems

- Policy on Electronic Authorization and Authentication

- Policy on Service Standards for External Fees

- Directive on Stewardship of Financial Information Systems

- Directive on Losses of Money or Property

- Financial Information Strategy Accounting Manual

Policy Framework for People Management

- Values and Ethics Code for the Public Service

- Policy on Telework

- Policy on the Duty to Accommodate Persons with Disabilities in the Federal

Public Service

- Policy on Prevention and Resolution of Harassment in the Workplace

- Policy on Learning, Training and Development

- Policy on Interchange Canada

- Directive on Interchange Canada

Policy Framework for Management of Compensation

- Guideline on Common Financial Management Business Processes for Pay Administration 


\section{Annex 7: CIO and CIO-related Legislation and Regulations}

The statutes and Regulations in this list are referred to as sources of authority and requirements in Treasury Board policies for which the $\mathrm{CIO}$ is currently responsible or has been responsible in the past. The statutes are listed alphabetically and for each one the policies that cite it are listed. [References in square brackets are to the 2009 Consolidated

Statutes of Canada, found on the Department of Justice Justice Laws Website:

http://laws.justice.gc.ca/eng/MainPage.]

Access to Information Act [R.S. 1985 c. A-1]

- Policy on Government Security

- Policy Framework for Information and Technology

- Access to Information Policy

- Policy on Information Management

- Policy on Privacy

- Policy on the Use of Electronic Networks

- Communications Policy of the Government of Canada

Access to Information Act Heads of Government Institutions Designation Order [SI/83-113]

- Access to Information Policy

Access to Information Regulations [SOR/83-108, SOR/83-507, SOR/89-207]

- Access to Information Policy

- Policy on Privacy

Canada Evidence Act [R.S., 1985, c. C-5]

- Policy on Government Security

- Policy Framework for Information and Technology

- Access to Information Policy

- Policy on Information Management

- Policy on Privacy

Canada Labour Code [R.S., 1985, c. L-2]

- Policy on Government Security

Canadian Charter of Rights and Freedoms [R.S., 1985 Appendix II, No. 44]

- Policy on Government Security

- Policy on Privacy

- Policy on the Use of Electronic Networks

- Communications Policy of the Government of Canada

- Federal Identity Program Policy

Canadian Human Rights Act [R.S., 1985, c. H-6]

- Policy on Government Security

- Policy on the Use of Electronic Networks 
Canadian Multiculturalism Act [R.S., 1985, c. 24 (4th Supp.)]

- Communications Policy of the Government of Canada

Canadian Security Intelligence Service Act [R.S., 1985, c. C-23]

- Policy on Government Security

Copyright Act [R.S., 1985, c. C-42]

- Policy Framework for Information and Technology

- Policy on Information Management

- Communications Policy of the Government of Canada

Criminal Code [R.S., 1985, c. C-46]

- Policy on Government Security

- Policy on the Use of Electronic Networks

Criminal Records Act [R.S., 1985, c. C-47]

- Policy on Government Security

- Policy on Information Management

Crown Liability and Proceedings Act [R.S. 1985, c. C-50]

- Policy on the Use of Electronic Networks

Defence Production Act [R.S., 1985, c. D-1]

- Policy on Government Security

Department of Foreign Affairs and International Trade Act [R.S., 1985, c. E-22]

- Policy on Government Security

Emergency Management Act [S.C. 2007, c. 15]

- Policy on Government Security

Emergency Preparedness Act [R.S., 1985, c. 6 (4th Supp.)]

- Policy Framework for Information and Technology

- Policy on Information Management

- Communications Policy of the Government of Canada

Export and Import Permits Act [R.S. 1985, c. E-19]

- Policy on the Use of Electronic Networks

Federal Real Property and Federal Immovables Act [S.C. 1991, c. 50]

- Policy on Government Security

Financial Administration Act [R.S., 1985, c. F-11]

- Policy on Government Security

- Policy Framework for Information and Technology

- Access to Information Policy

- Policy on Management of Information Technology

- Policy on Privacy

- Policy on the Use of Electronic Networks

- Communications Policy of the Government of Canada

Interpretation Act [R.S., 1985, c. I-21]

- Policy on Government Security

Library and Archives of Canada Act [S.C. 2004, c. 11]

- Policy on Government Security

- Policy Framework for Information and Technology

- Access to Information Policy

- Policy on Information Management 
- Policy on Privacy

- Policy on the Use of Electronic Networks

- Communications Policy of the Government of Canada

National Defence Act [R.S., 1985, c. N-5]

- Policy on Government Security

Occupational Health and Safety Regulations, Canada [SOR/86-304]

- Policy on Government Security

Official Languages Act [R.S., 1985, c. 31 (4th Supp.)]

- Policy Framework for Information and Technology

- Access to Information Policy

- Policy on Information Management

- Policy on Privacy

- Communications Policy of the Government of Canada

- Federal Identity Program Policy

Patent Act [R.S. 1985, c. P-4]

- Policy on the Use of Electronic Networks

Personal Information Protection and Electronic Documents Act [S.C. 2000, c. 5]

- Policy Framework for Information and Technology

- Policy on Information Management

- Policy on Privacy

- Communications Policy of the Government of Canada

Privacy Act [R.S., 1985, c. P-21]

- Policy on Government Security

- Policy Framework for Information and Technology

- Access to Information Policy

- Policy on Information Management

- Policy on Privacy

- Policy on the Use of Electronic Networks

- Communications Policy of the Government of Canada

Privacy Act Heads of Government Institutions Designation Order [SI/83-114]

- Policy on Privacy

Privacy Regulations [SOR/83-508]

- Access to Information Policy

- Policy on Privacy

Public Servants Disclosure Protection Act [S.C. 2005, c. 46]

- Policy on Government Security

- Access to Information Policy

Public Service Employment Act [R.S., 1985, c. P-33]

- Policy on Government Security

Public Service Labour Relations Act [S.C. 2003, c. 22, s. 2]

- Policy on Government Security

Publication of Statutes Act [R.S., 1985, c. S-21]

- Communications Policy of the Government of Canada

Royal Canadian Mounted Police Act [R.S., 1985, c. R-10] 
- Policy on Government Security

Security of Information Act [R.S., 1985, c. O-5]

- Policy on Government Security

- Policy Framework for Information and Technology

- Policy on Information Management

- Policy on the Use of Electronic Networks

Statistics Act [R.S., 1985, c. S-19]

- Policy on Government Security

- Policy Framework for Information and Technology

- Policy on Information Management

Statutory Instruments Act [R.S., 1985, c. S-22]

- Communications Policy of the Government of Canada

Trade-marks Act [R.S., 1985, c. T-13]

- Policy on the Use of Electronic Networks

- Communications Policy of the Government of Canada

User Fees Act [S.C. 2004, c. 6]

- Access to Information Policy

Youth Criminal Justice Act [S.C. 2002, c. 1]

- Policy on Government Security 


\section{Annex 8: CIO and CIO-related Government Institutions}

The Government of Canada institutions in this list are all assigned a role as a "lead agency" under policies for which the CIO is now responsible or has been responsible in the past. The institutions are listed in alphabetical order, indicating the CIO-related

Treasury Board policies under which they are assigned a role.

Cabinet and Treasury Board

- Communications Policy of the Government of Canada

Canada School of Public Service

- Policy on Government Security

- Access to Information Policy

- Policy on Information Management

- Policy on Management of Information Technology

- Policy on Privacy

- Communications Policy of the Government of Canada

Canadian Security Intelligence Service

- Policy on Government Security

Communications Security Establishment

- Policy on Government Security

Department of Foreign Affairs and International Trade

- Policy on Government Security

Department of Justice

- Access to Information Policy

- Policy on Privacy

Department of National Defence

- Policy on Government Security

Department of Public Safety

- Policy on Government Security

Department of Public Works and Government Services

- Policy on Government Security

- Policy on Management of Information Technology

Information Commissioner of Canada

- Access to Information Policy

Library and Archives Canada

- Policy on Government Security

- Policy on Information Management

- Communications Policy of the Government of Canada

Privacy Commissioner of Canada

- Policy on Privacy 
Privy Council Office

- Policy on Government Security

- Access to Information Policy

- Policy on Privacy

- Communications Policy of the Government of Canada

- Service Improvement Framework

Royal Canadian Mounted Police

- Policy on Government Security

Service Canada (Department of Human Resources and Skills Development)

- Communications Policy of the Government of Canada

- Service Improvement Framework

Statistics Canada

- Policy on Information Management

Treasury Board of Canada Secretariat

- Policy on Government Security

- Policy Framework for Information and Technology

- Access to Information Policy

- Policy on Information Management

- Policy on Management of Information Technology

- Policy on Privacy

- Communications Policy of the Government of Canada

- Federal Identity Program Policy

- Service Improvement Framework 


\section{Annex 9 - CIO-related occupational groups (October 2010)}

\begin{tabular}{|c|c|c|c|}
\hline $\begin{array}{l}\text { Occupational } \\
\text { Group }\end{array}$ & Group title & Bargaining agent & Total \\
\hline $\mathrm{CM}$ & Communications & PSAC & 35 \\
\hline CS & Computer systems administration & PIPSC & 13,940 \\
\hline DA & Data processing & PSAC & 103 \\
\hline EG & Engineering and scientific support & PSAC & 6,886 \\
\hline EL & Electronics & IBEW & 1,157 \\
\hline EN & Engineering and land survey & PIPSC & 3,322 \\
\hline EC & Economics \& social science services & CAPE & 13,191 \\
\hline ES & Economics, sociology and statistics & CAPE & 6 \\
\hline GT & General technical & PSAC & 2,660 \\
\hline HR & Historical research & PIPSC & 139 \\
\hline IS & Information services & PSAC & 3,729 \\
\hline LS & Library science & PSAC & 379 \\
\hline OE & Office equipment & PSAC & 10 \\
\hline PR & Printing Operations & PSAC & 24 \\
\hline SI & Social science support & CAPE & 6 \\
\hline Total & ClO-related & & 45,552 \\
\hline AS & Administrative services & PSAC & 30,020 \\
\hline CR & Clerical and regulatory & PSAC & 27,383 \\
\hline EX & Executive & Not represented & 5,467 \\
\hline PL & Leadership programs & Not represented & 150 \\
\hline PM & Program administration & PSAC & 23,117 \\
\hline Total & General administration & & 86,137 \\
\hline Total & $\begin{array}{l}\text { Core public administration all } \\
\text { categories }\end{array}$ & & 213,801 \\
\hline
\end{tabular}

\section{Notes}

Source: Treasury Board Secretariat Office of the Chief Human Resources Officer

1. Data are based on October 2010 file for active employees only, i.e. employees not on Leave Without Pay. They include all employment tenures (full-time, part-time, indeterminate, term) and are based on effective employment classification (i.e. includes acting appointments).

2. Data are for Departments and Agencies in the Core Public Administration, i.e. Departments that fall under schedules I and IV of the Financial Administration Act. (Separate Agencies are excluded).

3. The EC group represents the consolidation of the ES and SI groups, which is still under way.

4. The PL group combines Management Trainee (MM) and Career Assignment Program (CAP).

5. Bargaining agents:

- CAPE - Canadian Association of Professional Employees

- IBEW - International Brotherhood of Electrical Workers

- PIPSC - Professional Institute of the Public Service of Canada

- PSAC - Public Service Alliance of Canada 


\section{Annex 10: Government Information}

This table provides a summary overview of the categories of information that the Government of Canada works with and of activities that its information holdings support. It is based on the list of government departments headed by Ministers. It also includes the major central agencies (Finance, PCO and TBS) and agencies that are effectively headed by Ministers and count as de facto departments (Canada Revenue Agency, CIDA, and the regional economic development agencies grouped together). In other cases, agencies are included in the larger ministerial portfolio (e.g., cultural agencies under Canadian Heritage, security agencies under Public Safety).

Departments are listed in column 1. Column 2 summarizes the incidence of five sources from which information is obtained by government departments: in-house scientific research; regulatory and enforcement activities; administration of departmental programs; foreign and domestic intelligence; and central agency support to government decision-making and resource allocation. Column 3 indicates three categories of how government information is used, drawing on the various information sources. These are: support to policy development and program operations within individual policy sectors; information-based programs, as a sub-set of departmental programs; and information in support of defining and implementing the strategic direction of the government as a whole. The fourth column indicates the number of on-line information service websites or portals that were established by each department under the Government On-Line (GOL) initiative. The complete list, as well as the complementary list of transactional services, is available in the GOL final report (Canada PWGSC 2006: Annex B).

Additional details and commentary on the information in this annex are available in chapter 5 of the dissertation. 


\begin{tabular}{|c|c|c|c|}
\hline Department & Information sources & Information activities & $\begin{array}{l}\text { GOL } \\
\text { Info } \\
\text { Services } \\
\end{array}$ \\
\hline $\begin{array}{l}\text { Agriculture and Agri- } \\
\text { Food }\end{array}$ & $\begin{array}{l}\times \text { In-house science } \\
\times \text { Regulation and enforcement } \\
\times \text { Program administration }\end{array}$ & $\begin{array}{l}\times \text { Policy and operational support } \\
\times \text { Information-based programs }\end{array}$ & 5 \\
\hline $\begin{array}{l}\text { Canada Revenue } \\
\text { Agency }\end{array}$ & $\begin{array}{l}\times \text { Regulation and enforcement } \\
\times \text { Program administration }\end{array}$ & $\times$ Policy and operational support & \\
\hline Canadian Heritage & $\times$ Program administration & $\begin{array}{l}\times \text { Policy and operational support } \\
\times \text { Information-based programs }\end{array}$ & 3 \\
\hline $\begin{array}{l}\text { Canadian International } \\
\text { Development Agency }\end{array}$ & $\times$ Program administration & $\times$ Policy and operational support & 2 \\
\hline $\begin{array}{l}\text { Citizenship and } \\
\text { Immigration }\end{array}$ & $\begin{array}{l}\times \text { Regulation and enforcement } \\
\times \text { Program administration } \\
\times \text { Foreign and domestic intelligence }\end{array}$ & $\times$ Policy and operational support & \\
\hline Environment & $\begin{array}{l}\times \text { In-house science } \\
\times \text { Regulation and enforcement } \\
\times \text { Program administration }\end{array}$ & $\begin{array}{l}\times \text { Policy and operational support } \\
\times \text { Information-based programs }\end{array}$ & 3 \\
\hline Finance & $\begin{array}{l}\times \text { Regulation and enforcement } \\
\times \text { Central agency roles }\end{array}$ & $\begin{array}{l}\times \text { Policy and operational support } \\
\times \text { Information-based programs } \\
\times \text { Government strategic direction }\end{array}$ & 6 \\
\hline Fisheries and Oceans & $\begin{array}{l}\times \text { In-house science } \\
\times \text { Regulation and enforcement } \\
\times \text { Program administration }\end{array}$ & $\begin{array}{l}\times \text { Policy and operational support } \\
\times \text { Information-based programs }\end{array}$ & 3 \\
\hline $\begin{array}{l}\text { Foreign Affairs and } \\
\text { International Trade }\end{array}$ & $\begin{array}{l}\times \text { Program administration } \\
\times \text { Foreign and domestic intelligence }\end{array}$ & $\begin{array}{l}\times \text { Policy and operational support } \\
\times \text { Information-based programs } \\
\times \text { Government strategic direction }\end{array}$ & 2 \\
\hline Health & $\begin{array}{l}\times \text { In-house science } \\
\times \text { Regulation and enforcement } \\
\times \text { Program administration }\end{array}$ & $\begin{array}{l}\times \text { Policy and operational support } \\
\times \text { Information-based programs }\end{array}$ & 4 \\
\hline $\begin{array}{l}\text { Human Resources and } \\
\text { Skills Development }\end{array}$ & $\begin{array}{l}\times \text { Regulation and enforcement } \\
\times \text { Program administration }\end{array}$ & $\begin{array}{l}\times \text { Policy and operational support } \\
\times \text { Information-based programs }\end{array}$ & 1 \\
\hline $\begin{array}{l}\text { Indian Affairs and } \\
\text { Northern Development }\end{array}$ & $\times$ Program administration & $\begin{array}{l}\times \text { Policy and operational support } \\
\times \text { Information-based programs }\end{array}$ & 2 \\
\hline Industry & $\begin{array}{l}\times \text { In-house science } \\
\times \text { Regulation and enforcement } \\
\times \text { Program administration }\end{array}$ & $\begin{array}{l}\times \text { Policy and operational support } \\
\times \text { Information-based programs }\end{array}$ & 7 \\
\hline Justice & $\times$ Program administration & $\begin{array}{l}\times \text { Policy and operational support } \\
\times \text { Government strategic direction }\end{array}$ & 2 \\
\hline National Defence & $\begin{array}{l}\times \text { In-house science } \\
\times \text { Program administration } \\
\times \text { Foreign and domestic intelligence }\end{array}$ & $\begin{array}{l}\times \text { Policy and operational support } \\
\times \text { Information-based programs }\end{array}$ & 3 \\
\hline Natural Resources & $\begin{array}{l}\times \text { In-house science } \\
\times \text { Regulation and enforcement } \\
\times \text { Program administration }\end{array}$ & $\begin{array}{l}\times \text { Policy and operational support } \\
\times \text { Information-based programs }\end{array}$ & 4 \\
\hline Privy Council Office & $\begin{array}{l}\times \text { Foreign and domestic intelligence } \\
\times \text { Central agency roles }\end{array}$ & $\times$ Government strategic direction & 2 \\
\hline
\end{tabular}




\begin{tabular}{|l|l|l|l|}
\hline Public Safety & $\begin{array}{l}\times \text { Regulation and enforcement } \\
\times \text { Program administration } \\
\times \text { Foreign and domestic intelligence }\end{array}$ & $\begin{array}{l}\times \text { Policy and operational support } \\
\times \text { Information-based programs }\end{array}$ & 5 \\
\hline $\begin{array}{l}\text { Public Works and } \\
\text { Government Services }\end{array}$ & $\times$ Program administration & $\times$ Policy and operational support & 2 \\
\hline $\begin{array}{l}\text { Regional Economic } \\
\text { Development Agencies } \\
\text { (ACOA, WED, etc.) }\end{array}$ & $\times$ Program administration & $\times$ Policy and operational support & 3 \\
\hline Transport & $\begin{array}{l}\times \text { Regulation and enforcement } \\
\times \text { Program administration } \\
\times \text { Foreign and domestic intelligence }\end{array}$ & $\times$ Policy and operational support & 1 \\
\hline $\begin{array}{l}\text { Treasury Board } \\
\text { Secretariat }\end{array}$ & $\times$ Central agency roles & $\begin{array}{l}\times \text { Policy and operational support } \\
\times \text { Government strategic direction }\end{array}$ & 2 \\
\hline Veterans Affairs & $\times$ Program administration & $\begin{array}{l}\times \text { Policy and operational support } \\
\times \text { Information-based programs }\end{array}$ & 1 \\
\hline
\end{tabular}

